BUILDING INFORMATION MODELLING FOR ASSET \& FACILITIES MANAGEMENT

BY

AMBER HADDOCK

A thesis submitted to the Victoria University of Wellington in fulfilment of the requirements for the degree of Master of Building Science

Victoria University of Wellington

2018 


\section{RESEARCH TITLE \\ BUILDING INFORMATION MODELLING FOR ASSET AND FACILITIES MANAGEMENT}

Identifying the data needed within a BIM model for asset and facilities management and understanding academic research versus the reality of integrating BIM for asset owners and facility managers.

\section{RESEARCH QUESTION}

Can Building Information Modelling provide a solution for Asset and Facilities Management within the context of New Zealand?

\section{ABSTRACT}

Building Information Modelling (BIM) is an expanding knowledge field driven as a design process within the Architecture, Engineering and Construction industry (AEC). Building Information Models have been predominately used in pre-construction for clash detection and modelling benefits as a collaborative tool. Confusion and false interpretation are common amongst many interested parties, as BIM is often spoken about as a design tool, be it Revit or similar, but not its purpose, as a process. A commonly understood language throughout the construction industry is referred to as model development in BIM, reported as Level of Development Stages. Currently 6 stages are developed (LOD 100, 200, 300, 350, $400,500)$. With this in mind, Building Information Modelling has been used in the construction industry commonly at a stage of development (LOD 300), components are modelled to enable enough data for the model to be used in the construction phase of a project, and often only theoretical research of BIM to the operational and maintenance lifecycle of a building is acknowledged (LOD 500).

This study explores the use of Building Information Modelling as a digital process to understand the necessary inputs (in specific elements) of data for outputs of a BIM process to the stage of model development at a buildings operational and maintenance platform. $A$ comprehensive literature review, a study of companies "traditional approach" to managing their assets and facilities, as well as a "new approach" study of Building Information Modelling, to manage assets was undertaken within the context of New Zealand. 
The expected approach for the future of managing assets from this research suggests a positive opportunity to raise the profile of Building Information Modelling in the asset and facilities space to manage assets and facilities better. For the past generation, technological inventions have been introduced every week, with the trend guaranteed to continue, there is a resilience for change as well as an appreciation for change. It is suggested that as the global construction industry matures in BIM so will the use of BIM in Asset and Facilities Management. There are few software applications developed for the Building Information Modelling Asset/Facilities Management space, the case studies presented in this research paper have implemented Autodesk's Building Ops application as well as a unique tailored approach. Both New Zealand case studies have shown a positive/beneficial use in Building Information Modelling in Asset and Facilities Management. As the construction industry matures we expect to see BIM AM/FM used more frequently, especially for asset owners.

\section{Key Words:}

- Asset Information Model (AIM),

- Asset Management (AM),

- BIM Execution Plan (BEP),

- BIM Management Plan (BMP),

- Building Information Modelling (BIM),

- Common Data Environment (CDE),

- Construction Management (CM),

- Construction Operations Building Information Exchange (COBie),

- Design and Construct (D\&C),

- Design Build (DB),

- Design Build Operate (DBO),

- Early Contractor Involvement (ECI),

- Employer's information Requirement (EIR),

- Facilities Management (FM),

- File Transfer Protocol (FTP),

- Integrated Project Delivery (IPD),

- Level of Detail (LoD), 
- Level of Development (LOD) ,

- Level of Information (LOI),

- Mechanical Electrical Plumbing (MEP),

- Model Element Author (MEA),

- Model Production Delivery Table (MPDT),

- Project Implementation Plan (PIP),

- Project Information Model (PIM),

- Project Management Plan (PMP),

- Project Team Integration (PTI),

- Request for Information (RFI). 


\section{ACKNOWLEDGMENTS}

Thank you to Dr Fabricio Chicca for his role as my Victoria University Supervisor representative for 2017/18 and the entire 5 years of study I have undertaken at Victoria University.

Thank you to Dan Jurgens and Opus International Consultants for your ongoing support throughout my study and the growth I have achieved in my time with the company.

Thank you to Rob Stuart, who believed in me and my work from the very start. Thank you to Brett and Kerin and Russell Group for your support and guidance throughout my 2017 year and for my sponsorship as a keystone student. I look forward to my future endeavours with the company.

Thank you to my scholarship companies, Building Research Association of New Zealand, Ministry of Business Innovation and Employment, New Zealand BIM Association, Russell Group and Opus International Consultants.

Thank you to all the respondents, academics and industry professionals that have become a part of my research and helped this research come together.

Finally, thank you to my family and friends, it has been an absolute roller-coaster of a ride but 5 years on and I would never look back. You've been all the support and guidance a young 24 year could ever need and want and without all of your support I wouldn't have achieved all that I have today. A special thanks to my Mum and Grant, Dad and Mel and Mariah and Karl, you are all my biggest supporters. 


\section{TABLE OF CONTENTS}

RESEARCH QUESTION

ABSTRACT

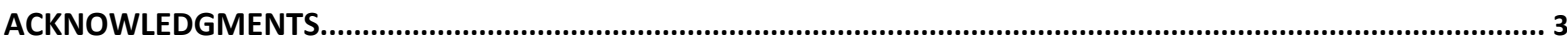

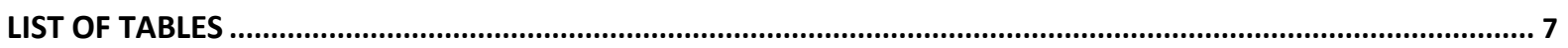

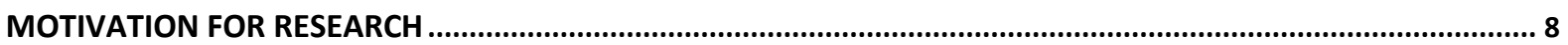

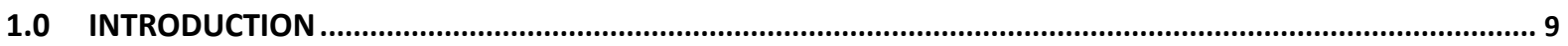

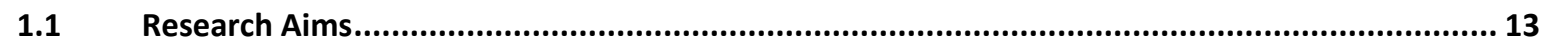

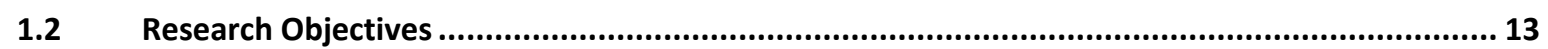

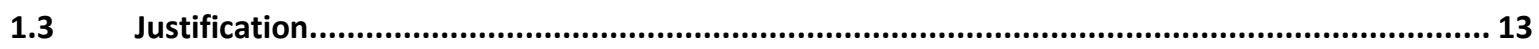

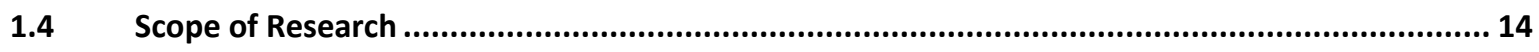

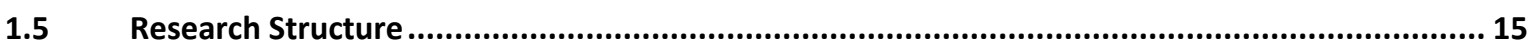

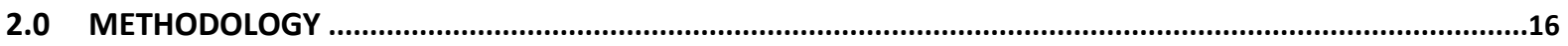

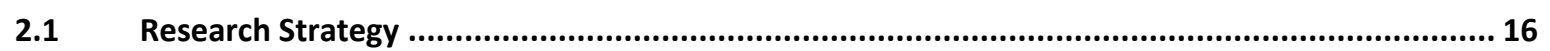

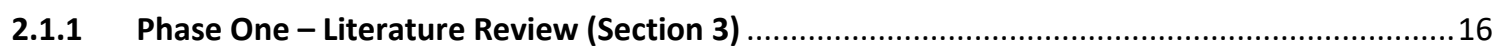

2.1.2 Phase Two - Data Collection - Survey \& Case Studies .......................................................... 16

2.1.3 Phase Two - Initial Research Limitation.......................................................................... 16

2.1.4 Phase Three - Data Collation \& Analysis of Cases ..............................................................17

2.1.5 Phase Four - Conclusions, Recommendations \& Next Steps............................................ 18

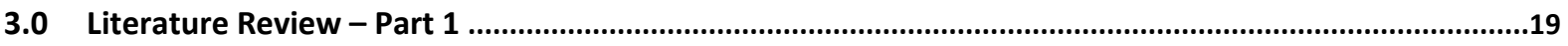

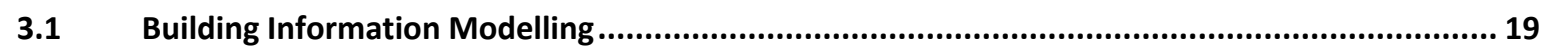

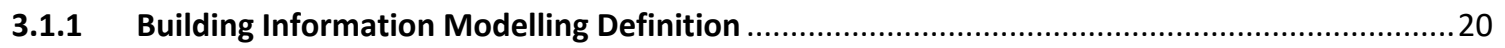

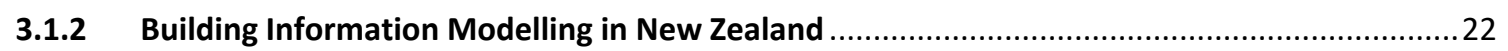

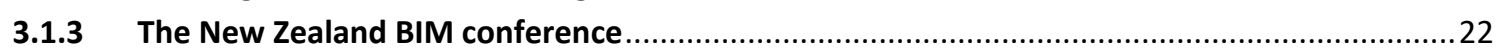

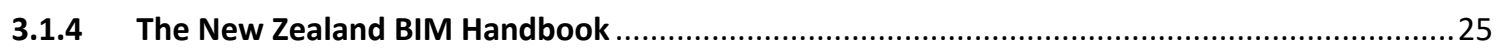

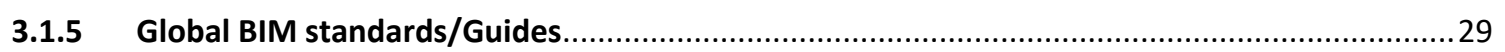

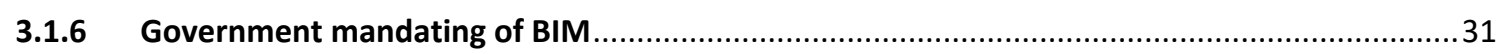

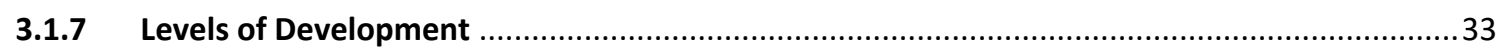

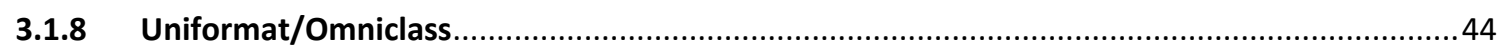

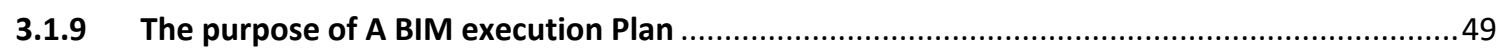

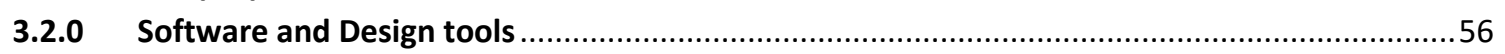

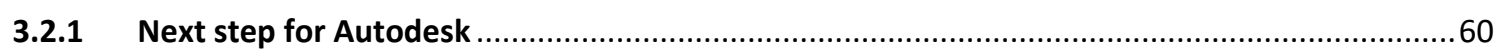

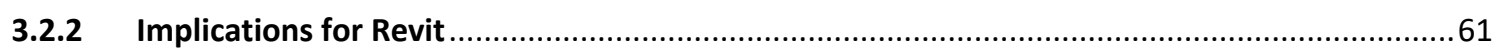

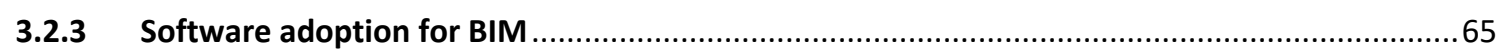

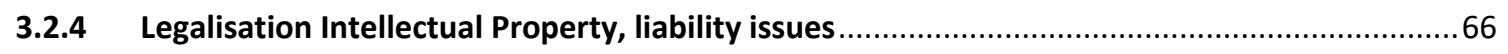

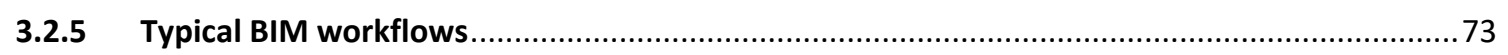

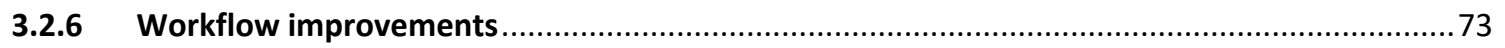

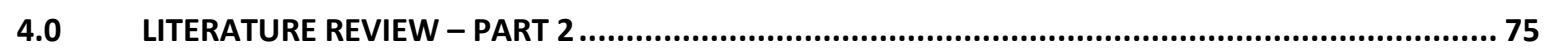

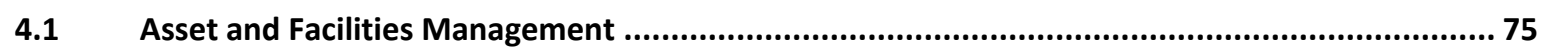

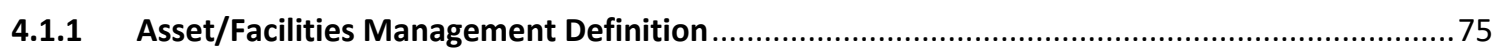

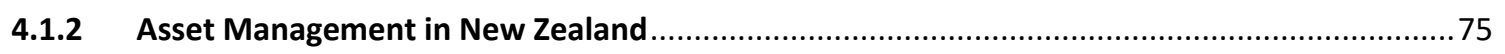

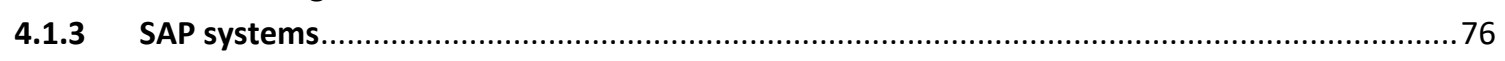

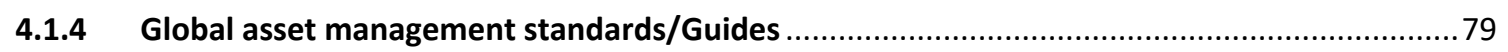

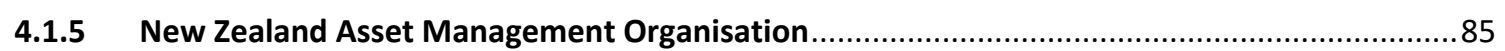

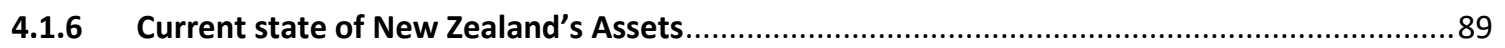




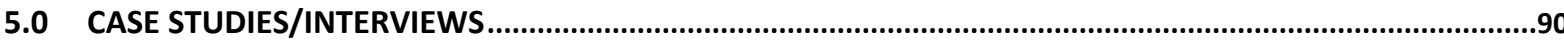

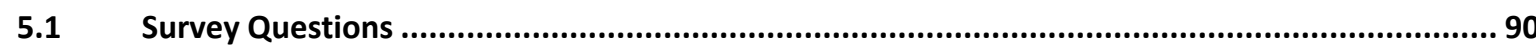

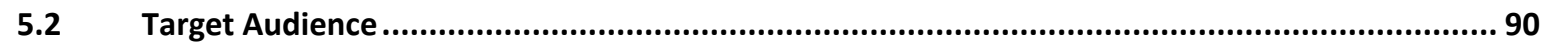

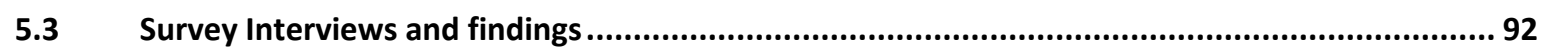

6.0 CASE STUDY - AUTODESK BUILDING OPS/360 GLUE........................................................ 93

6.1.1 Case Study 1 - Mason Brother Precinct Building (BECA) ...............................................93

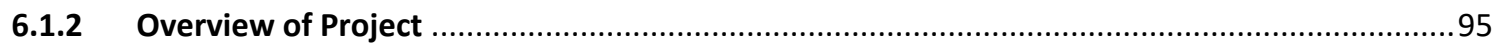

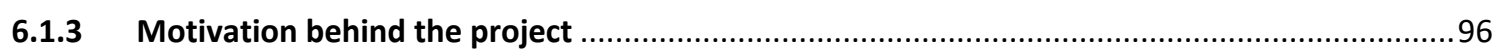

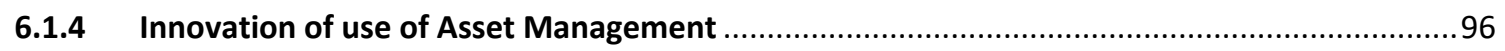

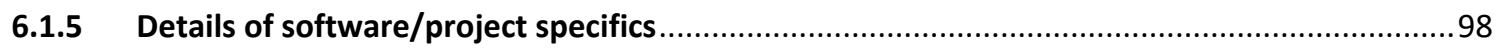

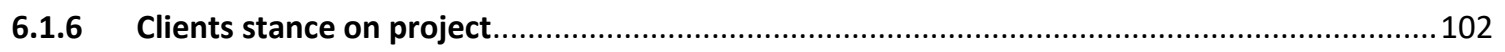

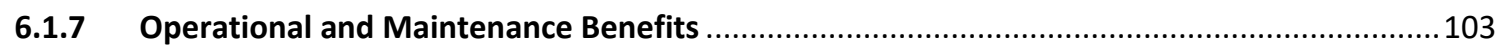

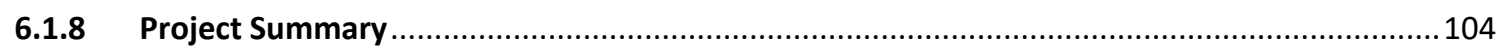

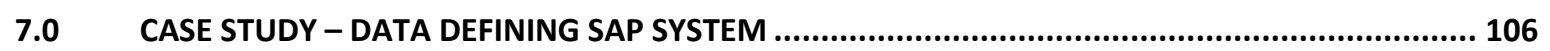

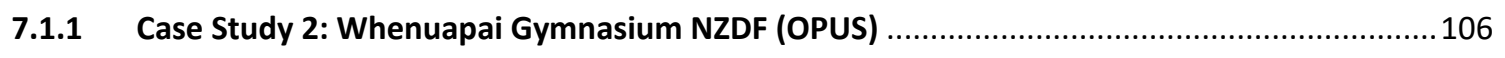

7.1.1 Building Information Modelling at Company X................................................................. 107

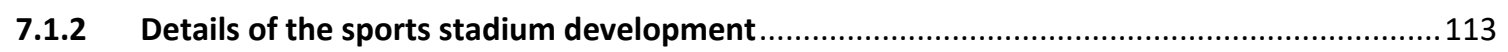

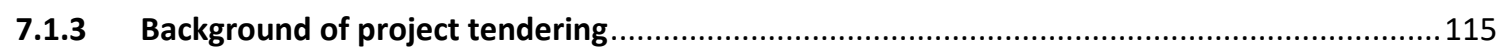

7.1.4 Pre-existing current asset Management Systems: Review of current procedures .................116

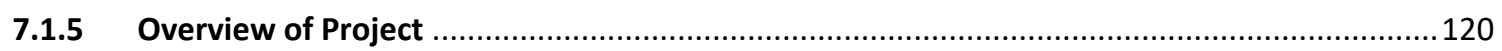

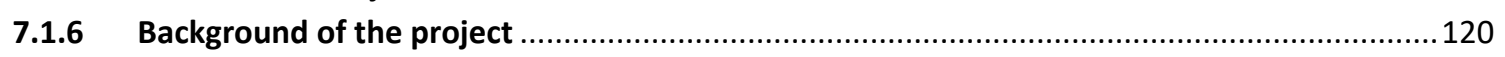

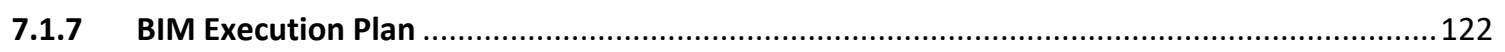

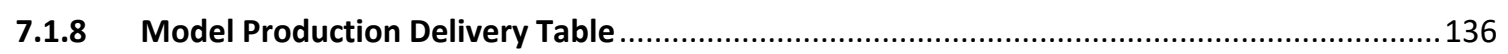

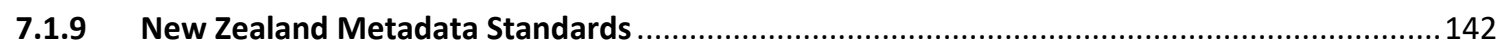

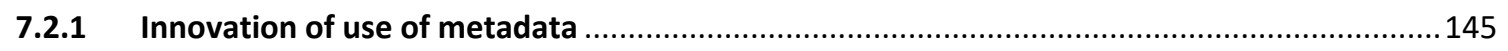

7.2.1 Data in alignment with NZ Metadata Standard ................................................................... 149

7.2.2 Internal correspondence of Quality Assurance on BIM model..............................................173

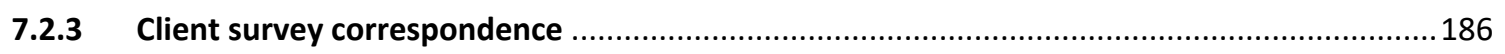

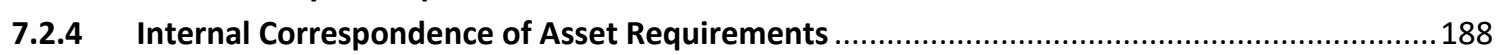

7.2.5 Jubail Royal Commission Infrastructure Programme......................................................... 189

7.2.6 Current client SAP system in line with BIM Modelling ...................................................... 197

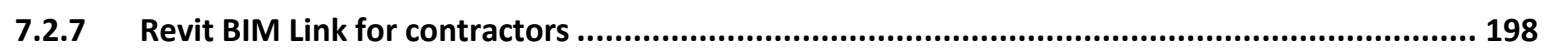

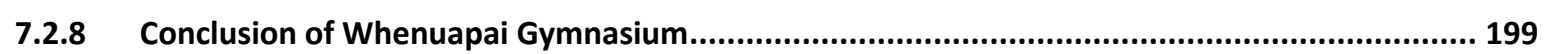

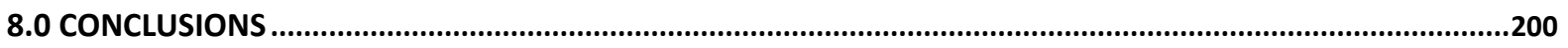

8.1 Benefits of BIM in Asset and Facilities Management ....................................................... 201

8.2 Potential Barriers of Building Information Modelling for Asset and Facilities Management ..... 201

8.3 Misconceptions of Building Information Modelling .......................................................... 201

8.4 Building Owners vs Design team and who is the beneficiary ........................................... 202

G.5 Global use of Building Information Modelling............................................................. 203

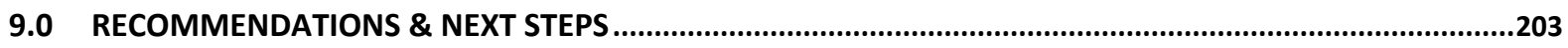

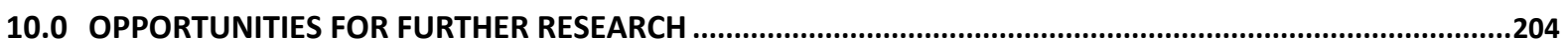

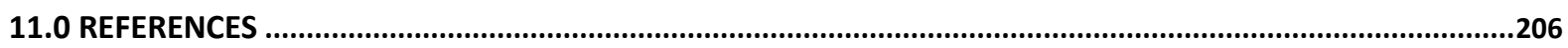

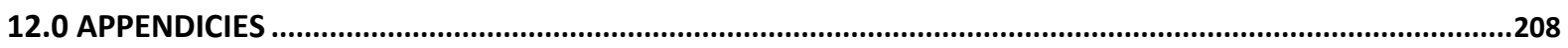




\section{LIST OF FIGURES}

Figure 1: Proportional split of whole of life costs of an asset

Figure 2: BIM Maturity Model originating from Mark Bew Figure 3: Building Information Modelling Lifecycle Model Figure 4: Model Federation Diagram Figure 5: Fundamental platforms in a BIM project Figure 6: Production of BEP development

Figure 7: Project Roles and Responsibilities

Figure 8: Workflow classification

Figure 9: BIM related software through different lifecycle stages

Figure 10: Multidiscipline figure

Figure 11: ECI procurement chart

Figure 12: SAP tool attributes

Figure 13: Global Metadata Schemata

Figure 14: Definition of relationships between assets

Figure 15: Understanding the process of services

Figure 16: Project Benefits Diagram across different aspects of a project

Figure 17: Mason Brothers Building, 139 Pakenham Street West, Wynyard Quarter

Figure 18: Design details of Wynyard Quarter

Figure 19: 3D Model on iPad and construction information to ensure the latest models in hand

Figure 20: Additional Data able to be captured, enabling a link for asset management

Figure 21: Digital Dashboard showing completeness of information against the critical assets

Figure 22: 3D models, critical assets, their data and documentation handed to IPhone for operational use

Figure 23: Common Data Environment Model

Figure 24: Exported navigable 3D model and visualisations produced from co-ordinated Building Information Model.

Figure 25: Information Requirements

Figure 26: Information Hierarchy

Figure 27: GIS Platform

Figure 28: Design details of the Gymnasium

Figure 29: Ground floor plan of Gymnasium

Figure 30: Reporting structure

Figure 31: Four reporting tools

Figure 32: Workflow check

Figure 33: Naming convention asset Meta data spreadsheet

Figure 34: Solibiri Model Checker example

Figure 35: Solibiri Model Checker example

Figure 36: Solibiri Model visualisation

Figure 37: Solibiri Model Changes
Figure 38: Naming Conventions

Figure 39: Solibiri Model Checker example

Figure 40: Columns descriptions

Figure 41: Naming conventions

Figure 42: Graphical user interface

Figure 43: NZAMS Unit of Measure Definition

Figure 44: Asset Life Expectancy

Figure 45: unique Identifier example

Figure 46: NZAMS Building Code List

Figure 47: Element ID for Revit

Figure 48: Revit Schedule Programming

Figure 49: IFC export tab

Figure 50: Data populating

Figure 51: Autodesk warning clash detection

Figure 52: Window Detailing

Figure 53: Door schedule detail

Figure 54: Type parameters information column

Figure 55: Type parameters information column

Figure 56: Solibri Model Checker information take off

Figure 57: Wall descriptions from solibri

Figure 58: Solibri areas and volume tab

Figure 59: Asset metadata information

Figure 60: Type parameters information column

Figure 61: Parameter value

Figure 62: Solibri Model Checker design phases

Figure 63: Solibri ominiclass table

Figure 64: Parameter value model exits for example

Figure 65: Element data selection (Solibri)

Figure 66: Design Phase selection

Figure 67: Project lifecycle diagram

Figure 68: Project Strategic Objectives

Figure 69: Five staged project process

Figure 70: 24 Governance Bodies

Figure 71: Parameter value

Figure 72: Asset Management Questions

Figure 73: Simplified Decision Tree

Figure 74: Uniformat Decisions

Figure 75: Design Capture fields 


\section{LIST OF TABLES}

Table 1: LOD 100 BIM Forum

Table 2: LOD 200 BIM Forum

Table 3: LOD 300 BIM Forum

Table 4 : LOD 350 BIM Forum

Table 5: LOD 400 BIM Forum

Table 6: LOD 500 BIM Forum

Table 7: Model Element Table

Tables 8: Delivery Manual Table

Tables 9: Omniclass spreadsheet

Tables 10: LOD Spec Sheet

Table 11: Uniformat table classification

Table 12: Asset Categories

Table 13: Authorised use of BIM

Table 14: Model Production Delivery Table

Table 15: Excel Spreadsheet Model Production

Delivery Table

Table 16: Excel Spreadsheet MPDT Design and

Contractor

Table 17: Excel Spreadsheet data requirements

Table 18: Metadata spreadsheet

Table 19: Metadata spreadsheet

Table 20: Metadata spreadsheet

Table 21: Metadata spreadsheet

Table 22: Metadata spreadsheet
Table 23: New Zealand Asset Metadata data table

Table 24: New Zealand Asset Metadata code list

Table 25: NZAMS asset classes

Table 26: Parameters

Table 27: Unit of measure column

Table 28: NZAMS File Format Instructions

Table 29: Unit of measure column

Table 30: Unit of Measure table

Table 31: Unit of Measure table

Table 32: Space ID classification spreadsheet

Table 33: Design team vs Construction team metadata

Table 34: Type parameters information column

Table 35: Instance parameters information column

Table 36: NZAMS specified systems

Table 37: MDPT Shared Parameters

Table 38: Existing Parameters

Table 39: NZAMS code list

Table 40: Asset metadata requirements

Table 41: Room number and naming conventions

Table 42: Asset Management Tree

Table 43: Levels within the Asset Management tree

Table 44: Asset Management Strategies 


\section{MOTIVATION FOR RESEARCH}

Currently, Building Information Models are being used for clash detection in the design phase successfully, with little research in the operation and maintenance stages of a building. It seems illogical as $87 \%$ of the cost of a building is endured at an operational phase. Because of these reasons stated above, this has been the biggest driver and motivation for my research (BRANZ, 2016).
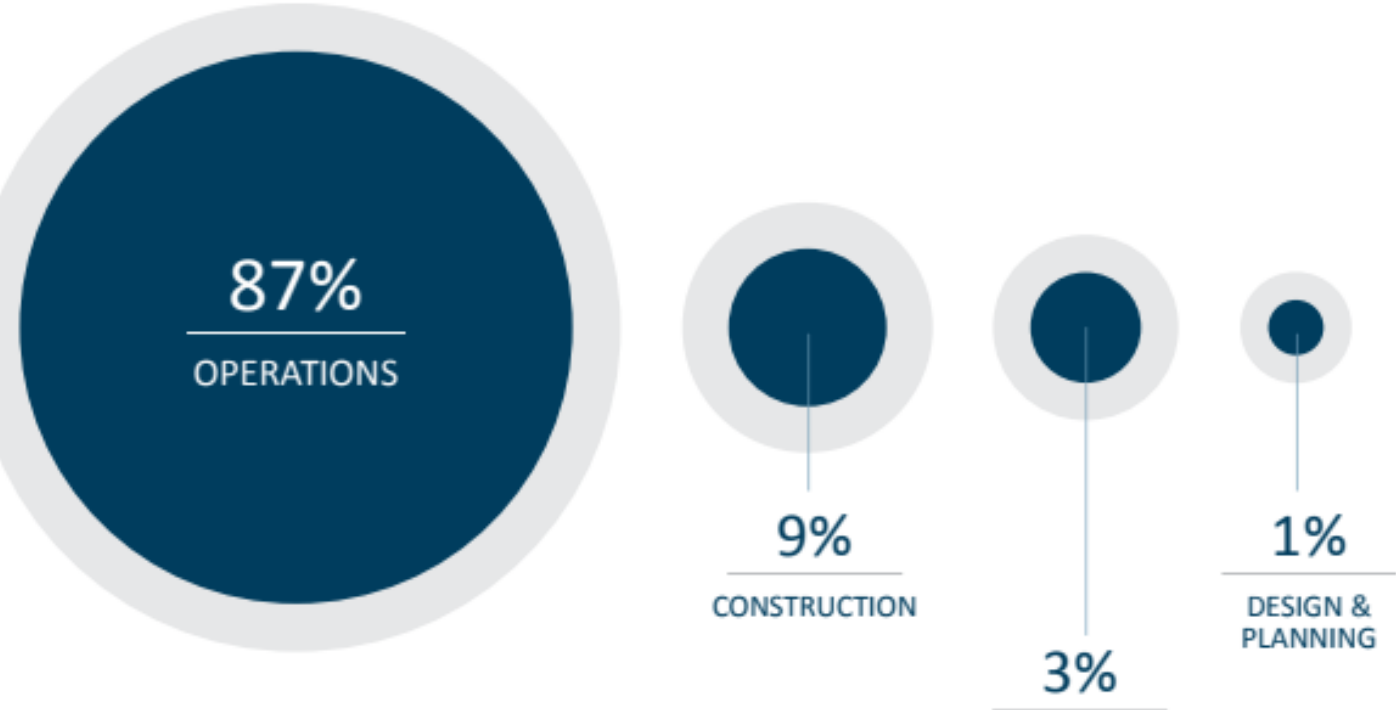

TRANSITION

Figure 1: Proportional split of whole of life costs of an asset 


\subsection{INTRODUCTION}

Building Information Modelling is currently being used, discouraged, encouraged, mandated and delivered globally within the construction industry. BIM historically is partially used successfully in the construction industry for design clash detection; the process allows the project team to collaboratively integrate their design to ensure that there is a "no surprise design" throughout the construction phase. The UK government has recognised that BIM helps to provide success in boosting delivery and operational efficiency, reduce costs and improve value, as well as a reduced carbon footprint (Gurevich, Sacks, \& Shrestha, 2017). The UK government embraced the BIM process by mandating its use to maturity Level 2 on all centrally procured projects by 2016 .

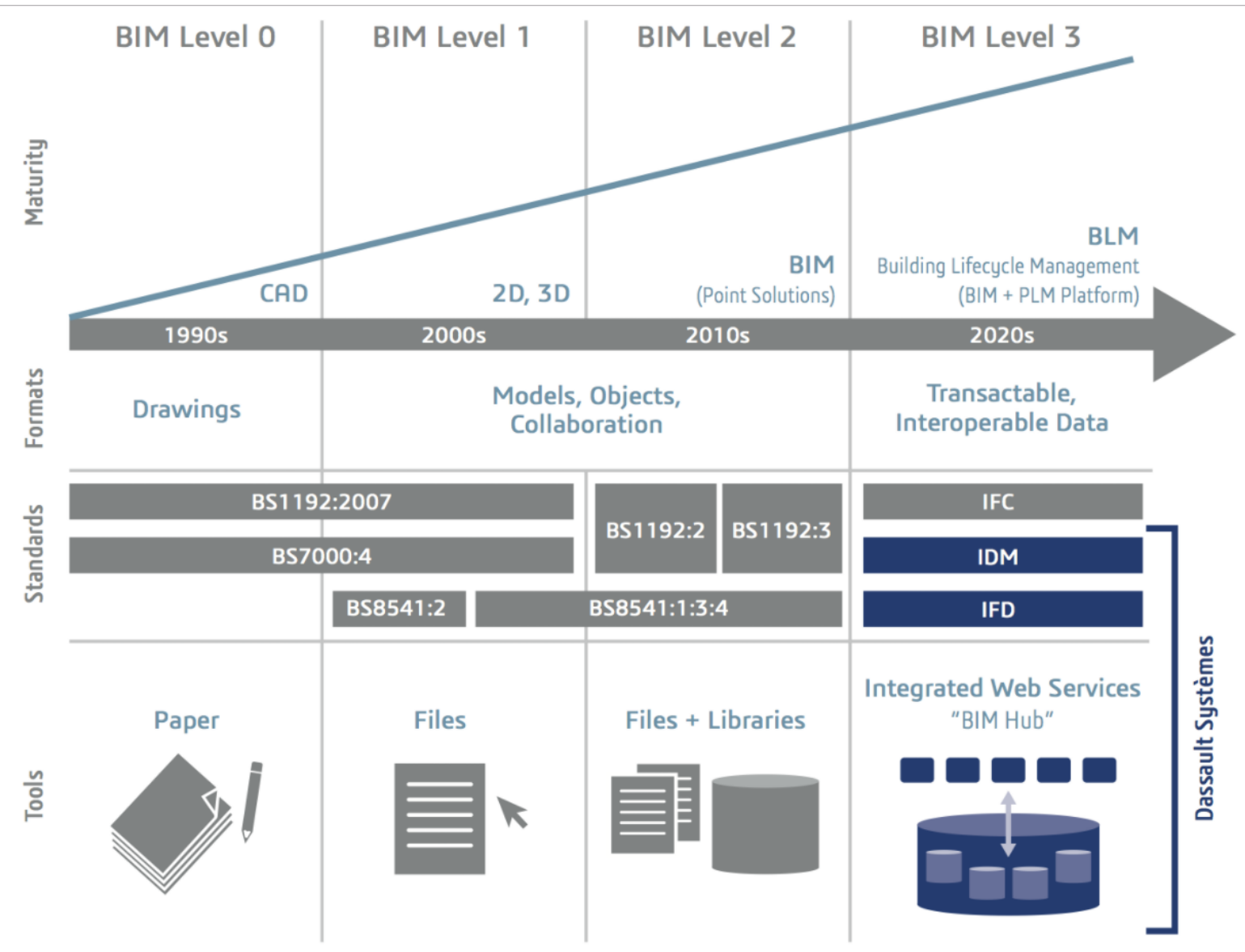

Figure 2: BIM Maturity Model originating from Mark Bew

As shown in figure 2, BIM maturity levels were developed in 4 stages as a way of becoming the accepted definition for the criteria in being deemed BIM-compliant. The adoption process through the maturity levels shows the journey the industry has adopted, from the drawing board to computer and now the digital environment. 


\section{The levels of maturity are defined below:}

BIM Maturity Level 0 - No collaboration, 2D CAD drafting, paper and electronic printed documents.

BIM Maturity Level 1 - A combination of 3D CAD drawings and 2D drafting and the electronic sharing of data is carried out from a common data environment (CDE). Models are not shared between parties.

BIM Maturity Level 2 - This is the basis for collaborative working, all parties work in their own 3D CAD models, not necessarily on a single, shared model. The collaboration comes from how the parties collaboratively exchange information. The data/information is shared through a common data environment combined to make a federated BIM model. The CAD software utilised must be capable of exporting to the common file formats (IFC, COBie for example). As specified below the UK government has mandated government projects to this BIM Level 2.

BIM Maturity Level 3 - Ultimately this is the future goal of BIM collaboration. BIM level 3 involves full collaboration between all disciplines using a single, shared project in a centralised model. All parties can access and modify the same model. This defines OpenBIM, issues around liability and copyright currently are hindering on the industry progressing with Level 3 BIM. It is suggested that these issues intend to be solved by originator/read/write permissions and later by shared-risk procurement such as partnering.

The UK to date is the only country to mandate standards with other countries such as the United States and Scandinavia implementing BIM by adopting standards and introducing professional associations (Gurevich et al., 2017). With a shift in process, the construction industry is slowly migrating to adopting Building Information Modelling. Places such as Finland has standardised Building Information modelling procedures and although they aren't mandated like the UK, the adoption of BIM is said to be high. A probable issue with mandating Building Information Modelling is the speculation that when enforcing the use of BIM, users are said to implement this as a benchmark to cross the line as opposed to implementing it to achieve better objectives. Although the UK have seen positive enforcement with the mandate there are situations where BIM has not reflected a positive use however where necessary boxes have been checked. 
This research looks to determine at what stage the necessary data inputs are required, through analysing current studies and practices, to determine what data/how much is needed, and through what software these data fields can be utilised in the operational and maintenance stage of a project. To achieve this, a thorough literature review, exploring case studies using BIM and understanding current use of Facility Management/Asset management was researched. Identifying the extent of data needs and software implementation requirements were challenged to understand the BIM process at the level of Facility and Asset Management.

Lack of use of a BIM model in the operational stages is the ultimate barrier in this study due to the need for new software and complicated procedures for the operational and maintenance requirements. It seems illogical, however, that the drive for this is not pushed further as the vast majority of studies indicate reduced costs and time as well as the fact that a buildings operational/maintenance phase is the highest contributing cost over a building's lifecycle (Oti, Kurul, Cheung, \& Tah, 2016).

Documented case studies and literature identified many scenarios where extensive data was imputed into the model with the misinterpretation that such inputs would be crucial and provide better use of the model at later stages, for example, operational phases. Subsequently, this exposed the need to identify and document necessary data inputs for operational/maintenance outputs unique to every project and to not over produce unnecessary data (British Institute of Facilities Management, 2015). Traditional approaches of construction phases see the Facilities/Asset Manager come into the project at the operational stage, therefore the data entered into the models and associated data often has not been discussed with the end user. To completely understand what information is needed in the operational phase, it seems prudent that engaging the right stakeholders in the onset of a project is crucial. The two case studies presented in this research both engaged the Facility Manager at the beginning of the project. BIM seems to be changing the way people in the construction industry work as well as ensuring the right stakeholders provide input at the necessary points. 
Construction experts and large organisations are currently exploring and implementing the use of BIM in the AM/FM space with companies starting to consider the adoption of such procedures. There is a positive outlook on the future uptake of BIM within multiple organisations and among construction professionals. There is a great stance from clients who do not see the benefits of such a process, clearly identifying BIMs potential as a virtual building technology and its implications from a legal point of view is necessary ("Building Information Modelling ( BIM ) for Facilities Management--Literature Review and Future Needs," 2014). The majority of research suggests that BIM uptake in the FM/AM space will naturally become second nature to businesses, as education becomes greater, government drive is recognised, and software becomes easier to transfer data. For example, specific software such as Revit (modelling tool), COBIE (data exchange) and Ecodomus (Facility Data Management Platform via common data environment) will naturally progress to improve exchanging data from one to another in an easier and more user-friendly way. It is likely that current problems with software may become obsolete as time progresses (Management, 2013).

It is not feasible to suggest that BIM in the FM/AM replace current practices at this present point in time but perhaps be introduced gradually until the process is well developed and confidence in this area is gained amongst industry to which BIM FM/AM becomes the norm. It is speculated that as the trust and use of BIM throughout industry progresses the likes of governance bodies in New Zealand will follow the government trends of overseas governing bodies and start to mandate the use of BIM in government construction projects. There has been no indication from any government agency or body to suggest a BIM governing framework and it isn't expected to be mandated in the immediate future (NZ BIM Conference). Building Information Modelling is likely to start to replace two dimensional drawings, CAFM systems and the likes, the new way of collaborative work will draw an end to many current tools and processes, it isn't expected to see dramatic change however will enforce more succinct practice ("Building Information Modelling ( BIM ) for Facilities Management--Literature Review and Future Needs," 2014). 


\subsection{Research Aims}

The research aim will be to answer the research question identified above. The intent of this thesis is to understand what data is needed for BIM in the asset and facilities management stage for full utilisation by the building owner/operator. This is achieved by exploring current literature as well as case studies. It is also essential to provide a data spreadsheet method to systematically analyse the necessary data inputs for a general construction projects. This is an important deliberation to consider going forward for the use of BIM in asset and facilities management as there appears to be no formal documents specifying data requirements. Current BIM model spreadsheets and formal data check sheets are predominately for the predesign to construction phases only as BIM often is not utilised at the operational stage of construction.

\subsection{Research Objectives}

- This thesis will assess to see if BIM can provide a solution for asset management.

- The purpose is to understand current industry processes and compare against a BIM process

- The idea of the thesis is not to confirm the efficiency of BIM in AM/FM but to test the hypothesis of whether BIM provides a solution for Asset and Facilities Management.

- This research will review current BIM processes and demonstrate the use of BIM within the New Zealand context

- A review some of existing methods of Asset and Facilities management practices

- Present recommendations and next steps to accelerate the adoption of BIM in the asset and facilities management stages

\subsection{Justification}

Building Information Modelling for asset and facilities management is at an undeveloped level and because of this, there is more of a theoretical approach and evidence developed than tested methods. As the scope of a master's thesis is limited and there are pressing time restrictions the focus of the thesis is in the New Zealand market for simplicity purposes and the ability to access information. For the testing aspect of this section of the thesis an individual project is chosen, the reason for this is that completely analysing a BIM project and 
interpreting uncommon language is timely. The limitations to this is that comparing the data and processes will be done in a theoretical form allowing next steps or further research to be documented. The main project Whenuapai gym will be compared to The Mason Brothers building to allow for conclusions to be drawn.

\subsection{Scope of Research}

Commonly, Building Information Models are being used for clash detection in the design phase successfully, with little research in the operation and maintenance stages of a building. With the current documented successes of BIM it seems illogical that BIM uptake in the Facilities/Asset Management stage hasn't been further explored, with $85 \%$ of the cost of a building being endured at an operational phase. This research is limited to exploring only the potential of Building Information Modelling (BIM) in the facilities and operational stage. It focuses on the current use of BIM in this stage and the potential BIM could have in the New Zealand industry.

This research explores the subject from a New Zealand perspective only, with few global exemplars. The student author is a New Zealander working within the New Zealand construction industry and the research and opinions is a majority of the experience of this market. The research does assume that the reader will understand the construction and built environment to capture the definitions and overviews of the AEC industry.

The scope of the research excludes the following definitions, research and discussions around Building Information Modelling:

a. Success case studies of the overhaul of Building Information Modelling: this research focuses on an aspect (Facilities/Asset Management) although the author acknowledges the importance of understanding the success of BIM as a general overview

b. BIM maturity: This is a scaled system that measures the countries associated performance and their current stance, for example the United Kingdom is mandated to BIM maturity level 2.

c. Construction procurement/procurement models how this is understood to be delivered \& integrated project delivery 
d. Legal implications of Building Information Modelling: who owns the model through the process of BIM. Commonly the BEP will document whom owns the model at what stages. It can be assumed that at the end of a project the building owner will need/want to own the BIM model. The architect is likely to retain overall design responsibility. The architect is unlikely to accept responsibility for the design model that other parties have contributed too, here lies the issue and ownership of intellectual property.

e. Legal and technological aspects: how do contracts evolve in a digital modelling space f. Cost estimation and fabrication of modelling aspects in comparison to traditional approaches

g. BIM on existing buildings, the research focuses only on implementing BIM on a new construction project

The researcher acknowledges that the importance of the above topics is crucial in a Building Information Modelling space however for this research and the limited nature of a Masters project the definitions and associated understanding are excluded from the scope of this research. The author does however feel the reader should have a general overview of the sited topics and recognises that these topics are all relative to the success of any given BIM project.

\subsection{Research Structure}

The thesis includes ten main sections, which are specified to introduce the topic of Building Information Modelling in a levelled manner. Sections 1-3 progressively inform the reader of the basis and fundamentals of BIM and introduce the following section of research accordingly. As the research progresses the overall tone of the information progresses from a low level to a higher level of understanding.

Following the introductory sections, the comprehensive literature review links to the case studies presented in the last section with referencing common uses of Facilities Management systems today. 
After the case studies a series of results are analysed to present conclusions, recommendations and next steps for further research in this field of Building Information Modelling in Asset and Facilities Management.

\subsection{METHODOLOGY}

\subsection{Research Strategy}

\subsubsection{Phase One - Literature Review (Section 3)}

The purpose of the literature review was to generate an in-depth understanding of the existing research around the subject of Building Information Modelling in asset and facilities management. The purpose of this investigation is to form the foundations of the following sections and phases of the research. The literature review formed the basis of the questions in the respondent's surveys and the information needed from the case studies. The development of the survey and case study analysation was formed from the literature review.

\subsubsection{Phase Two - Data Collection - Survey \& Case Studies}

The second phase of the study included analysing of two case studies with experienced industry professionals. The information for case study 2 was firstly initiated as an email correspondence with the researchers fellow employee. Following this process the employee then provided a link to the entire project, a large proportion of the information that was gathered is not and will not be in the public eye. To ensure the information was gathered in the correct and ethical manner Victoria Universities ethical procedures were considered. The data and information has been offered against a confidentiality agreement.

The goal of the investigation was to compare two different case studies that are currently underway or recently completed within the New Zealand construction industry. As BIM for asset and facilities management is a new concept that few companies/industries are exploring the number of case studies to select was limited and few and far between.

\subsubsection{Phase Two - Initial Research Limitation}

To date, as far as this research has reached, there seems to be only one completed case study and one being currently implemented, the data has been offered for use of this project against a confidentiality agreement. 
This was a limitation to this research, although the data is limited in that there are only two case studies available, comparisons were still able to be made. The goal of the research was to find two case studies for comparison, to determine a possible solution for asset and facilities management.

The research had two respondents and case studies of which one respondent was analysed on various occasions with the project being followed throughout the entire pre-design/design phases. The second respondent of case study number one had no correspondence with multiple documents on said case study handed over to be reviewed and documented. Although case study 1 was limited in the information that was gathered as opposed to case study 2 , comparisons were still able to be made.

The information gathered with case study two was designed to work alongside the project to document all information related to the project as it progressed. The weekly meetings were also designed to generate discussion and document key issues and successes with the project. The first case study was purely used as a comparison mechanism.

The two respondents were:

- $\quad$ A global Building Information Modelling Manager for a large consultancy firm

- $\quad$ A senior engineer/BIM consultant for a large consultancy firm in New Zealand

\subsubsection{Phase Three - Data Collation \& Analysis of Cases}

The results and outcomes of both case studies were analysed and collated during phase three of the research structure. The two case studies were broken down and compared to representing similar sized projects within the New Zealand construction industry. Although only apparently one of the case studies had been fully implemented to the operational stage, an analysis was still able to be made as most of the data input needed was documented in the design phase of the project. Reviews were carried out on the two case studies, the researcher scrutinised the two BIM construction managers of both projects and transcribed their learnings and input for the projects. Note these transcripts are not included. 


\subsubsection{Phase Four - Conclusions, Recommendations \& Next Steps}

In the final phase of the research, conclusions and further steps are drawn and presented as a way of the understanding Building Information Modelling in the Asset and Facilities Management space and to educate the construction industry to understand the data inputs for this stage of BIM. The final section of research is to collaborate all the information gathered and present to the construction industry as a BIM AM/FM dictionary. 


\subsection{Literature Review - Part 1}

The following literature review is split into two main categories with subtopics in each category. The two main categories address the research question in its two parts, to then combine the information for the basis of further research in the following phases. The understanding and implementation of Building Information Modelling is firstly discussed, followed by defining current uses and systems in the Asset and Facilities Management space. The first stage of research also investigates how various countries and government organisations have adopted BIM procedures and standards and their stance on mandating this process. From there, the combined Building Information Modelling for Asset and Facilities Management is explored. The literature review concludes with identifying the current state of the New Zealand asset portfolio and where BIM lies in the operational phase.

When considering BIM adoption in the construction industry and the Asset and Facilities Management space aspects throughout the design phase need to be considered. Issues associated with BIM in $\mathrm{AM} / \mathrm{FM}$ include perception, standards, policies, information management and skills. A key issue with current business as usual approach sees many different organisations and roles take part along the building life cycle, as BIM was introduced as a through life approach this defers from the current approach creating an uncertain shift for the key stakeholders (V. Singh, 2014). Ibrahim (2014) notes that the biggest challenge to overcome is the identification of critical/crucial data and ensuring that the output satisfies the facilities management requirements. Other issues, including defining the necessary information needed in the model as well as the use of specific software is documented. Both points develop on the aspect that a BIM AM/FM project requires extensive stakeholder engagement that is currently not the business as usual approach.

\subsection{Building Information Modelling}

Building Information Modelling (BIM) is a term that has become pervasive in the architectural, engineering and construction (AEC) industry over the past 20 years but more so in the last 5 years (Aconex, 2016). 2D dimensional CAD workflows were the Business as usual approach, the United States, Western Europe and Soviet Block competed to create an architectural software solution that had the means and ability to disrupt the 2D CAD (Aconex, 2016). There are many definitions and defined processes in adopting BIM, however depending on the 
user/reader there is no one definition that fits all and commonly a definition is adopted that suits the user be it design, construction or operation (Aconex, 2016).

\subsubsection{Building Information Modelling Definition}

As stipulated above there are many definitions of BIM and the focus will vary from designer to constructors and operators.

The UK NBS organisation defines BIM as a process for creating and managing information on a construction project across the project lifecycle (NBS, 2016). One of the key outputs of this process is the Building Information Model, the digital description of every aspect of the built asset. This model draws on information assembled collaboratively and updated at key stages of a project. Creating a digital Building Information Model enables those who interact with the building to optimize their actions, resulting in a greater whole life value for the asset.

In a more simplistic definition, the US explains Building Information Modelling is a digital representation of physical and functional characteristics of a facility. As such, it serves as a shared knowledge resource for information about a facility, forming a reliable basis for decisions during its lifecycle from inception onward (NBS, 2016).

Similarly, the New Zealand Building Research Association (BRANZ) simplistically defines BIM as: It involves building better processes using a model with real life attributes within a computer and sharing that information to optimise the design, construction and operation of that asset. Used well, BIM can build better performance over the whole life of a built asset. (BRANZ, 2016). 


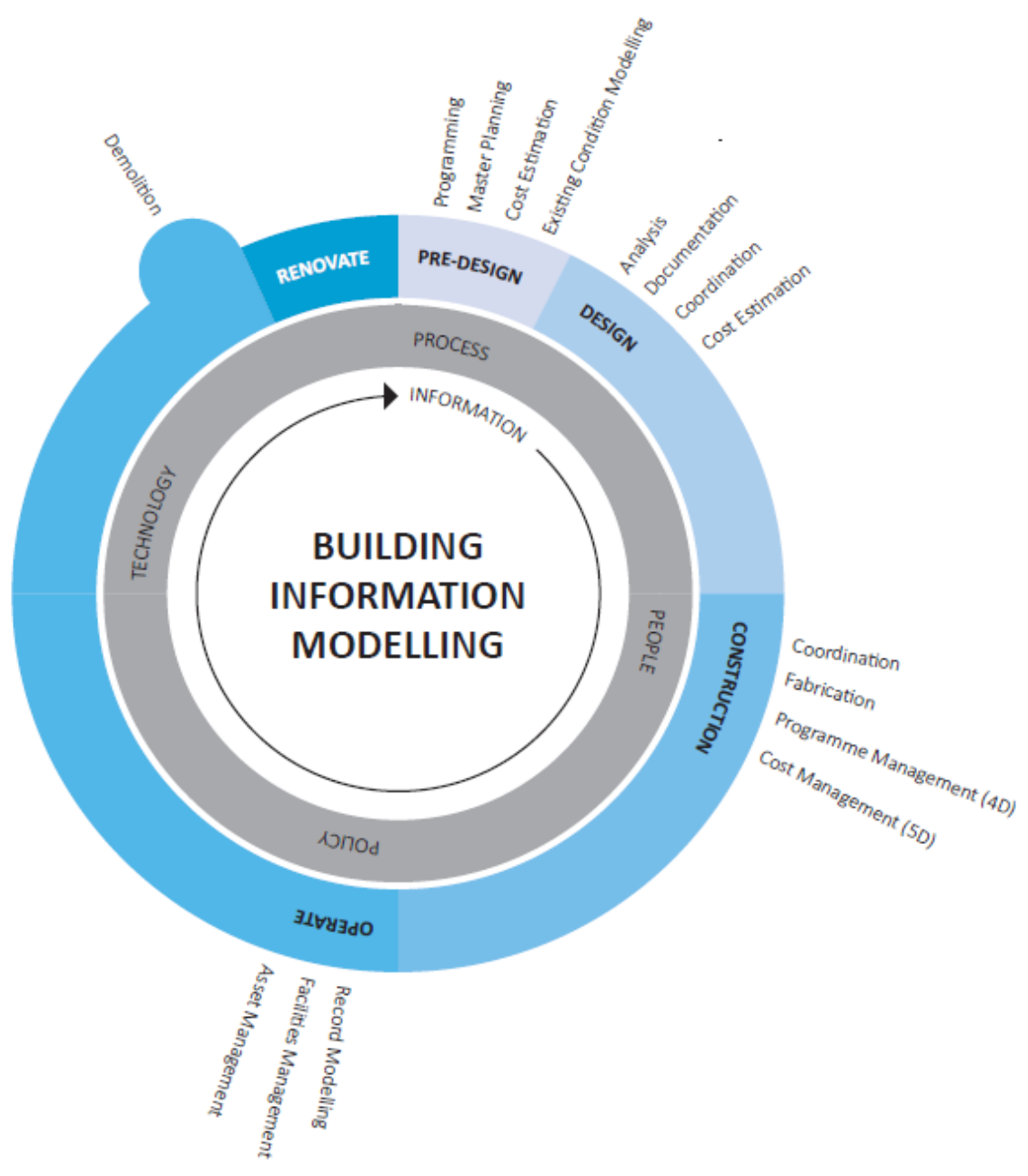

Figure 3: Building Information Modelling Lifecycle Model

Although these definitions defined above are vastly different, they all allude to the same principles. As this research focuses on the New Zealand construction industry, the adopted definition for this research is defined by BRANZ.

Furthermore, the New Zealand BIM Handbook 2016 acknowledges that: BIM can contain information/data on design, construction, logistics, operation, maintenance, budgets, schedules and much more. The information contained within BIM enables richer analysis than traditional processes. Information created in one phase can be passed to the next for further development and reuse (BRANZ, 2016). 
The key principle is that BIM is not any single act or process. It is not creating a 3D model in isolation from others or utilising computer-based fabrication. It is being aware of the information needs of others as you undertake your part of the process (BRANZ, 2016).

\subsubsection{Building Information Modelling in New Zealand}

On the more significant and complex project, designers are now utilising 3D modelling. In doing so this is now resulting in improved coordination. Main contractors are now requiring their supply chain to provide construction phase BIM inputs to increase coordination as well as reducing wastage and in assisting digital handover to the asset owner (Reding, 2014).

The depths of the supply chain that can support a BIM project in New Zealand is limited due to the apparently slow acceptance and application of the process. It is explained that when preparing a Project BIM Brief and evaluating the BIM evaluation and response template it should be ensured that the clients goals and delivery team is matched.

An increasing number of projects are requiring BIM to be maintained throughout the construction phase to provide as-builts at handover. The maintenance of the model may be undertaken by the contractor or agreed to in the designer's scope of work.

\subsubsection{The New Zealand BIM conference}

The New Zealand Construction Industry is slowly progressing in the Building Information Modelling space, construction professionals throughout New Zealand have formed groups and organisations to help escalate BIM's uptake in New Zealand. The New Zealand BIM conference was held on 25/26 October 2017 to share the current uses of BIM and experiences in New Zealand amongst a wide range of New Zealand Industry Professionals. The agenda of the conference was to bring together key stakeholders in the building, constructing and designing industries to discuss the current and future applications of BIM in New Zealand.

Karl Fitzpatrick a BIM Manager for the Auckland International Airport spoke on experiences in BIM from a Nordic Proficiency. The Nordic climate has very harsh weather conditions, because of this there is a need for innovation, and for quick construction. Finland is ranked number two in the world for ICT and has an open share of data, something New Zealand does 
not have and consequently there are small silos that create barriers to data share within New Zealand. What New Zealand could take from the Nordic way in how they share data to better improve the entire construction industry. This leads onto processes and people collaborating, the Nordic have achieved BIM data share due to high use of collaboration, where this is lacking for New Zealand. New Zealand sits among many small silos where data share is seen as a misconduct, for collaboration and improved process the New Zealand construction industry requires a change in thinking and doing for example data share.

A panel of construction professionals made up of Tim Melville (President Elect), Tim West (BIM construction manager Fletcher Construction), Dennis Burns (Director Archaus) and Steve Davis (Director Assemble) they were asked how can construction professionals support the uptake of BIM in New Zealand?

One of New Zealand's biggest issues is that buildings aren't valued and developers are there to make money, not to value the integrity of the building. Currently New Zealand sits in a silo where the perception in some BIM situations is foreseen to be around plagiarism and collaborating. The thinking needs to be shifted to working together to create better outcomes.

Steve Davis, director of Assemble spoke on the adoption of the New Zealand BIM hand book and how the industry has progressed from the 2014 version 1 to the 2016 version 2 . The BIM hand book was created in 2014 as a starting point for the New Zealand construction industry to have a reference to a document when, a wanting to understand BIM and B implementing it. The BIM handbook was created off other countries publications, the aim was to take from already published references and not to reinvent the wheel. Version 2 was created based on industry recommendations and learnings as they have come about, the handbook is a living document. It is noted that the future of the handbook will look in more detail of asset and facilities management as New Zealand or other parts of the world are in an infinite state.

Mark Thomas, CEO of Next Space defined BIM for whole of life construction. BIM in this area is not just the management of modelling but information management. It is suggested that for BIM to be successful it needs to escape the CAD world. Currently models are not user 
friendly with excess data. BIM outside CAD requires model structures and data requirements, tools needed to create and edit data should be different. Forms of data to be linked with all components of the building. "Deconstruct CAD data" get data for every component to be linked out. It is not suggested that legalising and mandating BIM within the New Zealand Construction market is the way to go as it is likely to shift to be market driven.

Nick Clements, BIM project leader at Masterspecs explained metadata in BIM, and the way in which BIM models can be used to make decisions and resolve issues. BIM software can be categorised as followed:

- $\quad$ BIM authoring: Revit, archicad, vectorworks

- $\quad$ Checking/validating: Solibiri

- $\quad$ Collaboration: BIM 360 glue

- Data transfer: IFC, Solibri, COBIE

Currently there is no industry wide standard for Facilities Management systems such as SAP and the likes, because of this each organisation is determining their own standard and consequently there is no ability to compare as well as no distinguished best approach.

Chris Vorster, BIM Manager at Architetus defined the implications of BIM in multi-stakeholder projects. For a BIM project success, the client must be the process of the BIM brief. New Zealand does not have a common data environment and therefore it seems impossible to fully utilise BIM without this. It can be assumed that there is no common data environment due to sharing of intellectual property, protection of data and data mining. It is not clear nor has a solution arisen to move past these issues, suggestions have been made to extend IP protection using technology as well as watermarking content in Revit but has not yet been achieved.

The New Zealand BIM conference is an effort to bring together industry lead professionals to share their experience and lessons learnt in implementing and engaging with Building Information Modelling. The aim of the conference is to not glorify organisations and their use with BIM to be seen as a gold medal winner but more importantly to educate and learn from how others and their experience. 


\subsubsection{The New Zealand BIM Handbook}

The New Zealand BIM Handbook was released in 2014 as a starting point for the New Zealand market and was developed from adopting other countries similar documents. As a part of lessons learned and industry recommendations, version two of the NZ BIM handbook was released in 2016. Version 2 of the handbook provides more detail from that of version 1 around workflows, common data environment and levels of development. As well as this a BIM evaluation and response template has been added. It can be understood that the NZ BIM handbook is a living document and as the country further develops it would assume an updated version be published to meet the current industry performance. The NZ BIM handbook is currently structured in the way a typical project is progressed and details aspects such as project establishment, design, procurement, construction, handover and operation. The appendices provide a more detailed over view of the sections (BRANZ, 2016).

The driver of this handbook has been driven by the BIM acceleration committee and the Ministry of Business, Innovation and Employment. This version of the New Zealand Handbook does not detail every aspect of BIM in detail and focuses on the design and construction of the building life cycle. For the purpose of this research the New Zealand Handbook currently is not likely to create any insight into the future development of BIM in asset and facilities management, a further version of the handbook will be released as this process develops.

The handbook is structured to fall in line with the typical progression of a project:

- $\quad$ Project establishment/briefing

- Design

- $\quad$ Procurement

- $\quad$ Construction

- Handover

- Operation

The New Zealand BIM Handbook (Appendix 1) references international standards, codes and guidelines specifically PAS1192 (Appendix 2) and the UK standards. The New Zealand Construction Industry is tasked with publishing design document guidelines and works in line 
with the handbook to co-ordinate BIM and design. The focus of both organisations is to define the responsibilities of both parties involved in the design and construction phase by phase.

The New Zealand BIM handbook provides high level detail where a BIM execution plan allocates and defines specific procedures and is project specific down to the minute details. There are three main documents referred to in the NZ BIM Handbook, A project BIM Brief, BIM evaluation and response template and BIM execution plan. All these documents have been adopted from already published documents in the global AEC industry. The BIM Handbook documents BIM basics, the legal implications of BIM, typical work and modelling and documentation practice (BRANZ, 2016).

As an informative document the New Zealand BIM handbook defines BIM basics. This section of the handbook is a good resource for beginners and is targeted at a low level. The first step of BIM is understanding its uses as part of a common language this is referred to in appendix D of the handbook (Appendix 3 attached).

Models and federation in the current New Zealand market often occurs with each designer or sub trader producing their own model. The models are then combined to create a single model. Changes needed are made in the individual models. The diagram below graphically represents this typical work flow. 


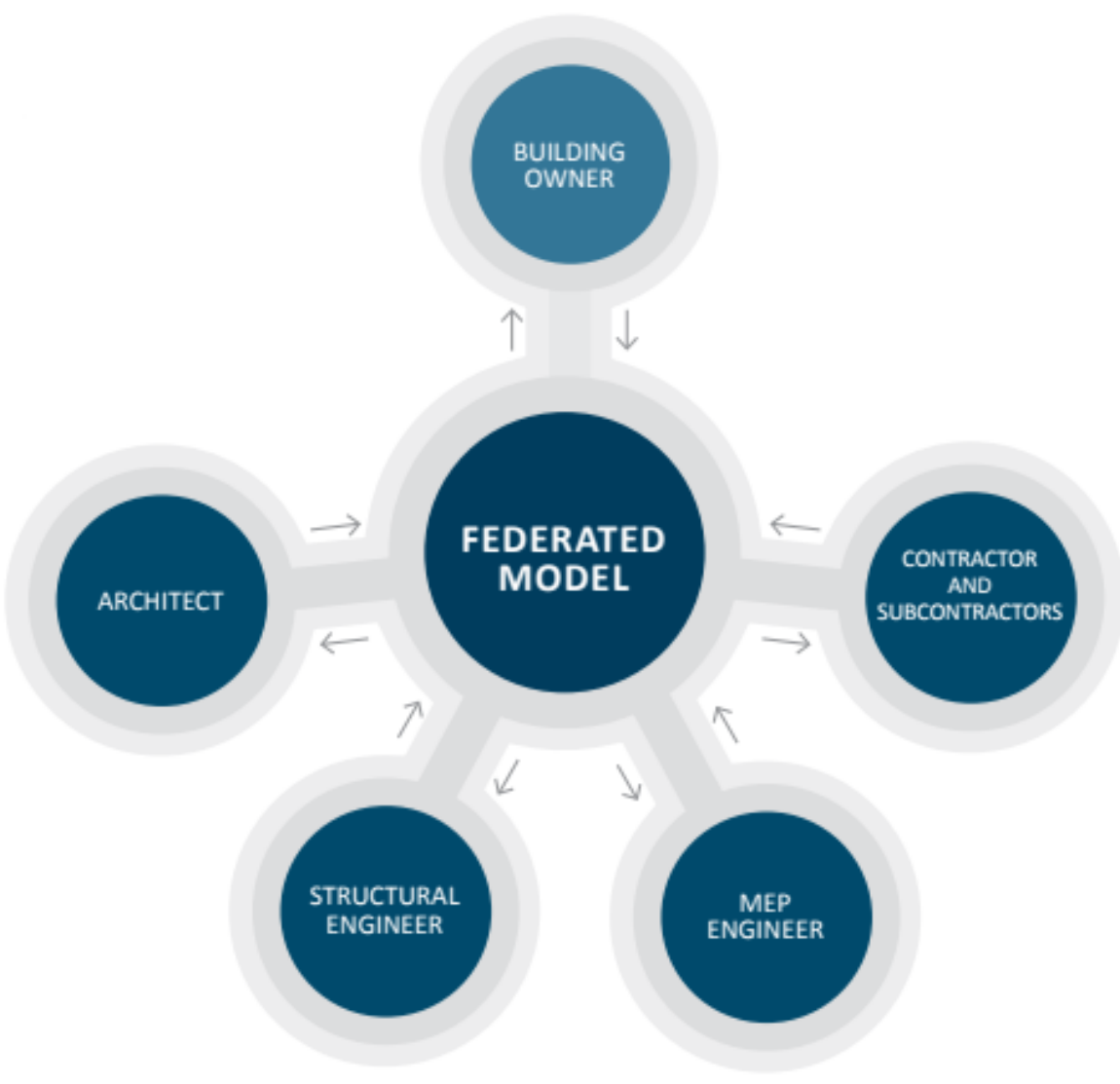

Figure 4: Model Federation Diagram

In the New Zealand Construction sector contractors are looking to streamline the process of BIM to drive out risk and reduce errors, ultimately this is likely to have greater potential for the construction stage (Cunningham, 2015). Contractors need to leverage the models for the designers, for this to work both the designers and construction phases need to be coordinated via the BIM brief. Specifically, these factors need to be considered:

- $\quad$ Modelling to a construction level

- $\quad$ Construction level detailing

To maximize the leveraging, it is said the following steps can be followed:

- Educating the clients about what is expected in the construction phase in a project BIM brief

- $\quad$ Defining deliverable requirements

- $\quad$ Designers identifying time and financial impacts

- Design models identifying what they can and cannot be used for in the project plan 
- Contractors identifying the time and financial benefits and passing these savings onto the client

- $\quad$ Procurement methodologies

- $\quad$ Regular audits

- $\quad$ Appropriate value being assigned to as built handover

Although the handbook has focused on design and construction through BIM the document acknowledges Facilities Management through BIM. As a process driven structure, the FM/AM world has been operating in a BIM process longer than any other but often facilitate their data from manually as Built drawings to the Computer Aided FM System. It is important to acknowledge that the AM/FM stage is fully data driven and as BIM matures in NZ the information that is linked to the models is important. The information needed to be handed over needs to be project specific and facilitated by the FM team, subsequently the FM team needs to be engaged at the onset of a project. Data structure is defined in Appendix A (Appendix 4 attached).

The FM/AM requirements are to be identified at the time the Project BIM Brief and defined in the BEP. This is often not the case as designers facilitate what is needed for the construction phase only. All parties involved in the entire project from design through to operation need to be tasked in the project plan. Although the BIM handbook explains the fundamentals of $\mathrm{BIM}$ in AM/FM there is no specific documentations of how and what to do at this stage of the BIM process. The only certainty documented is having to define the data needed for the operational stage. No government/global standard has specified how BIM adopts in the operational phase, whom will be first. The UK government has always lead the BIM adoption as well as government mandating. It can be assumed that the United Kingdom will facilitate some form of BIM AM/FM adoption soon. 


\subsubsection{Global BIM standards/Guides}

There are no international BIM standards formally established within the AEC industry, each government commonly, has their own in-house standards. The US government were the first organisation to produce US National BIM standard version 1 in 2006, before the UK government had released their first standard for Revit, the US government had already released their second publication of integrated project delivery. For BIM standardisation, 2009 included the development of Australia's National guidelines for digital modelling, UK BIM standard for Revit and UK CAD standard for model naming. BIM standards help to detail project information needed in a BIM world without these the specific information needed and responsibilities blur. As there is no one global standard, the number of standards are growing significantly with BIM uptake increasing. Each standard from government to government slightly differs depending on the software used and protocols implemented. The titles of documents are also not standardised, and execution plans, protocols and documents are not standardised. The AEC industry could benefit from having a global standard to mitigate current issues by commonly implementing such issues together and building on stronger standardisation (Standards et al., 2015).

The US national BIM standard was developed by Building Smart Alliance and in 2015 NBIMS-US version 3 was released. This standard is extremely large and hard to navigate around the document and is not user friendly. The UK standardisation is based on BS 1192 available for both Revit and Bentley users, in order to access these documents you must be a member of National Institutes of Building Science (Standards et al., 2015).

An international BIM standard is being developed as a benchmark for manufacturers and designers as a single source of truth for the entire construction industry. NATSPEC and Master spec are working in collaboration and using the IFC standard as the core standard. It can be assumed that the NBS BIM Object Standard has the leading edge in BIM adoption globally. These international standards have been developed to assist the creation of BIM objects from all construction professionals, including manufacturers right through to content developers. This standard considers local regional differences (Standards et al., 2015). 
NBS is the UK trusted specification recognised as the UK's trusted standard. This standard is free-to-use for the UK industry. This standard is attracting the development in a global stage. NATSPEC is an Australian government owned organisation and supports open global systems. The fundamental focus of NATSPEC is the "I" in BIM and how the information is linked to the digital models. Creating a centralised global standard will identify the information needs for a project (Masterspecs New Zealand, 2016).

Master specs New Zealand provides specifications and solutions for the NZ construction industry whom is owned by the New Zealand Institute of Architects and Masters Builders association. BIM is the result of a digital revolution in the global construction industry. A single project should adopt the same standards, value is added in a BIM world from people, process, policy and technologies. More assets are being created in a BIM environment, with information being created in this. Virtual assets also known as BIM objects require standardisation in order to create an industry wide understanding, this is likely to improve the efficiency of BIM. Being able to compare data across built assets will increase lessons learned and development in influencing future projects (Masterspecs New Zealand, 2016).

The biggest standardisation benefit of BIM standards is the information recorded that allows for comparison, and common approaches to the modelling will make BIM objects to be used easily, ensuring a consistent and intuitive approach. An example on a manufacturing perspective is that objectives are unified for different projects. With this all in mind, this is the start of a common data environment. From an entire construction perspective, it is believed that everyone in the AEC industry stands to benefit from a global standardisation.

The international BIM standard developed by NATSPEC is broken down to 5 sections. These five sections define the requirements for BIM objects, the information contained within a BIM object, the minimum geometry requirements of the BIM object, the functional requirements embedded within a BIM object as well as defining metadata requirements. 
The following documents have been referred to:

\begin{tabular}{|l|l|}
\hline ISO 15686-4:2014 & $\begin{array}{l}\text { Building Construction - Service life planning - Part 4: Service } \\
\text { life planning using Building Information Modelling }\end{array}$ \\
\hline ISO 16739:2013 & $\begin{array}{l}\text { Industry Foundation Classes (IFC) for data sharing in the } \\
\text { construction and facility management industries }\end{array}$ \\
\hline ISO/PAS 16739:2005 & $\begin{array}{l}\text { Industry Foundation Classes Release 2x, Platform Specification } \\
\text { (Ifc2x Platform) }\end{array}$ \\
\hline ISO 80000-1:2009 & Quantities and units - Part 1: General \\
\hline
\end{tabular}

The ISO published standards is complete and published, however is likely to follow with further updates.

\subsubsection{Government mandating of BIM}

As Building Information Modelling has had a huge uptake throughout the global construction industry this has led to governments mandating this process as they see benefit in adopting the BIM procedures. Building Information Modelling provides improvements in productivity and cost saving within the AEC industry. Adoption is widely spread globally with governments accepting adoption. In 2003 The United States rolled out there national BIM program mandating BIM adoption for all Public Sector works and have progressively become active partners with BIM vendors and software developer. There is also a big push in the US to educate in Universities in the field of BIM and develop a community of BIM users, Indiana University issued project delivery requirements in BIM. It is believed that over $70 \%$ of construction firms in the US are utilising BIM (Smith, 2014b). The NBIMS-US Project was introduced as an industry standard to help foster innovation and uptake on BIM (Standards et al., 2015).

As it stands the UK have the leading edge in BIM adoption in the global construction industry. The British Standards Institute have formal liaison with the specified committees. In 2016 the UK government as part of their construction strategy required all centrally produced construction projects to achieve level 2 BIM, if your organisation is not level 2 compliant then you will not be able to source any government projects. The aim of this strategy for the UK is to achieve $20 \%$ savings in procurements costs (Smith, 2014b). 
Scandinavian Countries, Norway, Denmark, Finland and Sweden were among the earliest adopters of BIM. In 2007, the Confederation of Finnish Construction Industries had mandated all software packages to pass IFC Certification. This is a vendor neutral file that can work with any necessary software. Denmark has seen to mandate its state clients to adopt BIM practices. Sweden has developed a best practice approach that has sat outside of any government drive and government led guidelines (Hooper, 2015). The Swedish government is set to follow in the path of the US in facilitating nationwide implementation. The Swedish transport have mandated the use of BIM since 2015.

In Germany BIM is demanded on $90 \%$ of construction projects, rather than a government drive the drive is on commercial and residential building (I. Singh, 2017). Historically the German government is said to be conservative and consequently there was no real drive to adopt BIM. In 2015 the German government allude to a Digital Building Platform BIM task group to create a BIM strategy (I. Singh, 2017). With Germans federal system it is not likely to implement a natural mandate, none the less Germany still has a strong BIM usage.

Like the Nordic, Singapore has a small market sector to which the government has responded by creating a central repository for codes and regulations. The Singapore Building \& Construction Authority CORENET designed the world's first BIM electronic e-submission for all projects greater than 5,000sqm. In 2010 the Building \& Construction industry set up an initiative dispensing grants through the BIM fund to cover the cost of training, consultancy, and hardware and collaboration software. The same authority also developed a library of building and design objects. The next step for Singapore is to standardise BIM modelling conventions (Hooper, 2015).

In 2014 the French government put an initiative to develop 500,000 houses using BIM with an allocated budget of $\$ 20$ million pounds by 2017 . It is forecasted that the French government will mandate the procurement of BIM in 2018, the government as part of the Digital Transition Plan introduced BIM as a way of achieving sustainability and reduce costs (I. Singh, 2017). 
China has had the slowest uptake of BIM and less than $15 \%$ of the China construction industry is said to be using BIM. It is said that the slow rate of adoption is associated to the resilience of change and resistance towards new management (James, 2015). The government supports and encourages the use of this technology, however, there is no mandatory obligations to adopt BIM in the China construction industry (I. Singh, 2017).

Globally BIM has had a huge uptake for the most part of the construction industry mainly due to the need for better project outcomes. In a global survey it was reported that over $60 \%$ of BIM users reported a positive return on investment (Smith, 2014a). The range of uptake within BIM governments varies and for the most part the uptake of government mandating has alluded by data taking the adoption of the process providing quantifiable business benefits by improving collaboration, reducing costs, and overruns of construction phases.

One of the biggest driving forces to investment in BIM allures to the fact that buildings use approximately $40 \%$ of global energy and emits one third of global greenhouse gas emissions. Realising this governments globally have set the objective of reducing energy and using BIM as a way of solving such issues(Ghaffarianhoseini et al., 2017).

\subsubsection{Levels of Development}

"The Level(s) of Development (LOD) describes the level of completeness to which a model element is developed" (BIMForum, 2015). It describes the steps to which a BIM element can logically progress from the lowest level of conceptual approximation to the highest level of representational precision. 5 LOD's are defined as below. Each subsequent level builds on the previous level and includes all the characteristics of the previous levels (BIMForum, 2015).

Level of Development is a scale developed to understand the content/data that is expected to be included in specific model elements throughout the design, construction and operation process of BIM. The Level of Development is a tool for the construction industry that enables practitioners to specify the reliability of Building Information Models at various stages throughout design, construction and operation. A global Level of development understanding has been documented as a response to the issues associated with deliverables in a BIM model for authors to define their model elements and for users to clearly understand the usability 
and limitations of the models. The global BIM forum's Level of Development Specification was revised in 2016, originally released in 2008. The LOD specification was developed as an interpretation of the LOD schema by the American Institute of Architects (AIA) and organised according to Uniformat 2010, the intent of this was to develop a framework and standardise it so it becomes a communication tool (BIMForum, 2015).

Levels of Development create clarity and work in parallel with a BIM execution plan and are incorporated in Model Element Authorising (MEA). Model Element Authorising relates to the way in which data is integrated, from where, from who and for what. An example is that the modelling team agree to model elements from the national BIM object library, and/if the model requires custom elements an appropriate BIM Authoring tool template shall be used. LOD does not differentiate models as a whole but the elements that make up that model(s). The New Zealand BIM handbook explains that LOD represents the extent at which an element is to meet the details required as specified by all team members as referenced from the BIM Forum. An element meets the LOD when all aspects of the LOD has been meet, it is important to note that all requirements of the LOD specified must meet the requirements of the previous LoD, for example an element only meets LOD 350 if the previous LOD 100, 200 and 300 have been meet. Likewise, the Level of Development Specification reads identical to this. These specifications documented have not been developed as a framework or requirement but more as a language that is spoken for understanding by various people who may use these models/data. The BIM forum acknowledges that the LOD are not specified by design phase but more directed as a milestone or deliverable. Currently there are no detailed design standards and often architects/designers have developed in house specifications that differ from one firm to the next (BIMForum, 2015).

The New Zealand BIM handbook documents the importance of understanding that a model is not defined as a certain LoD but all elements and assemblies within the project model meet various levels of development. The LOD is the extent at which an element is developed for design, construction, planning, management and coordination.

The New Zealand BIM handbook discusses the comparison of Level of Detail Vs Level of Development. Level of detail is the amount of "detail" that is imputed into the element 
where-as level of development is the elements geometry and attached information to which the model is relied on (BRANZ, 2016). The intricate precision within an element such as a chair, the chair may have details down to the nuts and bolts, however when placed into the model the chair may be the wrong size and not contain specific dimensions. The difference can be clearly noted by level of detail relating to input and level of development creating reliable output (BIM Acceleration Committee, 2014).

There are four main terms that branch under the parent description of Level of Development. These include level of detail as defined above, level of accuracy, level of information and level of co-ordination and together define the information of each given element and create a common known language of different levels of development.

Level of accuracy (Loa) relates to the measurements of an object for example an HVAC system may be $100 \mathrm{~mm}$ out when modelled and the manufacturers specifications indicates the model is out by $100 \mathrm{~mm}$. The level of accuracy is only defined once a product is selected, there needs to be clarity to ensure that the element can be instructed in a way that is model, if not there is no point modelling to as close as the millimetre (BIMForum, 2015).

Level of information (LOi) is also commonly known as level of data, in order to achieve true BIM for operation (Facilities/Asset Management) LoD needs to define what information is needed to be supplied in each element. This information can also relate to costing and engineering. NATSPEC BOEM is the only standard developed, the construction industry has not widely utilised this due to the complexity (BIMForum, 2015).

Level of coordination (LOC) does not relate to an individual element but the co-ordination of multiple elements. For example, an architectural window may be placed in a structural wall, and this can be picked up in the BIM model through co-ordination (BIMForum, 2015).

Together these four key areas form the necessary requirements/principals of Level of Development and are necessary for the different level as specified below. 
There are currently 6 stages of levels of development have been adopted by many parts of the construction world in response to understanding the amount of data/necessary modelling parameters within elements of a BIM model. Both the New Zealand BIM Handbook and the LOD US Specification read identical with description of each LOD. Multiple sources have adopted the LOD SPEC as published by BIMFORUM (shown in Appendix 5).

The tables below represent each LOD and their definition:

LOD 100 - The Model Element may be graphically represented in the Model with a symbol or other generic representation but does not satisfy the requirements for LOD 200. Information related to the Model Element (i.e. cost per square foot, tonnage of HVAC, etc.) can be derived from other Model Elements (BIMForum, 2015).

LOD 100 elements are not geometric representations. Examples are information attached to other model elements or symbols showing the existence of a component but not its shape, size, or precise location. Any information derived from LOD 100 elements must be considered approximate. BIMFORUM associates elements with a UniFormat naming convention (BIMForum, 2015).

\begin{tabular}{|c|c|}
\hline UniFormat: B1080.10 Stair Construction & UniFormat: B2020.30 Exterior Window Wall \\
\hline $\begin{array}{l}\text { Assumptions for all stair systems are } \\
\text { included in other modelled elements that } \\
\text { indicates the approximate overall } \\
\text { dimensions of the stair layout }\end{array}$ & $\begin{array}{l}\text { Solid mass model representing overall building } \\
\text { model, wall elements that are not } \\
\text { distinguishable by type or material. }\end{array}$ \\
\hline No graphical example & No graphical example \\
\hline
\end{tabular}

LOD 200 - The Model Element is graphically represented within the Model as a generic system, object, or assembly with approximate quantities, size, shape, location, and orientation. Non-graphic information may also be attached to the Model Element.

BIMForum interpretation: At this LOD elements are generic placeholders. They may be recognizable as the components they represent, or they may be volumes for space 
reservation. Any information derived from LOD 200 elements must be considered approximate. BIMFORUM associates elements with a UniFormat naming convention (BIMForum, 2015).

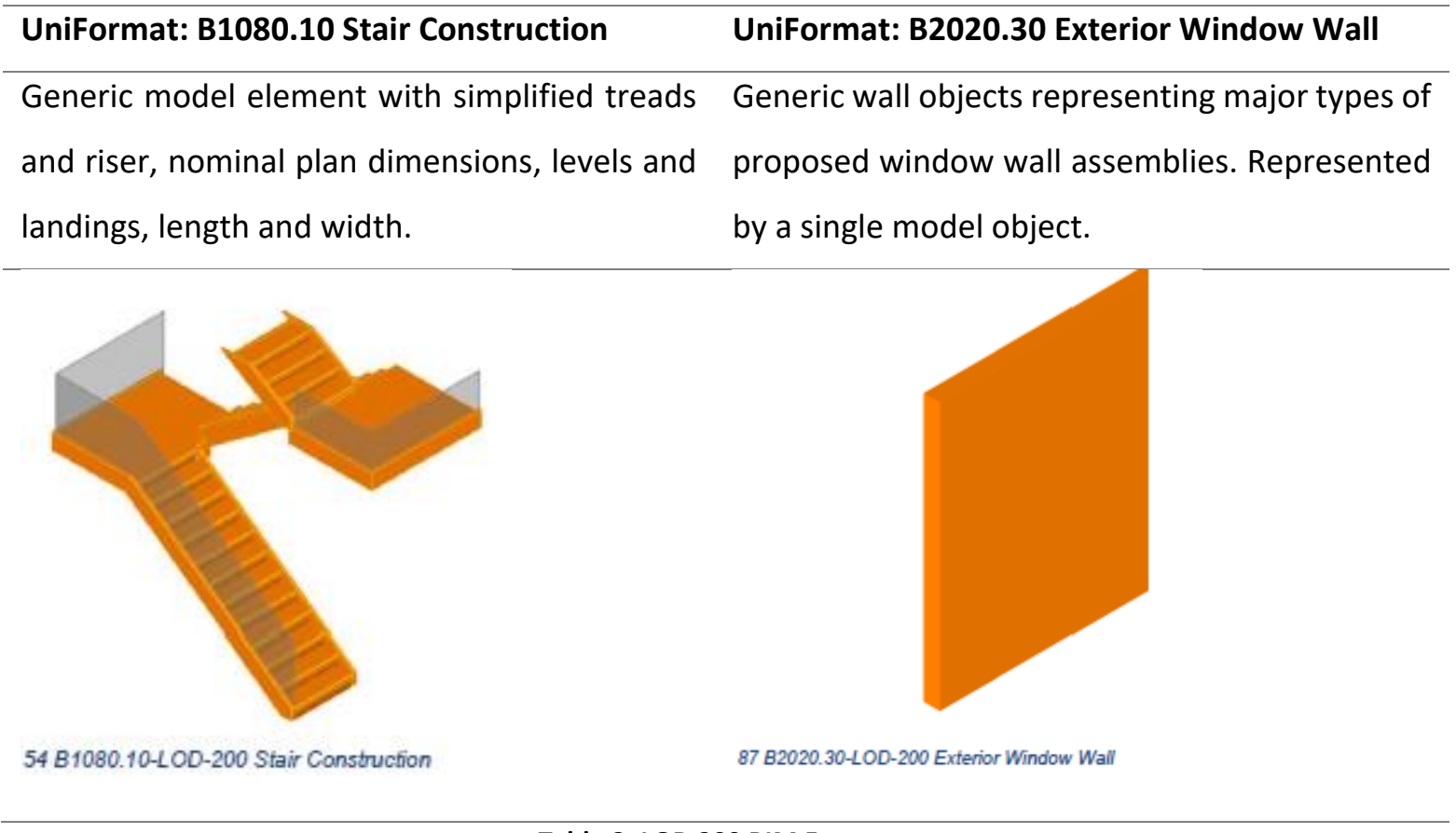

Table 2: LOD 200 BIM Forum

LOD 300 - The Model Element is graphically represented within the Model as a specific system, object or assembly in terms of quantity, size, shape, location, and orientation. Nongraphic information may also be attached to the Model Element.

BIMForum interpretation: The quantity, size, shape, location, and orientation of the element as designed can be measured directly from the model without referring to non-modelled information such as notes or dimension call-outs. The project origin is defined and the element is located accurately with respect to the project origin. BIMFORUM associates elements with a UniFormat naming convention (BIMForum, 2015).. 
Major stair supports are modelled (stringers, Specified location and orientation of face and treads and risers are modelled to indicate glass, nominal face dimensions and thickness of design specified nosing conditions. glazing, structural support of systems to be modelled, operable components defined.
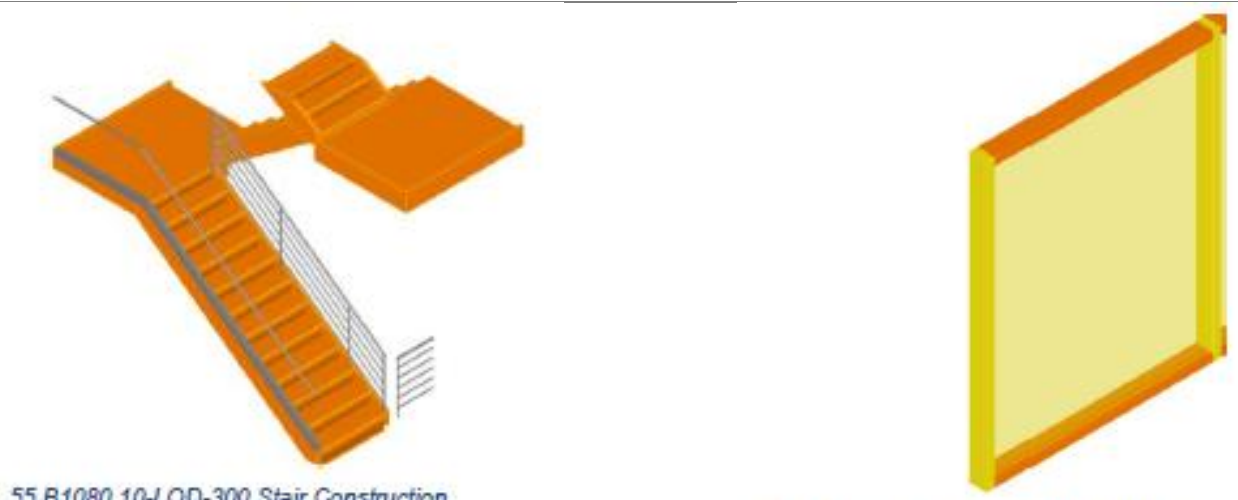

55 B1080.10-LOD-300 Stair Construction

88 B2020.30-LOD-300 Exterior Window Wall

Table 3: LOD 300 BIM Forum

LOD 350 - The Model Element is graphically represented within the Model as a specific system, object, or assembly in terms of quantity, size, shape, location, orientation, and interfaces with other building systems. Non-graphic information may also be attached to the Model Element.

BIMForum interpretation. Parts necessary for coordination of the element with nearby or attached elements are modelled. These parts will include such items as supports and connections. The quantity, size, shape, location, and orientation of the element as designed can be measured directly from the model without referring to non-modelled information such as notes or dimension call-outs. BIMFORUM associates elements with a UniFormat naming convention (BIMForum, 2015).

\begin{tabular}{lll}
\hline UniFormat: B1080.10 Stair Construction & UniFormat: B2020.30 Exterior Window Wall \\
\hline Secondary stair supports are modelled & Mullion and shapes and geometry defined. \\
(hangers and brackets) & Actual anchorage layouts, actual panel \\
& dimensions.
\end{tabular}




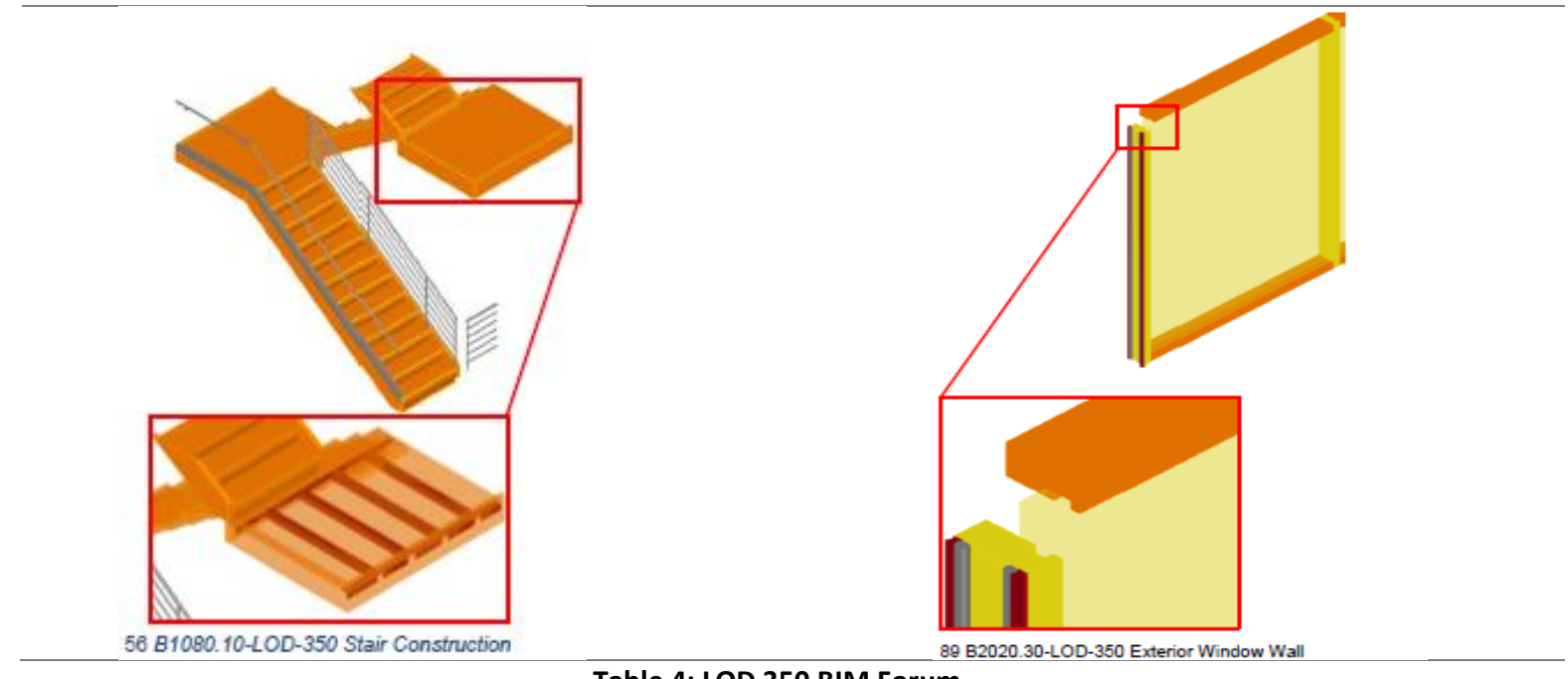

Table 4: LOD 350 BIM Forum

LOD 400 - The Model Element is graphically represented within the Model as a specific system, object or assembly in terms of size, shape, location, quantity, and orientation with detailing, fabrication, assembly, and installation information. Non-graphic information may also be attached to the Model Element.

BIMForum interpretation. An LOD 400 element is modelled at sufficient detail and accuracy for fabrication of the represented component. The quantity, size, shape, location, and orientation of the element as designed can be measured directly from the model without referring to non-modelled information such as notes or dimension call-outs. BIMFORUM associates elements with a UniFormat naming convention (BIMForum, 2015).

\section{UniFormat: B1080.10 Stair Construction}

All stair elements are modelled to support fabrication and installation.

\section{UniFormat: B2020.30 Exterior Window Wall}

Complete mullion extrusion profiles. Interface details between wall systems and wall support systems including sealants. 


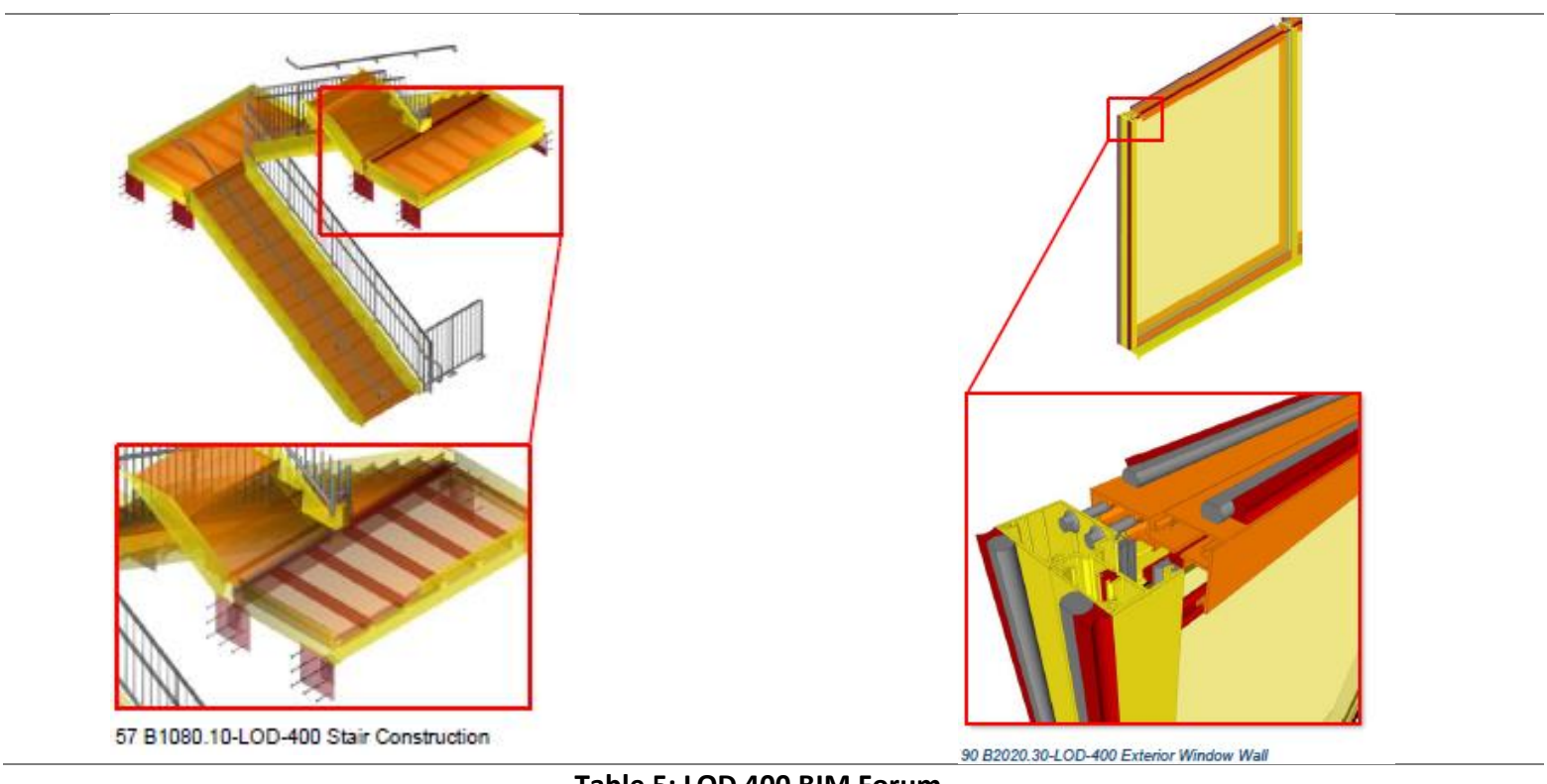

Table 5: LOD 400 BIM Forum

LOD 500 - The Model Element is a field verified representation in terms of size, shape, location, quantity, and orientation. Non-graphic information may also be attached to the Model Elements.

BIMForum interpretation. Since LOD 500 relates to field verification and is not an indication of progression to a higher level of model element geometry or non-graphic information, this Specification does not define or illustrate it. BIMFORUM associates elements with a UniFormat naming convention (BIMForum, 2015).

Uniformat: B1080.10 Stair Construction
$\begin{aligned} & \text { LOD } 500 \text { represents the field verified LOD } 500 \text { represents the field verified } \\ & \text { representation in terms of shape, size }\end{aligned}$ representation in terms of shape, size quantity,
quantity, and orientation. Non graphic and orientation. Non graphic information may
information may be attached if additional be attached if additional asset model data is
asset model data is required (this is project required (this is project dependent).
dependent).

Table 6: LOD 500 BIM Forum 
The LOD specification includes a model element table as used in the gymnasium project execution below. The MET was designed in accordance with CSI UniFormat and lists the relevant attribute tables for each system (Charette \& Marshall, 1999). Each user has the capability to adapt the table to each given project. The table includes columns for defining the LODs for various milestones. Each milestone column has three sub-columns LOD, MEA and notes, users are to modify accordingly.

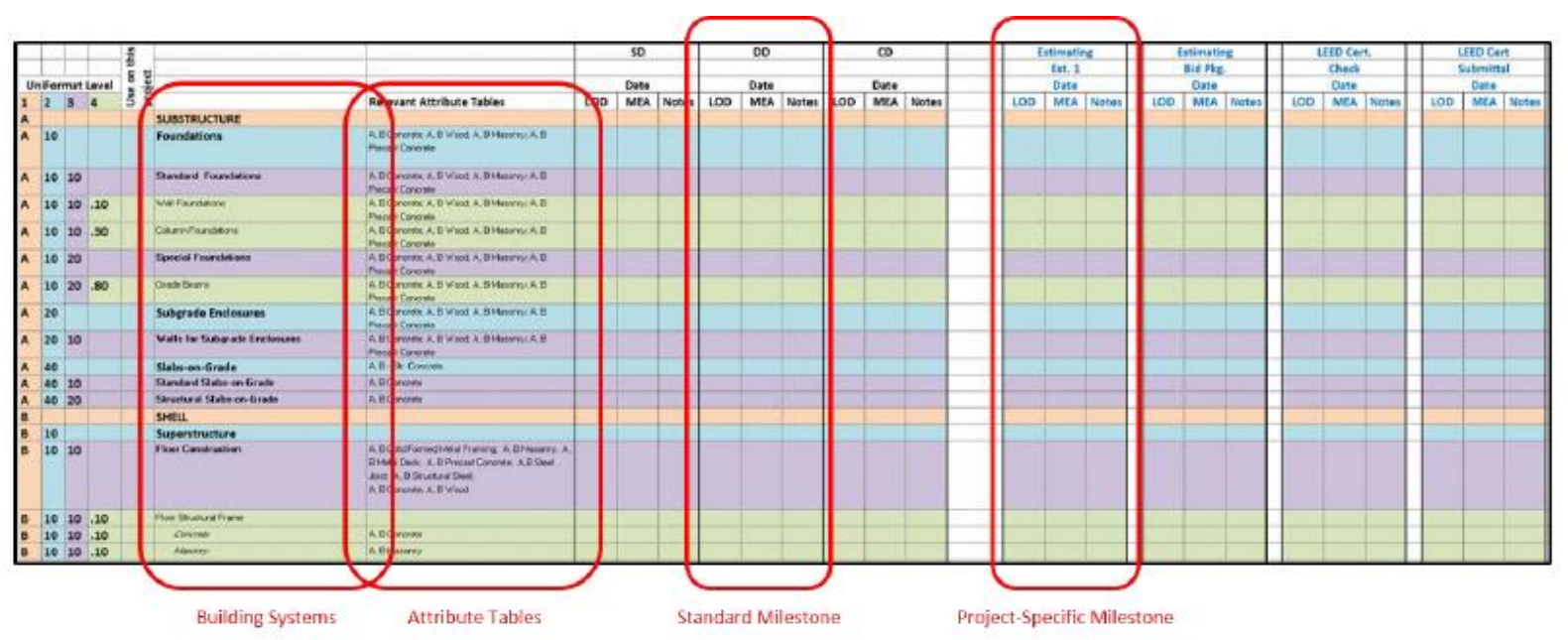

Table 7: Model Element Table

See uniformat/omniclass for naming conventions below (Charette \& Marshall, 1999).

The concept of Levels of Development is defined at a very high level with great detail, the issue with this is when applying this to the real world it is not easy to follow nor is the process in doing so clear. The Nordics region, in 2017 released a document BIM Basic Information Delivery that is an alternative to Level of Development but explained in a more simplistic manner.

The BIM Basic Information Delivery Manual (IDM) has four sub sections as defined below:

1. Why are we sharing this information unambiguously? In order to secure and reuse information more efficiently and effectively as defined by the figure below (BuildingSMART, 2017): 


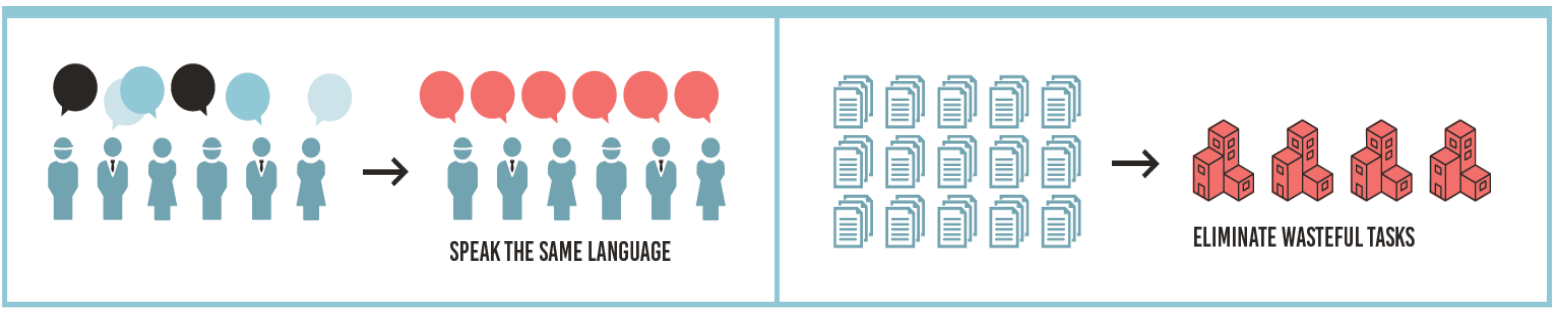

2. How are we going to share this information unambiguously? Knowledge and practical experiences have shown that there is a significant common denominator. We are not developing something new, but rather using existing structures, based on openBIM IFC.

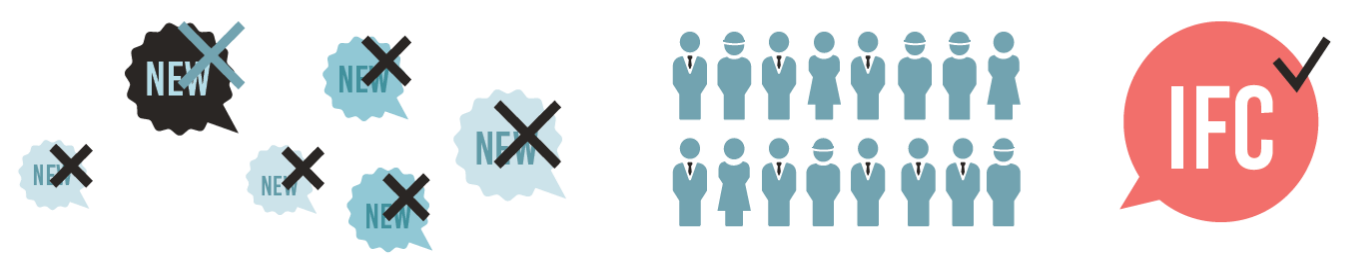

3. Which structure will we use? As shown below the basic checklist is documented to ensure every party involved, will always be able to find and supply the right information in the right place.

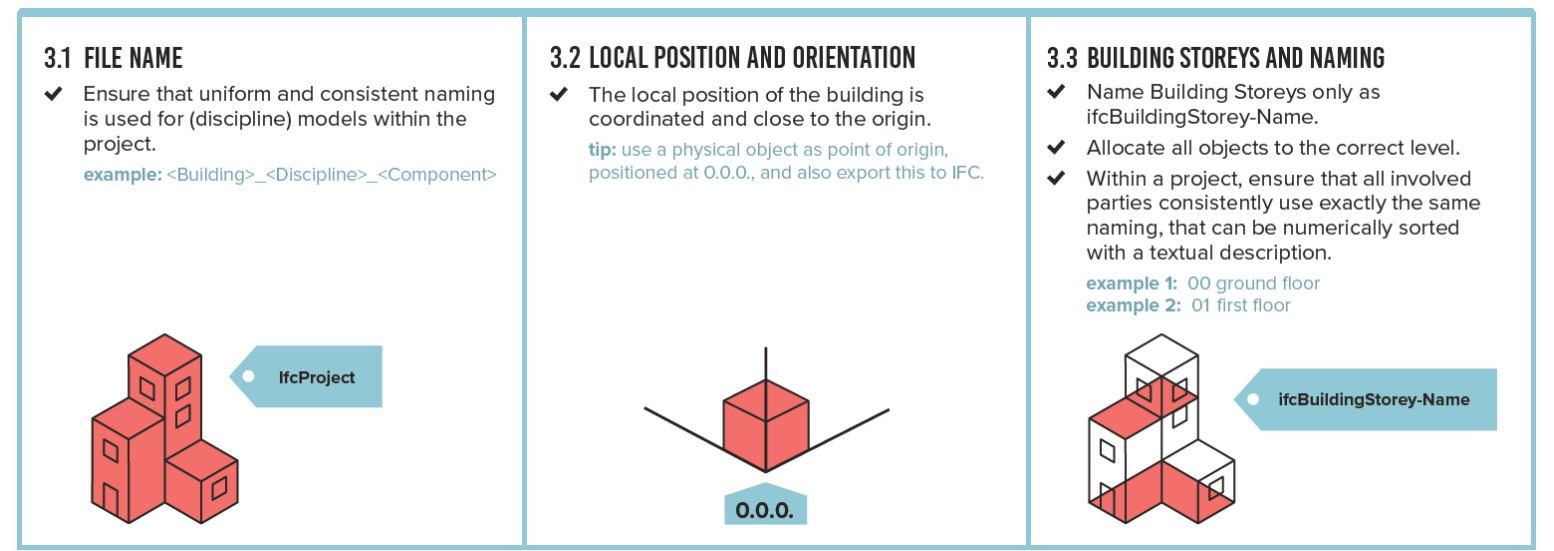




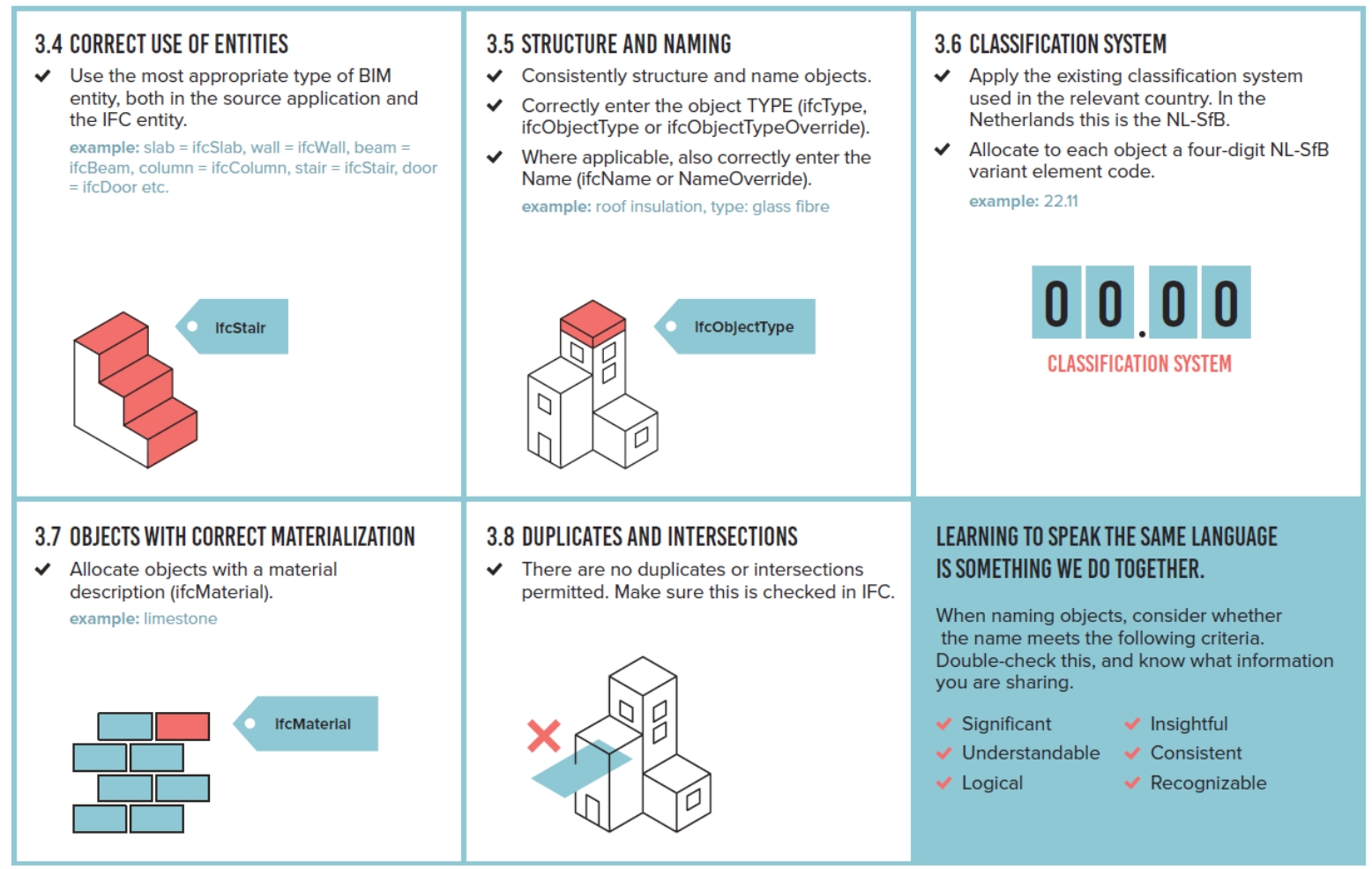

4. How can we secure other/future object information? Object information is secured in the correct properties and property sets as defined in the IFC.

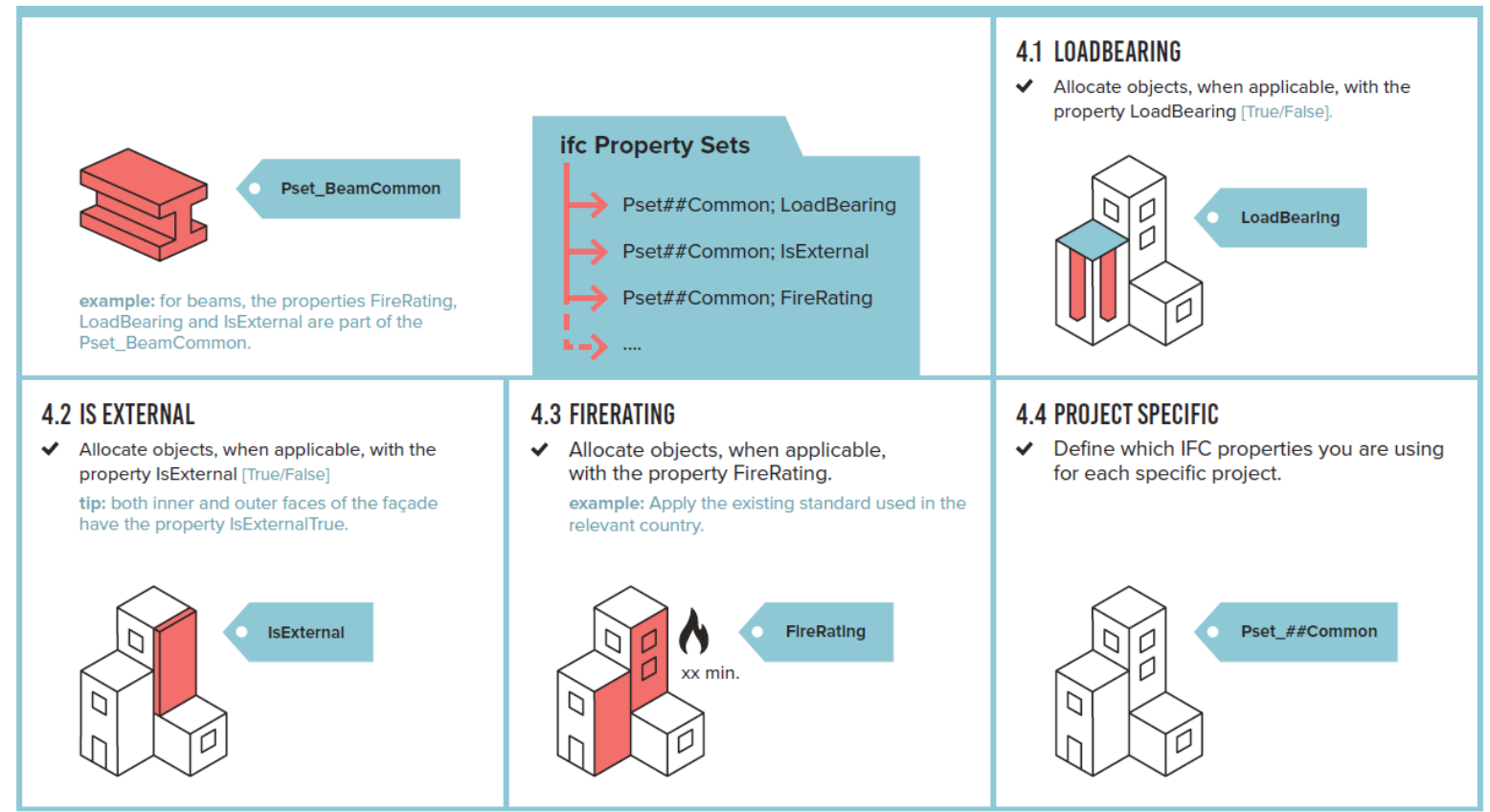

Tables 8: Delivery Manual Table 
When LODs were first designed back in 2004 each author adopted these and made them their own concept. This has resulted in slightly different meanings and subsequently nobody really knowing what LOD and its elements stand for. This however does not allude from the fact that there is a common meaning for LOD's and the elements defined within. Places such as the Netherland have defined an alternative to LOD's being An Information Deliverance Manual Basic IDM (as defined above) and RvB BIM being the most commonly used (Tardif \& Aeronautics, 2017). It can be suggested that although there isn't specifically a standardised LOD document many parties refer to the LOD specification developed by the BIM forum. It can be suggested that LOD specifications like the BIM forum are a good base and platform but should be tailored to become project specific.

\subsubsection{Uniformat/Omniclass}

The Omniclass is a construction clarification system designed as a means of organising and retrieving information and provides a means to drill into data to gather the information required for a particular use. OmniClass draws from Uniformat for elements. OmniClass is designed to provide a standardised basis for classifying information throughout the full facility life cycle from conception to demolition/reuse. "OmniClass consists of 15 hierarchical tables, each of which represents a different facet of construction information. Each table can be used independently to classify a particular type of information, or entries on it can be combined with entries on other tables to classify more complex subjects"(Delany, 2018).

\section{OmniClass/UniFormat}

The 15 inter-related OmniClass tables are:

- $\quad$ Construction Entities by Function - Table 11

- $\quad$ Construction Entities by Form - Table 12

- $\quad$ Spaces by Function - Table 13

- $\quad$ Spaces by Form - Table 14

- $\quad$ Elements (includes Designed Elements) - Table 21 
- $\quad$ An Element is a major component, assembly, or "construction entity part which, in itself or in combination with other parts, fulfils a predominating function of the construction entity" (ISO 12006-2). Predominating functions include, but are not limited to, supporting, enclosing, servicing, and equipping a facility. Functional descriptions can also include a process or an activity.

- $\quad$ A Designed Element is an "Element for which the work result(s) have been defined." (ISO 12006-2).

- Work Results - Table 22

- $\quad$ Products - Table 23

- $\quad$ Phases - Table 31

- $\quad$ Services - Table 32

- $\quad$ Disciplines - Table 33

- $\quad$ Organizational Roles - Table 34

- $\quad$ Tools - Table 35

- Information - Table 36

- $\quad$ Materials - Table 41

- $\quad$ Properties - Table 49

The LOD Spec sheet only used table 21 , as defined above for OmniClass descriptions as an identified standard for naming conventions. Table 21 associates each element with a specific number. The excel OmniClass spreadsheet shows the following (Delany, 2018): 


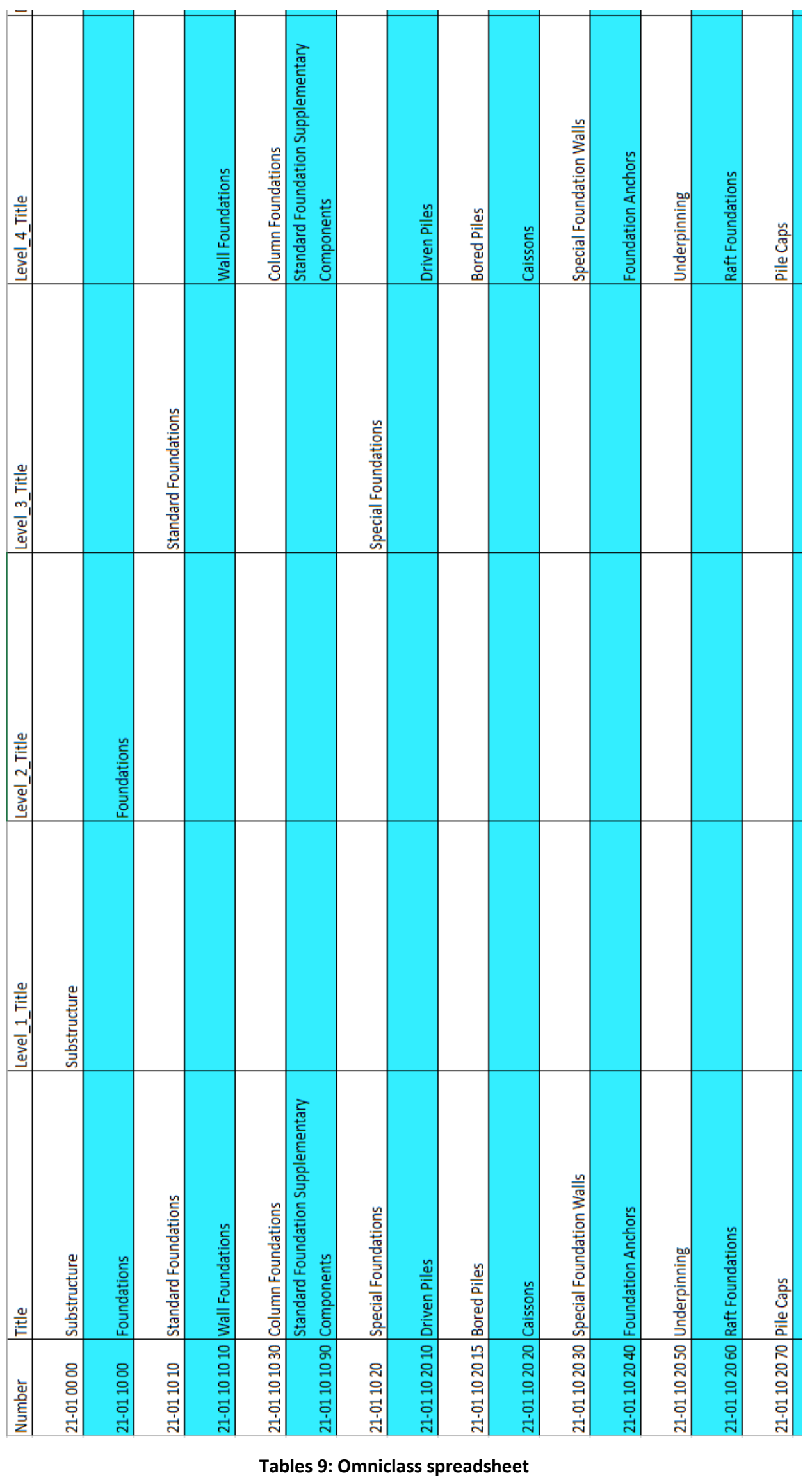


And from this the associated numbers were defined on the LOD Spec Sheet:

\begin{tabular}{|c|c|c|c|c|c|c|c|c|c|c|c|c|c|c|c|c|c|c|c|}
\hline$\Delta t$ & A & $\mathrm{BC}$ & C D & $\mathrm{DE}$ & $\mathrm{F}$ & G & $\mathrm{H}$ & I & J & K & $\mathbf{L}$ & $M$ & $\mathrm{~N}$ & $\mathrm{O}$ & $\mathrm{P}$ & Q & $\mathrm{R}$ & S & $\mathrm{T}$ \\
\hline 1 & & & & & & & & & & & \multirow{2}{*}{\multicolumn{6}{|c|}{ Omniclass Level }} & \multirow{4}{*}{ 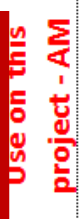 } & \multirow{4}{*}{ 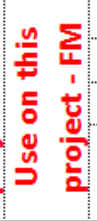 } & Mile: \\
\hline 2 & & & & & \multicolumn{5}{|c|}{ Uniformat Level } & & & & & & & & & & \\
\hline 3 & & & & & & & & & & & & & & & & & & & \\
\hline 4 & & & & & 1 & 2 & 3 & 4 & 5 & & $\frac{\frac{0}{0}}{\frac{0}{10}}$ & 1 & 2 & 3 & 4 & 5 & & & \\
\hline 38 & & & & & A & 60 & 10 & & & & 21- & 01 & 60 & 10 & 00 & 00 & A & & Building Subdrainage \\
\hline 39 & & & & & A & 60 & 10 & .10 & & & 21- & 01 & 60 & 10 & 10 & 00 & & & Foundation Drainage \\
\hline 10 & & & & & A & 60 & 10 & .20 & & & 21- & 01 & 60 & 10 & 20 & 00 & & & Underslab Drainage \\
\hline 11 & & & & & A & 60 & 20 & & & & 21- & 01 & 60 & 20 & 00 & 00 & A & & Off-Gassing Mitigation \\
\hline+2 & & & & & A & 60 & 20 & .10 & & & 21- & 01 & 60 & 20 & 10 & 00 & & & Radon Mitigation \\
\hline 13 & & & & & A & 60 & 20 & .20 & & & 21- & 01 & 60 & 20 & 20 & 00 & & & Maethane Mitigation \\
\hline 14 & & & & & A & 90 & & & & & 21- & 01 & 90 & 00 & 00 & 00 & ? & & Substructure Related Activities \\
\hline 15 & & & & & $A$ & 90 & 10 & & & & 21- & 01 & 90 & 10 & 00 & 00 & & & Substructure Excavation \\
\hline 16 & & & & & A & 90 & 20 & & & & 21- & 01 & 90 & 20 & 00 & 00 & & & Construction Dewatering \\
\hline 17 & & & & & A & 90 & 30 & & & & 21- & 01 & 90 & 30 & 00 & 00 & & & Excavation Support \\
\hline 18 & & & & & A & 90 & 30 & .10 & & & 21- & 01 & 90 & 30 & 10 & 00 & & & Anchor Tiebacks \\
\hline 19 & & & & & A & 90 & 30 & .20 & & & 21- & 01 & 90 & 30 & 20 & 00 & & & Cofferdams \\
\hline ;0 & & & & & A & 90 & 30 & .40 & & & 21- & 01 & 90 & 30 & 40 & 00 & & & Cribbing and Walers \\
\hline ;1 & & & & & A & 90 & 30 & .60 & & & 21- & 01 & 90 & 30 & 60 & 00 & & & Ground Freezing \\
\hline
\end{tabular}

Tables 10: LOD Spec Sheet

Like Omniclas, uniformat is a standard document (E1557) established to classify building elements. The standard was designed to provide a common language. The uniformat standard is designed with three levels as shown below: major group elements, group elements and individual elements. Specifically Uniformat ensures consistency in the economic evaluation of a building project from, design, construction, operation /maintenance through to end use (BIMForum, 2015). 
ASTM Uniformat II Classification for Building Elements (E1557-97)

\begin{tabular}{|c|c|c|}
\hline $\begin{array}{c}\text { Level 1 } \\
\text { Major Group Elements }\end{array}$ & $\begin{array}{c}\text { Level } 2 \\
\text { Group Elements }\end{array}$ & $\begin{array}{c}\text { Level } 3 \\
\text { Individual Elements }\end{array}$ \\
\hline \multirow[t]{2}{*}{ A $\quad$ SUBSTRUCTURE } & A10 Foundations & $\begin{array}{ll}\text { A1010 } & \text { Standard Foumdations } \\
\text { A1020 } & \text { Special Foumdations } \\
\text { A1030 } & \text { Slab on Grade }\end{array}$ \\
\hline & A20 Basement Construction & $\begin{array}{ll}\text { A2010 } & \text { Basement Excavation } \\
\text { A2020 } & \text { Basement Walls }\end{array}$ \\
\hline \multirow[t]{3}{*}{ B SHELL } & B10 Superstructure & $\begin{array}{ll}\text { B1010 } & \text { Floor Construction } \\
\text { B1020 } & \text { Roof Construction }\end{array}$ \\
\hline & B20 Exterior Enclosure & $\begin{array}{ll}\text { B2010 } & \text { Exterior Walls } \\
\text { B2020 } & \text { Exterior Windows } \\
\text { B2030 } & \text { Exterior Doors }\end{array}$ \\
\hline & B30 Roofing & $\begin{array}{ll}\text { B3010 } & \text { Roof Coverings } \\
\text { B3020 } & \text { Roof Openings }\end{array}$ \\
\hline \multirow[t]{3}{*}{ C INTERIORS } & C10 Interior Construction & $\begin{array}{ll}\text { C1010 } & \text { Partitions } \\
\text { C1020 } & \text { Interior Doors } \\
\text { C1030 } & \text { Fittings }\end{array}$ \\
\hline & C20 Stairs & $\begin{array}{ll}\text { C2010 Stair Construction } \\
\text { C2020 Stair Finishes }\end{array}$ \\
\hline & C30 Interior Finishes & $\begin{array}{ll}\text { C3010 } & \text { Wall Finishes } \\
\text { C3020 } & \text { Floor Finishes } \\
\text { C3030 } & \text { Ceiling Finishes }\end{array}$ \\
\hline \multirow[t]{5}{*}{ D SERVICES } & D10 Conveying & $\begin{array}{ll}\text { D1010 } & \text { Elevators \& Lifts } \\
\text { D1020 } & \text { Escalators \& Moving Walks } \\
\text { D1090 } & \text { Other Couveying Systems }\end{array}$ \\
\hline & D20 Plumbing & $\begin{array}{ll}\text { D2010 } & \text { Plumbing Fixhures } \\
\text { D2020 } & \text { Domestic Water Distribution } \\
\text { D2030 } & \text { Sanitary Waste } \\
\text { D2040 } & \text { Rain Water Drainage } \\
\text { D2090 } & \text { Other Plumbing Systems } \\
\end{array}$ \\
\hline & D30 HVAC & $\begin{array}{ll}\text { D3010 } & \text { Energy Supply } \\
\text { D3020 } & \text { Heat Generating Systems } \\
\text { D3030 } & \text { Cooling Generating Systems } \\
\text { D3040 } & \text { Distribution Systems } \\
\text { D3050 } & \text { Terminal \& Package Units } \\
\text { D3060 } & \text { Controls \& Instrumentation } \\
\text { D3070 } & \text { Systems Testing \& Balancing } \\
\text { D3090 } & \text { Other HVAC Systems \& } \\
\text { Equipment } & \end{array}$ \\
\hline & D40 Fire Protection & $\begin{array}{ll}\text { D4010 } & \text { Sprinklers } \\
\text { D4020 } & \text { Standpipes } \\
\text { D4030 } & \text { Fire Protection Specialties } \\
\text { D4090 } & \text { Other Fire Protection Systems } \\
\end{array}$ \\
\hline & D50 Electrical & $\begin{array}{ll}\text { D5010 } & \text { Electrical Service \& } \\
& \text { Distrbution } \\
\text { D5020 } & \text { Lighting and Branch Wiring } \\
\text { D5030 } & \text { Communications \& Security } \\
\text { D5090 } & \text { Other Electrical Systems }\end{array}$ \\
\hline \multirow[t]{2}{*}{$\begin{array}{l}\text { E EQUTPMENT \& } \\
\text { FURNISHNNGS }\end{array}$} & E10 Equipment & $\begin{array}{ll}\text { E1010 } & \text { Commercial Equipment } \\
\text { E1020 } & \text { Instinutional Equipment } \\
\text { E1030 } & \text { Velicular Equipment } \\
\text { E1090 } & \text { Other Equipment }\end{array}$ \\
\hline & E20 Furnishings & $\begin{array}{ll}\text { E2010 } & \text { Fixed Furnishings } \\
\text { E2020 } & \text { Movable Furnishings }\end{array}$ \\
\hline \multirow[t]{2}{*}{$\begin{array}{l}\text { F SPECIAL CONSTRUCTION } \\
\& \text { DEMOLITION }\end{array}$} & F10 Special Construction & $\begin{array}{ll}\text { F1010 } & \text { Special Structures } \\
\text { F1020 } & \text { Integrated Construction } \\
\text { F1030 } & \text { Special Construction Systems } \\
\text { F1040 } & \text { Special Facilities } \\
\text { F1050 } & \text { Special Controls and } \\
& \text { Instrumentation }\end{array}$ \\
\hline & $\begin{array}{l}\text { F20 Selective Building } \\
\text { Demolition }\end{array}$ & $\begin{array}{ll}\text { F2010 } & \text { Building Elements Demolition } \\
\text { F2020 } & \begin{array}{l}\text { Hazardous Components } \\
\text { Abatement }\end{array}\end{array}$ \\
\hline
\end{tabular}

Table 11: Uniformat table classification 


\subsubsection{The purpose of A BIM execution Plan}

A BIM execution plan, should define who does what, when they do it, and where they do it. The objective of a BIM execution plan is to document modelling practice, and most importantly to be used as a communication tool. The questions that need to be kept in mind is what does the project need, what are the opportunities and goal in mind. The importance of a BIM execution plan is understanding when and where to start. Starting to early means there may be nothing to begin on and starting to late may mean there is no not enough time (McPartland, 2017). It is important to document modelling responsibilities and model ownership.

The New Zealand BIM handbook 2016 presents an exemplar of a BIM execution plan (labelled as appendix Hi within the NZ BIM handbook, shown as Appendix 6). Although this document may not be the best practice form a global AEC industry format sense, the research presented in this thesis considers the New Zealand construction industry as the primary source with reference to global practice. Therefore, it is important to consider what the NZ BIM faculty is producing for their industry and suggest for use in the New Zealand AEC industry. Like many BIM associated documents the BEP is generalised to consider a range of different projects (BIM Acceleration Committee, 2014).

In comparison to the likes of the UK BIM template the BEP version is generally basic and provides for the minimal information that would be required to execute BIM ensuring the plan defines why BIM is being used, the goals, objectives and responsibilities through the life cycle of the project is defined. It can be assumed that because this document is only provided as a template guide, individual companies/organisations will have developed a BEP that is specific to how they execute projects and commonly communicate. This creates an industry wide problem in regard to not having a standardised template. The figure below executes the 4 fundamental platforms in a BIM project (BRANZ, 2016). 

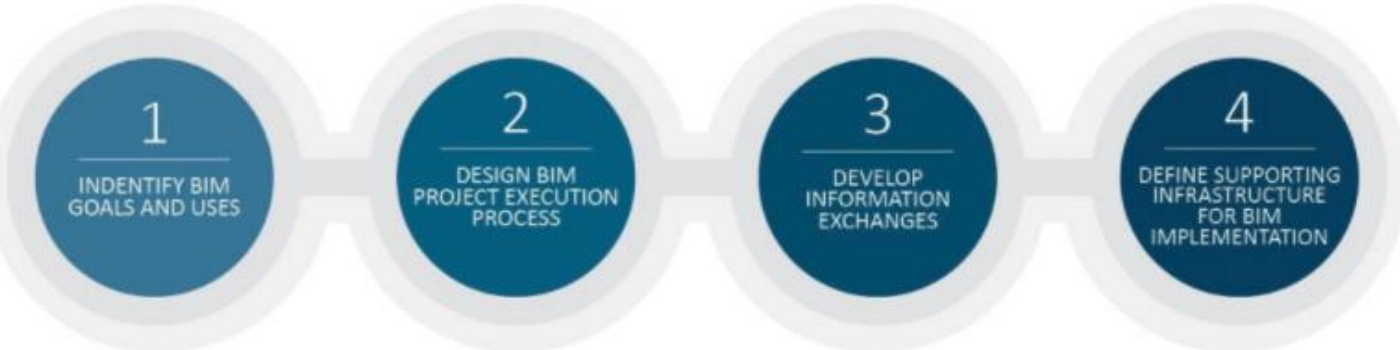

Figure 5: Fundamental platforms in a BIM project

The purpose of a BIM execution plan (BEP) is to produce a detailed plan that defines how specifically a project is to be executed, monitored and organised with the idea of BIM as an overall goal. Like a project execution plan a BEP provides an outline that ensures all parties involved in the project are aware of their responsibilities within the production of the project. A BEP should become a living document to ensure that as the project develops the document reflects any necessary changes. The figure below was developed by the NZ BIM handbook and reflects that of figure 5 (BRANZ, 2016) :

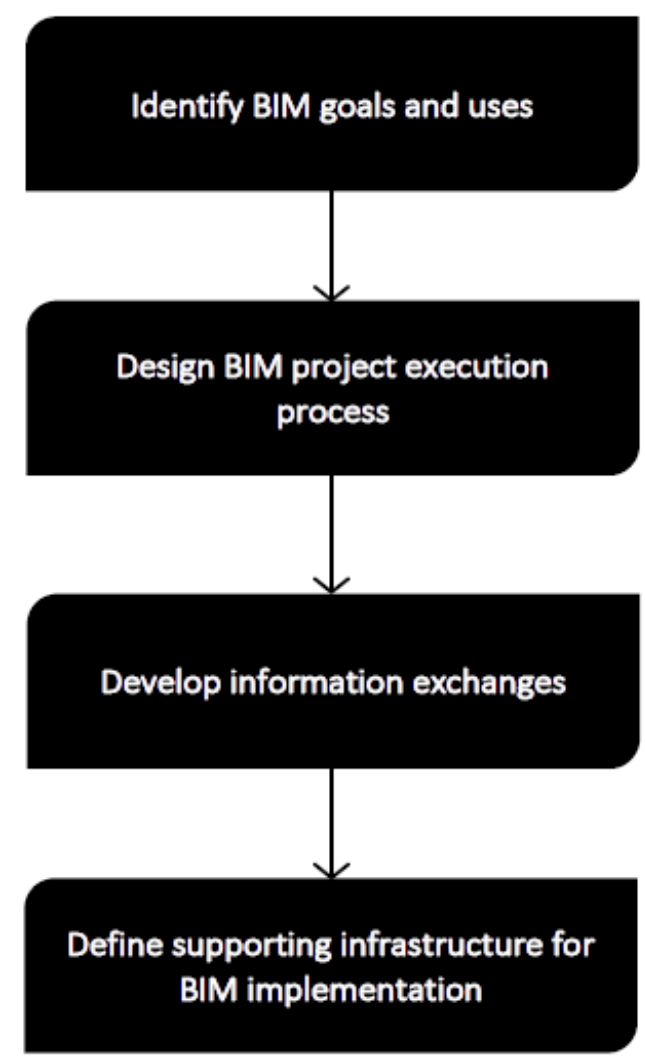

Figure 6: Production of BEP development 
A BIM execution plan was produced for the sports centre for the design, construction and operation of the building to ensure the requirements are meet for the client (sports centre owner) by the company whom were engaged to provide the design services. The BEP allows for all information to be captured in this one document to create a single source of truth (BRANZ, 2016). The BEP is authored to ensure all team members understand the following:

- $\quad$ Authorised uses

- Collaboration methodologies

- Exchange requirements

- Expected levels of development

- Information requirements

- Project Deliverables

- Protocol; compliancy requirements

- Roles and responsibilities

- Standards, methods and procedures

All revisions and amendments are communicated to the BIM managers from each of the consultant teams listed in the document. As such, each BIM manager representative have the authority to develop, agree and deliver this BEP on behalf of their respective companies. All project members within a project team are expected to familiarise themselves with this document and apply documented procedures to every day working methods. All queries and concerns are directed to the Project BIM manager for execution and guidance.

Within the BIM execution plan version control and ownership is documented, the standard parameters are included and are project specified.

The following information is captured in a BIM execution plan.

1. BIM standards

2. Project Overview

3. Management

4. Planning and Documentation

5. IT solutions

6. Standards, methods and procedures (SMPs)
A. Glossary of terms
B. Task information delivery plan 
C. Master information delivery plan

D. Model production and delivery table

E. File naming convention guide

F. Content creation guide

G. Drawing sheet template

H. Annotations, dimensions, abbreviations and symbols

I. CDE audit gate report

J. Clash Retention (detection): Methodology

K. Guidance Notes

For the Whenuapai Gymnasium the following standards were used to develop and produce the design and implementation to standardise the model for common data integrity in the AEC industry. The common language in this instance is developed by incorporating these standards:

\section{United Kingdom:}

- BIM Protocol Building Information Model (BIM) Protocol CIC/BIM

- BS ISO 55000 Asset Management - Overview, principles and terminology.

- BS 1192 + A2:2016 Collaborative production of architectural, engineering and construction information. Code of practice

- BS 1192-4 Collaborative production of information Part 4: Fulfilling employer's information exchange requirements using COBie - Code of practice".

- BS 7000 series Design Management Systems - Guide to managing design in construction

- BS 8534 Construction procurement policy

- BS 8536-1 Code of practice for Facilities Management (Buildings infrastructure)

- BS 8536-2 Code of practice for Asset Management (Linear and Geographical Infrastructure)

- BS 10012 Data Protection

- BS ISO 120006-2 Building Construction - Organisation of information about construction works Part 2: Framework for classifications - Uniclass

- $\mathbf{C I C / I N F ~ M A N / S ~ O u t l i n e ~ s c o p e ~ o f ~ s e r v i c e s ~ f o r ~ t h e ~ r o l e ~ o f ~ I n f o r m a t i o n ~ M a n a g e m e n t ~}$

- COBie-UK-2012 Construction-Operations Building Information Exchange.

- CDM 2015 Construction Design Management Regulations 2015 
- PAS 55-1:2008 Asset Management - Specification for the optimized management of physical assets

- PAS 91:2010 Construction related procurement - pre-qualification questionnaires

- PAS 1192-2 Specification for information management for the capital/delivery phase of construction projects using building information modelling

- PAS 1192-3 Specification for information management for the operational phase of assets using building information modelling

- PAS 1192-5 Specification for security-minded building information modelling, digital built environments and smart asset management

International:

- BIM forum LOD specification version

- Uniformat 2010

New Zealand:

- $\quad \mathrm{NZ} \mathrm{CIC}$ guidelines

For the project the roles and responsibilities were defined as per PAS-1192-2, the roles and responsibilities structure is generalised and should be tailored to project specifics (British Standards Institution, 2013). 


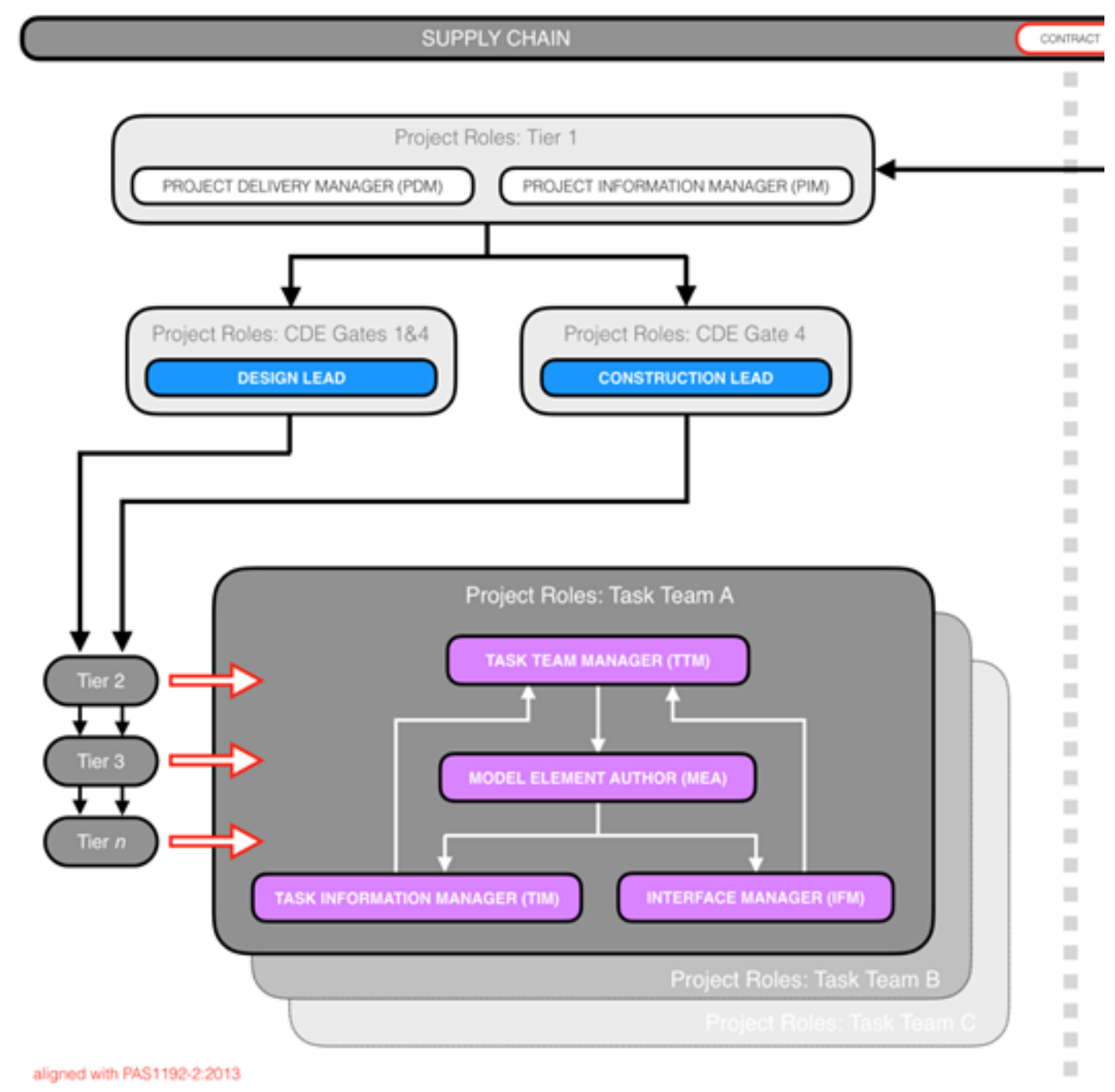

Figure 7: Project Roles and Responsibilities 


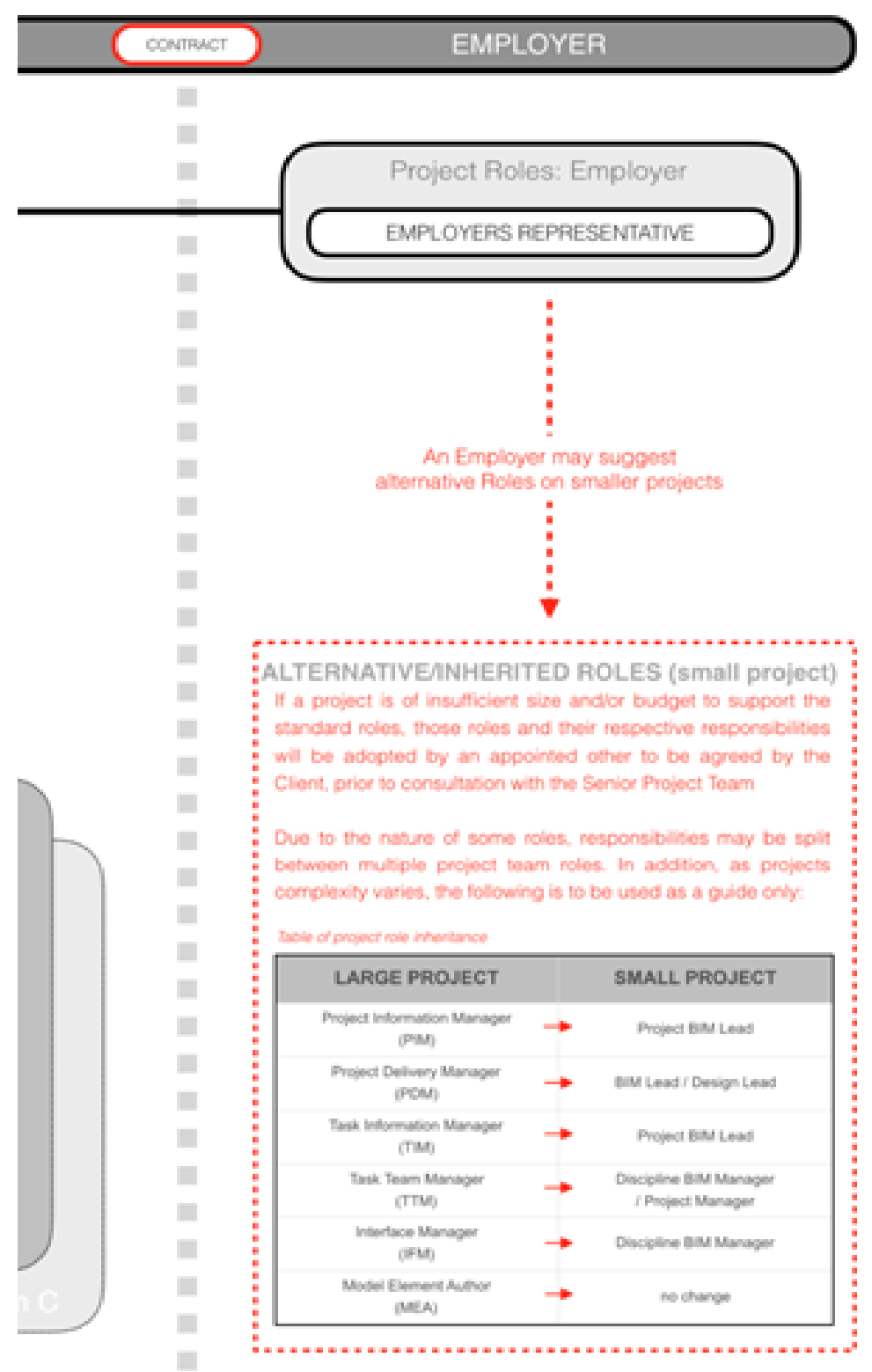

Figure 7: Project Roles and Responsibilities

As well as the structures defined above the workflow classification defines the processes in regard to role definition, check, review, approve, authorise. Again, this should be adapted and made project specifics. 


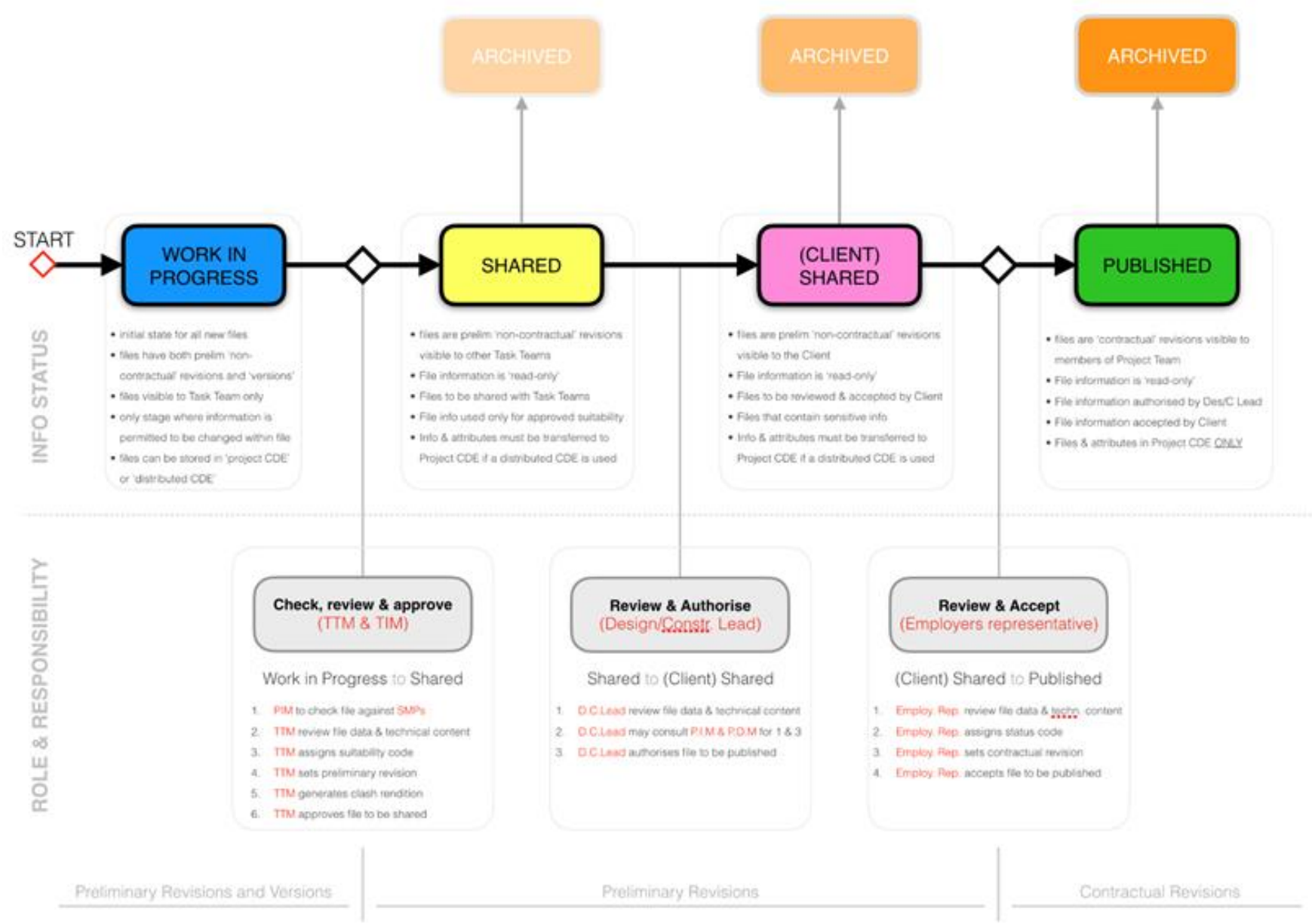

Figure 8: Workflow classification

See section 7 below for further information on the sport stadium Building Information modelling execution plan.

\subsubsection{Software and Design tools}

For Building Information to be fully utilised in the asset and facilities management space, different software applications are required. Building Information Modelling software may be broken down into four different silos based on the output they are required to perform (The BIM Hub, 2016). These include the following:

1. Building Information Modelling authoring software:

- $\quad$ Autodesk Revit

- Archicad Graphisoft

- Nemetschek Allplan

- Nemetschek Vectorworks Architect 
- CADSoft Envisioneer

- Tekla

2. Building Information Modelling checking validating softwares

- Naviswork

- Solibri

- Tekla

- Vico

- Revisto

3. Building Information Modelling collaboration softwares

- $\quad$ Autodesk BIM 360

- Dynamo

- Revisto

4. Building Information Modelling data transfer softwares:

- IFC

- Uniformat

- Collibre

- $\quad$ COBIE

- Ideate BIM link 
The diagram below graphically represents the use of specific softwares in a Building Information Modelling environment.

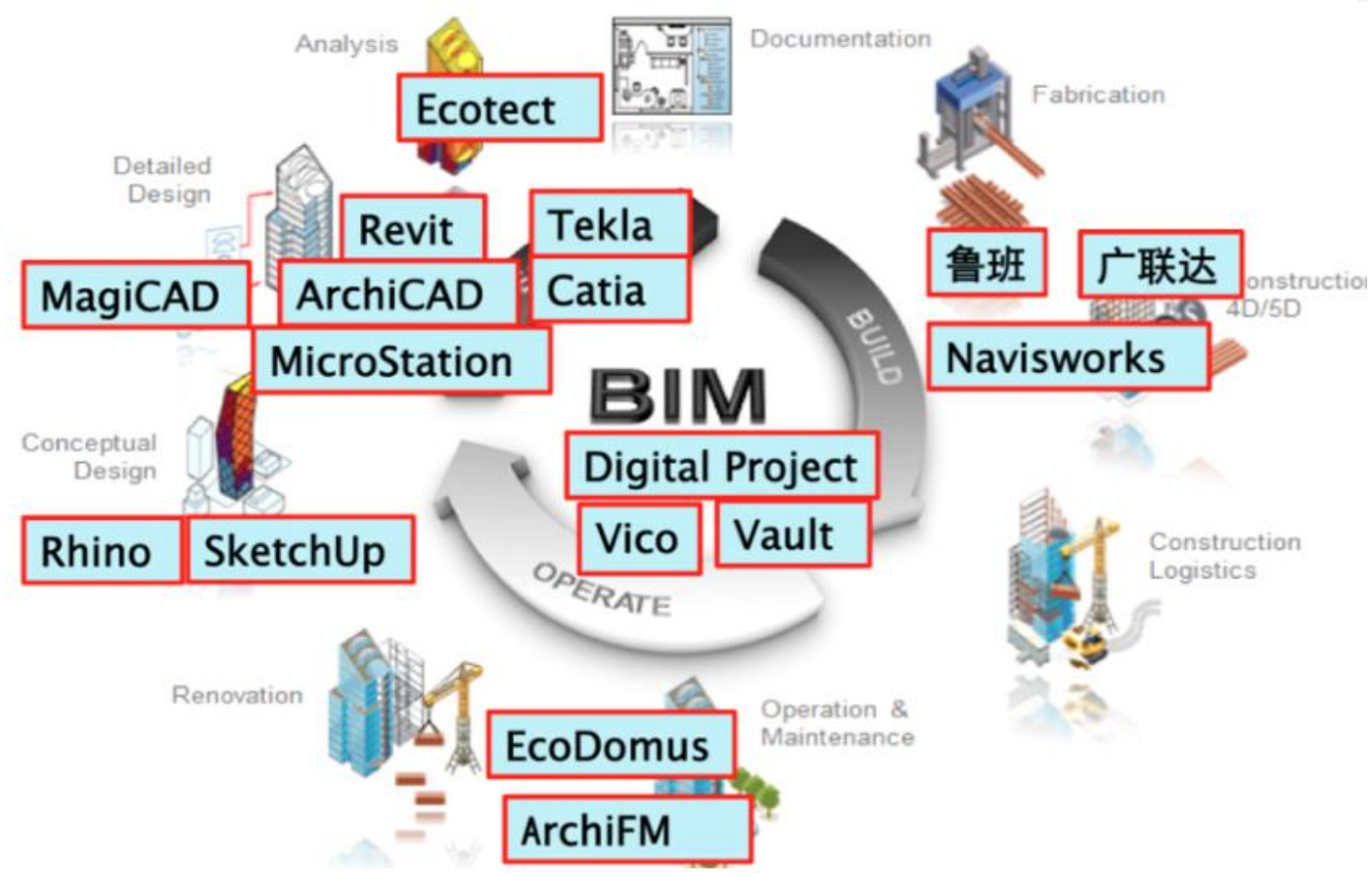

Figure 9: BIM related software through different lifecycle stages

The most commonly used software programme is Revit Autodesk; a design software tool. Revit was first released in 2000 and was intended to allow building professionals to design and document a project through a three dimensional model, like Revit, Archicad and reflex were also working with three dimensional building models (Autodesk, 2017). The key development that Revit had over the likes of Autocad is that it was the first software that developed parametric components using a graphical "family editor" rather than a programming language, and all relationships between components, views, and annotations were captured by the model so that a change to any element would automatically propagate to keep the model consistent. For example, moving a wall would update the neighbouring walls, floors, and roofs, correct the placement and values of dimensions and notes, adjust the floor areas reported in schedules, redraw section views, etc., so that the model would remain connected and all documentation would be coordinated (The BIM Hub, 2016). Today BIM is a leading software tool for Building Information Modelling and supports a multidiscipline design process for collaborative design (Autodesk, 2017). 


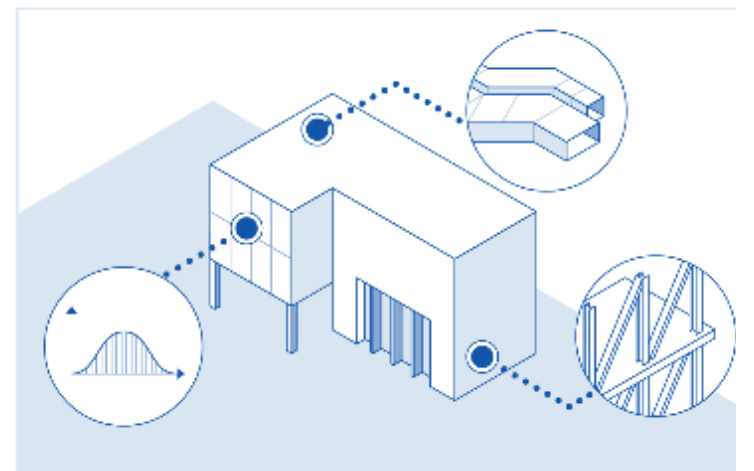

Design

Model building components, analyze and simulate systems and structures, and iterate designs. Generate documentation from Revit models.

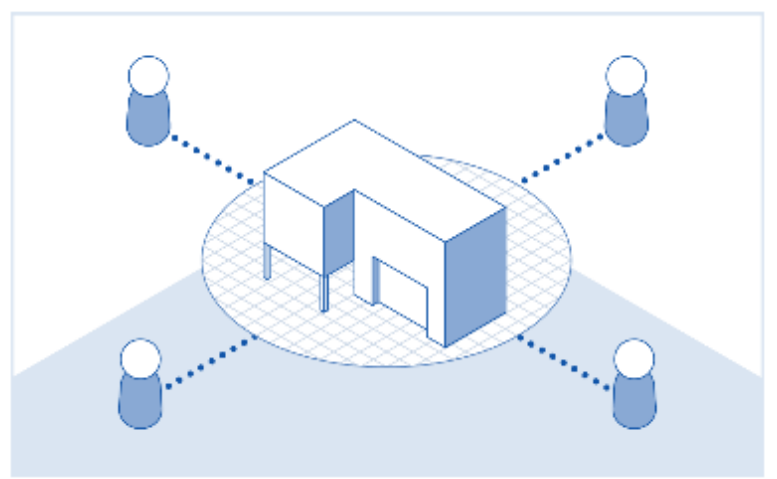

Collaborate

Multiple project contributors can access centrally shared models. This results in better coordination, which helps reduce clashes and rework.

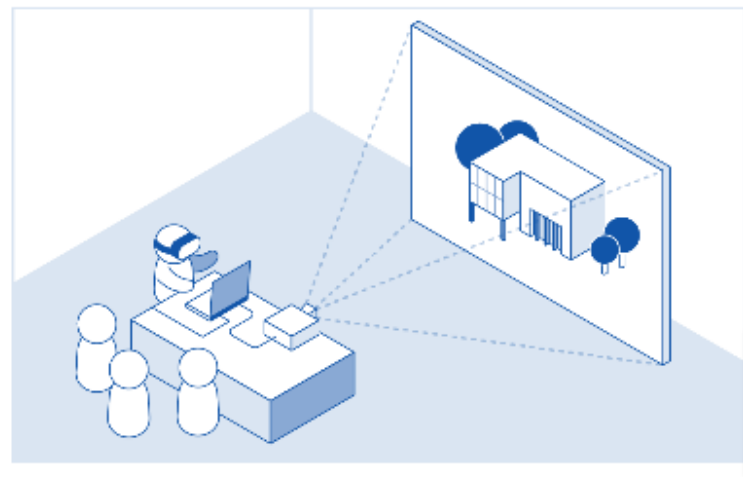

Visualize

Communicate design intent more effectively to project owners and team members by using models to create high-impact 3D visuals.

Figure 10: Multidiscipline figure

The solution that Revit creates is collaborative BIM with work sharing Revit allows multiple team members to work on a project at the same time using a centrally shared model, as well as this Revit has the ability to import/export data with commonly used formats (Autodesk, 2017).

Revit has adapted as a software tool specifically for disciplines including architectural design, structural engineering, MEP engineering and construction professionals.

- Revit for architectural design: offers features for every phase of the project allowing designers to capture and communicate creative concepts and precise design intent. The four 
key features Revit offers for architectural design is design and documentation, analysis of building performance, visualisation generating photorealistic renderings and multidiscipline model data sharing with engineers and the likes for improved co-ordination.

- Revit for structural engineering design: offers concrete reinforcement allowing detailed reinforcement designs, design to steel workflows showing higher detail, design documentation as well as a structural analysis prior to construction

- $\quad$ Revit for MEP engineering: offers features that allows engineers/designers and contractors across MEP to co-ordinate and detail more effectively and precisely. The four key features Revit offers for MEP design is integrated design, analysis of interference detection early in the design process, conceptual energy analysis data for engineering-driven calculations, documentation and fabrication.

- Revit for Construction professionals allows for decisions to be made in the preconstruction phase helping minimise constructability risks. The four key features Revit offers construction experts is smarter decision making with the planning and preconstruction decisions earlier, better communication and in the technical side preparation for fabrication and modelling of steel connections (Autodesk, 2017).

\subsubsection{Next step for Autodesk}

An article published by Autodesk "Where Next for BIM", highlights Autodesk vision of the next generation of BIM tools. Historically Revit was Sonata, in 2012 Revit became cloud based (centralised filing) and became market leading above SolidWorks application by Dassault Systems. Most companies identify code as having a 10 year life span, hence the arrival of cloud based Revit in 2012, and the cloud is market leading from the topical window based application (Awe, 2017).

When improving software versions there are two options, to improve the current versions by supporting previous methodologies or by starting fresh on a different application. For the improvements of Autodesk Revit, CEO Carl Boss posed that most of the work for this version of cloud based Revit was already defined (Awe, 2017).

It is said that Autodesk Revit is evolving as a BIM tool in the area of cloud, by providing a common data environment. Many issues arise as data is stored in small silo pods as opposed 
to a single platform. The versions are expected to tackle collaboration and workflow. Revit, historically was in three workspaces for engineering design and MEP professionals (fabricators and contractors). Tools disciplinary specific were developed for the nature of each industry profession however can all relate to the same project. The latest version of Revit has all the separate disciplines merged back to one. A common data environment is an online place for collecting, managing and sharing information amongst a team working on a project. A CDE can take many forms depending on the size and complexity of a project.

The next phase of Revit is said not to focus on modelling faster or larger models but introducing an enabling platform, a common data environment and cloud-based version. The project Quantam is an approach towards a data centric process. Autodesk alluded that they wanted an app that offers the right level of knowledge and not overload of data. Jim Awe chief software editor at Autodesk explained: "The key consideration is how to get data to flow smoothly in two directions throughout the ecosystem. In one direction, you have the continuum of design / make / use as you consider a system from concept to fabrication. In the other direction, you have all the major systems of the building that must coordinate with each other (Structure, Facade, Site, MEP, for example). A giant database is not needed for all the data if we have interconnectedness between databases" (Awe, 2017).

Quantum has been suggested to not replace Revit or become another version but to be a tool that offers levels of integration and connectivity not seen before and to move away from own product silo (currently how Autodesk products align). One of the biggest downfalls for Autodesk with their large portfolio of products is that they have not been able to utilise all the IP historically created, project Quantum is a research strategy to explore how this could be implemented given the change in technology landscapes. IP stands for intellectual property and is a digital media transport system and regains property rights over creations of the mind and fields of law.

\subsubsection{Implications for Revit}

As one of the biggest BIM tool drivers, Revit split to three users as defined above, there was suggestion that this may split back to the three user faces of architectural, structural and MEP. Furthermore, it is assumed that instead of different user applications, Revit will grow to have 
specific tools and direct manufacturing capabilities. Revit was not developed in house by Autodesk and consequently the design user face of this was out of Autodesk hands (Vysotskiy, Makarov, Zolotova, \& Tuchkevich, 2015). Historically Revit files are able to be exported and imported to other software applications, however this is not displayed in an identical manner throughout, and this is because there is not a file-based data exchange, something quantum is trying to quantify. Without this interface there is not that direct mirror of design display. The benefit for Autodesk is that they have the data base of Revit and there is no need for exporting of files etc.

As Quantum develops, and its capabilities increase it is expected that Revit will be morphed into this development. From a user perspective, performance issues are present with Revit due to the increase in complex models and somewhat bad practice. Most design software programmes require computers/hardware to have capability to withhold large files and data, of all the software programmes Revit requires the most RAM and fastest SSDs the need for an alternative solution is required (issues are common with slow computer usage), hence the development of cloud-based processes. "If you're in an application that requires a high level of detail - for instance, if the data is for fabricating the panels and components - what actually gets sent back to Revit is not at the same level of detail. Revit would receive a display mesh that's the right size and looks about right, which can be displayed in context for the architect to see how it looks. If the architect did want to see the panel in all its manufactured glory, then they could double-click the panel and see the manufacturer's information (Awe, 2017). If you try to model every single part in Revit to a fabrication level of detail, you will undoubtedly slow it down as it's overwhelmed with data" (Awe, 2017).

Autodesk fusion was developed from scratch and therefore is one of the few Autodesk products able to be utilised outside of the windows application and works on a cloud-based application.

As the Quantum growth spikes it is likely that Revit's capabilities will be taken and embedded into the cloud, Revit sees promise in a development path as opposed to software updates that have previously been the business as usual approach (Awe, 2017). 
Quantam will become what is described as an eco-system by contrast if quantum was to build this code-based system by scratch the development would have taken months. In using the application of Revit there has been rapid development and is said that the application may acquire other software's solutions into the eco-system (Awe, 2017).

Revit is largely utilised in the AEC industry as a design tool to co-ordinate different parties, the Revit software is a helpful visualisation tool to picture the design as well as identifying clash detection. Often with the introduction of Building Information Modelling different parties input data into the Revit model creating a pool of incorrect information and data at the wrong hierarchy, possibly because of the lack of understanding in how to correctly input data. Commonly the data that now stands in the model is re-worked correctly for the purposes of exporting data to contractors (pre-fabricators for example). Quantum looks to eliminate this data wastage/rework by creating what is said to be a contract between the CAD system and manufacturer. The contract will ensure interface points between systems. What this means is that both the required data inputs between all parties is agreed, for example the architect will define what data he/she needs for their design, the manufacturer will define their data schedules and together an agreed scope will be implemented. All parties will work in a centralised model, when changes are made to the design a flag is indicted to the entire project team. Quantam is said to enable the selection of the right tool for the right job maintaining the shared eco-system for all parties involved (Awe, 2017).

It is suggested that Quantum will provide some solutions to existing workflow issues like described above through data discrepancies. Ultimately, the development of Quantam is said to give users the ability to select the software specific to their disciple: this being Revit for designers or grasshopper for engineers and then to equally progress in a quantum environment, this means each party can continue to use their preferred software. What happens when these interfaces connect (different design disciplines Revit vs Grasshopper), it is assumed that they would interact via the interface points (a common language of data would be developed in quantum). Mixing levels of details and parametric constraints is one of the objectives of quantum (For example, how does the data from the design disciplines communicate with each other) (Awe, 2017). To achieve the collaboration, the natural boundaries of the disciplines are represented in workflows, for example the specified 
discipline will submit their work in the system and then this would update the interface points. The interface points are not competing for control but informing each other of the change. Revit is said to still play a major role in the BIM process.

Nevertheless, quantum is in its infinite development stage and at this point does not provide a complete solution, for example how does this work if there is no web connection for example offline mode? Awe mentions that the biggest barrier to BIM is the interoperability and collaboration is in software utilisation. The reality of ownership of data is still in question and working with client/end users in identifying their stance and level of comfortless in this process is necessary (Awe, 2017).

API would be available to competitors, as they recognise that AEC firms now run multiple tools to complete their projects. This could potentially have big benefits for companies like Bentley, which has a huge suite of analysis tools, and popular point solutions, such as McNeel Rhino. The big question will be, will these vendors want to play in Autodesk's ecosystem? Clients/users may make that decision for them, by choosing to adopt (or not) a Quantumbased system."

With quantum, it is important to note that this is not a next generation Revit and Revit will remain window based for the foreseeable future. As quantum develops it is said to take a load of Revit and drawing into the cloud space, with the possibility of Revit dissolving into quantum (a long-term goal). Revit as it stands has limited capability in expanding and with the development of quantum has avoided these areas such as civils and fabrications (areas Revit never was seen to develop in). Quantam is a vision for Autodesk and its main achievement will be to kill parts of the problems Revit BIM work flows suffer (Awe, 2017).

When the AEC industry first adopted BIM, interoperability, there was always a challenge/issue with having no interchange standards to help mitigate any issues. Quantum looks to mitigate these issue, subsequently Autodesk products will be more heavily relied upon.

With the launch of Quantam the aim is to provide a platform ecosystem that considers the future of a design make / workflow for the AEC industry. Quantam is a progressing and the 
development of this is said to change the industry of AEC to mitigate historical issues in BIM and provide better workflows.

The present business as usual approach in a BIM environment consists software usage and collaboration of multiple stakeholders. Revit and Autodesk products are one of the major players in the BIM world. The article presented above indicates from a software development process a lot of uncertainty. From a BIM user, it can be assumed from a hierarchy perspective that the BIM software developers would provide such clarity to the users of the software's and the way in which they predict their software to be utilised. With uncertainty created from software developers such as Autodesk and huge majority of progression in these tools/systems the users of the tools have that much more uncertainty. With the issues highlighted in the BIM world there is no clear route alignment as to where the future of BIM may lead and therefore it is no surprise that there is collaboration and integration issues when no one party has the answers nor certain scope as to where the world of BIM is headed. There is certain promise with the future of BIM the question lies in where and what will happen.

\subsubsection{Software adoption for BIM}

Other commonly used software programmes include industry foundation classes for data sharing, computer aided facilities management systems (CAFM) with the most common being COBIE. COBIE, short for Construction Operations Building Information Exchange, is an iterative process with four defined data drops, Drop 1 project titles such as site location, and representation including function and performance, Drop 2 gateway for selection of main contractor, spreadsheet will now also contain a spreadsheet of furniture and equipment for each room, drop 3 defined price should reflect any differences between designed and installed equipment, drop 4 should contain all information for operation and maintenance, drop $3 \& 4$ are the responsibility of the contractor (Tardif \& Aeronautics, 2017). While COBIE has caused confusion and frustration by many parties due to its difficulty in use, contrary to this the UK government has mandated the use of COBIE within the BIM standardisation (Management, 2013). Does this then reflect on the resilience for change in human behaviour as opposed to the intended use of the tool? 
COBIE is a tool that has been developed when there is not a direct integration between BIM and the facilities management system and provides a BIM data exchange to transfer the information. COBIE developer provides a framework for the information attributes required for major building systems. There has been a number of developed interfaces for importing and exporting COBIE directly into and out of FM: interact database.

The COBIE standard was developed to define information for assets that are delivered as a construction project aligning with the principles of data for Building Information Modelling. COBIE data is defined in .CVS, or .XLS files organized into multiple spreadsheets that correspond with the COBIE table.

\subsubsection{Legalisation Intellectual Property, liability issues}

Building Information Modelling from a practical and legal perspective was acknowledged in the building law and regulation conference held in Wellington in June 2014. The conference attendees acknowledged the use of BIM in the AEC industry and provided an overview from a legal perspective (Stewart, Saxton, Associate, Ellison, \& Watts, 2014). Discussing the issue and presenting the associated paper were three practicing solicitors from firms across New Zealand. The situation was solely aligned with the New Zealand legalisation system and AEC industry. Because of the nature of the subject matter this only highlighted the context of New Zealand. The key risk with Building Information Modelling is not the use of BIM but the potential failure of the parties involved to adequately detail the agreed scope in the consultancy agreement. A common dispute that has historically occurred is whether a service is included in the scope agreement or whether there is now the power form one party to be entitled to variation costs. This means one of two things, either the consultant is entity to cost or time relief from carrying out these services or deciding who the design fault is responsible to (Stewart et al., 2014). The importance of defining the scope of the service and defining the responsibilities of each consultant is important. Developing a BIM management plan that details model elements for contract works and tracking of inputs of model elements that defines the LOD will initiate clear understandings of each party. 
The New Zealand BIM schedule sets the framework to develop a project specific, the BIM schedule is the first attempt in New Zealand to create a standard form document to regulate the use of BIM in a contract. The idea is that the schedule will be a supplementary document to the consultant agreement (Reding, 2014). If a specific consultant/designer comes into the project part way through they agree to an accession deed. All parties are required to agree to the BIM management plan and the Project execution plan.

Unlike traditional contract documents the BIM schedule creates multiparty relationships, however the breech of relationships is not clear and traditionally the principal was always to retain the role of enforcing rights and obligations, as this role is now shared this enforcement is unclear (BRANZ, 2016).

The increased liability profile of consultants - in any model prepared by multi stakeholders and error by one has the possibility of a domino effect. While most parties are aware of their responsibilities with the model contributions they are less contented to be held liable for an error or omission caused by another party. Furthermore, the concerns are still significant around the difficulty in pinpointing the source of the design problem and party.

Liability within a federated BIM model is able to be identified as the federated model is made up of the individual design models. Identifying whom was responsible for design discrepancies would be possible by analysing the individual models (For example, architecture, and engineering). If, however there is an error when co-ordinating the federated model whom then is responsible. The industry is still debating the need for an administrative role (BIM manager) to deal with this issue (Stewart et al., 2014).

A collaborative model however creates more difficulty in identifying liability. To pinpoint the party responsible for this type of modelling the scope of service for each consultant and the agreement is heavily relied upon. If the parties intended to share the design responsibility a contractor structure can be adapted (Smith, 2014b).

Liability in negligence - duty of care is owed by all responsible parties, architects, engineers and project managers. They are required to prevent damage. Duty is owned by both the 
principal and subsequent owners. In this sense it is important to understand the relationship between parties and whether it is reasonably foreseeable.

An allegation of professional negligence must be supported by current uptake in the market for example, if everyone else is doing what the design consultant is doing then he or she is required to exercise the required standard of care. In a commercial context it is often found for example a structural engineer is often held accountable to a commercial building owner. "Anyone who plays an active and critical role in controlling the controlling the construction project may owe a duty to the building owner (Stewart et al., 2014).

Disclaimers act as a buffer for design consultants to provide as much protection as possible and can include the following:

- A statement of purpose for which the document/model is prepared

- Identification of the specific person whom the document was prepared for.

- A statement of who may rely on the model

- A statement that the professional does not contemplate the use by any other persons for another purpose.

In the BIM environment, the BIM schedule should set out the intended use of the model and the intended users. On reviewing a BIM schedule this should be kept in mind.

Due to the nature of Building Information Modelling and its juvenile stature from a legal perspective it may be difficult to identify what inputs or data was relied on. From a legal perspective it is unknown how lawyers will navigate the discovery process, should BIM be found as an issue in litigation. It may be that the lawyers are provided a password to access the CAD models. It is more than likely that the lawyers will not have the skill set to navigate around these models. The design formats will need to be reviewed in their native file format which also creates greater issues for inexperienced CAD drivers (Udorm, 2012).

Fitness for purpose is where a party warrants that the completed works will reflect the principal's contract. Importantly, the intended purpose of the work must be properly identified for the clause to take effect. The use of BIM mean that design consultants are more likely to utilise a fitness for purpose because the design requirements are clearer. "For 
example, a services engineer may be more willing to accept a fitness for purpose warranty linked to an ambient temperatures range in a building if the services engineer is comfortable that it can rely upon the analysis of building performance from the BIM model" (Bryde, Broquetas, \& Volm, 2014).

There is a possibility that any party who inputs an element into the BIM model impliedly assumes responsibility.

Duty to warn, lack of inspection and communication resulted in one of the first known claims related to the use of BIM in the US. There was failure from an architect to pass on the information to the contractor on the little space for plumbing in the ceiling plenum. When the contract tor was $70 \%$ through they ran out of room. This demonstrates that it is critical that the parties in the BIM project team communicate.

Increased complexity in intellectual property rights - a key issue associated with BIM is the intellectual property rights due to the missing of information and inputs from design consultants (Stewart et al., 2014).

Both design consultants and the principal require rights over the intellectual property either by ownership and licence. The usual process around intellectual property rights are as followed:

a) Either the design consultant or the principal owns the intellectual property and grants the other a licence to use; or

b) The design consultant and the principal jointly own the intellectual property with a reciprocal licence to use.

These parameters still exist however in the setting of a BIM project the settings will require more thought. Because of the collaborative nature of BIM new intellectual property rights arise. BIM software and protocols allow for tracking on specific elements, especially in federated models (Stewart et al., 2014). 
Contrary to this a BIM model allows data inputs by multiple parties at the same time. BIM would still allow the individual design consultant to identify the model elements they created, determining this will be time consuming. The simplest intellectual agreement would consist of ownership by principal or joint ownership by all design consultants, this however may not be acceptable by a design consultant. Design consultants are more than likely going to want to retain individual ownership of their own intellectual property to ensure they receive their own financial reward for their individual property information created. Ownership is linked to the design consultant's respective services as set out in the BIM schedule. Licences to use the intellectual property would need to be consistent with the specified use of the model as defined in the BIM schedule (Stewart et al., 2014).

Impact on insurance - To mitigate a design consultant's potential liability for damage or loss they must maintain professional indemnity (PI) cover. Principals will require all design consultants to have PI insurance. Due to the importance of PI insurance both the principal and design consultants in the event of a consultants ability to claim under its PI policy (Stewart et al., 2014).

For reference the UK government published a Best Practice Guide for Professional Indemnity Insurance and can be referred to. Although BIM differs away from traditional ways of working the way in which PI insurance is utilised should not be changed. It is however not apparent how BIM related activity will be covered by PI insurance. If shared responsibility by both parties is for the services prepared is split either proportional or joint and several liability will be documented (Philip;, 2012). Any liability one design consultant incurs due to the negligence of another will not be covered by the PI insurance.

The most appropriate policy is Owner Controlled Professional Indemnity Insurance (OCPI) which provides cover to the principal for loss or damage. The two main attributes behind OCPI include: 
a) The owner is a loss payee but each named design consultant (and the contractor in a design and construct contract) is protected as the policy includes a cross liability and waiver of subrogation clause; and

b) The principal does not need to prove that any one design consultant has been negligent; all design consultants are covered by the policy, so the negligence does not need to be sheeted home to any one design consultant.

Collaboration and project delivery in a BIM environment, design consultants cannot operate in silos. It is suggested that BIM works best when there is a working culture facilitates a similar level of communication. Project participants will work best when all project participants are involved as early as possible (Stewart et al., 2014).

NEC contracts can be an alternative as NEC contracts were designed to foster a collaborative approach to contracting, with this in mind it would appear to be a good fit. Despite this NEC is not the answer as it does not foster the communication required for BIM. The good faith obligations created with IPD, it does not facilitate contractors' contribution or best for project aspects through NZS3910:2013.

With BIM one of the biggest progressions in the construction industry is the concept of good faith. In contract law, the implied covenant of good faith and fair dealing is a general presumption that the parties to a contract will deal with each other honestly, fairly, and in good faith, so as to not destroy the right of the other party or parties to receive the benefits of the contract (RJHA limited, 2010). The term good faith has been highlighted by major construction projects in New Zealand, the courts and local governments have started to recognise good faith in construction contracts. Good faith represents a none binding contract, it is unsure where good faith in the court of law and construction documents starts and ends. It is suggested that in this case the obligation between principal and contractor to share information will extend to the full design team, creating that multi-disciplinary work structure (Tan, 2011).

To maximise the benefits of BIM, project participants need to be involved as early as possible. Early contractor involvement may be the solution. 
ECI procurement may can be defined as below:

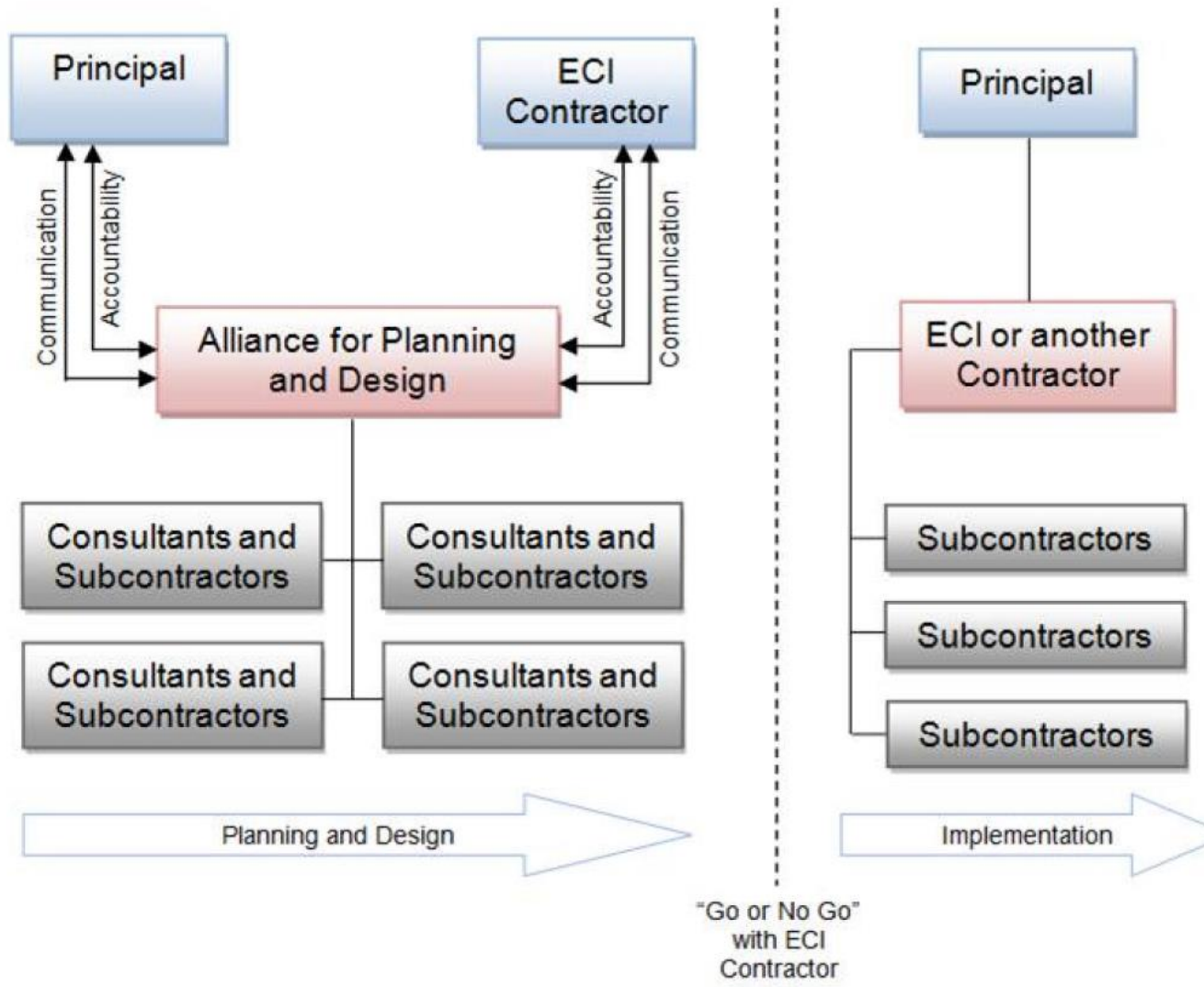

Figure 11: ECl procurement chart

Contractual risks of BIM are highlighted with the onset of a contract and in respect to the term good faith (Wondimu et al., 2016). The risk does not lie with the adoption of BIM itself but with the contractual obligations between parties. It is suggested that careful consideration needs to be taken when formally agreeing to certain aspects of BIM. Because BIM is bypassing traditional approaches of contractual obligation, BIM contracts must reflect these approaches and be accepted by all parties. 


\subsubsection{Typical BIM workflows}

There is not one workflow that is best suited to be adopted in every BIM project and like every project, each process though in essence may have the same deliverables, adopts a specific process. Autodesk published an article that outlines adopting and adapting A BIM workflow. Once deciding to adopt BIM principles the next question is often centred on how to do this. The intelligence of 3D modelling is increasing, Autodesk considers Minecraft in endorsing these skills (Newton, 2015). Minecraft is a game developed by the Swedish where players place building blocks carefully within a grid to maximise the use of the space. Process and workflows have matured as technology progresses with integration and interoperability breaking down silos. New Zealand AEC industry is commonly held back because of silos created be it engineers and architects or the likes. With cloud computing adopting such a tool has meant that installation and access is simpler and less of a burden in one having and paying for hardware investment. One significant improvement with foster BIM modelling is 3D modelling enables the power to digitally view the design as opposed to 2D drawings, this allows everyone to understand the implications on a full-scale 3D model. Perhaps more significant from a money saving scheme is that when changing an element in a BIM model this changes all drawings etc. that are associated to that element (often 2D drawings need every drawing sheet amended, a very timely exercise) (Newton, 2015).

\subsubsection{Workflow improvements}

$\mathrm{BIM}$ is moving beyond a project approach to institutionalise BIM as standard practice and adopting their process. Most organisations start the adoption stages with introducing a BIM manual including information standards and outlines in an improved electronic data sharing environment. The manuals are utilised by the project team initiating standards and protocols as well as aligning to contracts. This allows for insurance on compliance aspects and performance measures.

Commonly in the AEC industry design and build contracts are implemented in which a partial design may be outlined, and the projects take off quickly with the thought process developed as the design is constructed. BIM works differently to this as the workflow to BIM includes 
careful initial planning that is deliverables are decided prior to design. The ability to access models on phones and data and cloud-based platforms is useful on site particularly.

The biggest advancement in improved processes is pilot projects and effectively lessons learnt from what has been done. As BIM workflows are centred on 3D technology and modelling tools this starts with the need to collect reality via survey tools to understand the environment. It is important that any workflow starts with a clear indication of the exact environment. Workflows of conceptual design should address any early onset problems and consistent workflows should allow easy transition from stage to stage. The biggest advantage in BIM advancement is openness acknowledge a joint venture. "It is all about working together and designing standards and protocols in the beginning" (Newton, 2015).

How both firms and government organisations are approaching BIM implementation is progressing in a chaotic but somewhat measured way. The need to understand and upskill on specified tools for project deliver is crucial as well as learning to use whatever tools achieves the deliverables in the most efficient way (Roepke, 2016).

"A key element of such BIM progression is the need to integrate tools and processes within organizations as well as with all stakeholders across the entire project lifecycle. Collaborative workflows that break down barriers are central to improved processes and better-quality project outcomes (Roepke, 2016). 


\subsection{LITERATURE REVIEW - PART 2}

\subsection{Asset and Facilities Management}

\subsubsection{Asset/Facilities Management Definition}

Asset: is an item, thing or entity that has potential or adds actual value to an organisation. Asset management involves the balancing of costs, opportunities and risks against the desired performance of assets to achieve specific objectives" (The Institute of Asset Management, 2015). Value can be tangible or intangible, financial or non-financial and includes consideration of risks and liabilities. It can be positive or negative at stages of asset life.

Facilities Management: encompasses multiple disciplines, which allows for the functionality of the built environment by integrating all people, places, process and technology" (International Facilities Management Organisation, 2014)

Asset Management: Coordinated activity of an organisation to realise value from assets. Realisation of value will normally involve a balancing of costs, risks, opportunities and performance benefits.

Life Cycle: the time interval that commences with the identification of the need for an asset and terminates with the decommissioning of the asset or any liabilities thereafter.

\subsubsection{Asset Management in New Zealand}

New Zealand's minister of finance acknowledges that New Zealand needs improved information about, and management of our existing assets. The government has $\$ 116$ billion of existing infrastructure assets and a forecasted $\$ 50$ billion of spend over the next 10 years (New Zealand Treasury, 2015). The key challenges of New Zealand's assets include a number of aging infrastructure networks that need renewing. For an example the schooling estate has assets that are over 40 years old and parts of our water network are over 100 years old. As well as this over $50 \%$ of the social housing stock is over 40 years old and one of the biggest challenges is trying to understand what the true cost are and when they will be incurred. The response is to develop national, shared data standards for infrastructure to develop a more transparent infrastructure pipeline data.

The NZ government's vision by 2045 is to strengthen asset management by developing metadata standards for roads, buildings and waters and to establish regional centres of excellence or similar for collating and making available the data obtained through shared 
through metadata standards. New Zealand has mature asset management practices, which provide a good understanding of intended levels of service and whole of life costs of investment (New Zealand Treasury, 2015). There is widespread use of shared infrastructure data standards to allow for networks to be benchmarked and interdependencies to be better understood.

The response is to strengthen asset management practices to ensure NZ's infrastructure assets are making the best contribution to quality services. The NZ government reports that asset management is managed differently over various sectors (New Zealand Treasury, 2015). Asset management can become more effective by collecting the right kind of data using shared data standards, a number of reports have concluded that data should be more effectively used, and the right kind of data needs to be collected.

The action plan is to strengthen asset management practices by developing national metadata standards to ensure consistent base to build. This will mean that local governments will have a long-term view of their investment requirements to make more informed decisions. This will improve the three main asset classes across New Zealand including water assets, road and buildings and to be able to make informed decisions including deferring asset renewals where appropriate and reduce consultant/contractor expenditure.

\subsubsection{SAP systems}

Companies have evolved that focus solely on Facilities management which has largely lead to the outsourcing of facilities management. When outsourcing facilities management this means that the complete management and decision making authority is outside of the organisation that normally would occupy that building or an owner (Mohan, 2013). The key objective of facilities management is to help maximise business returns and establish long term advantages. For a building to be utilised to reduce the buildings life-cycle costs. When organisations outsource their facilities management a contrast usually arises between what the client's long-term goal is and the supplier's incentive. This can be caused by a number of things, the building owner not necessarily knowing what they need and the supplier not understanding what the client wants this could be that the owner wants to rule out all reactive maintenance whereas the facility manager on a day to day basis is the person on the tools, that is fixes the problem as it arises. Outsourcing facilities management has its 
advantages including the external organisation being more equipped with the latest skills and information technology and management (Mohan, 2013).

Specifically, facilities management is based on the premises that any organisation is linked to the physical environment to which it operates. The aim of facilities management is not to just optimise running costs but also to raise efficiency in management to the related asset for people and processes. Facilities management is a process that produces results based on user satisfaction:

- Space - Adapted to changing needs and effectively utilised

- Environment - to create a heathy and sustainable working environment

- Information technology - To support effective communications

- Support services - To provide quality services to satisfy users

- Infrastructure - to provide appropriate capability and reliability

Each organisation whom preforms facilities management systems has adopted a specific software that purposely suits their needs and overall outcomes. Implementing a facilities management system allows the user to manage their asset in a specific way. It is important to note that the facilities manager is not normally responsible for the management of the core production of the company (British Institute of Facilities Management, 2014).

One of the most common facilities management software's on the market currently is SPM assets, this drives a planned approach as opposed to reactive. SPM asset is tailored specifically for local government, housing providers, community housing, commercial territory, education schools and hospitals (SPM Assets, 2016). The SAP programme provides evidencebased work programme interfacing with an existing operational asset/works management system.

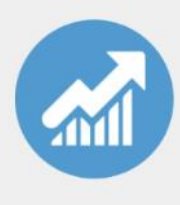

Analytical

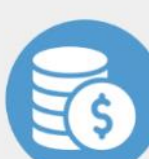

Risk Based

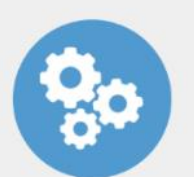

Infield Assessment Apps

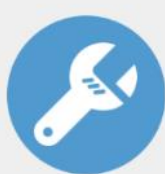

Lifecycle Modeling

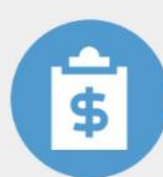

Self Service Reporting

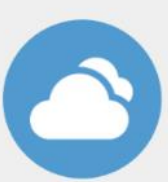

Works Programmes

Figure 12: SAP tool attributes 
eMaint has evolved as a cloud based management tool that provides maintenance operations in any maintenance department and can be accessed across any browser based device (SPM Assets, 2016).

FM5000 Facilities Management Software developed by Real Asset Management is a leading provider in facilities management software. The developed work management apps allow organisations to streamline processes and reduce property maintenance costs, this software is rated number 1 in Australia (Real Asset Management, 2017).

There are many different software's and maintenance providers and depending upon your company's core objectives depends on what software will best fit the needs of your organisation. There are many contributing factors as to why organisations utilise specific software's, this ranges from the different processes and procedures each provide as well as licencing and cost factors. Facilities management is driven by the client needs and achieved when the provider (Facilities Manager) understands what the client wants.

An article published by Nical and Wodynski (Nicał \& Wodyński, 2016)enhancing facility management through BIM 6D acknowledges a variety of disparate FM systems. In any situation whether it is BIM related or tradition FM system approaches for the operation phase a comprehensive set of well-structured information on the built asset is required. The majority of the article focuses on new investments. Traditional approaches recognise facilities management as a non-core part of construction and therefore the operation of a building is not seen as adding value. With the operation life cycle stage of a building contributing to $80 \%$ of costs more and more building owners see the imperativeness of thinking more about how to target this stage. Customarily the handover process from construction to operation takes several weeks. In the BIM space the construction sector is lagging with the uptake in operational maintenance. The perceived understanding on construction projects focuses on the design and construction of a building instead of whole life cycle of a building. It is suggested that the focus changes from end to beginning i.e. rather than incorporating a Facilities Manager after construction, identifying those needs at pre-design stage (Nicał \& Wodyński, 2016). 
Facilities managers on a day-to-day basis require building components to be located quickly and easily. In many situations, components require prompt reaction. Traditionally the FM provider will rely on paper sources and subjective judgement based on experience. This may lead to reduced productivity, safety and security and provides a risk. Through the integration of a BIM model the real-life resource location can shed a new light on the issues raised in traditional asset management approaches. A barcode-based system (each asset component has a barcode label to identify the asset and associated components) allows for a more accurate data field for the asset. For asset owners it is crucial to understand the business operations taking place within the asset. BIM provides a basis for planning with a historical data base of the existing building (Nicał \& Wodyński, 2016).

The article underlines that within BIM it is critical that the data associated is accurate and precise. BIM for facilities management still is in an infantile state and requires further research. Notably the perceived benefits give reason to adopt such a procedure. Can it be assumed that one of the biggest barriers and issues associated with facilities management practices is the inability of owners to understand and document the processes necessary to manage their assets and the data. Or is it reason enough to assume that there is a resilience in changing from one process to another especially moving to a digital based environment (Nicał \& Wodyński, 2016).

\subsubsection{Global asset management standards/Guides}

The New Zealand Asset Metadata Standard v 1.06 was drafted in June 2016 (see Appendix 7). The metadata standard provides asset managers and their suppliers with a specification to refer to. The specification is designed to support data creation, collection, storage and analytical capabilities. Most importantly this standard was developed as a point of reference to establish a common understanding of asset data. The standard will benefit both residential and light commercial building whom asset manager use the data to inform funding and investment (Havakis, 2017).

Asset manager's main objective is normally to maximise the service delivery. To achieve these types of decisions, (capital and operational) the data and information should be standardised. "They create the basis for standardised and harmonised data, which drive evidenced-based 
investment decision-making across public assets in New Zealand". These standards recognise whole of life management of assets and the lifecycle of asset themselves. The specifications have been developed with two reasons in mind, ensure a geospatially digital data standard for new assets and to ensure any asset management to maintain the asset have a similar approach.

The main objective of this standard is to streamline the transfer of digital data when managing specific assets. This will extend processes including creating, storing, and capturing and/or analysing data. Adopting these standards increase efficiency as well as:

- Eliminating duplication

- Improving process efficiency - accepting process and checking against design criteria

- Improving customer service to both internal and external customers

- Improving the quality of authority systems for operational and business requirements

- Providing a structure for consistent recording of authority owned assets

- Managing assets better to reduce ongoing maintenance costs

This standard is designed to capture asset information in a repeatable format to ultimately provide intelligent decision-making. The table below sets out the asset categories:

\begin{tabular}{|l|l|l|c|c|}
\hline \multirow{2}{*}{$\begin{array}{l}\text { Building Act } \\
\text { Classification }\end{array}$} & \multirow{2}{*}{ Type of Building } & \multicolumn{2}{|c|}{ Example } & \multicolumn{2}{c|}{$\begin{array}{c}\text { Light } \\
\text { Commercial }\end{array}$} & Residential \\
\hline \multirow{4}{*}{ Housing } & Detached dwelling & House & & $\checkmark$ \\
\hline & Multi-unit dwelling & Apartment building & & $\checkmark$ \\
\hline & Group dwelling & Marae & & $\checkmark$ \\
\hline \multirow{2}{*}{$\begin{array}{l}\text { Communal } \\
\text { residential }\end{array}$} & \multirow{2}{*}{ Community service } & Hotel & & $\checkmark$ \\
\hline & & Hostel & & $\checkmark$ \\
\hline
\end{tabular}




\begin{tabular}{|c|c|c|c|c|}
\hline \multirow{2}{*}{$\begin{array}{l}\text { Building Act } \\
\text { Classification }\end{array}$} & \multirow[b]{2}{*}{ Type of Building } & \multirow[b]{2}{*}{ Example } & \multicolumn{2}{|c|}{ Included in Standard } \\
\hline & & & $\begin{array}{c}\text { Light } \\
\text { Commercial }\end{array}$ & Residential \\
\hline \multirow{5}{*}{$\begin{array}{l}\text { Communal } \\
\text { residential }\end{array}$} & \multirow{2}{*}{ Community service } & Hall of residence & & $\bar{v}$ \\
\hline & & Boarding house & & $\checkmark$ \\
\hline & \multirow{3}{*}{ Community care } & Hospital & & $\checkmark$ \\
\hline & & Old people's home & & $\checkmark$ \\
\hline & & Prison & & $\checkmark$ \\
\hline \multirow{12}{*}{$\begin{array}{l}\text { Communal } \\
\text { non-residential }\end{array}$} & \multirow{7}{*}{ Assembly service } & Church & $\checkmark$ & \\
\hline & & Cinema & $\checkmark$ & \\
\hline & & Swimming pool & $r$ & \\
\hline & & Stadium & $\sqrt{ }$ & \\
\hline & & Theatre & $\checkmark$ & \\
\hline & & Museum & $\checkmark$ & \\
\hline & & Hall & $\checkmark$ & \\
\hline & \multirow{5}{*}{ Assembly care } & College/school & $\checkmark$ & \\
\hline & & Kindergarten & $\checkmark$ & \\
\hline & & Day-care institution & $\checkmark$ & \\
\hline & & $\begin{array}{l}\text { Early childhood } \\
\text { centre }\end{array}$ & $\checkmark$ & \\
\hline & & $\begin{array}{l}\text { Centre for disabled } \\
\text { people }\end{array}$ & $\checkmark$ & \\
\hline \multirow{11}{*}{ Commercial } & \multirow{11}{*}{$\sqrt{2}$} & Offices & $\checkmark$ & \\
\hline & & Retail & $\checkmark$ & \\
\hline & & Police station & $\checkmark$ & \\
\hline & & Post office & $\checkmark$ & \\
\hline & & Restaurant & $\checkmark$ & \\
\hline & & Storage facility & $\checkmark$ & \\
\hline & & Bank & $\checkmark$ & \\
\hline & & Transport terminal & $\checkmark$ & \\
\hline & & $\begin{array}{l}\text { Television or radio } \\
\text { station }\end{array}$ & $\checkmark$ & \\
\hline & & Amusement park & $\checkmark$ & \\
\hline & & Service station & $\checkmark$ & \\
\hline
\end{tabular}




\begin{tabular}{|l|l|l|c|c|}
\hline \multirow{2}{*}{$\begin{array}{c}\text { Building Act } \\
\text { Classification }\end{array}$} & \multirow{3}{*}{ Type of Building } & \multicolumn{2}{|c|}{ Example } & \multicolumn{2}{|c|}{ Included in Standard } \\
\cline { 3 - 5 } & & $\begin{array}{c}\text { Light } \\
\text { Commercial }\end{array}$ & \multirow{2}{*}{ Residential } \\
\hline \multirow{3}{*}{ Outbuildings } & & Laundry & $\checkmark$ & \\
& & Garage & $\checkmark$ & $\checkmark$ \\
\hline & Public toilet & $\checkmark$ & $\checkmark$ \\
\hline & Machinery room & $\checkmark$ & $\checkmark$ \\
\hline
\end{tabular}

Table 12: Asset Categories

The structure of standard includes:

- Condition

- Repairs, Maintenance and Operations

- Utilisation

- Demand

- Criticality

- Risk

- Resilience

- Design Performance, and

- Service Performance

The New Zealand Asset Metadata Standard is based on the global metadata schemata. This standard describes the data to be captured at three levels (Havakis, 2017).

- Physical (material or diameter)

- Metadata (date of construction)

-Asset management summary attributes (condition rating)

The diagram below, represents global metadata at a high level, in overview the schemata represents five volumes:

1. As Constructed or As Built Schema - this standard/volume represents elements required for making evidenced based decision. The structure is specified above.

2. Asset Management Intervention Schema - 
3. The invention methodologies - In this volume the standard documents interventions on management of assets from inspections to audits

4. The Evidence Based Investment Decision Making Analytics - this describes an asset in four levels on how you describe this from the risk of an asset right down to long-life economic yield

5. The Management Frameworks - this refers to the legislative asset requirements that asset managers must adhere by. 


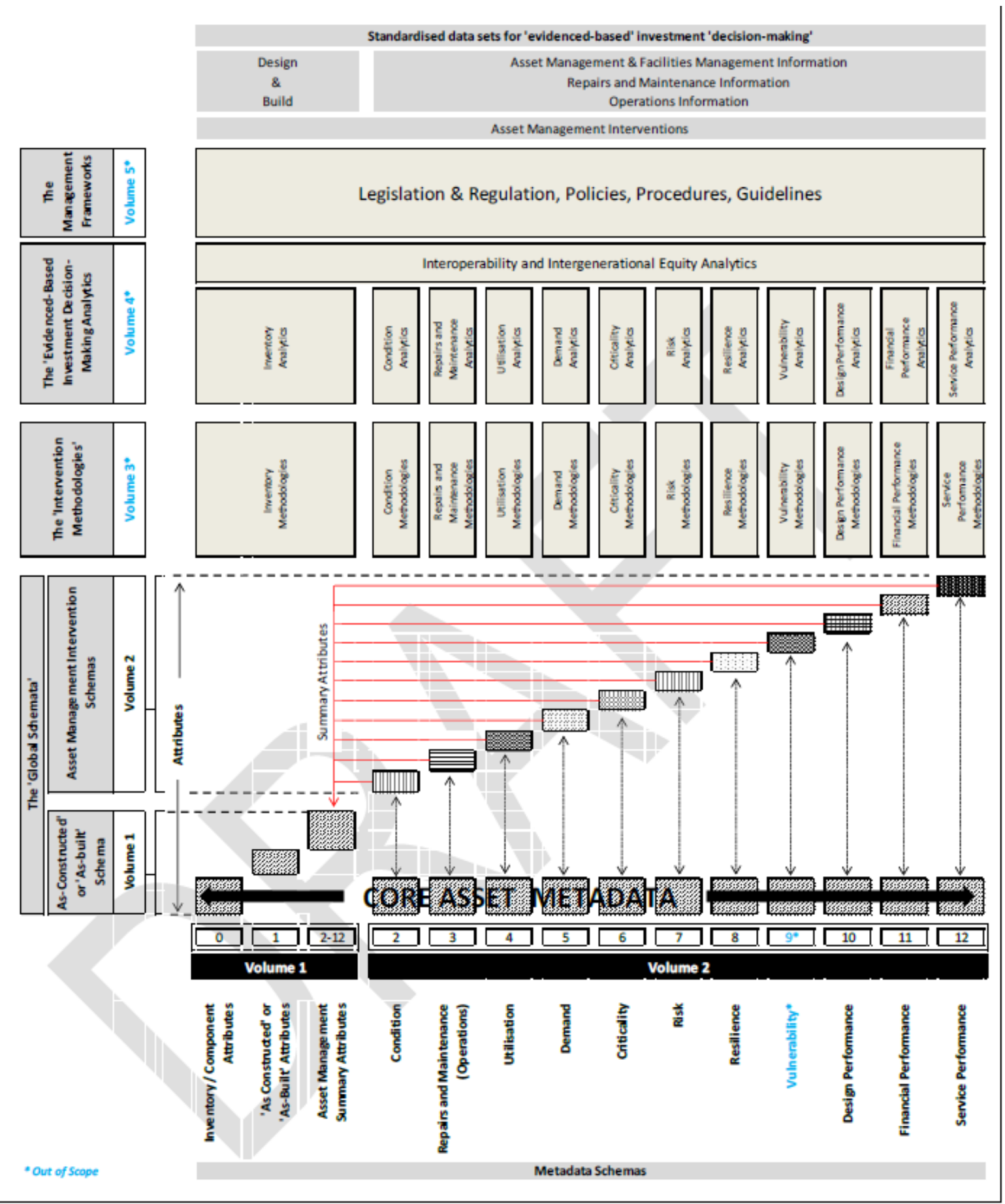

Figure 13: Global Metadata Schemata

The asset management framework is structured around the following legislation and regulatory requirements:

- The Building Act (2004)

- Health and Safety at Work Act (2015) 
- Resource Management Act (1991)

- The Housing Act (1955)

The New Zealand Asset Metadata Standard is a document that includes multiple schedules for asset managers to implement and follow. The document is not functional and to extract information may not be efficient. The standard is not documented as a user guide but more of a theoretical document that specifies and supports data in assets within the New Zealand construction industry (Havakis, 2017).

\subsubsection{New Zealand Asset Management Organisation}

The National Asset Management Steering (NAMS) group was established in 1995 and supported by the local government. NAMS group NZ has researched the degree of managing infrastructure and with this developed guidelines to present the best practice in asset management (IPWEA, 2015). The organisation has developed guideline and manuals based on industry reputation. The guidelines are distributed worldwide and recognise the world's best practice. The NAMS group has focused largely on infrastructure asset management (IPWEA, 2015).

Infrastructure management is structured to meet a level of service in the most cost-effective manner through the management of assets for present and future clients.

NAMS reports the key elements of asset management being:

- Taking a lifecycle approach

- Developing cost-effective management strategies for the long-term

- providing a defined level of service and monitoring performance

- Understanding and meeting the impact of growth through demand management and infrastructure investment

- Managing risks associated with asset failures

- Sustainable use of physical resources

- Continuous improvement in asset management practices 
NAMS New Zealand since the beginning has been the recognised as the core knowledge centre for asset management in New Zealand. One of the key published documents for asset managers is the International Infrastructure Management Manual supplement 2015. This brings together two key aspects ISO 55001 (what is required) and IIMM (how to get there). There are three global recognised standards and can not only be used for physical assets and any type of assets (IPWEA, 2015).

The following guidelines are represented below:

- ISO 55000 Asset management - Overview, principles and terminology

- ISO 55001 Asset management - Management systems requirements

- ISO 55002 Asset management - Management systems guidelines for the application of ISO 55001.

ISO 55000 highlights that effective control and governance of assets in realising value through managing risk and opportunity to achieve the desired cost risk and performance. This standard provides a structured approach for the development and control of assets. The following figure is taken from ISO 55000 and describes the relationship between Asset Management and there systems (IPWEA, 2015).

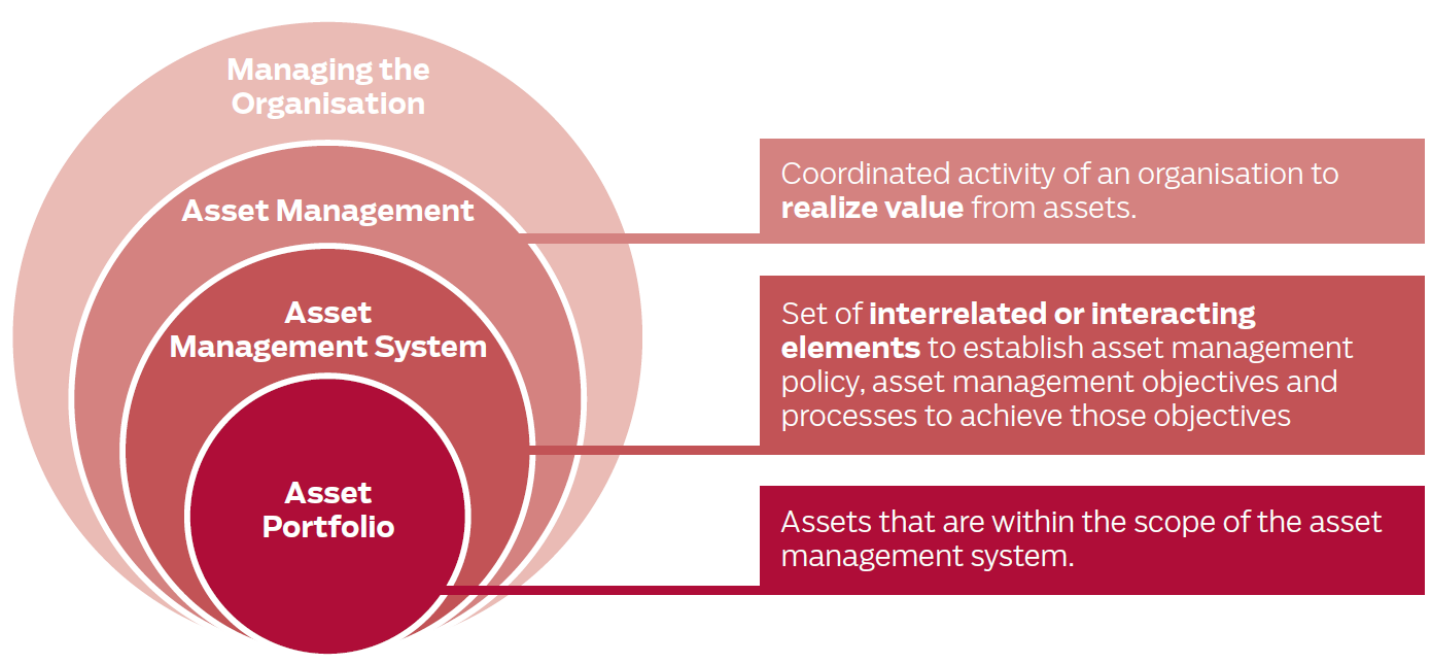

Figure 14: Definition of relationships between assets 
The standards above are utilised by the following people for specific purposes:

- Those who consider improving the realisation of value for their organisation

- Those who implement maintenance and improvements of and AM system

- Those involved in am activities and service providers

- Internal and external parties of stakeholder who assess the legal and contractual requirements in the organisation

By following this standard, the following objectives are addressed:

- improved financial performance;

- Better informed asset investment decisions;

- Better managed risk;

- Improved services and outputs;

- demonstrated social responsibility;

- Demonstrated compliance;

- enhanced reputation;

- improved organisational sustainability; and

- Improved efficiency and effectiveness.

ISO main aim of the standard is to promote good practice and insurers and finances require these standards to be applied to provide evidence that assets are being effectively managed.

The figure below represents the process in understanding and defining what services assets should deliver. The questions this standard helps to answer are the following:

- What are my required levels of service and performance delivery?

- How will demand for these change over time?

- What is the current state of my assets?

- Are they capable of meeting these demands now and in the future?

- How resilient is the organisation to manage the unexpected? 


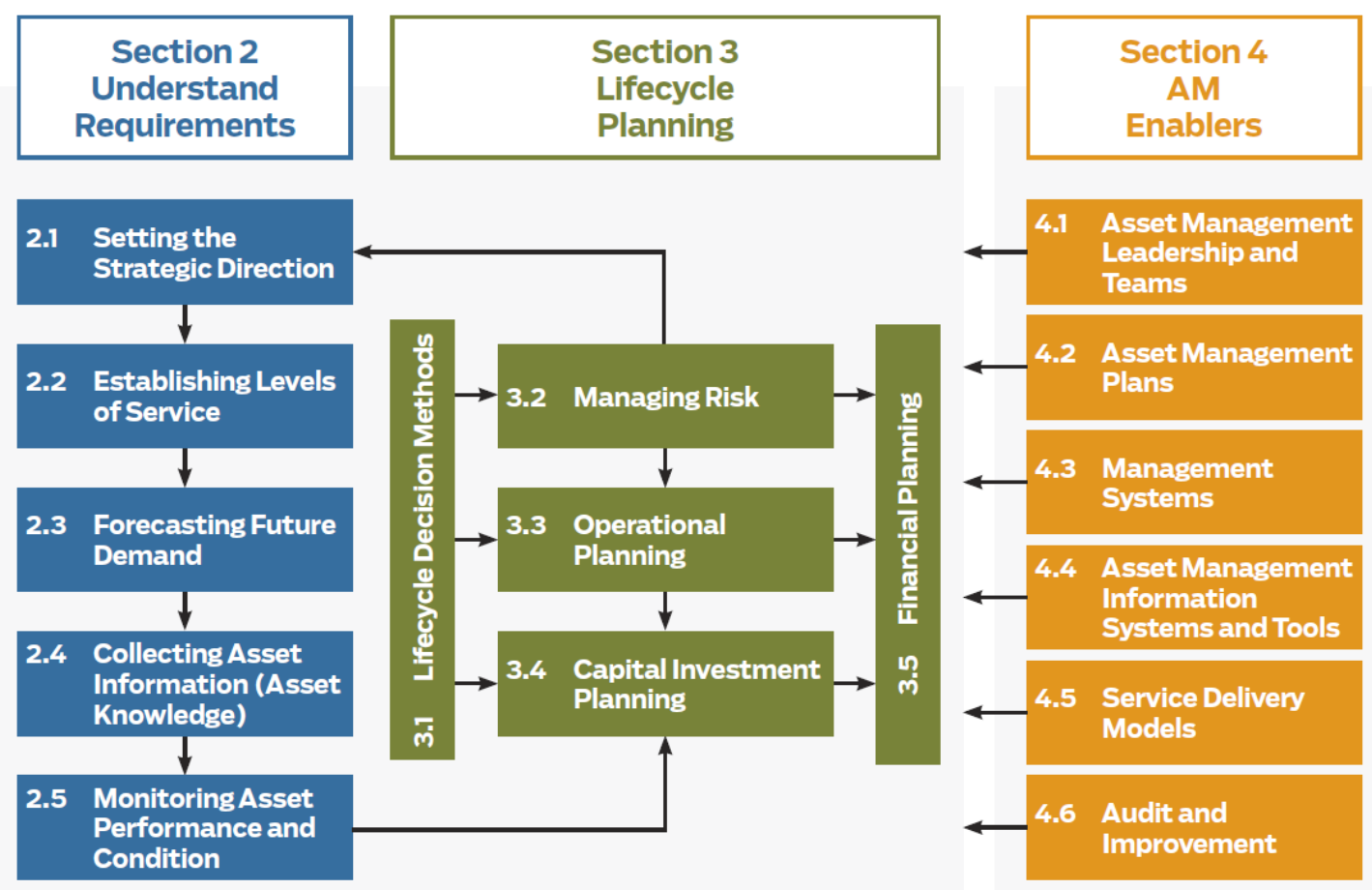

Figure 15: Understanding the process of services

ISO 55001 does not provide specific direction in how an organisation should go about achieving those requirements. Rather the ISO provides a guidance. Whilst applying the document to assets there are 10 parts to the ISO and include the following:
4. Context of the organisation
5. Leadership
6. Planning
7. Support
8. Operation
9. Performance Evaluation
10. Improvement

ISO part 8 deals with the operational planning and control and deals with the processes needed to implement the planning. 
This includes establishing a criterion for the development of operational processes. The document deals with any risks associated planned changed that impacts AM objectives. Including risk management, change management. In summary controlling the processes that can impact on the AM objectives and assessing risks.

\subsubsection{Current state of New Zealand's Assets}

The New Zealand government owned assets range from commercial forests to property plant and equipment. At the end of the 2016/2017 financial year New Zealand's Assets are valued at $\$ 313.6$ billion and therefore the opportunity to better manage these opportunities creates a big opening for Building Information Modelling (Ministry of Business innovation and employment, 2017). The productivity benefits of BIM in asset operation by BRANZ New Zealand. It is said that the greatest advantage for public sector asset managers is likely to arise from the ability to create and manage building and infrastructure assets faster and more economically with less environmental impact (Ministry of Business innovation and employment, 2017). In the United States over 60\% of organisations using BIM to procure and manage assets report a greater return on investment. It is said that the level of BIM engagement rewards asset managers with higher skill and more extensive implementation of the technology. With BIMS positive impact on sustainable design the adaption of the technology is a major driver.

Within the building sector BIM implementation is starting to change the way in which public assets are procured. The New Zealand government have acknowledged that implementing BIM allows exploitation of the sustainable lifecycle benefits the technology has to offer. 


\subsection{CASE STUDIES/INTERVIEWS}

\subsection{Survey Questions}

In part two of the research a targeted case study review was conducted. The case studies were presented to only a handful of people due to the limited of consultants with the expertise in this field of work. At no point throughout the transcript or research was the respondents name mentioned. Because of the nature of the case studies there was recognition of where they came from in the New Zealand construction industry and whom the client for the projects were. In order to follow Victoria Universities ethical procedures, ethics was carefully considered when conducting the research.

The goal of the research was to find two projects to allow for comparison, because Building Information Modelling for Asset and Facilities Management is a new concept and to date there is only two projects in New Zealand that utilise this concept this limited the case studies. Ideally for research purpose it would have been beneficial to have over 5 respondents to allow for a better comparison in regard to project deliverables. This somewhat limited the scale of the responses and meant that the data ambiguity was limited. Because of the limited case studies overseas projects were explored as a point of difference but not relied on. The level of experience from the respondents was relatively similar, both main respondents had both international and New Zealand expertise.

\subsection{Target Audience}

Working at a large construction consultancy company I am privileged to be able to use my contacts through both the construction industry and the academic world. As Building Information Modelling use in New Zealand is a fairly new concept the industry use is limited and so too is the utilisation amongst experts, consequently engaging experts was a limitation. Following the New Zealand BIM conference, I was able to get the contacts of those professionals whom are directly involved in the New Zealand BIM projects.

Taking into consideration the time scale of the research and the projects currently on the market, it was recommended that only one project needed to be analysed and if there was the potential of getting information on two to allow for comparison then this would be an ideal situation. 
The following professions were taken into consideration to gather such research

- A BIM expert

- A construction professional

- An architect

- An engineer

- A project manager

The case study respondents:

\section{Case study correspondence No.1: Global BIM Manager}

This case study respondent has been implementing BIM technologies for over 10 years and supporting clients in his current role.

He has given BIM advice to private clients, government bodies and industry associations on the strategic direction and implementation of BIM methodologies. This is further demonstrated through being a co-author of the BIM Knowledge and Skills Framework for the Australian Construction Industry Forum/Australasian Procurement and Construction Council (ACIF/APCC). This Framework has helped to support clients develop a strategic approach to BIM adoption to deliver improved efficiencies and productivity and increased innovation in the management, design, construct and operations phases of a built asset.

He provided leadership at a company level to develop a house policy, and documentation to gain the BS 1192 accreditation for his company.

His industry experience has allowed him to build a reputation as a leader in the field of BIM. He is well recognised and highly regarded within the industry through his relationship skills, active involvement with BIM practitioners, and presence within the industry. This includes his involvement on the NZ Collaborate Leadership Committee, who look to improve the functional use of BIM and Digital delivery across the AECO industry in Australasia, by identifying, reviewing, endorsing and implementing BIM best practices.

\section{Research correspondence No.2: Digital Delivery and Technical Fellow}

This interviewee has been implementing BIM technologies and processes to improve project delivery efficiency within his company. This extends to helping his clients across Asia Pacific understand the benefits that digital delivery can bring to their projects. Also identifying key benefits that can be achieved throughout a project life cycle and working with the supply 
chain to understand the most efficient way in which to deliver these. Through his understanding of technology and process he advises his clients on the most efficient way in which to deliver the information they need for Facility and Asset Management.

\subsection{Survey Interviews and findings}

The case study authors both have a high level of experience and leadership in regard to Building Information Modelling both in the New Zealand construction industry and in the global AEC industry. The common findings within their case studies both acknowledge that utilising BIM in a construction project has its benefits which are defined in the conclusions below. Both believe that BIM provides huge benefits in the design of a building, eliminating re-work and decreasing errors. Both of these experts share a common endorsement for Building Information Modelling in the operational phase. However, both parties have slightly different approaches. Expert one sees BIM AM/FM being utilised efficiently by using a "off the shelf product". This means that within the project specified below, for the operational BIM aspects were pushed to an Autodesk product that can be utilised by any person/organisation, it just involves having a knowledge of the product and training the necessary personal in driving the product. While expert two in their project endorsement saw BIM AM/FM being utilised in aligning to an already existing Asset Management system, as this project is currently still being developed there was no clear conclusion of whether this solution worked. Both parties took different approaches where one succeeded in one area the other did so in another. Although the projects have utilised the operational stages of BIM, these approaches are both vastly different finding it hard to show comparisons and define a best use approach. In essence both projects provide evidence that by utilising BIM in this stage of a buildings lifecycle provides benefits to the design team in regard to less re work clash detection and for the asset management team creates a clear visual indication of the asset as well as quick and clever operational use (defined below).

Case study two provides significantly more detail than case study one, due to the researcher's professional relationship with the company. The time period of this research was constrained which created a limitation for case study two. At the conclusion of this research the gymnasium project was only completed to the design stage providing no 
proof within the operational stage of a building. Case study one provides evidence of BIM right through to the operational use. Most details associated with case study one is at a high level and don't provide detail like case study two. Having documented both case studies allows comparisons to be made, case study one's main purpose for inclusion is the evidence of the operational use which is still being developed in case study two.

\subsection{CASE STUDY - AUTODESK BUILDING OPS/360 GLUE}

\subsubsection{Case Study 1 - Mason Brother Precinct Building (BECA)}

BECA is a New Zealand owned consultancy firm that has over 3000 employees through the Asia pacific. 8 countries, 20 offices and 3300 employees BECA has over 75 disciplines upholding a diverse and wide range of skillset. BECA is a leader within the New Zealand construction industry in BIM and in particular BIM in asset and facilities management, being the only published project to reach this level of development.

Jon Williams, BECA's BIM expert acknowledges that $80 \%$ of buildings being occupied in 2050 will already be built and this therefore creates great opportunity for improvements in the current building stock. With this in mind the end output of a building (operation) should be a focus point (Williams, 2015).

Within a BIM process there is no strategy or approach that is a one fit solution for every project. Therefore, BIM within each project needs to be tailored accordingly. Most asset owners are not involved in the design and construction of a project and therefore BIM workflows become complicated as the desirable goal is often lost. The starting point of a BIM journey is simple and involves asking the right questions to determine the desired outcome. It is important for the BIM consultant to work with the client to understand the outcomes needed. It is different for every client and project, contrary to traditional approaches BIM highlights the 'start with the end in mind' philosophy and is illustrated in the diagram below. 


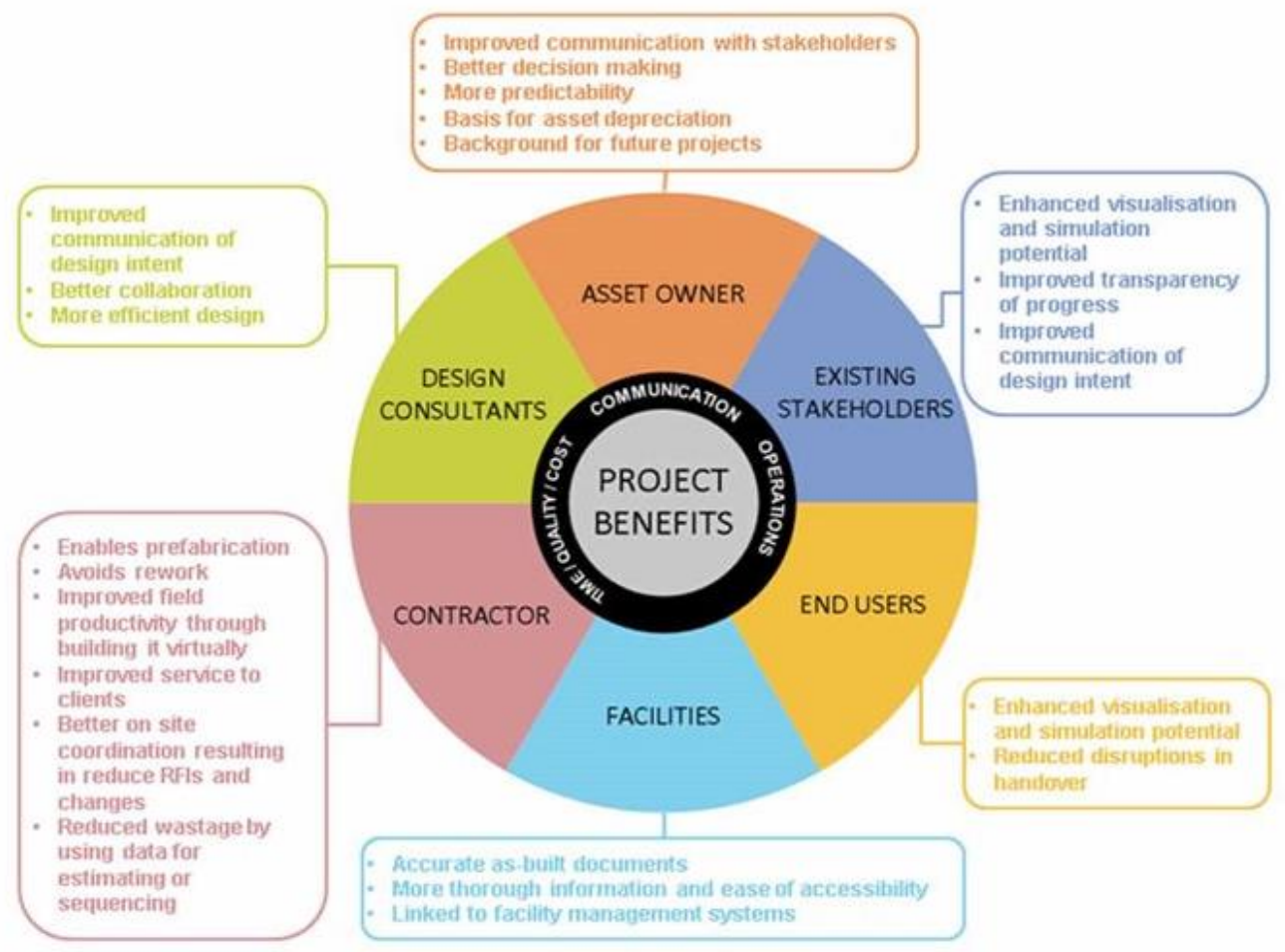

Figure 16: Project Benefits Diagram across different aspects of a project

"The difference between the above process and what has been seen on many projects, is starting at the end to confirm what is really wanted, rather than at the beginning with a focus on what can be produced" (Williams, 2015).

With this philosophy in mind BECA's BIM team worked alongside Precinct Properties to develop a client lead BIM Asset and Facilities Management scheme that identified what the user wanted as the end result and subsequently become New Zealand's first BIM AM/FM fully integrated project. 


\subsubsection{Overview of Project}

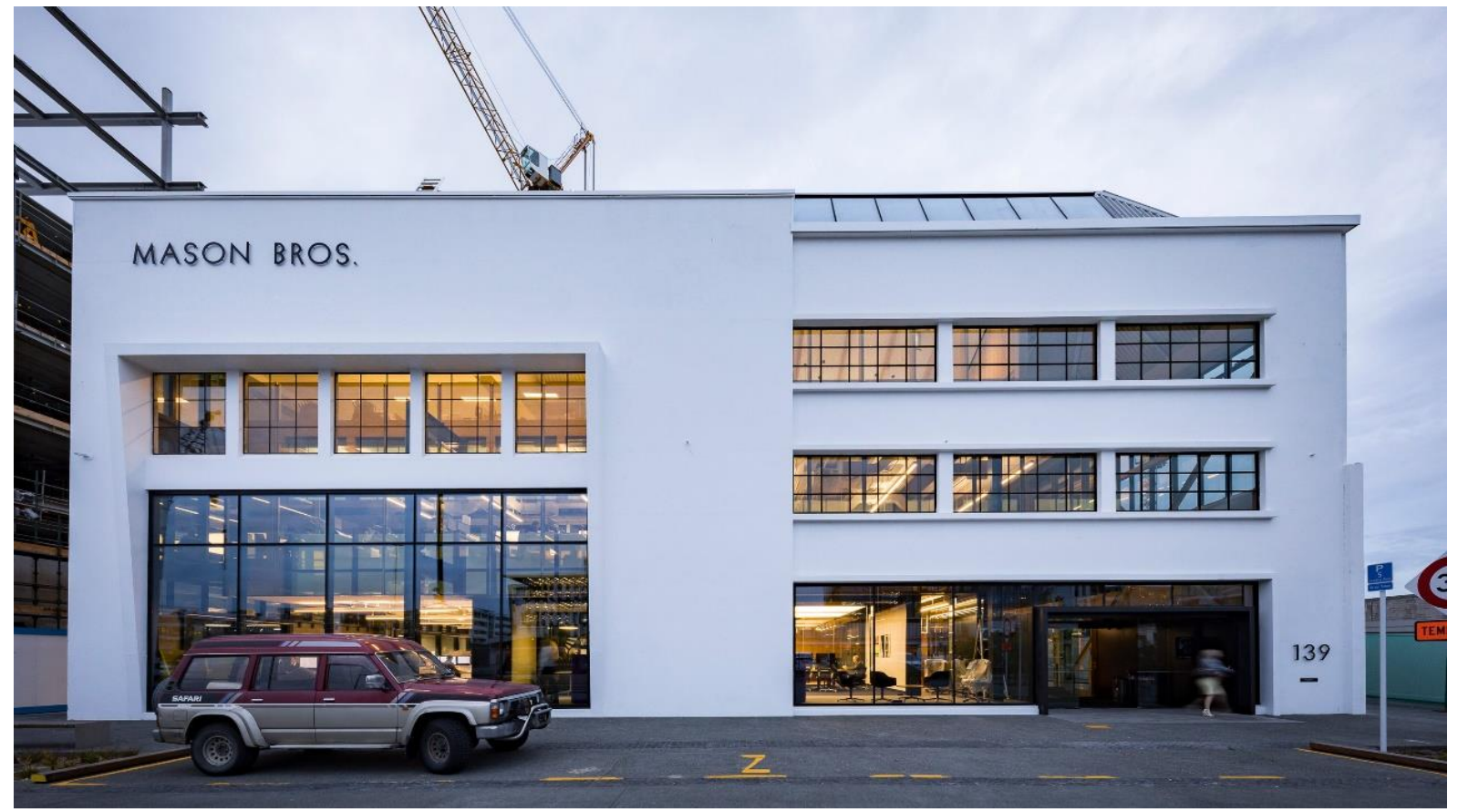

Figure 17: Mason Brothers Building, 139 Pakenham Street West, Wynyard Quarter

Located on Auckland Waitamata harbour sits Wynyard Quarter, acquiring the Wynyard Quarter Innovation Precinct. The key philosophy behind the project was to deliver a sustainable urban environment to foster innovative thinking. Mason Bro's Building comprises of 5,600m2 of commercial floor space is the latest development completed in December 2016. For the client the biggest driver of the project was making the building highly efficient to run in an operations and maintenance perspective.

For Beca and precinct Properties the chosen solution was a cloud-based, mobile (BIM 360 glue) technology allowing 3D models to be taken onto site, on iPads and extra data to be captured back into the 3D model. A web interface captures data input from the contracting supply chain and links essential documentation such as operations and maintenance manuals and commissioning documentation and warranties to specific 3D assets. Delivering an iPhone efficiencies, for the operational team enabling accurate financial forecasting of renewals and maintenance activities to deliver an enhanced level of service to building tenants. 


\subsubsection{Motivation behind the project}

A buildings operational cost contributes to $85 \%$ of the total building cost (ref) therefore the handover phase from design/construction to operation/maintenance is important. Traditional approaches such as paper-based trails are more difficult to keep up to date and not easily accessible to multiple parties. Traditionally all project parties use their own formats to create this information. To solve this problem BECA delivered an innovative asset management solution whereby all asset information can be delivered onto the client's iPhone, taking a tedious based process into a digital environment.

\subsubsection{Innovation of use of Asset Management}

All information in respect to the project is created in one space enabling for greater transparency creating certainty that the deliverable will be achieved. In order to move from a traditional delivery method to a digital space many traditional approaches had to change including:

- Contracting team and sub-contractors aware on the requirements to be met including the information deliverables and the technology to deliver on

- Configuring the cloud and mobile technology so that the data could be captured in a way that made sense

- Led training workshops to show them how to deliver the information required

- Communication of information to supply chain

- 3D model process as well as data outside of the 3D model but linked into the model for final handover

- Autodesk products: Revit, BIM 360 Field, and building ops the flow of critical data across all applications, (one of the biggest challenges for the project was that certain data created in an each of the applications did not cross over in all applications, this required figuring out the problems and mitigating them).

- BIM 360 glue is a new product to the market released in 2017 (version 4) therefore the use of the application is somewhat new, BECA has become experienced and well skilled in this area and is working with the developers of Autodesk helping them to understand the issues and developed workflows that didn't create additional work.

- Working with the 360 glue and building ops to for further development on these products. 
BIM project case study digital asset delivery BIM to FM: BECA's Building Information team were engaged by the client to provide assert delivery consultancy to implement, monitor and provide the final digital handover. The Beca team trained the contractors ((NZ strong) and sub-contractors (As-built) on how to deliver the information required using the cloud and mobile technology that was chosen to be implemented on the project. The Beca BIM team and the BECA project management team reported in conjunction with one another to ensure that all necessary asset data completeness of information required for handover was achieved. With the use of latest mobile and cloud-based technology to capture critical data, Beca on behalf of the client precinct properties achieved a New Zealand first in this method of digital project delivery. This has enabled the essential information created through design and construction such as 3D models, assets and their associated data and documentation to be delivered onto the operational team's iPhone'. This project is one of the first to be globally achieved and will work with the clients ongoing Asset and Operational management activities.

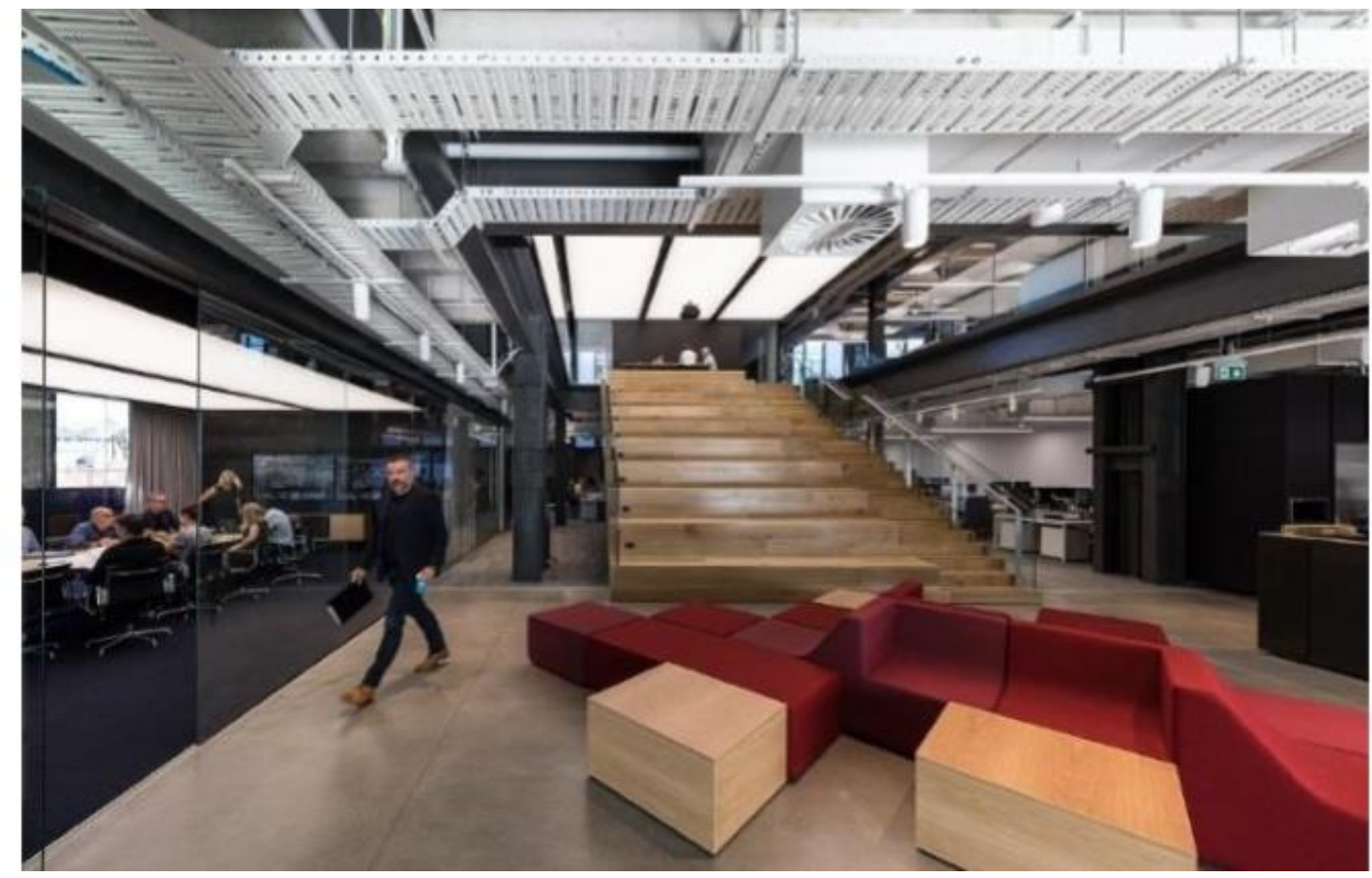

Figure 18: Design details of Wynyard Quarter 


\subsubsection{Details of software/project specifics}

Client: Precinct Properties (15 plus building throughout New Zealand, 3000,000m2 office, \$1 Billion expenditure expected by 2020).

Current tenants Mason brothers, existing building stripped to structure and fitted out for completion on $23 / 12 / 2016$

Beca were engaged as a Digital Asset Information Manager their key tasks:

- Set up and implement BIM 360 glue

- Train the contractor in this

- Monitor and report on asset information

- Handover 3D models to client's phone

- 1600 different assets

Deliverables by client included COBIE file format to handover structured data, UK standard data deliverable 2016 with 4 data drops, this was revised and changed to an IFC file data format due to ease of project. The client and BECA defined specific deliverables to understand the clients need. These aspects included:

- Neutral data delivery BIM 360 glue

- Data rich models from construction, link into system

The project specifics:

- $\quad$ CSV file for all data

- $\quad$ BIM 360 ops (client picked solution

- $\quad$ Revit model published to cloud

- $\quad$ Cloud published to BIM 360 field

- Additional data added to model through iPads (meaning that the data implementer does not need to be Revit savvy)

- $\quad$ Specify all building services

- Model pushed to fabrication

- If you click on an element in 360 glue this will show the specific details of the element, you can also scan a barcode in 360 glue to understand what the element is 
- $\quad$ BIM 360 ops live portfolio, as built were responsible for updating data

- $\quad$ Live link to BMS system

Innovation: The mason brothers building is the first New Zealand project to use BIM 360 field to deliver the project in Autodesk's application. The mason brothers building is the first project to capture all essential asset information in the BIM 360 field as well as Building ops (iPhone technology used for operations management) globally.

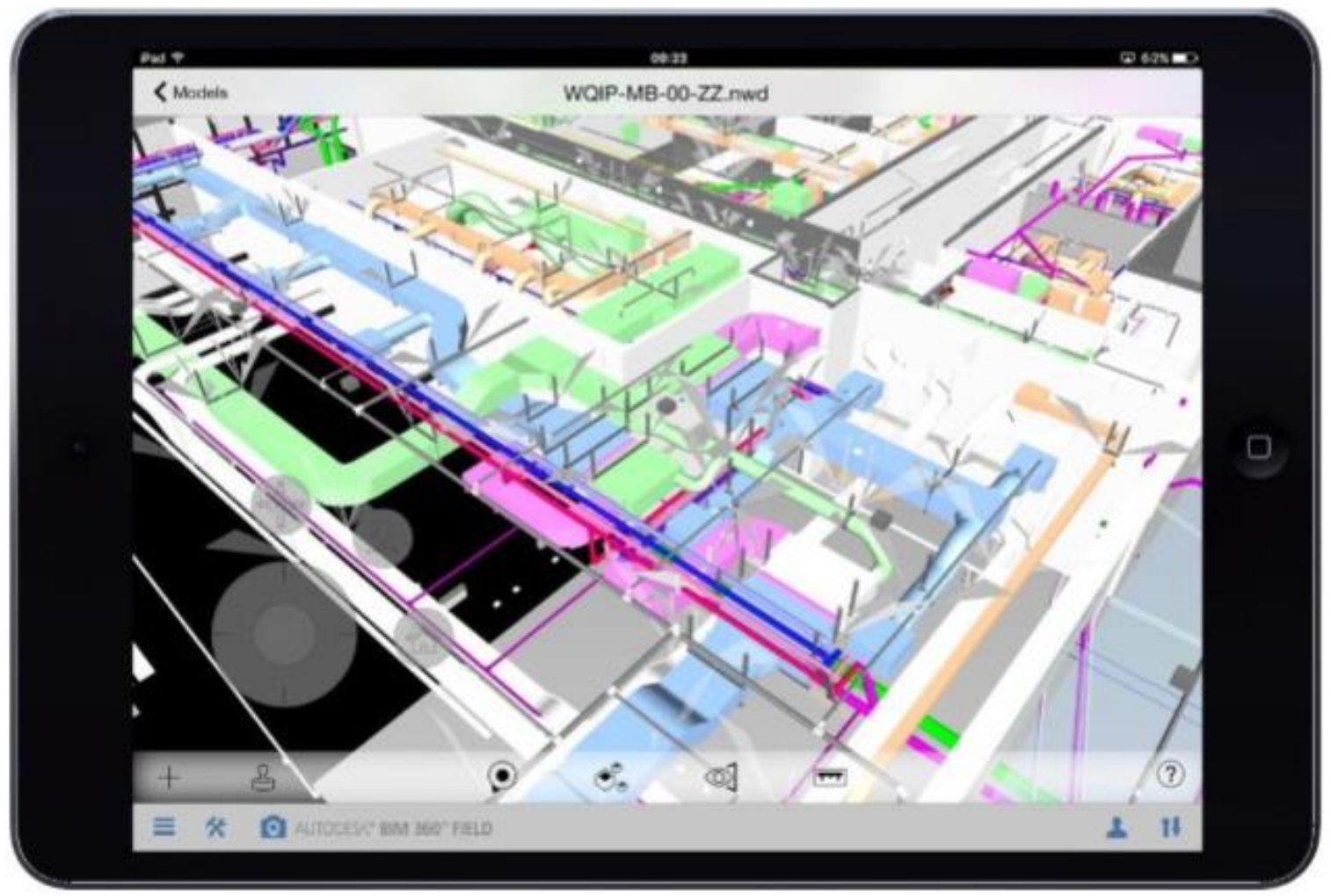

Figure 19: 3D Model on iPad and construction information to ensure the latest models in hand

Autodesk 360 is a project management platform that covers all aspects of the construction project and allows total control from conceptualisation to delivery. BIM 360 glue is a cloudbased platform that allows the user access to storage and collaborative workspace through the cloud. Because of the cloud-based technology all work can be shared at any time. The software has a documentation module that has the ability to connect all members of the project team to view, publish, review, mark up and approve project documents.

Benefits of 360 glue:

- Sharing and viewing all design files even if the user does not have software that was used to create these files 
- Upload DWG onto your mobile device and edit, no software required

- Mobile viewing 2D, 3D DWF files with the Autodesk Design review app and annotate 2D drawings

Autodesk 360 features:

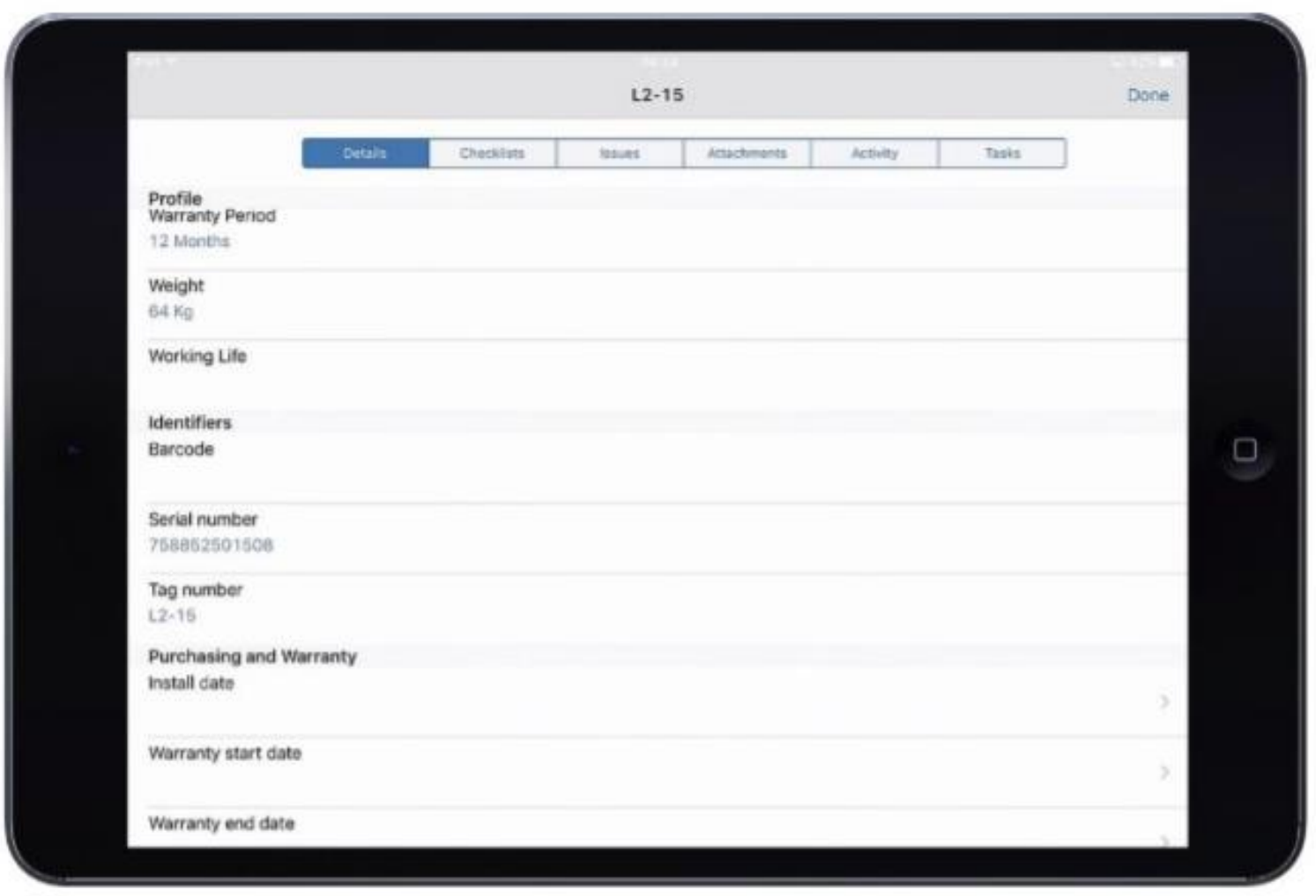

Figure 20: Additional Data able to be captured, enabling a link for asset management

- Pushpin construction issues

- Project status and description

- Safety inspection

- Streamline job site inspections

- Track key performance indicators

- Dashboards

- Quality assurance/quality control

- Identify trends and minimize contractor risk

- Construction tracking

- Standardized checklist templates

- Real-time data 
- Building information modelling (BIM)

- Integrate with Navisworks

- Navigate and interact with models on an iPad

- Manage field performance

- View field data updates

Autodesk BIM 360 ops is a mobile first asset and maintenance management solutions that gives contractors and building owners the ability to foresee the value of BIM in building operations. The handover process is transformed by connecting BIM asset data created during building design and construction to building operations.

Implementing BIM 360 glue produces system results in detailed up-to date information on the buildings plant and equipment instantly available.

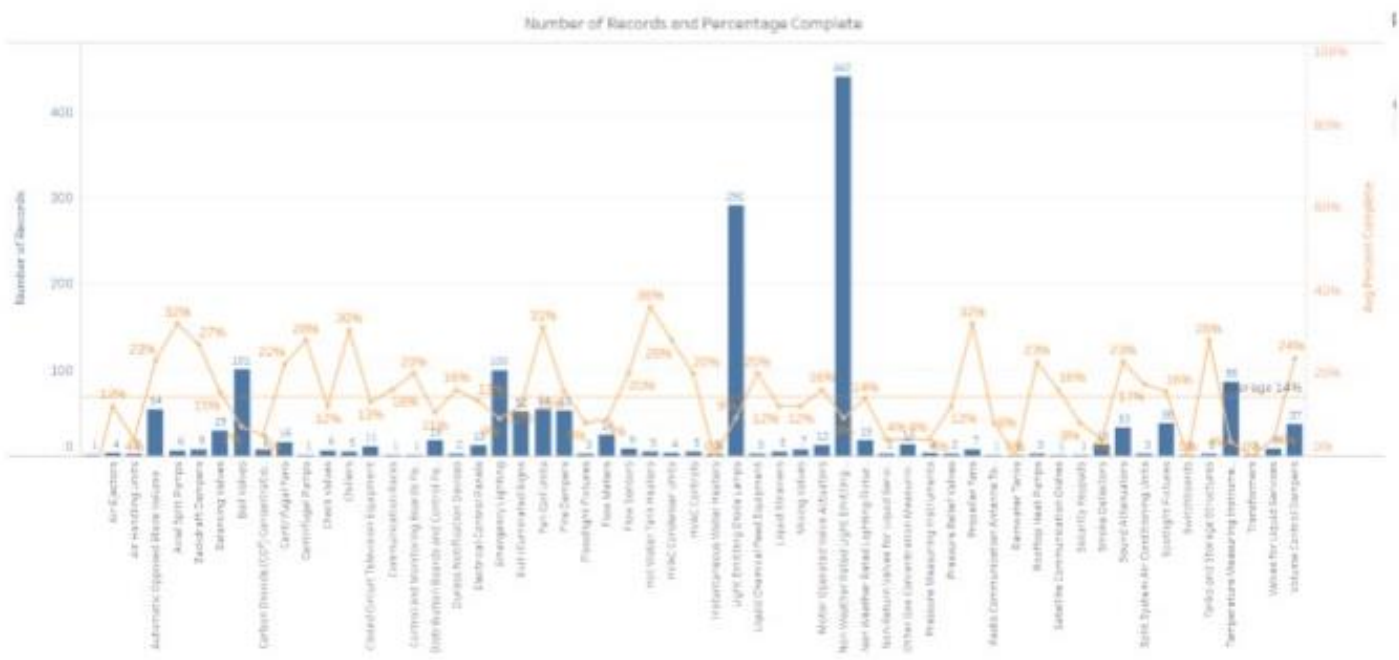

Figure 21: Digital Dashboard showing completeness of information against the critical assets

The following was achieved and delivered by the BECA team for the client:

- Reused data the was created for its original purpose

- Central point for all 3D models that can be accessed by anyone anywhere

- Digital reporting tools

- Trained the contractor and the supply chain on using the cloud and inputting the data

- Detailed log of servicing and repair over the lifetime of an asset

- Better accuracy in programme planned maintenance

- Strategic information on CAPEX planning decisions

- Building lifecycle analysis 


\subsubsection{Clients stance on project}
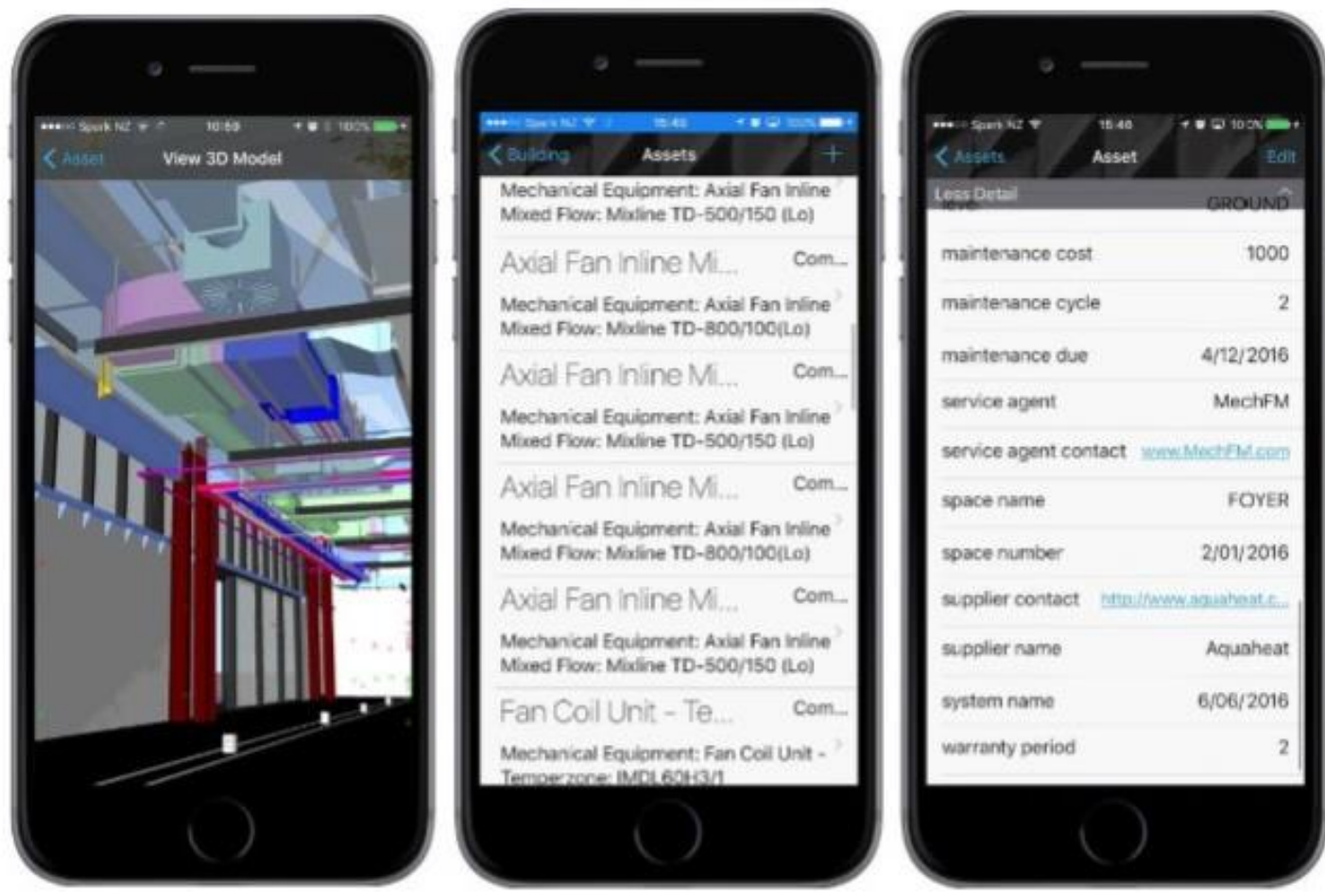

Figure 22: 3D models, critical assets, their data and documentation handed to IPhone for operational use

The client (precinct properties) and the contractor (BECA) worked in alliance to capture the needs of the future asset management procedures needing to be implemented as well as the possible solutions that are available/will be available in the market. During the project it was agreed a neutral data handover of models was to be delivered as the client was deciding on the application that was going to be used. During this process Autodesk released there Building Ops application that hadn't yet been delivered in the market space. The BECA team had to become familiar with this application as well as delivering in Revit, BIM 360 glue and field. A key aspect to this was understanding the limitations and restrictions of Ops and to identify the potential use for Precinct Properties.

With the cloud-based technology, mobile application and capturing information in the 3D environment allowed all contributing parties' data input through the supply chain to be captured. Essential documentation such as operations, and maintenance manuals, commissioning documentation and warranties be linked to 3D models within BIM 360 glue. BIM 360 field allowed data to be downloaded to iPad and taken to site. 
Once the contractor become familiar with these processes and applications they then trained the supply chain on how to use the technology and inputting the data. This included:

- Downloading 3d models and data onto the iPad to take to site

- Inputting the data required through the iPad and web browser

- Upload the required documentation such as commissioning documents and maintenance manuals

- Link the appropriate assets in the BIM 360 environment

As built was commissioned by NZStrong as the subcontractors to provide the construction modelling and coordination for building services. All contractors and subcontractors worked together to ensure the correct data was captured, as Built were also responsible for physically barcoding the appropriate assets and then scanning the physical assets on the iPad. This link then enabled the iPhone application to be able to scan the appropriate asset barcodes and pull up their specific information.

\subsubsection{Operational and Maintenance Benefits}

The client was able to see the asset data completed to date as well as monitoring the digital asset data. Creating dashboards was the key success in achieving this which indicatively showed the percentage of completeness of the asset to date. The dashboard information was provided to the project management team. Tableau was implemented as the display data dashboard, this enabled the live data to be extracted from BIM 360 field to another online database that then fed to the tableau data base.

For the client an essential deliverable was to have work orders raised against assets in the easiest possible way. This was achieved within the iPhone environment with the information at their fingertips. The operational team is able to have all assets within the building displayed in the Autodesk Building Ops application specifying data on the assets as well as 3D models. The information is already being used by the operations team in their daily activities. Precinct properties digital asset information manager acknowledged that for the duration of the project BECA were able to provide clarity on BIM within the operational phase to provide direction which a lot of others couldn't. 


\subsubsection{Project Summary}

Like this project, similarly a project in the USA (Arskansas Children's hospital) has implemented the application BIM 360 ops (Mergenschroer, 2015). The projected use of the Building Ops application suggests that the use of BIM and Autodesk's products will streamline BIM to FM workflows, significantly increase staff productivity. In order to implement such an application, the following information is said to be needed:

- Obtain existing drawings/digital as builts

- Obtain existing reports for major equipment

- Develop a digital database for existing drawings

- Develop a link to the BMS system

- $\quad$ Available to all major equipment

- Provide the facilities team with complete verified data

- $\quad$ Provide operators with mobile devices capable of viewing documents

- Train operators on use of data base and mobile devices

All this information is directly related to that of the BECA project and all the pre-project information is somewhat similar. Although this project isn't operational currently, the process is identical, and It can be predicted that that the use of Building Ops will be similar and provide similar benefits.

Overall the project implemented by BECA for precinct properties seems to be one of the most innovative for the New Zealand BIM industry to date. The biggest reasons for its success' is the delivery of BIM in asset management. Autodesk building ops was the "off the shelf" product used by BECA to implement such process. Autodesk's product has not been used successfully, BECA worked closely with Autodesk to implement this application and to pass on to Autodesk any educated learnings along the way.

If this was the first project to utilise this tool no one can be sure that it provides that of what a facilities manager needs to achieve. In this case the contractor was significantly involved in the project in working with Autodesk and the client. Autodesk was eager to work with this contractor, possibly because they still had some uncertainty in how to fully implement their tool. The correspondence between the contractor and client suggests a huge amount of 
collaboration and very careful communication. This suggests a lot of time and money from both sides to implement the tool. Both companies here are large organisations that have the utilities and money to invest in this situation, for smaller companies this may not be the case. As Autodesk was relied on significantly, for any other company to utilise Autodesk's tool the same correspondence is assumed to be needed, Autodesk may provide clarity on certain aspects however it is unlikely they will support the project like they have with this project unless there is an incentive that could be money or product recognition.

The contractor and facilities manager worked together on the scheme of this project for the operation of the mason brother's project, this is not often a common approach that the facilities manager has such involvement throughout this process. The facilities manager was technologically advanced in this project. Commonly facilities managers are building operators that are more hands on that is they fix the problem.

Although the project has many positive factors there are two major factors that may be barriers in adopting this tool. The biggest challenge is the integration of traditional facilities managers. Introducing people to a complex IT solution that are not privy to that type of software not only takes time but training as well as their willingness to want to learn. The other apparent issue lies with pre-existing assets, it would be unlikely that an established organisation is likely to utilise this concept in parallel to an existing FM/AM system. There would be a lot of rework and time to establish assets depending on the organisations maturity in the FM space and to further progress them in the Building 360 ops. 


\subsection{CASE STUDY - DATA DEFINING SAP SYSTEM}

\subsubsection{Case Study 2: Whenuapai Gymnasium NZDF (OPUS)}

In November 2017 the company in question was informed that a large Canadian consultancy company was granted consent to take compulsory acquisition of all existing company shares. Following the approval of the unconditional offer, the company was incorporated. The acquisition process meant the amalgamation of the two companies. The combined companies will operate in a total of 40 countries with a 42,000-strong work force.

On 4 December 2017, the Canadian company became the dominant owner of the company specified and all its subsidiaries. While the exact details for integration of the businesses aren't yet available, it is expected that there will be no disruption to their ability to deliver a great service by both organisations for their existing clients now and into the future.

Both companies in question are accredited with British Research Establishment (BRE) Level 2 BIM (BS 1192) (British Institute of Facilities Management, 2014), as well as international experience using BS 1192. The company identified in this section has experience of applying BS 1192 principles across organisations, on projects in NZ, UK, Australia, Scandinavia and the Netherlands, across a variety of sectors. They are the only NZ based company to be accredited under this world leading BIM framework. They were awarded the accreditation late in 2017 in their Christchurch, Wellington and Auckland offices. The accreditation is also present in their UK office and they have been applying this standard to their projects for many years.

"Designing today means thinking about the future use - for the first time we are getting much closer to having a true digital mirror of our physical world. BIM, connected to the power of the cloud, offers new and more innovative ways of working to help meet those engineering and construction challenges of today and future infrastructure needs (Company X)".

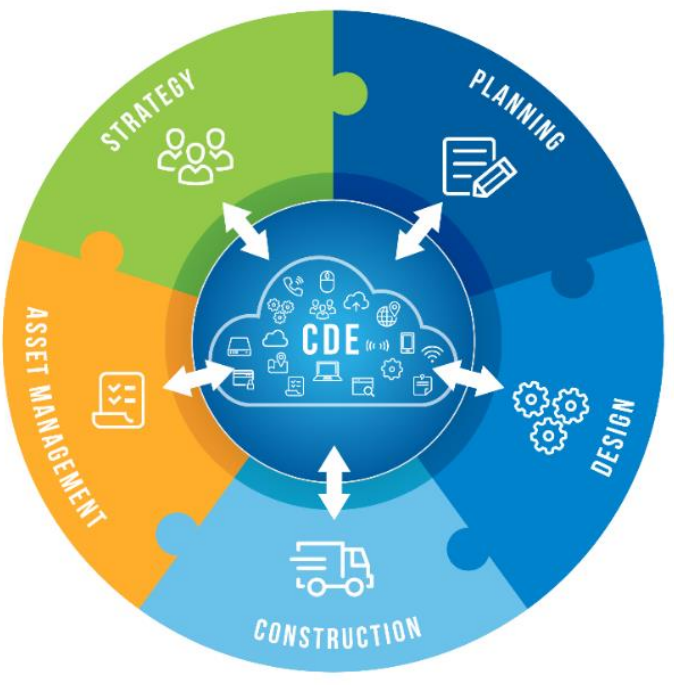

Figure 23: Common Data Environment Model 
The main reason for adopting a strategic BIM programme is to improve the development of asset information through visible, granular collaboration, enterprise wide quality control, and the definition of an agreed "common language" to be used by all project participants.

The objective is to engrain collaboration methodologies and the use of a common data environment to ensure that the right information gets to the right people at the right time. The diagram above outlines the BIM process and the relationship to a Common Data Environment (CDE). The companies as a collective have adopted these objectives.

\subsubsection{Building Information Modelling at Company $X$}

Commonly the benefits of BIM are driven by cost savings, better data / information capturing, less rework - reduction of work effort through the elimination of errors / omissions / process and improved productivity.

The sharing and utilisation of models and information for design coordination and collaboration with both external consultants and internally between Company X's disciplines is considered business as usual. Company $X$ also regularly collaborates with contractors and subcontractors, allowing the review, coordination and integration of information such as steel framing or mechanical services fabrication models.

Company $X$ utilises the Autodesk Revit suite as its primary BIM and contract documentation authoring software but are able to author and integrate models and information from other authoring tools as required by the project team using a variety of platform agnostic file types (IFC, COBie and the likes). Over $90 \%$ of projects utilise Autodesk and Revit. 
Company X's Design Consultant (Task Team Member) BIM services offer:

- 3D control and planning for site utilisation purposes

- Analysis:

- Acoustic

- Building Services

- Fire

- Mechanical

- Energy

- Lighting Analysis such as shadows, daylight and artificial light

- Programmatic (Solibri) Building Code Compliance.

- Structural

- Sustainability

- Asset/Facility Management

- Clash Detection

- Cost estimation (5D)

- Digital Fabrication

- Disaster planning

- Material usage optimisation.

- Phase Planning (4D)

- Programmatic Code verification

- Tenancy and Occupant Management

- Visualisations

As specified above, the company have been accredited by the British Research Establishment in *Level 2 BIM as a service offering, as of the date of submission Opus is the only New Zealand based company to be accredited under this framework (https://www.bre.co.uk/BIMBSCListings (see Appendix 8)- Certification numbers BIM1001310013D inclusive). They are now implementing "Level 2 BIM" as a code of practice across all regions and sectors across the business (Building Research Establishment, 2016). 
The business understands the importance of whole of life information management and how all associated parties need accurate and relevant data. Achieving Level 2 accreditation was a very rewarding exercise for the company, being peer-reviewed on their fundamental methodologies, and that the information being created was accurate, consistent, and utilised repeatable workflows and aligned to international standards as opposed to a bespoke inhouse system. The following projects as shown in the table below were utilised as part of the accreditation process. The organisation did not solely run these projects but had involvement towards them (Building Research Establishment, 2016). 
Kiwi-Rail Augmented Reality
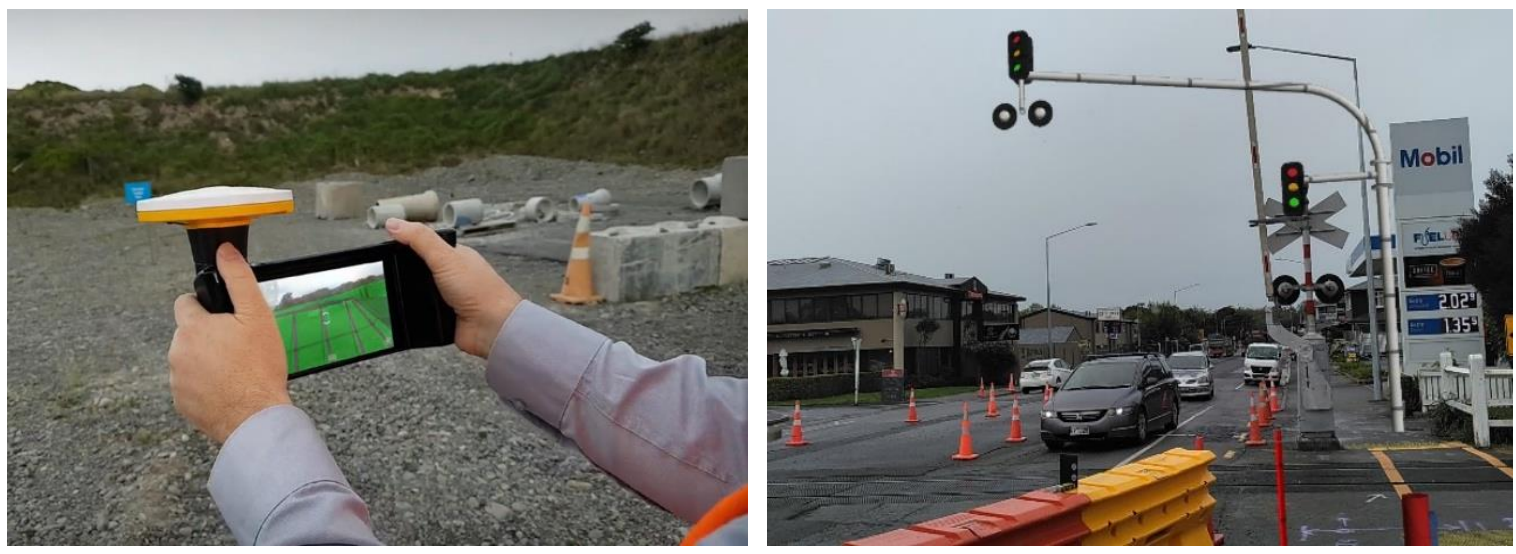

Justice Precinct
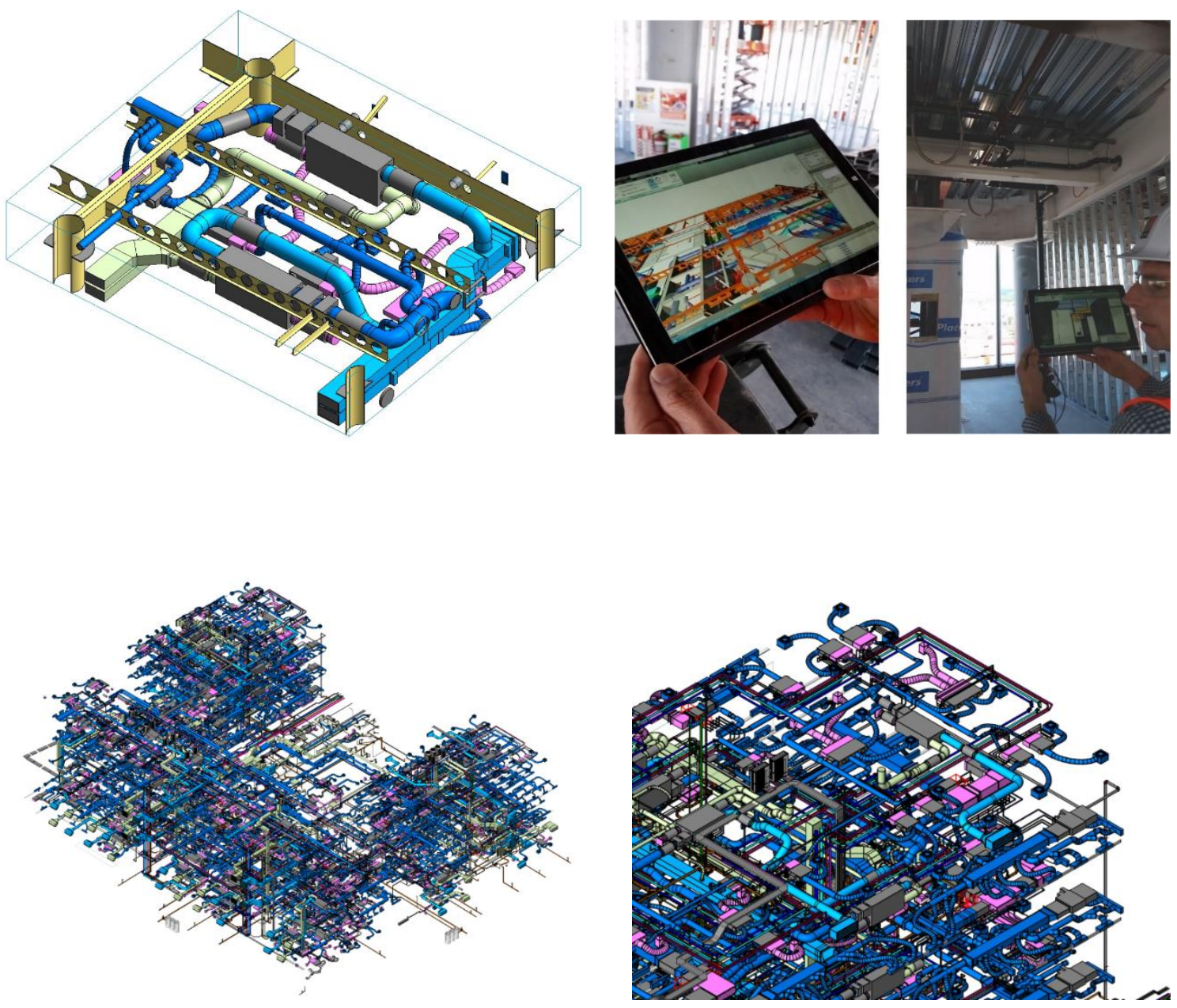

Hervey Bay Hospital - Emergency Dept. Redevelopment 

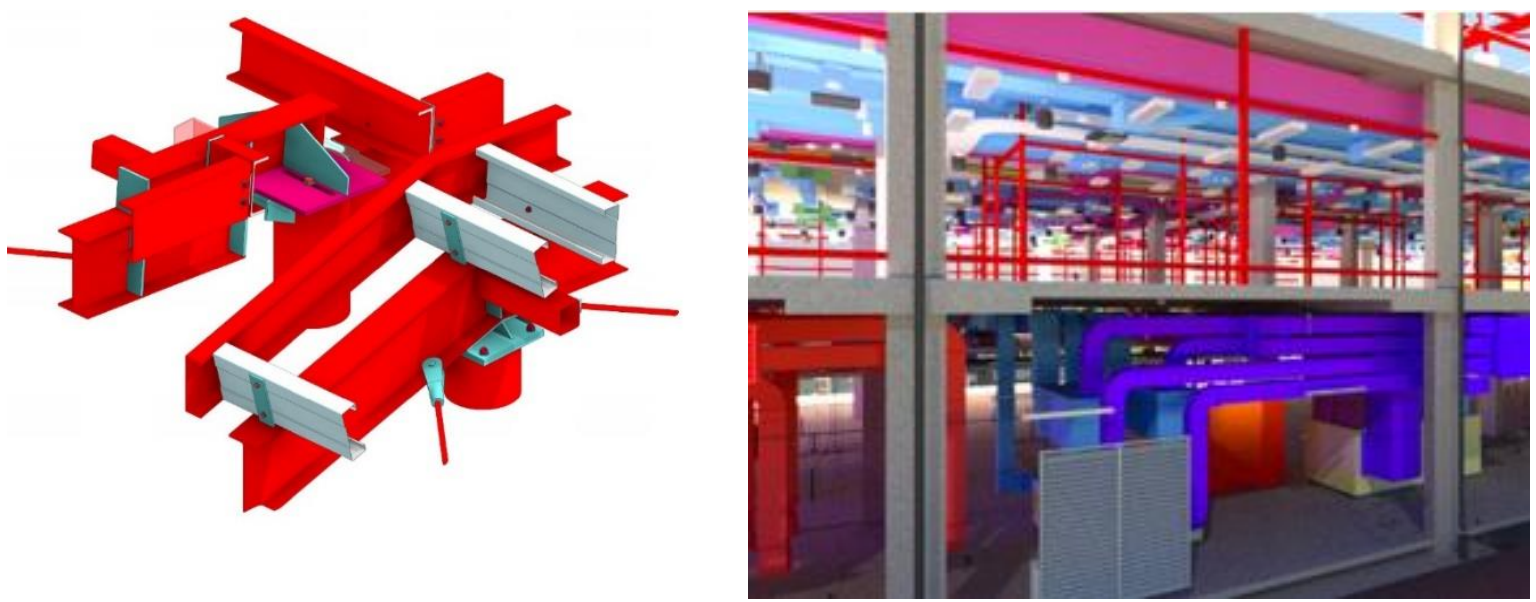

Wellington International Airport hotel and concourse
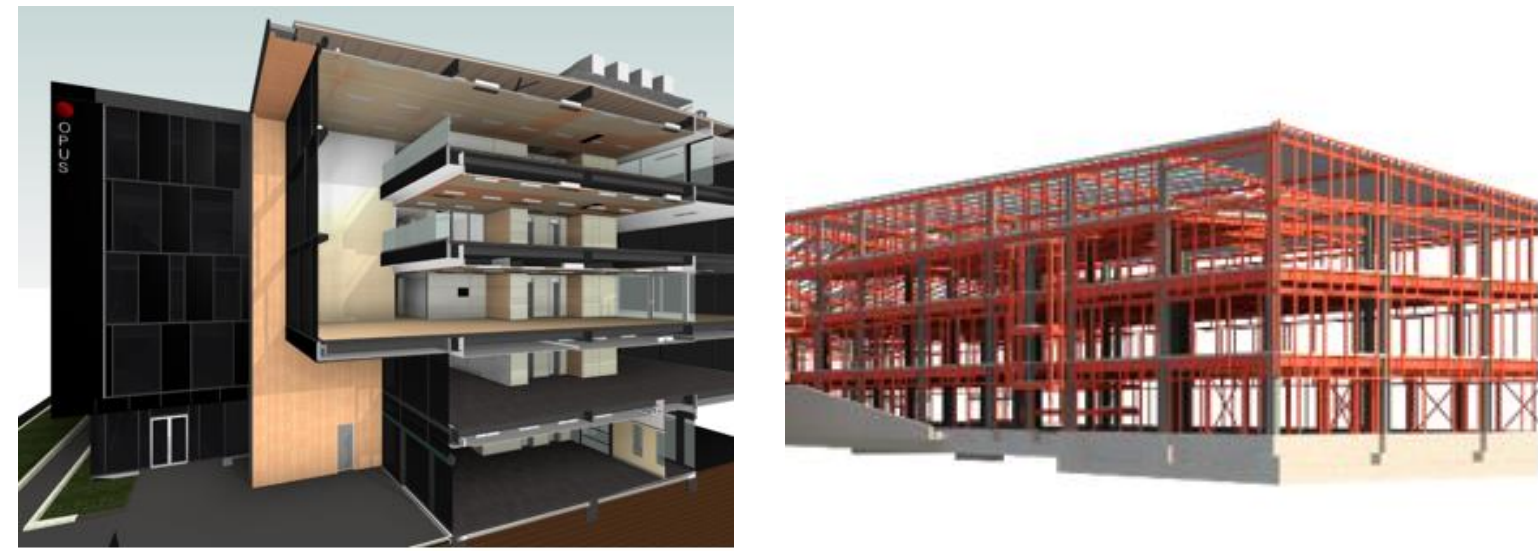

Opus Christchurch Office

Grey Base Hospital
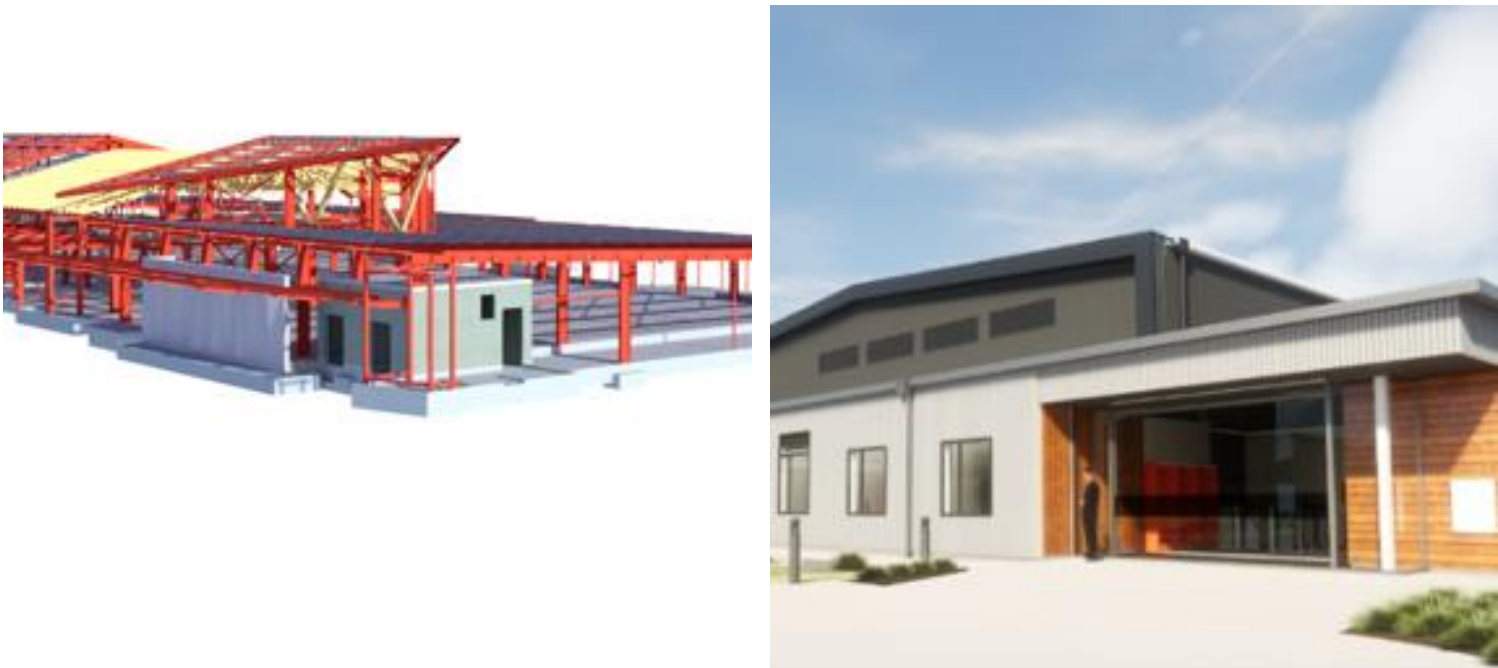

Hawkes Bay Airport - North

Whenuapai Gymnasium 


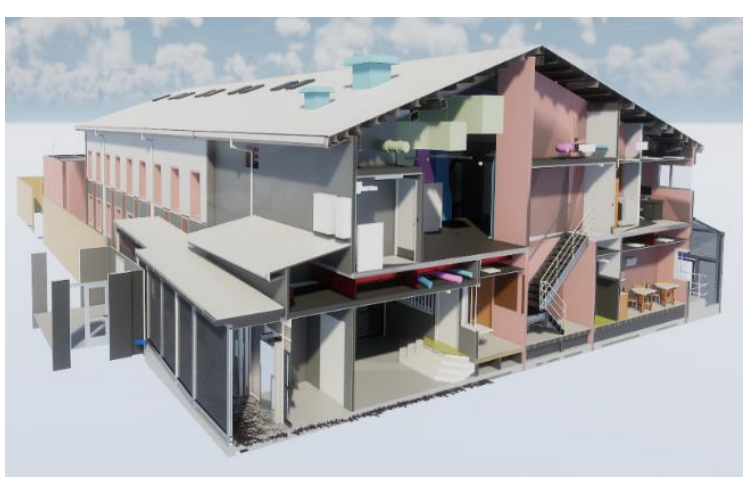

Department of Corrections
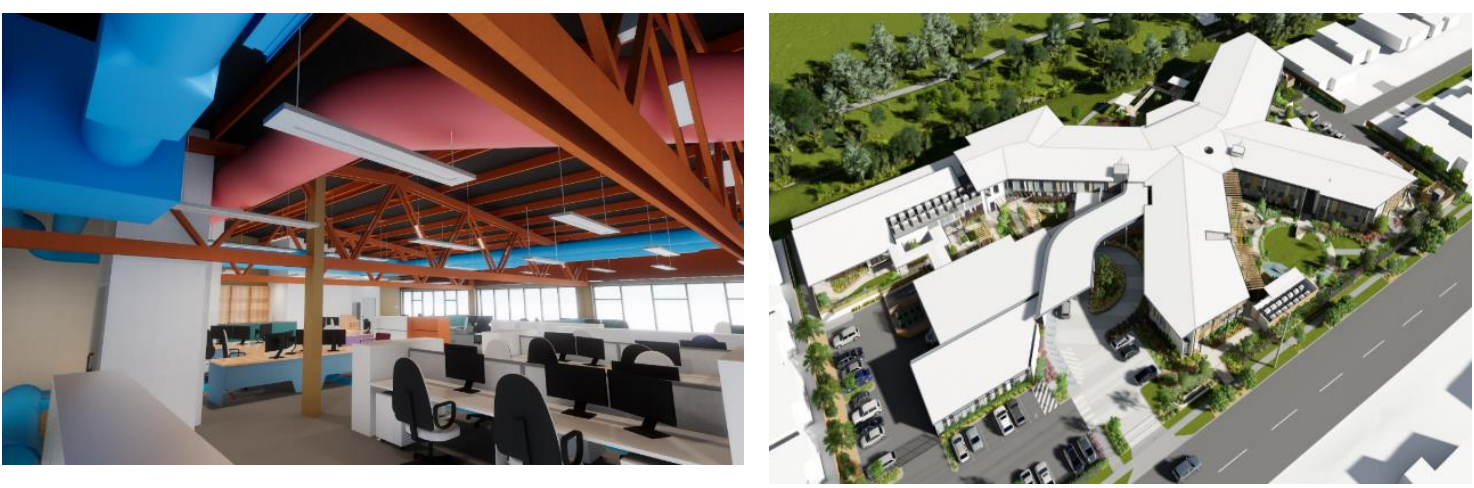

Multi-disciplinary 105 bed aged care facility at Taigum 


\subsubsection{Details of the sports stadium development}

The gymnasium is a new build at one of New Zealand's largest asset owner's precincts. Company $\mathrm{X}$ are providing design consultancy on all services and as an additional separate contract are defining and implementing BIM to whole of life asset management principles by piloting the recently released national (NZ) metadata standard (residential and light commercial buildings) integrated with Level 2 BIM principles. This required the authoring of a BIM Execution plan (see Appendix 9) and methodologies on defining what information is useful, how it is captured, information custodian assignments, quality control/verification and the integration with client's in-house infrastructure.

At the conclusion of the project the client will be provided a data-rich site verified BIM that is bi-directionally linked to the in-house AM/FM system (SAP) or equivalent. Additionally, the BIM Execution Plan and asset Meta data requirement templates developed during the project will be reused on subsequent CAPEX projects, forging the beginning of an accurate and consistent digital record of one of New Zealand's largest asset owners building portfolio.

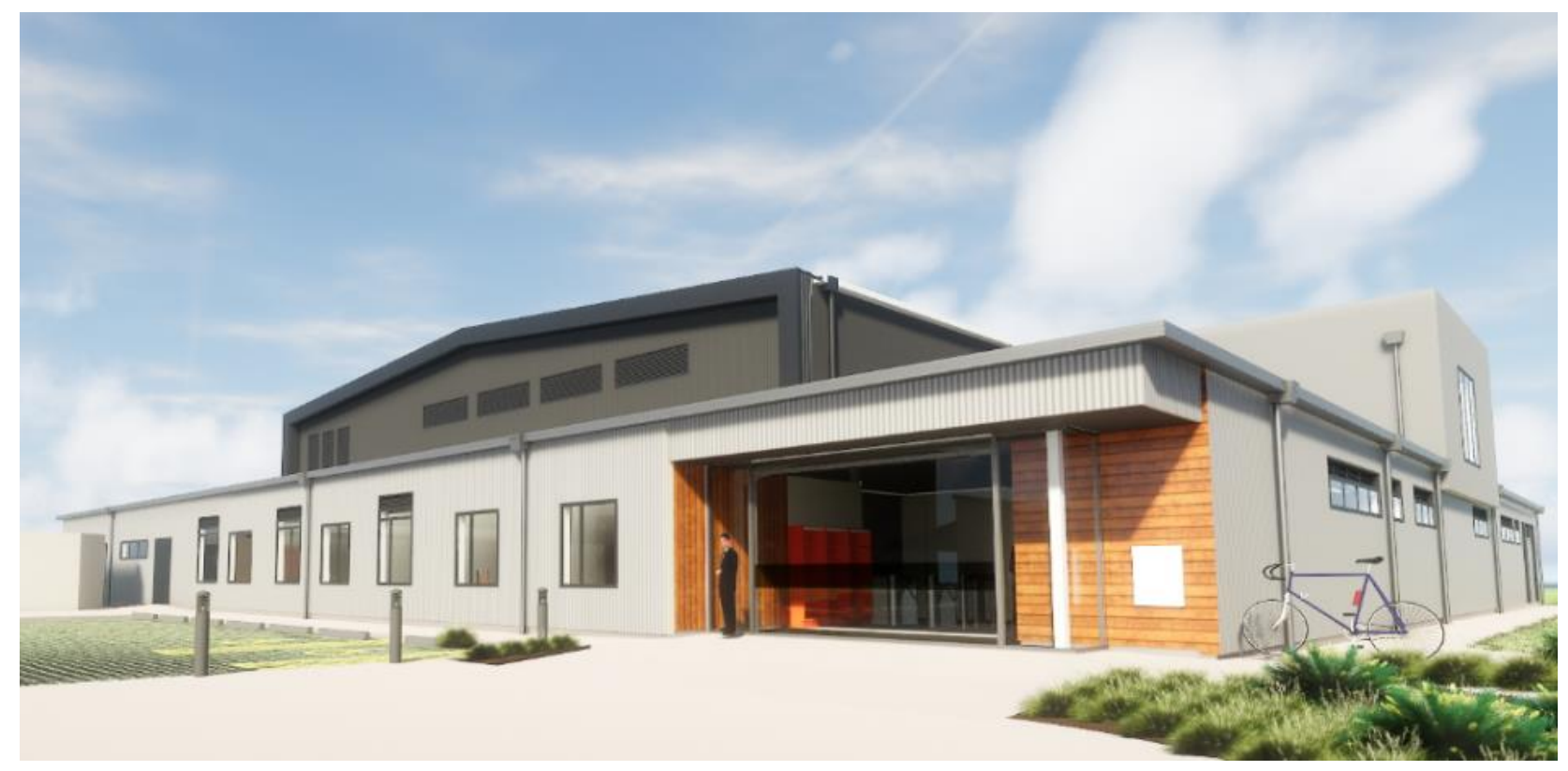

Figure 24: Exported navigable 3D model and visualisations produced from co-ordinated Building Information Model. 

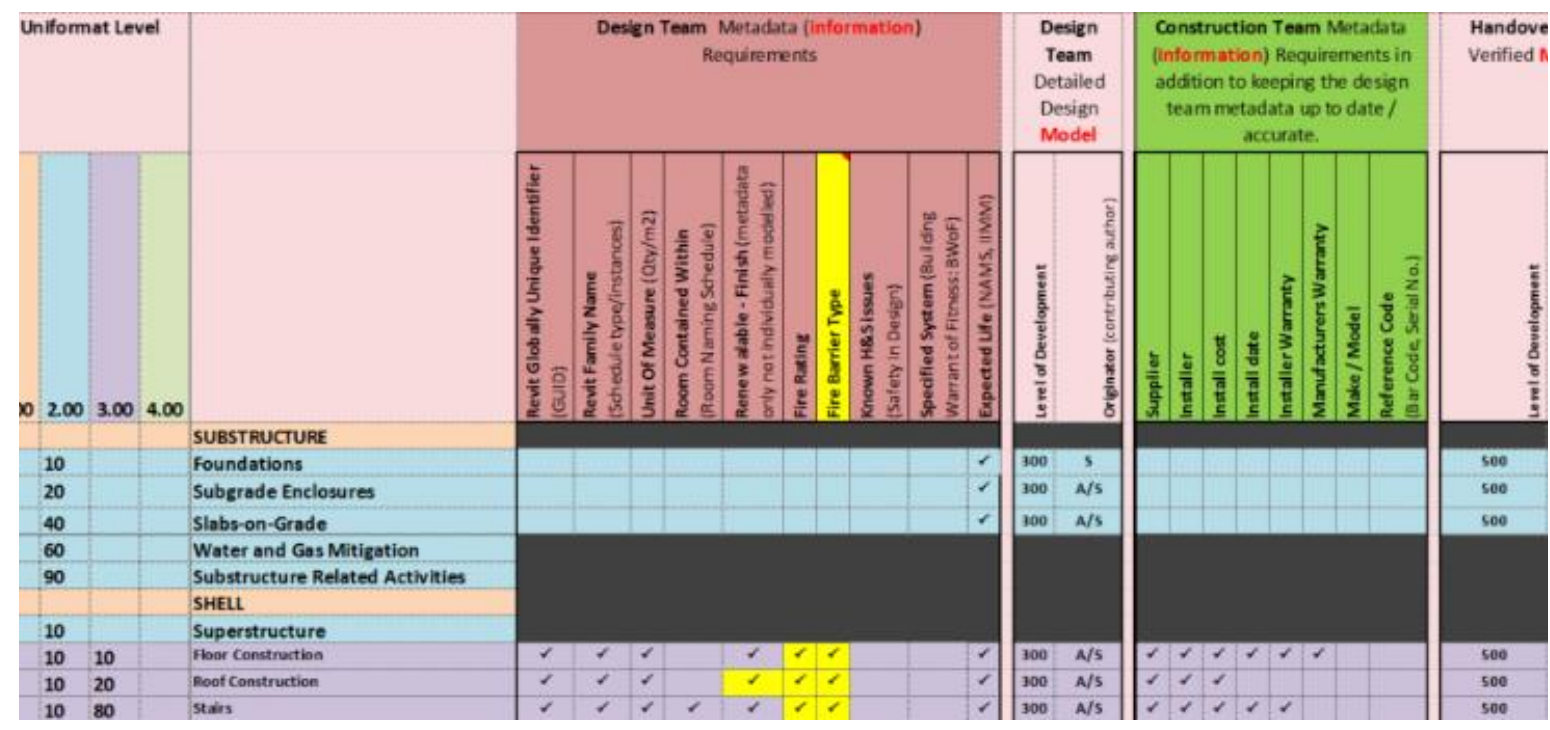

Figure 25: Information Requirements

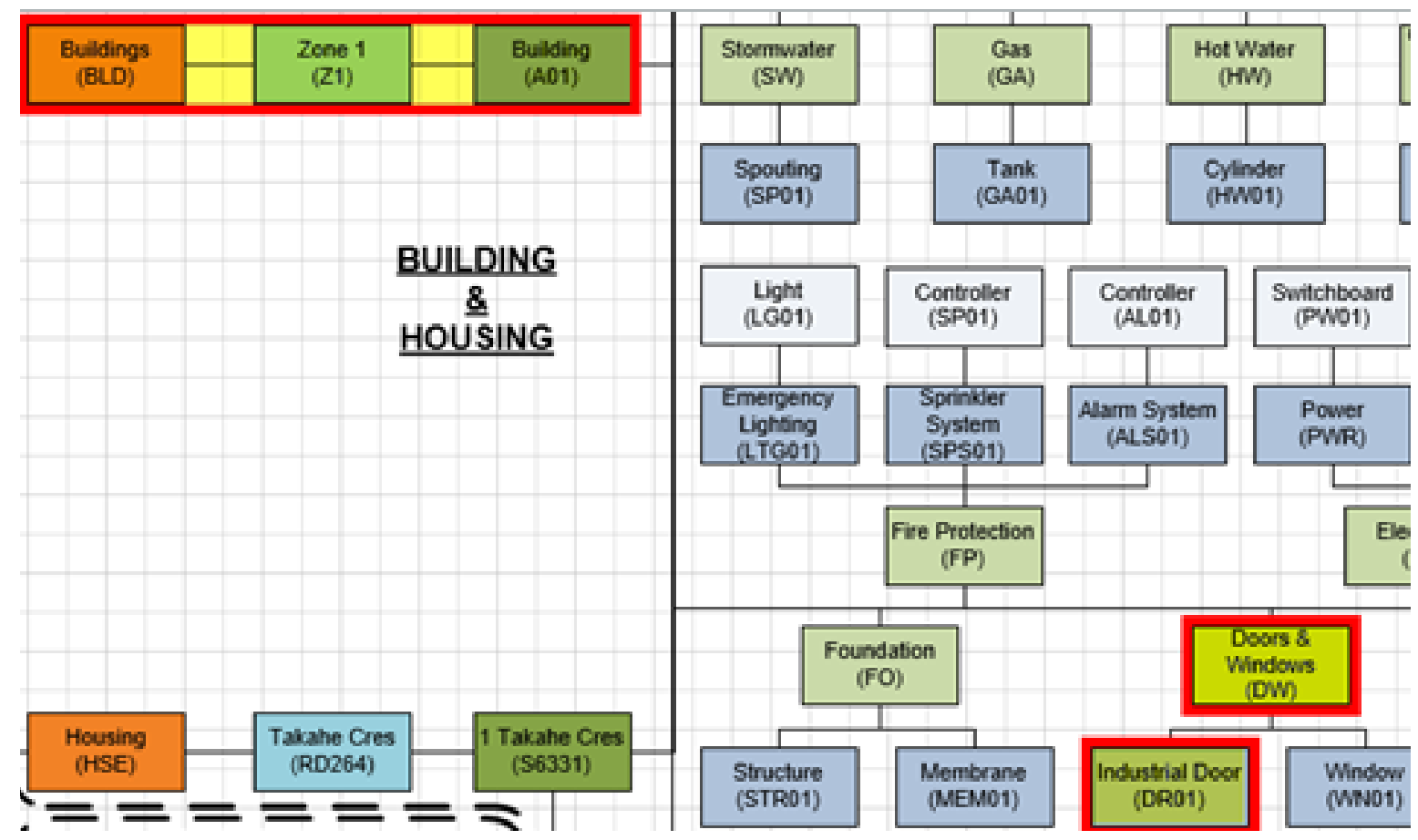

Figure 26: Information Hierarchy

The definition of digital modelling and information requirements of the $\mathrm{BIM}$, is integrating into the clients specific Asset/Facilities Management System and regulating data drop computational verification of BIM. This is how data is pushed into the BIM model with consideration of what needs to be included and developing a hierarchy in doing so. In figures 25 the spreadsheet outlines the design team and construction teams' necessary data requirements into the model. Figure 26 documents a hierarchy of data hierarchy. 


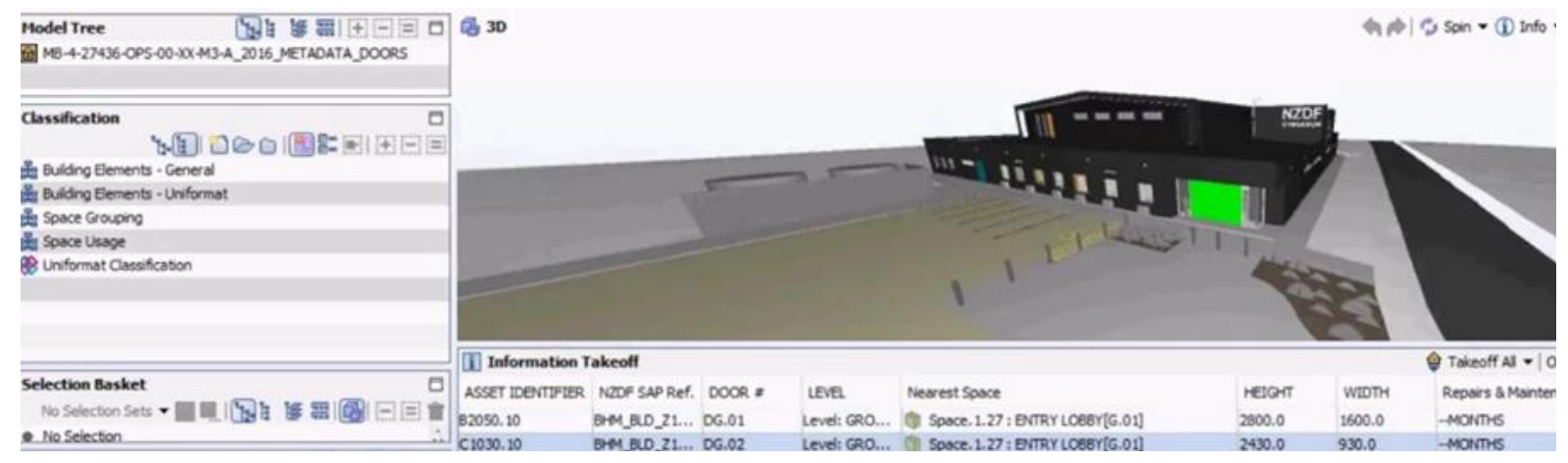

Figure 27: GIS platform

The buildings condition assessment was undertaken in an effort to understand the level of effort and investment needed to maintain these assets in sound condition.

A collaborative GIS platform was setup to enable information sharing and allowing all parties to contribute by rating the condition and providing remedial rankings based on their findings. This allowed all involved parties to visualise, interrogate and analyse the existing spatial data attributes, and provide inputs that were instantly available to all contributing members.

\subsubsection{Background of project tendering}

The organisation highlighted is a governing organisation responsible for delivering defence in New Zealand and provides essential support for the government's national security. This aligns with the New Zealand Defence Act 1990, guidelines and provisions have been progressed to support in defending the nation's sovereign territory. A defence estate is a strategic asset development for the company. Overall the aim of the strategic plan provides infrastructure and facilities to maintain skills and capability within the defence. A major upgrade of the organisations buildings, facilities and infrastructure has been specified in the estate regenerative programme with investment of $\$ 1.7$ billion over 15 years. "We're embarking on a project unlike any that has gone before, we're regenerating our estate so that our organisation can operate more efficiently and effectively (NZDF, 2017). Our footprint of camps and bases will remain the same - but it's how we modernise, that will be different. We're building a better future, one with better infrastructure, better camps and bases and better workplaces for our 14,000 military and civilian staff so that we continue to protect and 
enhance the security of New Zealanders and neighbours (Chief of Defence Force, Lt Gen Tim Keating)".

As highlighted by the organisations objectives there is major work being under taken and therefore the need to implement and innovate in supporting the future of the organisation is imperative. Building Information Modelling at present holds the largest uptake in the AEC industry because of its documented successes. Designers, contractors and building owners are buying into the BIM process, this is said to be because of the proven benefits those whom have adopted BIM have acknowledged. There is the potential to use this new process to improve the innovation and whole of life cycle for the future of the organisation and their buildings and infrastructure. The company identified whom have an ongoing relationship with this client when tendering, believed that with their Level 2 accreditation success and key organisational experts could create for the organisation an innovation that will reduce costs and help better manage their assets for the ongoing future.

\subsubsection{Pre-existing current asset Management Systems: Review of current procedures}

The company in question, currently outsource their facilities maintenance services with two main providers being utilised.

In May 2017 a review of one of New Zealand's largest asset owners, Facilities and Asset Management space was undertaken by an outsourced party. The purpose of this investigation was to review the way subject y (outsourced) is managing these assets and comparing their contractual obligations.

Here we refer to the following subjects as indicated below:

- Company X (client/asset owner)

- Company Y (service provider/asset \& facilities manager)

- Company Z (outsourced contract review panel)

This section of the research explores Company X's asset and facility management procedures in a traditional "everyday approach". This study considers Company $X$ as the owner of the asset and facilities (client) and Company $Y$ as the service provider to Company $X$ who is legally 
contracted to perform and undertake specific tasks and procedures identified in the contract. Asset Management is used within the contract between Company $X$ and Company $Y$ to enable Company $X$ (the client) to extract from the service provider (Company $Y$ ) to support the longer maintenance works (A. Haddock, 2017). The intent of this contract is to collate information on the asset portfolio and develop solutions that optimise the existing assets. Asset management is not defined within the contract, causing little clarity which leaves each party inferring the expectations from the associated section of the contract (A. Haddock, 2017). The contract specifies that Company $X$ shall expect from Company $Y$ the following four critical points:

- To provide maintenance planning

- Ongoing advice of Asset Conditions and carrying out condition assessments

- Proactively develop solutions for through life management

- Provide input into Company Y's planned maintenance programme

An overview of the contract is defined as understanding the Asset Information System to which delivers the service provider with the data and ability to advise Company $\mathrm{X}$ on estate assets from a knowledgeable position.

Company $\mathrm{X}$ engaged Company $\mathrm{Z}$ to undertake a review of the contract between Company $\mathrm{X}$ and Company $\mathrm{Y}$ as Company $\mathrm{X}$ was not satisfied because Company $\mathrm{X}$ was undertaking their contractual obligations in performing in the operational space of their assets and facilities.

In a meeting between Company $X$ and Company $Z$ the following concerns were outlined:

- An absence of readily available documentation (site reports, worksheets, maintenance records)

- Lack of subcontractor management

- Poor Communication

- A perceived trend of data manipulation to meet KPI's

- Data that is inaccurate and out of date

- Limited access to all electronic management platforms 
- A perceived lack of transparency with supporting documentation with no access to view maintenance records and reports

In a meeting between Company $\mathrm{Y}$ and Company $\mathrm{Z}$ the following concerns were outlined:

- Little clarity and decisions regarding direction from Company $X$ with regards to scheduled, unscheduled maintenance and asset management

- Gap in hand over processes

Common themes between both parties (the client and the service provider), crucial for the success of asset and facilities management:

- Management and operational documentation not up to date

- Inconsistencies of data management across the information systems

- Maintenance of critical items such as plant is overlooked

- Handover process of new assets for through life maintenance is not well managed

Both party $\mathrm{X}$ and $\mathrm{Y}$ raised concerns with regards to the contract, following review of current procedures and information it is evident that the majority of scheduled and unscheduled tasks are not being executed and in fact deferred. The primary issue with the above points indicates a level of unclear expectations.

Within the contract Company $\mathrm{X}$ are looking for Company $\mathrm{Y}$ to be the experts in managing their assets. Through operational and planned maintenance Company $\mathrm{Y}$ are to have a visceral and technical understanding of how each asset is performing. However, converting this into a format that optimises the assets performance and extends its life requires a more detailed approach.

For operational maintenance Company Y's refers to their maintenance plan - (WMS) Work Management System as the main maintenance management tool employed across each site of Company $X$. Additional to this Company $Y$ also has the tool SPM assets. Company $Y$ acknowledges that the majority of their maintenance reporting utilises the information from the WMS environment. When reviewing these systems, it did not identify any reporting from SPM asset data. To be able to support Company X's whole of Life Costs of the assets, both systems need to be updated with the latest data. Although evidence of Company Y's management for operational maintenance planning is shown, Company $Z$ was unable to 
identify how Company Y was applying their "subject matter expertise" and knowledge to the strategic plans as outlined by Company X. Company $Y$ has collected data on the assets but are missing crucial component information while the structure of the information management system needs to be realigned with the data hierarchy (A. Haddock, 2017).

As a tool SPM assets have the ability to analyse data and inform both parties but to do so more functional capabilities to the system need to be made available to avoid double handling information into another software application. For operational maintenance Company, $Y$ utilises a WMS system to manage their schedule and unscheduled activities. While there is a proportion of work being completed, there is a regular occurrence of open historical work orders as well as scheduling changes and cancelled work orders. For clarity on the work being carried out by Company $Y$, it is recommended by Company $Z$ that Company $Y$ carries out an internal audit to ensure the required outcomes including delivery of maintenance, legislative compliance and reviews are being carried out.

While the information above is indicative of a particular companies' way of managing their assets and facilities the "traditional/current" approach adopted by the likes presents many concerns and issues in the way the assets are being managed and maintained. The following key issues have been identified as critical improvements:

- Better management of asset data through establishing a condition assessment programme and delivering monthly electronic files.

- Ensuring all work order management tasks are regularly updated

- Undertake regular audits of the contract

- Ensure all management documentation is uploaded to the required portals

- Develop a handover process 


\subsubsection{Overview of Project}

In 2008 a request for interest for the design services for the development of the sports stadium was issued as an open tender.

\subsubsection{Background of the project}

Hobsonville airbase closed prior to 2008 and subsequently the base no longer had access to a gymnasium. The organisation was seeking professional services to design the gymnasium to service the needs of approximately 1500 personnel. The original RPF only specified a design consultant to provide the traditional typical services from architectural to fire and did not specify or acknowledge any use of BIM. The project was to be structured in two stages. Stage 1 included the concept design and costing. Once the organisation gained approval stage 2 was the engagement of consultants to produce developed and detailed design construction documentation and construction monitoring. As such the winning tender was awarded based on both non-price and price attributes.
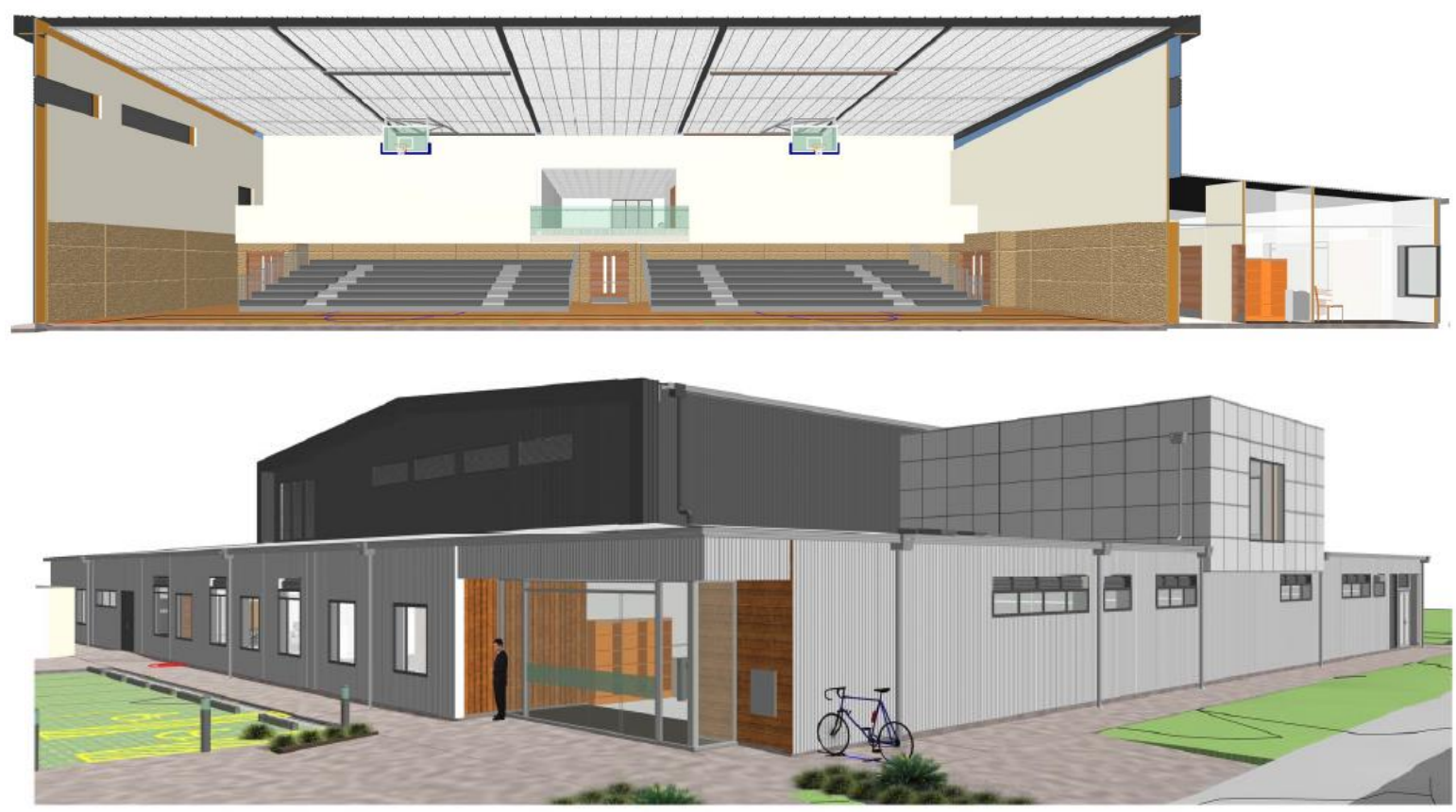

Figure 28: Design details of the Gymnasium

The scope of work included in the Gymnasium Building for RNZAF Base Whenuapai will be defined as a wellbeing zone and provides as an enhanced functionality in order to become the heart of the airbase in its role to support fitness and armed forces. The building is to be constructed with steel portal frames and a mezzanine floor. The main building is based around 
a large span steel portal frame with metal cladding. The inner structure is expressed and highlighted on the front and rear façade of the main sport hall volume as a negative detail, proudly mimicking the scale and form of traditional hangar buildings. Alongside this the gymnasium will provide seating for 300 spectators with specific facilities such as cardio and weights room. In regard to environmental and sustainable design the project includes harvesting water for reuse for toilet flushing and irrigation for exterior equipment washing. As well as this photovoltaic roof panels have been designed to be embedded in the roof profile. The design of the gymnasium has allowed for excess room on the roof for more panels as well as room in the plant room for future purchase of batteries.

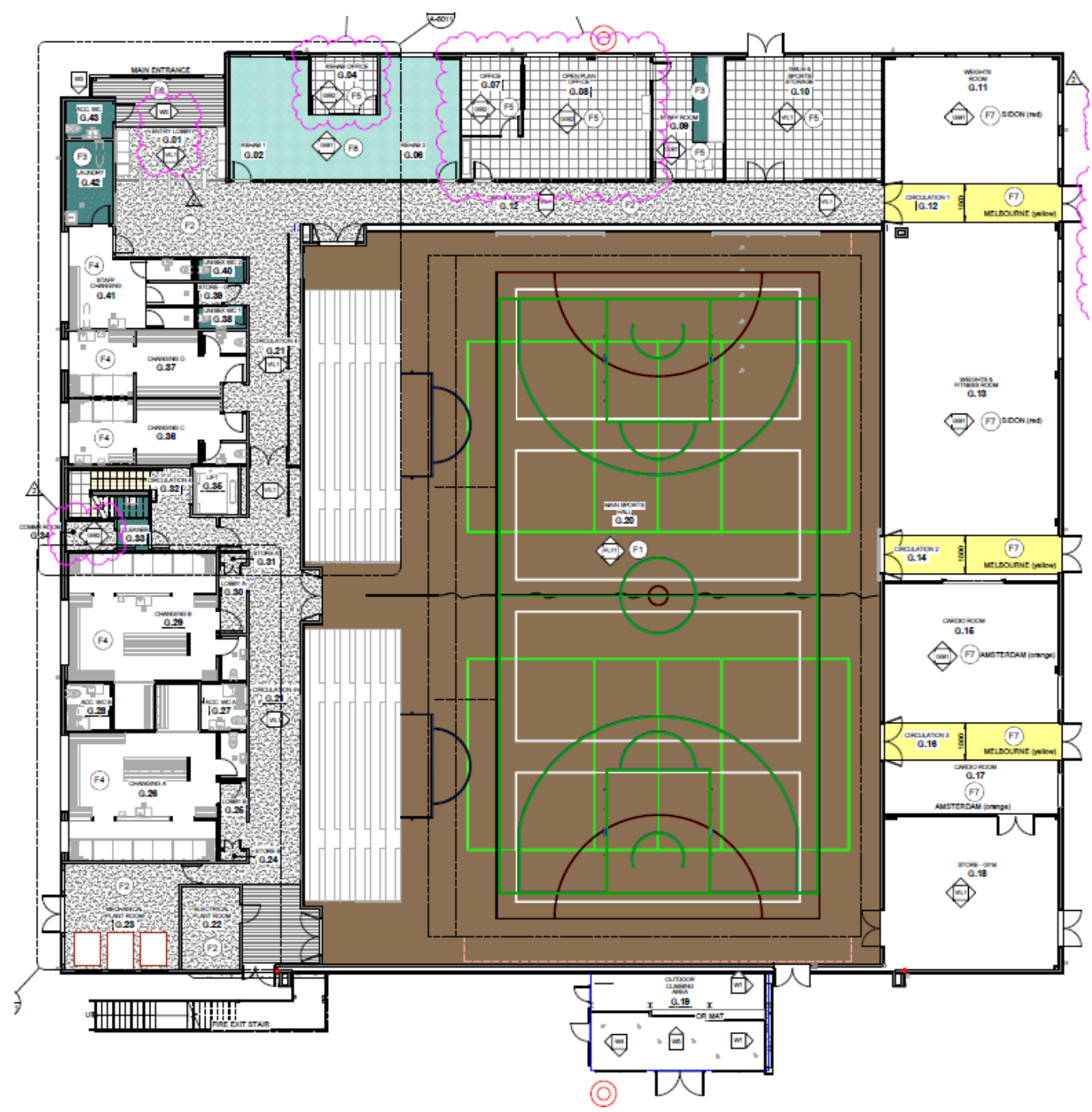

Figure 29: Ground floor plan of Gymnasium 
The buildings location is 19-23 Turi Street Whenuapai Base and is approximately $47 \mathrm{~m} \times 42 \mathrm{~m}$ in total floor area. For both gravitational and lateral load resisting structures portal frames have been designed as well as cross bracing. Services included in the design are electrical, lighting, communication, audio visual, security, transportation, ventilation heating and cooling, and typical plumbing and fire systems.

The three waters design is an objective to provide safe and efficient system that disposes waste and storm water into the on-site reticulation system.

\subsubsection{BIM Execution Plan}

The Whenuapai Gymnasium (Whenuapai Base Gymnasium) for the client is located at 23 Turi Avenue, the project is centred around the BIM execution plan that was detailed with all stakeholders in collaboration with one another. The BEP contains all the information needed from the design of the project to the construction completion (see Appendix 9). In essence the BEP is a detailed plan that defines how the project will be executed, monitored and organised to meet the digital delivery requirements. It is essential that all team members of the gymnasium understand the following requirements:

- Authorised uses

- Collaboration methodologies

- Exchange requirements

- Expected levels of development

- Information requirements

- Project deliverables

-Protocol compliancy requirements

- Roles and responsibilities

- Standards, methods and procedures (smps)

The project for the New Gymnasium includes the federated BIM model of all disciplines including associated asset/facilities management data. 
The following table represents roles and responsibilities defined for specific parties for the duration of the project.

\begin{tabular}{|c|c|c|}
\hline Role & Role Code & Responsibilities \\
\hline $\begin{array}{l}\text { Employers representative(s) } \\
\text { e.g. Client appointed BIM } \\
\text { representative }\end{array}$ & $E R(n)$ & $\begin{array}{l}\text { Produce plain language questions } \\
\text { Capture required standards, methods and } \\
\text { procedures } \\
\text { Author the Employer Information } \\
\text { Requirements (EIR) } \\
\text { Review the information exchanges against the } \\
\text { EIR }\end{array}$ \\
\hline $\begin{array}{l}\text { Project Delivery Manager } \\
\text { Nb. When not delineated as a } \\
\text { separate role responsibilities } \\
\text { transfer to Principle/Lead } \\
\text { Consultant. }\end{array}$ & PDM & $\begin{array}{l}\text { Collate projects deliverables and acts as a } \\
\text { single point of contact for deliverables. } \\
\text { Confirms auditing process has been adhered } \\
\text { to and collates audit documentation (audit } \\
\text { reports). } \\
\text { Owner of the Master Information Delivery } \\
\text { Plan (Master Information Delivery Plan) } \\
\text { Enforces program specific to the MIDP } \\
\text { Assures delivery of information exchanges } \\
\text { Approves information exchanges within the } \\
\text { common data environment to move to the } \\
\text { client visible location of the CDE. } \\
\text { Confirm supplier's ability to deliver } \\
\text { information requirements }\end{array}$ \\
\hline $\begin{array}{l}\text { Project Information Manager } \\
\text { Nb. This role is often referred to as } \\
\text { a "Project BIM Manager" }\end{array}$ & PIM & $\begin{array}{l}\text { Develops and gains consensus of the Project } \\
\text { Standards, Methods and Procedures } \\
\text { (SMPs)required by the Client } \\
\text { Assesses the Task Teams capability to } \\
\text { produce Information in Accordance with the } \\
\text { SMP } \\
\text { Ensures the availability of the Common Data } \\
\text { Environment to all Task Teams } \\
\text { Assures the Project Information Model (P.I.M) } \\
\text { is produced in accordance with the Project } \\
\text { SMPs } \\
\text { Manages risk associated to the production of } \\
\text { the Project Information Model (P.I.M) } \\
\text { Consulted by the Design / Construction Lead } \\
\text { on Authorising the Project Information Model } \\
\text { Consulted by the Design / Construction Lead } \\
\text { on the Volume Strategy and assigning the } \\
\text { appropriate LOD } \\
\text { Consulted by the Design / Construction Lead } \\
\text { on documenting and validating the } \\
\text { Information Requirements of the EIR }\end{array}$ \\
\hline
\end{tabular}




\begin{tabular}{|c|c|c|}
\hline Role & Role Code & Responsibilities \\
\hline $\begin{array}{l}\text { Task Team Manager } \\
\text { Consults the T.I.M }\end{array}$ & $\begin{array}{l}\text { (Disc)TTM } \\
\text { e.g. ATTM - } \\
\text { Architecture } \\
\text { STTM - Structure } \\
\text { MTTM - Mechanical } \\
\text { ETTM - Electrical } \\
\text { PTTM - Plumbing } \\
\text { OR } \\
\text { MEPTTM - When single } \\
\text { person delivery all } \\
\text { disciplines }\end{array}$ & $\begin{array}{l}\text { Task Team I.M Role appointments } \\
\text { Developing the Task Information Delivery Plan } \\
\text { (TIDP) and ensuring the availability of } \\
\text { competent resources to execute it } \\
\text { Reviewing and approving the information } \\
\text { produced by the Task Team against the task } \\
\text { brief, if its meets the EIR } \\
\text { Assigning the appropriate status (suitability) } \\
\text { of the information shared by the Task Team } \\
\text { Identifying and escalating risks associated to } \\
\text { the delivery of the Project Information Model } \\
\text { (P.I.M) }\end{array}$ \\
\hline $\begin{array}{l}\text { Task Information Manager } \\
\text { Instructs the T.T.M } \\
\text { Nb. When not delineated as a } \\
\text { separate role responsibilities } \\
\text { transfer to (discipline) Task Team } \\
\text { Manager }\end{array}$ & $\begin{array}{l}\text { (Disc)TIM } \\
\text { e.g. } \\
\text { ATIM - Architecture } \\
\text { STIM - Structure } \\
\text { MTIM - Mechanical } \\
\text { ETIM - Electrical } \\
\text { PTIM - Plumbing } \\
\text { oR } \\
\text { MEPTTM -When } \\
\text { single person } \\
\text { delivery all } \\
\text { disciplines }\end{array}$ & $\begin{array}{l}\text { Ensures the Task Team has the capability to } \\
\text { produce Information in accordance with the } \\
\text { Project SMP } \\
\text { Provides education and support to } \\
\text { Information Authors with respect to the } \\
\text { Project SMPs } \\
\text { Accepts / rejects that information produced } \\
\text { by the Task Team is compliant with the } \\
\text { Project SMP prior to being shared } \\
\text { Identifying and escalating risks associated to } \\
\text { the production of the Project Information } \\
\text { Model (P.I.M) } \\
\text { Developing the Task Information Delivery Plan } \\
\text { (TIDP) and ensuring the availability of } \\
\text { competent resources to execute it } \\
\text { Consulted by the Task Team Manager on } \\
\text { Developing the TIDP } \\
\text { Consulted by the Task Team Manager on } \\
\text { assigning appropriate suitability (use) of the } \\
\text { information shared by the Task Team } \\
\text { Consulted by the Project Information } \\
\text { Manager on developing and gaining } \\
\text { consensus of the SMPs } \\
\text { consulted by the Project Information } \\
\text { accordance with SMPs }\end{array}$ \\
\hline $\begin{array}{l}\text { Model Element Authors } \\
\text { Nb. When not delineated as a } \\
\text { separate role responsibilities } \\
\text { transfer to (discipline) Task Team } \\
\text { Manager }\end{array}$ & $\begin{array}{l}\text { (Disc)MEA } \\
\text { e.g. AMEA - } \\
\text { Architecture } \\
\text { SMEA - Structure } \\
\text { MMEA - Mechanical } \\
\text { EMEA - Electrical } \\
\text { PMEA - Plumbing }\end{array}$ & $\begin{array}{l}\text { Production of project outputs as determined } \\
\text { by the BEP } \\
\text { Ensure compliance with SMPs as stipulated in } \\
\text { BEP. } \\
\text { Develop constituent parts of the information } \\
\text { model } \\
\text { Model elements to the appropriate Level of } \\
\text { Development }\end{array}$ \\
\hline
\end{tabular}




\begin{tabular}{|c|c|c|}
\hline Role & Role Code & Responsibilities \\
\hline & $\begin{array}{l}\text { OR } \\
\text { MEPMEA - When single } \\
\text { person delivery all } \\
\text { disciplines }\end{array}$ & $\begin{array}{l}\text { Communicate issues back to Discipline BIM } \\
\text { Manager. } \\
\text { Continuous visual check during project } \\
\text { documentation construction and all releases } \\
\text { to extemal project team }\end{array}$ \\
\hline $\begin{array}{l}\text { Interface Manager } \\
\text { Nb. When not delineated as a } \\
\text { separate role responsibilities } \\
\text { transfer to (discipline) Task Team } \\
\text { Manager }\end{array}$ & $\begin{array}{l}\text { (Disc)IFM } \\
\text { e.g. AIFM-Architecture } \\
\text { SIFM - Structure } \\
\text { MIFM - Mechanical } \\
\text { EIFM - Electrical } \\
\text { PIFM - Plumbing } \\
\text { OR } \\
\text { MEPIFM -When single } \\
\text { person delivery all } \\
\text { disciplines }\end{array}$ & $\begin{array}{l}\text { Resolving spatial co-ordination issues with } \\
\text { other Task Team Interface Managers } \\
\text { Escalating unresolved co-ordination issues to } \\
\text { the Design / Construction Lead } \\
\text { Keeping the Task Team updated with agreed } \\
\text { resolutions \& progress reports }\end{array}$ \\
\hline
\end{tabular}

The Next section of the BEP explains who exactly is prudent to what role, it is not necessary for this research to expose these professionals but rather just acknowledge that this process has been/is specified as shown below. The structure below identifies the communication link, often these hirachies form a triangle. In this case the third tether reports to both second levels. It seems that there is double handling of information. The difference between the two is the prinicipal consultant reports to separate project managers on delivery and information that is then fed to the employee representitive. The reporting structure could be better utilised if the task team manager reported to the project managers and then to the prinicpal consultant. 


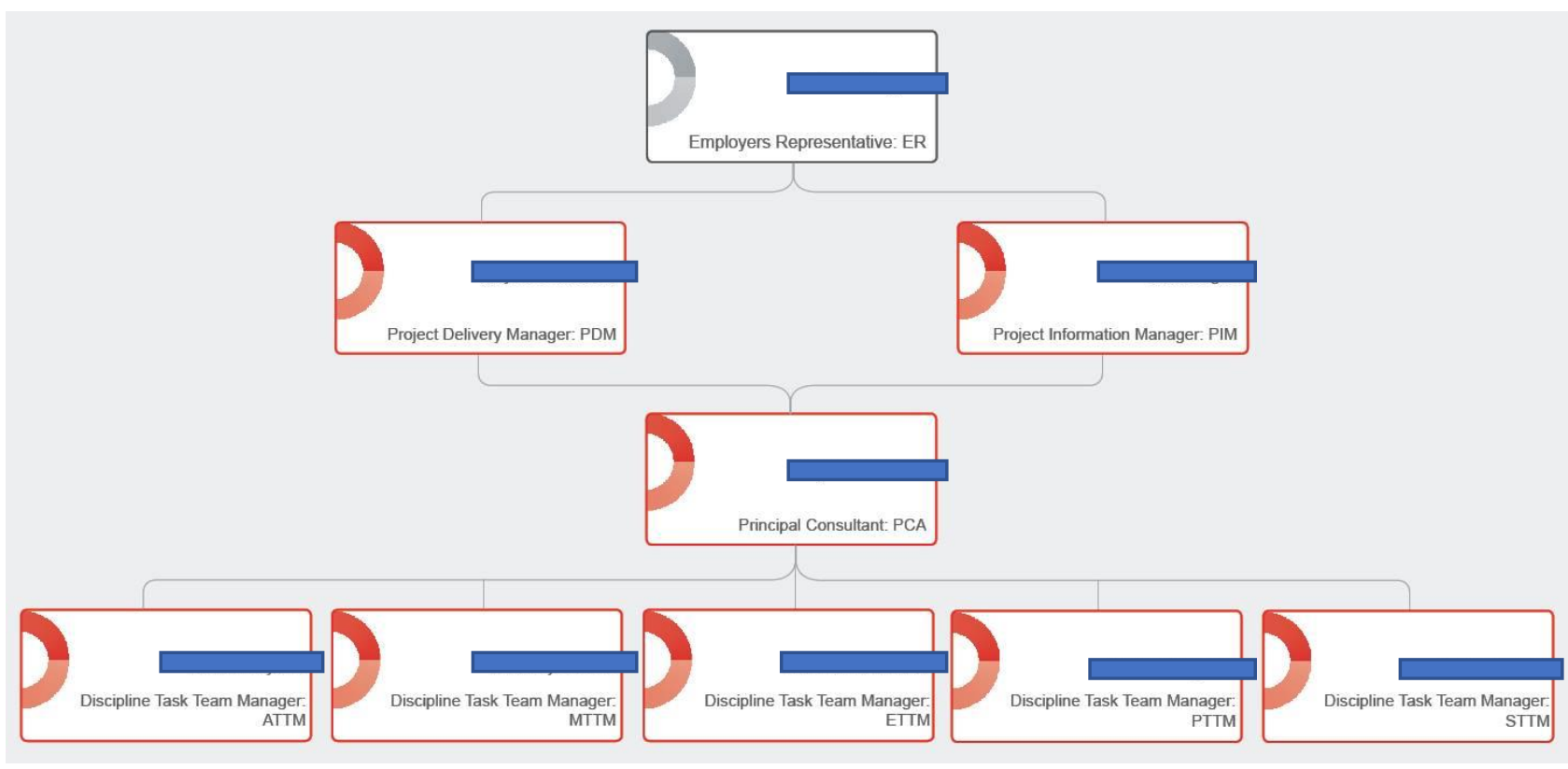

Figure 30: Reporting structure

Aside from the hierarchy levels, it is clear whom reports to who. Further to this, the BEP documents the key representatives and there contact details. There is a project delivery manager whom is responsible for the security and extranet access and distributing the documentation.

Section 3.7 of the BEP specifies the need for supporting information and were you can find this documentation, it is not clear however, where these documents lie in regard to being able to access them. It can be assumed that these would be issued in conjunction with the $B E P$, and as the BEP specifies the common data environment being share point that this would be the single source of the truth. It can be assumed that all project participants would have or will be granted access to this.

Role codes are documented with respect to BS1192:2007 and include ISO 13567, this standardises specific roles.

As this project goes further than the typical BIM use for design, section 3.9 that authorises the BIM use becomes important for the project as the table specifies disciplines that are expected to contribute during each project phase. As stated in the literature review one of the biggest issues with a BIM design approach is that stakeholders need to be engaged a lot 
early than a traditional design and build project. Particular asset and facilities managers are required to be introduced in the project before the onset of construction. The table below identifies each discipline and is tailored specifically to the project. These codes are sourced from BS 1192:2007 sections 10.2 and 10.3.

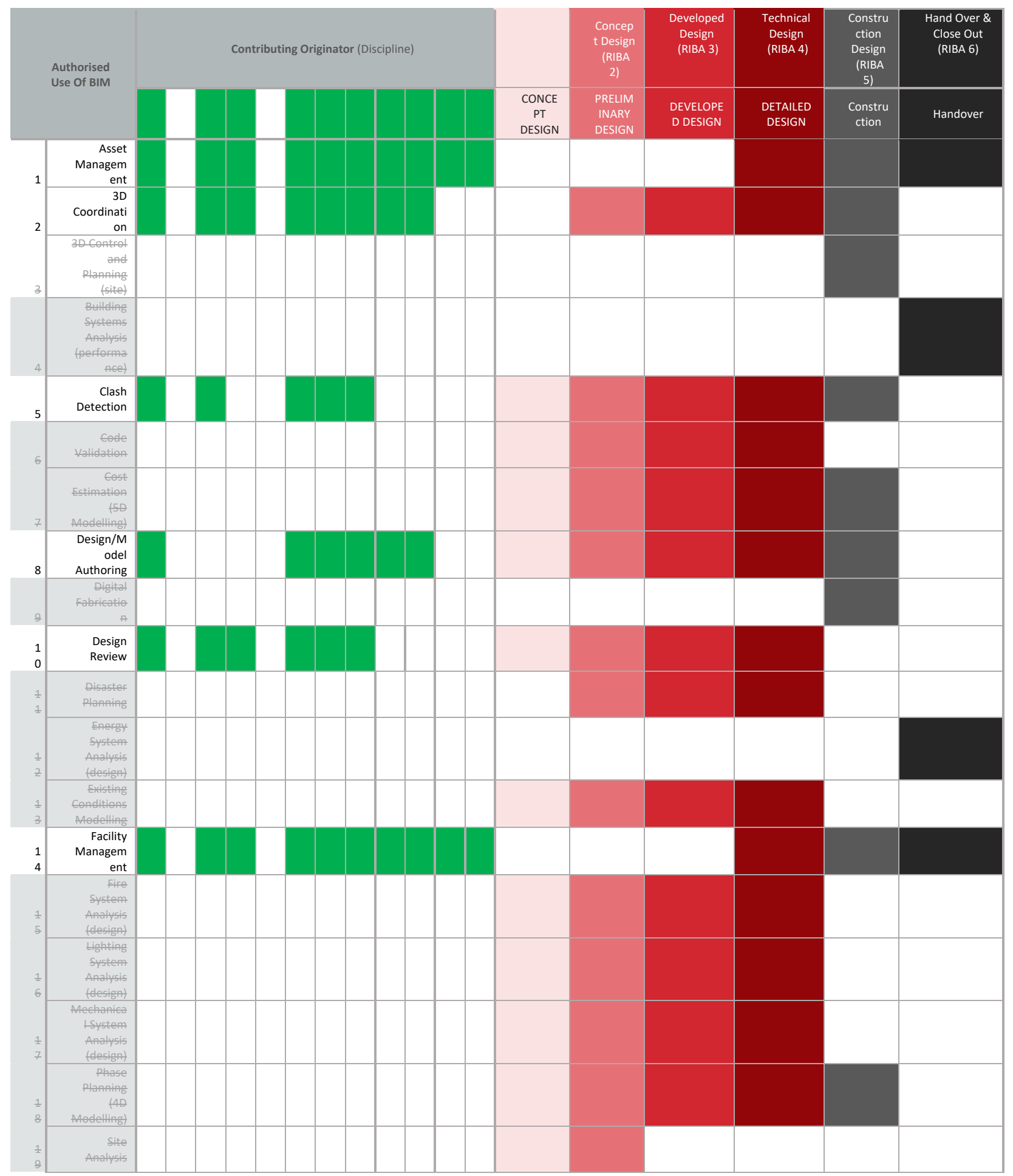




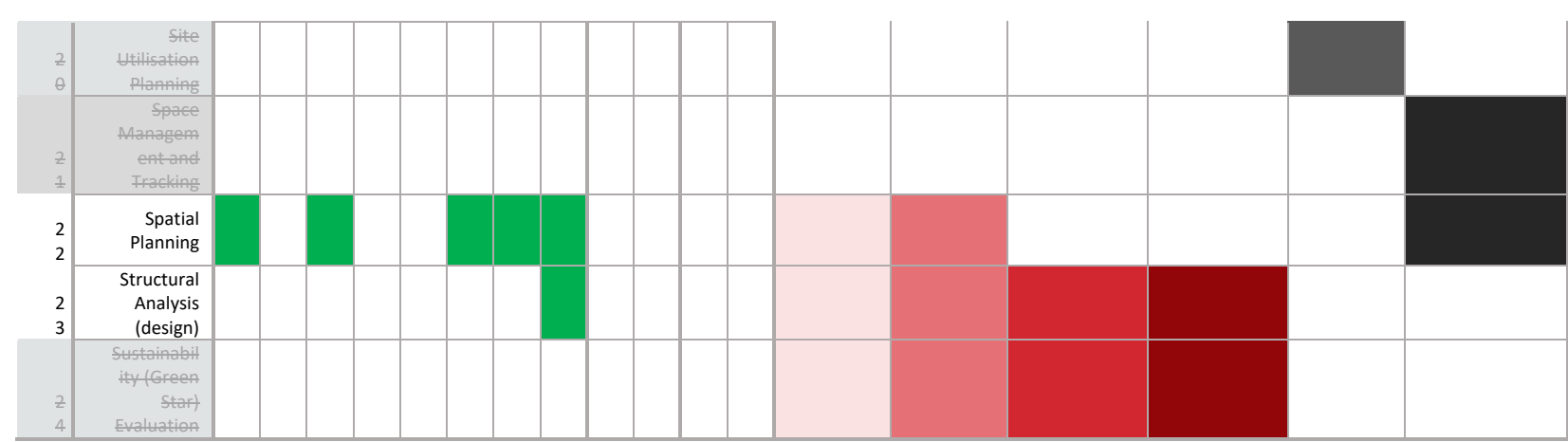

Table 13: Authorised use of BIM

The grey areas were introduced as a way of showing the items that are being considered but not necessarily being committed to. The table below includes four categories: authorised BIM use, the methodology, output and supporting information. This can be a tool for the design team to be aware of the output (see Appendix 11).

\begin{tabular}{|c|c|c|c|c|}
\hline \multicolumn{2}{|c|}{ Authorised BIM Use } & Methodology & Output & Supporting Information \\
\hline 1 & Asset Management & $\begin{array}{l}\text { Asset management Information (metadata) } \\
\text { is authored and associated to the BIM by } \\
\text { various stakeholders throughout the design } \\
\text { and construction phases. With a final } \\
\text { handover to the client after construction. }\end{array}$ & ${ }^{*}$ IFC and ${ }^{*} \mathrm{xls}$ & $\begin{array}{l}\text { Error! Reference source } \\
\text { not found. } \\
\text { Asset Meta Data } \\
\text { Requirements }\end{array}$ \\
\hline 2 & 3D Coordination & $\begin{array}{l}\text { Improved stakeholder engagement using } \\
\text { 3D models for effective communication } \\
\text { and resolution of coordination between } \\
\text { disciplines via the Common Data } \\
\text { Environment }\end{array}$ & Discipline BIM Models & $\begin{array}{l}\text { Error! Reference source } \\
\text { not found. }\end{array}$ \\
\hline 3 & $\begin{array}{l}\text { 3D Control and } \\
\text { Planning (site) }\end{array}$ & Not part of contract & Not part of contract & Not part of contract \\
\hline 4 & $\begin{array}{l}\text { Building Systems } \\
\text { Analysis } \\
\text { (performance) }\end{array}$ & Not part of contract & Not part of contract & Not part of contract \\
\hline 5 & Clash Detection & $\begin{array}{l}\text { Improved stakeholder engagement using } \\
\text { 3D models for effective communication } \\
\text { and resolution of coordination between } \\
\text { disciplines via the Common Data } \\
\text { Environment }\end{array}$ & Solibri Clash Report & $\begin{array}{l}\text { Process for Information } \\
\text { Exchange }\end{array}$ \\
\hline 6 & Code Validation & Not part of contract & Not part of contract & Not part of contract \\
\hline 7 & $\begin{array}{l}\text { Cost Estimation ( } 5 D \\
\text { Modelling) }\end{array}$ & Not part of contract & Not part of contract & Not part of contract \\
\hline 8 & $\begin{array}{l}\text { Design/Model } \\
\text { Authoring }\end{array}$ & $\begin{array}{l}\text { Model Element Authors to author } \\
\text { individual BIMs as per the MPDT }\end{array}$ & $\begin{array}{l}\text { Discipline/Trade BIM } \\
\text { Models }\end{array}$ & $\begin{array}{l}\text { Error! Reference source } \\
\text { not found. }\end{array}$ \\
\hline 9 & Digital Fabrication & Not part of contract & Not part of contract & Not part of contract \\
\hline 10 & Design Review & All disciplines to review technical designs & $\begin{array}{l}\text { Drawings, calculations, } \\
\text { specifications and reports }\end{array}$ & $\begin{array}{l}\text { Error! Reference source } \\
\text { not found. }\end{array}$ \\
\hline 11 & Disaster Planning & Not part of contract & Not part of contract & Not part of contract \\
\hline
\end{tabular}


AMBER HADDOCK I 300289126

\begin{tabular}{|c|c|c|c|c|}
\hline \multicolumn{2}{|c|}{ Authorised BIM Use } & Methodology & Output & \multirow[t]{2}{*}{ Supporting Information } \\
\hline 12 & $\begin{array}{l}\text { Energy System } \\
\text { Analysis (design) }\end{array}$ & Not part of contract & Not part of contract & \\
\hline 13 & $\begin{array}{l}\text { Existing Conditions } \\
\text { Modelling }\end{array}$ & Not part of contract & Not part of contract & Not part of contract \\
\hline 14 & $\begin{array}{l}\text { Facility } \\
\text { Management }\end{array}$ & $\begin{array}{l}\text { Asset management Information (metadata) } \\
\text { is authored and associated to the BIM by } \\
\text { various stakeholders throughout the design } \\
\text { and construction phases. With a final } \\
\text { handover to the client after construction. }\end{array}$ & *IFC and *xls & $\begin{array}{l}\text { Error! Reference source } \\
\text { not found. } \\
\text { Asset Meta Data } \\
\text { Requirements }\end{array}$ \\
\hline 15 & $\begin{array}{l}\text { Fire System Andysis } \\
\text { (designt }\end{array}$ & Not part of contract & Not part of contract & Not part of contract \\
\hline 16 & $\begin{array}{l}\text { Lighting System } \\
\text { Analysis (design) }\end{array}$ & Not part of contract & Not part of contract & Not part of contract \\
\hline 17 & $\begin{array}{l}\text { Anechanical System } \\
\text { Analysis (design) }\end{array}$ & Not part of contract & Not part of contract & Not part of contract \\
\hline 18 & $\begin{array}{l}\text { Phase Planning (AD } \\
\text { Anodellingt }\end{array}$ & Not part of contract & Not part of contract & Not part of contract \\
\hline 19 & Site Analysis & Not part of contract & Not part of contract & Not part of contract \\
\hline 20 & $\begin{array}{l}\text { Site Utilisation } \\
\text { Planning }\end{array}$ & Not part of contract & Not part of contract & Not part of contract \\
\hline 21 & $\begin{array}{l}\text { Space Management } \\
\text { and Tracking }\end{array}$ & Not part of contract & Not part of contract & Not part of contract \\
\hline 22 & Spatial planning & Not part of contract & Not part of contract & Not part of contract \\
\hline 23 & $\begin{array}{l}\text { Structural Analysis } \\
\text { (design) }\end{array}$ & Computational structural analysis & Calculations & $\begin{array}{l}\text { Error! Reference source } \\
\text { not found. }\end{array}$ \\
\hline 24 & $\begin{array}{l}\text { Sustainability } \\
\text { (Green Star) } \\
\text { Evaluation }\end{array}$ & Not part of contract & Not part of contract & Not part of contract \\
\hline
\end{tabular}

The common data environment is an important web based central file repository where all the project information is issued controlled and monitored. The CDE is not just limited to the assets in the BIM environment but include documentation and non-graphical information. If in some cases the asset is existing, historical files could be placed in here.

The CDE platform for the gymnasium project is SharePoint. In 2017 the company started the migration from server drives to all new projects being SharePoint and their corresponding $\mathrm{S}$ drive.

"We need to access our information clearly and quickly as one organisation, how we are organised currently is that each business manages their information in a particular way. When 
we focus on local clients that is fine but as the company is moving forward to a global organisation they need to be aligning their data share".

Three main locations where information can be stored, the same file is named, and fits together like a puzzle.

$S$ drive is the company drive, then share point is utilised for all project storage with PMAF 2 and above and sharing of information. PMAF is the internal accreditation that was developed to understand different levels of project in regard to project management. The companies' internal system includes four levels of PMAF certification.

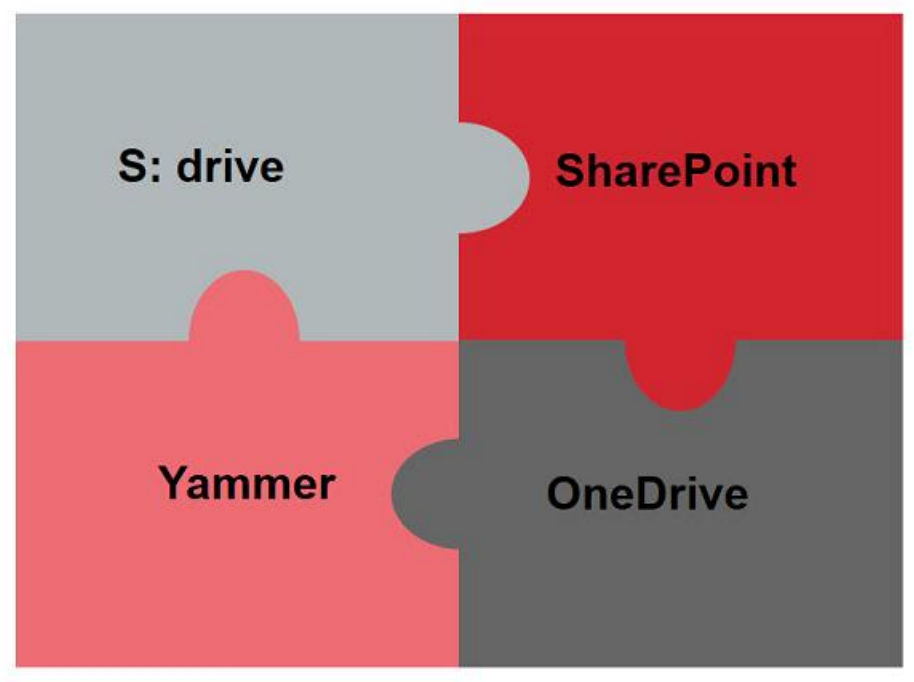

Figure 31: Four reporting tools

One drive for business is part of office 365 and provides a place in the cloud to share information, update and work on office projects it can be updated within the cloud space that being own personal share drive and shared with external and internal clients/people. Yammer is the tool used for communication and referred to more as an informal chat web browser.

Changes are being made to IT structure, this will take some time as there are huge file structures that need to be maintained within the organisation.

SharePoint: High level overview and vision:

- $\quad$ Existing Platform G drive, P drive, O Drive (current local drives)

- Limitations - data is soiled, cannot easily access data, search tool is not effective, and cannot share data with external parties

- All of the data is hidden away in little pockets through the company (regional silos) 
- No central files in the overall business, access to such documents is about who you know and what the projects are

- The challenge to have a platform that the entire company can access and know where to look when they need something ( for example SharePoint)

The vision for SharePoint:

- Hub for accessing everything note this will not be where everything is stored

- Project data, client data. Team data and technical data

- May be a point to link you somewhere

What is SharePoint?

- A web-based tool, browser-based tool

- Create/store and upload documents with all of the standard office documents

- $\quad$ Search documents for relevant content

- Version control

- Share with external parties

- Has a global search tool

- Access from anywhere that has an internet connection

- Office 365 platform is another part of this integrated platform

The need for S drive:

- Share point is ideal for all office documents and PDFs but is unable to be utilised for engineering files CAD or Revit so this is why a local network drive is being developed. As SharePoint develops it is likely the capability will extend to design files

- SharePoint will hold project management files, financial reporting, files final reports and the likes

- $\quad$ drive will hold engineering data files, Revit, Auto CAD, Raw data from LiDAR, drone footage and the likes

- $\quad S$ drive is currently being piloted within the company for quality assurance purposes

- SharePoint will hold personal team files for example team meetings and team information 
- The g drive files (currently regional drive for projects and supporting documents are saved too) will be taken to $S$ drive, in this transgression the business group has the chance to clean up data, archive and keep what eventually will be taken to SharePoint

- The Whenuapai Base Gymnasium 23 Turi Avenue is a good example of the information needed in a SharePoint, there is a link to the s drive for this Gymnasium where design files are kept

- For clients that have sensitive data and require information to be highly confidential SharePoint and S-drive have a function that looks as if anyone can access the project files. The project manager grants authority to those whom are authorised to have access to such information

- Projects get given specific provisions, the function pathway includes navigation to the Home page- SharePoint - new site filling in the information classification can be sensitive, if they are not a member of the project then they will not be able to access the folders

- SharePoint is currently being used for two things - Project delivery and ad-hoc sites (when a particular volume of people ask for a site)

- There are over 700 platforms running on the new platform, 60 company team sites in operation

- SharePoint is not yet the hub. this is ultimately the goal of the new implementation

- Imapps is a tool that links team members to email correspondence, within SharePoint when a project is set up a tick box is highlighted that allows the users to pin to outlook favourites, once the project is created, instructions are emailed

The next step for the company is:

- Consistent and logical navigation menus globally

- Consistent standard navigation menus across the entire site

- $\quad$ Styling theming consistent

- New SharePoint home

- New landing page for project sites

- Client sites for Major company clients will function similar to project sites 
- SharePoint will be tailored to the user and the projects and information that they are currently working on

\section{SharePoint Team Sites}

- $\quad$ Team sites for Business Units

- $\quad$ Teams Sites for PINS

- Team Sites ad-hoc requirements

- Business units by sectors and business units as a team's site, providing guidelines in how you store data to ensure this is done well

- Looking at using Office 365 groups will get into further detail in this TBC

Section 3.13 of the BEP defines the workflow for check, review, approve, authorise and accept.

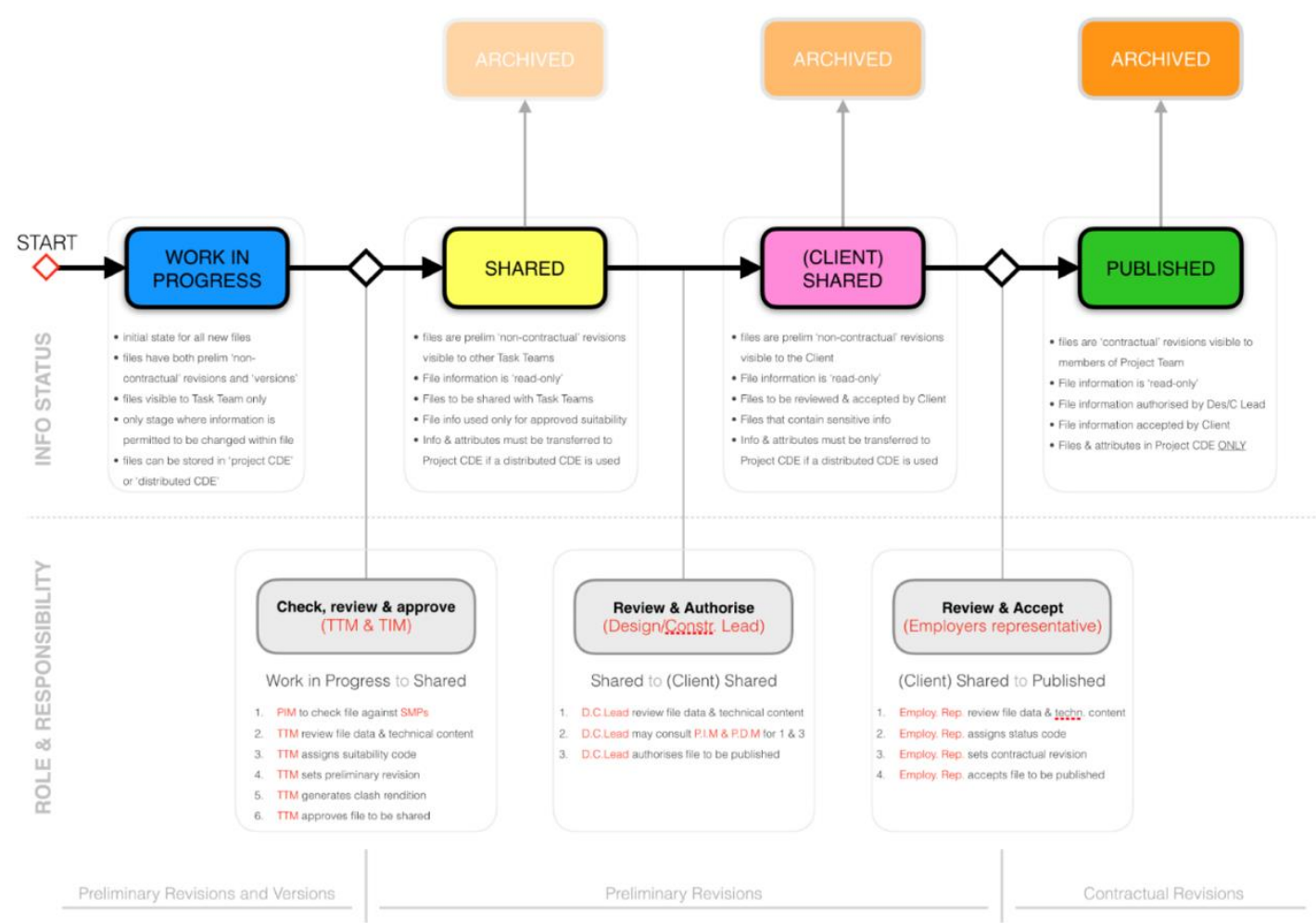

Figure 32: Workflow check 
Section 4 \& 5 of the BEP defines the planning and documentation of the project in regard to PAS1192, this is defined in the literature section and specifically what the standard refers to. This is somewhat generic, the schedule of meetings is project specific however the task information delivery plan, project information deliverables, master information delivery plan and model production and delivery table (see Appendix 12) have been amended to the project but comes from a model table of the NZ BIM templates. Section 6 of the BEP specifies how elements are saved, where the model originates from, and naming conventions and data segregation. These are standardised formations from the developed BEP templates.

The focus of this BIM project was on the delivery of the operations and the asset Meta data associated with the model and its deliverables. The asset Meta data attributes are sourced from the New Zealand Asset Metadata Standard - Residential Housing and Light Commercial Buildings. The Asset Meta data requirements are defined in the table below for the ongoing operation of the asset and facility management. The originator contributing author documents as per the project stages who is responsible for updating and creating the Asset Meta data requirements

${ }^{*}$ Red $=$ Bespoke attribute/example, Green = NZAMS attribute has been modified

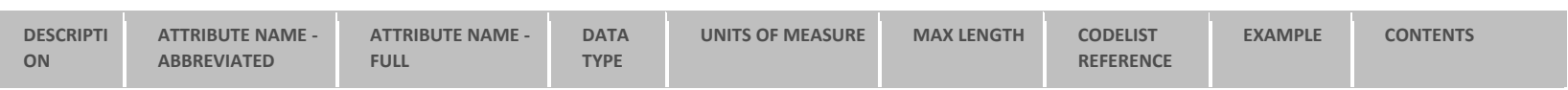

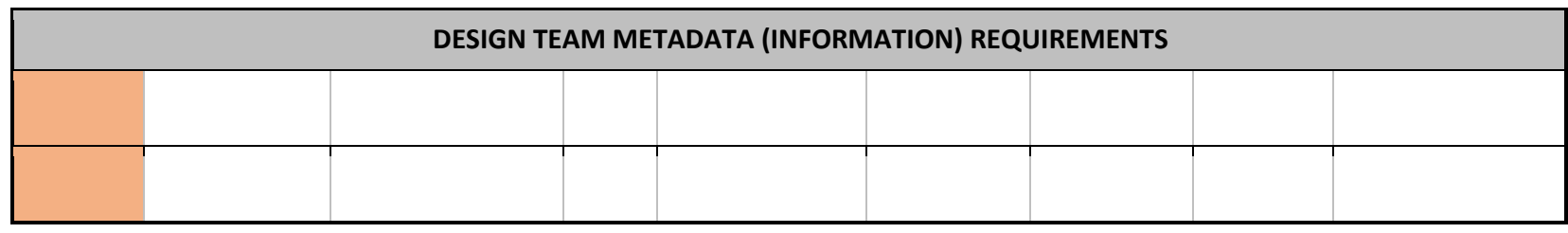

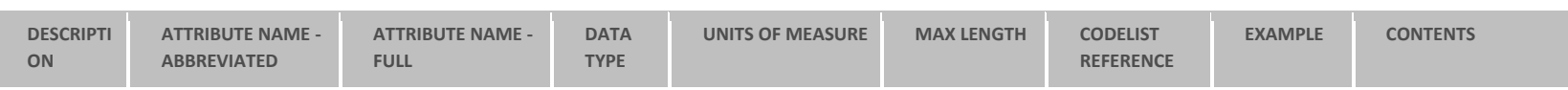

CONSTRUCTION TEAM METADATA (INFORMATION) REQUIREMENTS IN ADDITION TO KEEPING THE DESIGN TEAM METADATA UP TO DATE / ACCURATE. 
In conjunction with the main BEP, a contractors BEP was developed (see Appendix 10). The main purpose of this contractor specification was to consolidate all the elements of the BEP that a contractor needs to know and eliminate the unnecessary information from the original BEP specification.

This "Contractors BIM Specification" is a vetted version of the (design) Building Information Modelling Execution Plan (BEP) to advise the contractor the authorised uses of the BIM, required levels of development, associated information requirements, and responsibility of model element authors during the Construction \& Handover to Operations phases of this project.

This Contractors BIM Specification is a live document that is updated during the project's life cycle to ensure the project remains on schedule, captures technological and methodology advancements and meets the employer's information requirements. All revisions and amendments are communicated with all stakeholders as required. In the version presented below in the table, the asset Meta data requirements were developed and defined.

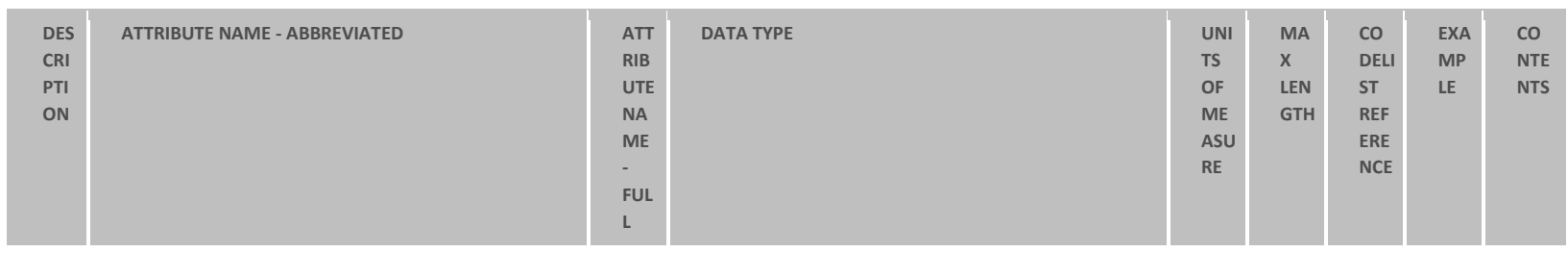

\begin{tabular}{|c|c|c|c|c|c|c|c|c|c|c|c|c|c|c|c|}
\hline \multicolumn{4}{|c|}{ CLASSIFICATION } & \multicolumn{12}{|c|}{ Project Attribute and Validation File Format Instructions } \\
\hline$\frac{\frac{2}{3}}{5}$ & 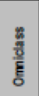 & 耪 & 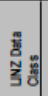 & $\begin{array}{c}\text { Attribute } \\
\text { Name- } \\
\text { Abbreviated }\end{array}$ & $\begin{array}{l}\text { Attribute } \\
\text { Name - Full }\end{array}$ & Data Type & $\begin{array}{l}\text { Units of } \\
\text { measure }\end{array}$ & $\begin{array}{l}\text { Max } \\
\text { Length }\end{array}$ & Comments & Contents & Example & $\begin{array}{l}\text { General } \\
\text { validztion } \\
\text { Rule }\end{array}$ & $\begin{array}{l}\text { Specific Valiastion } \\
\text { Rule }\end{array}$ & $\begin{array}{l}\text { CODELIST } \\
\text { Referenosos }\end{array}$ & 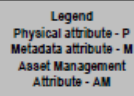 \\
\hline & & & & Permitno & $\begin{array}{l}\text { Pemit } \\
\text { Number }\end{array}$ & $\begin{array}{l}\text { Apphaf } \\
\text { Numenic }\end{array}$ & & $\begin{array}{l}20 \\
\text { chars }\end{array}$ & $\begin{array}{l}\text { No commas } \\
\text { included }\end{array}$ & 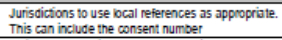 & & 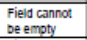 & Defaun $=$ N/A & & м \\
\hline & & & & PermitExp & $\begin{array}{l}\text { Permin Expiry } \\
\text { Date }\end{array}$ & Date & Time & & daimmyyy & $\begin{array}{l}\text { Inocites ne expiry dathe of the peemit or consent } \\
\text { issued }\end{array}$ & 36597 & 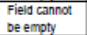 & Defoun $=$ NAA & & м \\
\hline & & & & Projojame & Project Name & $\begin{array}{l}\text { Alpha I } \\
\text { Numenic }\end{array}$ & & $\begin{array}{l}100 \\
\text { chars }\end{array}$ & $\begin{array}{l}\begin{array}{l}\text { No commas } \\
\text { included }\end{array} \\
\end{array}$ & 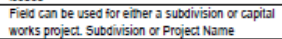 & $\begin{array}{l}\text { Rockbank } \\
\text { Rise }\end{array}$ & $\begin{array}{l}\text { Field cannot } \\
\text { be empty }\end{array}$ & & & M \\
\hline & & & & ProjtTpe & Project type & Apha & & $\begin{array}{l}10 \\
\text { chars }\end{array}$ & $\begin{array}{l}\text { No commas } \\
\text { included }\end{array}$ & Project Type & $\begin{array}{l}\begin{array}{l}\text { Capital } \\
\text { works }\end{array} \\
\text { W }\end{array}$ & $\begin{array}{l}\begin{array}{l}\text { Field cannot } \\
\text { De empoy }\end{array} \\
\end{array}$ & $\begin{array}{l}\text { Entry must De from } \\
\text { CODEUST }\end{array}$ & $\begin{array}{l}\text { Projed } \\
\text { Type }\end{array}$ & м \\
\hline & & & & Design_co & $\begin{array}{l}\text { Design } \\
\text { company }\end{array}$ & $\begin{array}{l}\text { Aphal } \\
\text { Numenic }\end{array}$ & & $\begin{array}{l}100 \\
\text { chars }\end{array}$ & $\begin{array}{l}\text { Nocommas } \\
\text { incluoed }\end{array}$ & Design company name ony & $\begin{array}{l}\text { Frese Charles } \\
\text { and } \\
\text { Associates }\end{array}$ & $\begin{array}{l}\text { Field cannot } \\
\text { De e empty }\end{array}$ & & & м \\
\hline & & & & Plan_No & Plan Number & $\begin{array}{l}\text { Alpha! } \\
\text { Numrencic }\end{array}$ & & $\begin{array}{l}20 \\
\text { chars }\end{array}$ & $\begin{array}{l}\text { Nocommas } \\
\text { incluoed }\end{array}$ & 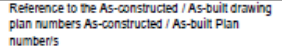 & $6080 \mathrm{R} 212$ & $\begin{array}{l}\text { Field cannor } \\
\text { be emplyt }\end{array}$ & & & м \\
\hline & & & & Constco & $\begin{array}{l}\text { Constuvution } \\
\text { Company }\end{array}$ & $\begin{array}{l}\text { Apha! } \\
\text { Numrenic }\end{array}$ & & $\begin{array}{l}100 \\
\text { chars }\end{array}$ & $\begin{array}{l}\text { Noccommas } \\
\text { incuoved }\end{array}$ & Consinction company name. & $\begin{array}{l}\text { Jamiesson } \\
\text { Construction }\end{array}$ & 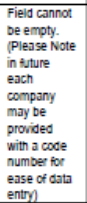 & & & m \\
\hline & & & & B10_Type4 & $\begin{array}{l}\text { Network } \\
\text { Type4 }\end{array}$ & Aphas & & $\begin{array}{l}10 \\
\text { chars }\end{array}$ & $\begin{array}{l}\text { Nocommas } \\
\text { incluoed }\end{array}$ & Netwox Type & $\begin{array}{l}\begin{array}{l}\text { Potable } \\
\text { (Potolite } \\
\text { wateri }\end{array} \\
\end{array}$ & $\begin{array}{l}\text { Field cannot } \\
\text { be e emply }\end{array}$ & $\begin{array}{l}\text { Entry mus be from } \\
\text { CODEUST }\end{array}$ & $\begin{array}{l}\text { Network } \\
\text { Type }\end{array}$ & m \\
\hline
\end{tabular}




\subsubsection{Model Production Delivery Table}

The Model Production Delivery Table (MPDT) specifies the associated data (Asset Meta Data) and the Project Team Members who are required to produce such information after each particular phase (see Appendix 12). The MDPT data specifications are as followed, the instructions were produced by the company in question;

The excel format sheet was developed in line with Uniformat as a classification system within the BIM (Revit model). OMTRAK has three classification columns. Uniformat, OMTrak ref, SAP ref* to cross reference the various systems used. Uniformat descriptions displayed below. *The reason for the SAP reference is to align the BIM process with the client's current asset management tool.

Within WebFM (Columns) G, H, I to match Uniformat 1-3 levels

- Column G (Service Name) = Uniformat Level $1(\mathrm{~A})$

- Column H (Subservice Code) = Uniformat Level 2 (A10)

- Column I (Subservice Name) = Uniformat Level 3 (A1010)

2. BIM (Revit model) is to provide geometric data (size, shape), unique ID and location (where is "it") OMTRAK is to hold all metadata and copies of the BIM required by the client.

3. OMTRAK will provide "information exchange" directly to the client/SAP

- Columns F-J = UniFormat Level is a standard for classifying building specifications- see the UniFormat descriptions Columns AA-AM (Design team Metadata (Information Requirements) $=$ Information the design team are responsible for populating at the detailed design phase.

- Columns AO-AP (Design Team Model) = The LOD required to be authored by the model element authors (MEA)* after the detailed design phase

- Columns AU-AB (Construction team Metadata) = Information the Construction team are responsible for populating after the construction phase. Nb. This includes updating the information populated by the design team (Columns AA-AM). 
- Columns BE-BF (Handover site verified model) $=$ The LOD required to be authored by the model element authors (refer to Stake holder discipline codes)

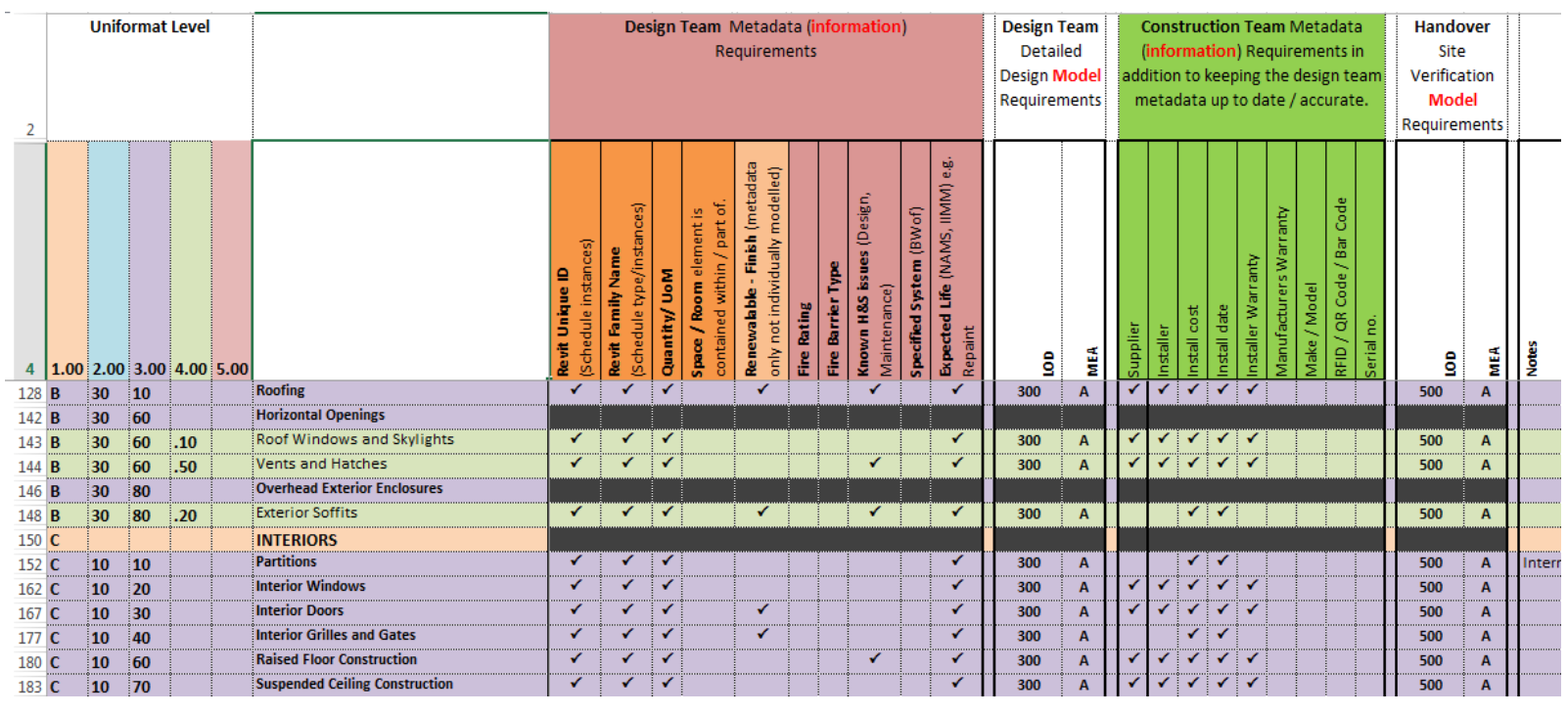

Table 15: Excel Spreadsheet Model Production Delivery Table

- Row 4 as shown in figure 15 schedules the UniFormat Levels, Metadata (information) requirements, delineates the Level of Development (LOD) and Model Element Authors (refer to these documents for more detail).

- Various UniFormat levels are intentionally excluded as they do not exist on this project or are at a level of granularity that is not required (rows 7-20)

- When sections are dark filled they are to illustrate the context only and/or are illustrating that they have been considered but not required i.e. rows 37-44

- When a tick is illustrated this indicates that this particular element requires the associated metadata (information) fields to be populated (in OMTRAK), this was indicated by the project team, based on the information gathered from the LOD specification

- The Handover Site verified columns (BE-BF) outlines the required LOD of all model elements which are to be 'site verified' before the model is handed over to the building owner. The main contractor to undertake the validation, Model Element Author (MEA) to undertake the model amendments

- The project team carried out a quality check to identify various elements with particular attention to items such as D2030 Storm water drainage equipment not needing to be modelled (LOD 100) and the information will be in the form of 2D information. 
- After detailed design "ARC" must author a LOD 300 representation of this model element

- $\quad \mathrm{ARC} / \mathrm{STR}$ indicated that $\mathrm{ARC}$ is the primary MEA, however this table is acknowledging reliance on STR fir design information

- There is no requirement for LOD 350 or LOD 400 - see written report for parameters around this.

- After handover the contractor is to confirm that the model element "stairs" has been fabricated as per the LOD 300* representation of the model provided by ARC. If geometric variations to the element have occurred during construction that fit within the definitions of LOD 300 then the MEA (ARC) will be responsible for updating the BIM with information provided by the contractor.

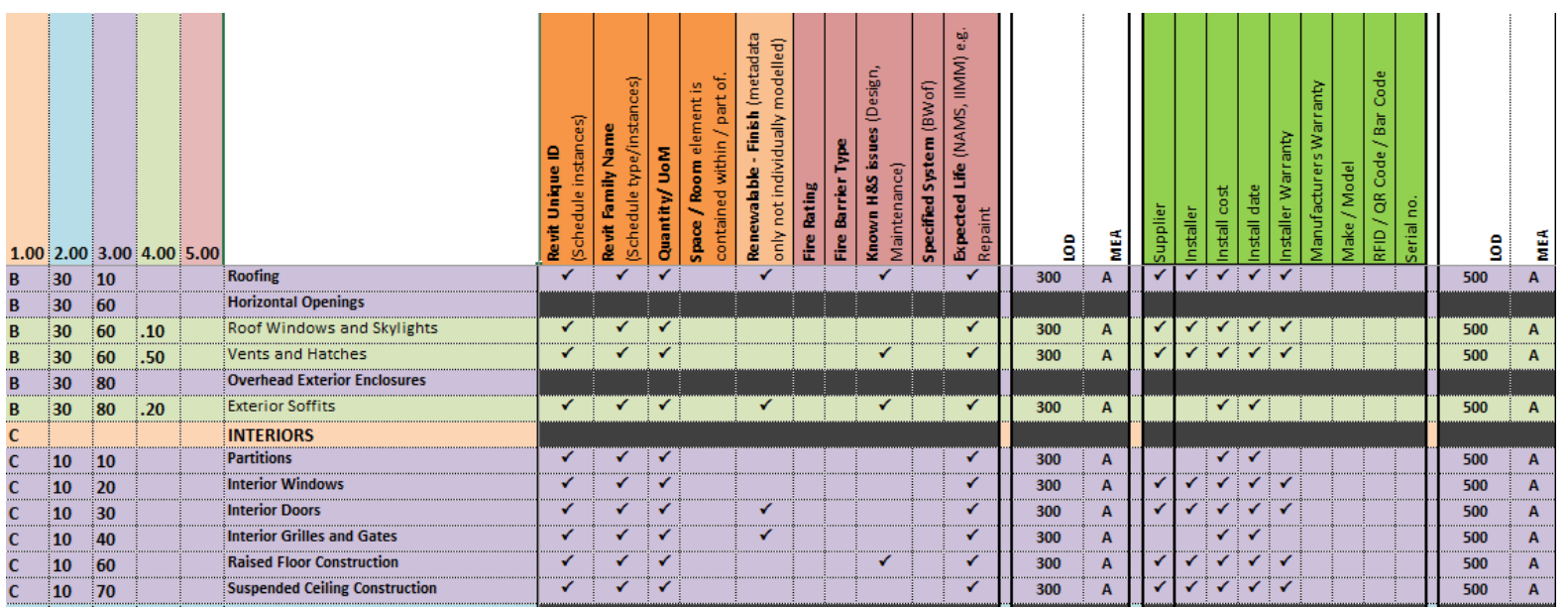

Table 16: Excel Spreadsheet MPDT Design and Contractor

The tick indicates the following metadata is required:

- Revit Globally Unique Identifier

- Revit Family Name

- Unit of Measure (Qty/m2)

- Room contained within (Room Naming Schedule)

- Renewable Finish (metadata only not individually modelled)

- Supplier

- Installer

- Install Cost

- Total Install Cost Sum Required 
- Install Date

- Installer Warranty

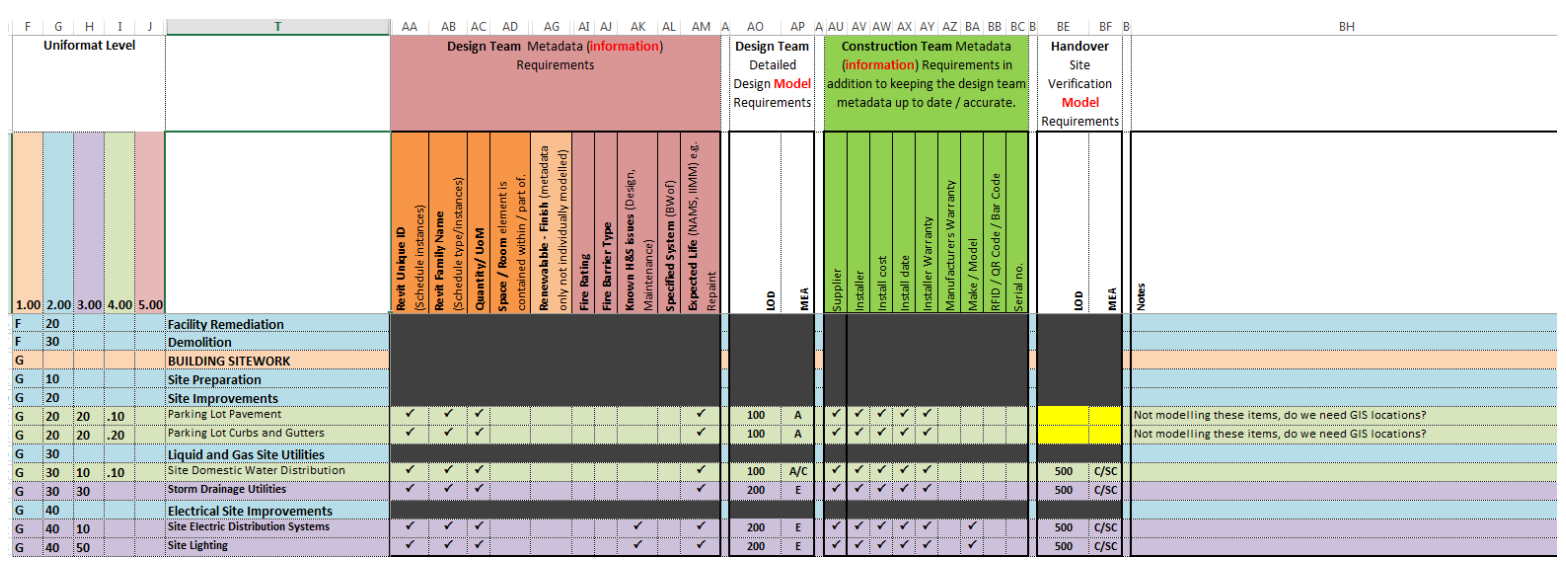

Table 17: Excel Spreadsheet data requirements

As shown in table 17 there are over 400 lines of data requirements and elements presented in this table that represents the entire Whenuapai Gymnasium. When rows are greyed out but still have an LOD indicated this means that there is a digital model of the element but not associated metadata. When rows are greyed out entirely as shown above, they are included to show context.

Metadata items in red such as Maint_Period are not in the NZAMS standard but created as required for example being specialised to the project, items in green are included in the NZAMS standard but modified to the project.

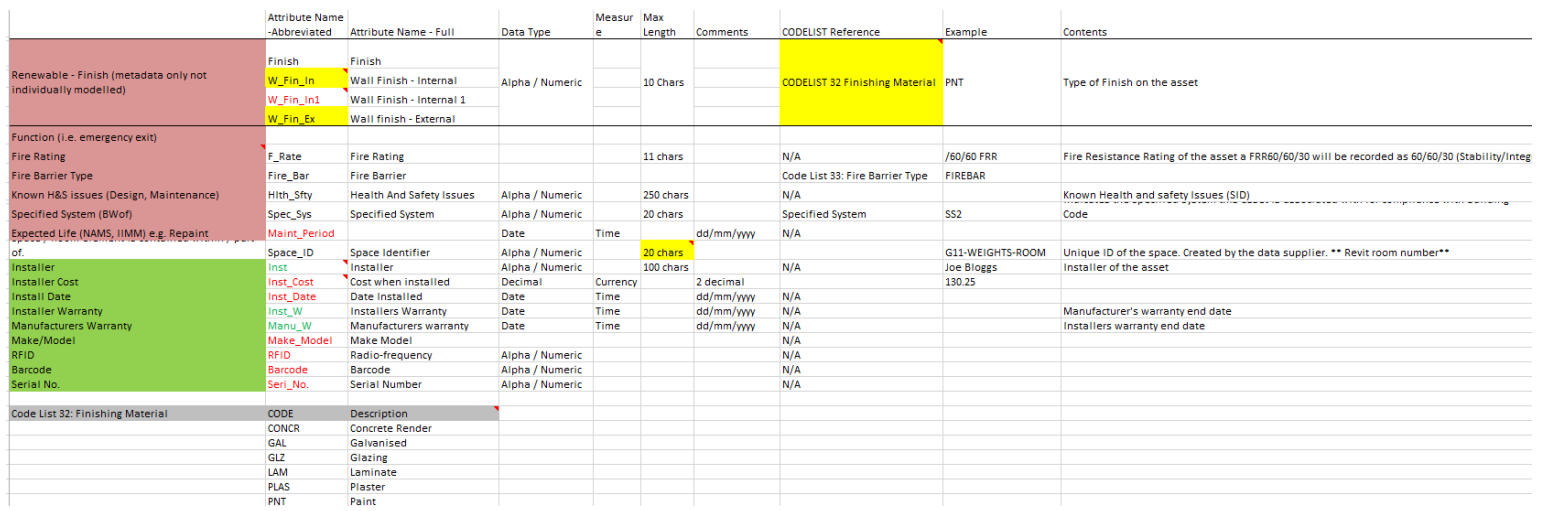

Table 18: Metadata spreadsheet

OMTRAK/WebFM advises the following metadata is typical on other projects including:

- Validation

- $\quad$ Asset ID 
- Asset Description

- Service Name

- Sub service code

- $\quad$ Site

- Structure

- Level

- Space

- Reference information

- Make

- Serial Number

- Model

- Quantity

- Retail price $\$$

- Install Date

- Wty Expiry Date

Requirements of the NZDF advise the base level metadata:

- Cost

- Quantity

- UOM- Unit of Measure

- Useful life

- Manufacturer

- Make

- Model

- $\quad$ Serial No

- Characteristic 1 - additional metadata requirements for specific elements

The Model Element Author (MEA) as per the project stages in the MPDT is responsible for updating the associated Asset Meta data requirements shown below during the stages that they are the responsible MEA. The asset data required is defined by the AM/FM that will be responsible for the operation and maintenance of the gymnasium following construction. In order to ensure a LOD 500 element model is achieved at construction hand 
over metadata requirements were aligned to certain disciplines to ensure the model was up to date and are as followed:

Design team metadata requirement:

- Renewable finishes

- $\quad$ Fire rating

- $\quad$ Fire barrier type

- Known H\&S systems

- $\quad$ Specified systems

- $\quad$ Expected life

\begin{tabular}{|c|c|c|c|c|c|c|c|c|}
\hline Description & $\begin{array}{l}\text { Attribute Name - } \\
\text { Abbreviated }\end{array}$ & Attribute Name - Full & Data Type & Units of Measure & Max Length & $\begin{array}{l}\text { CODELIST } \\
\text { Reference }\end{array}$ & Example & Contents \\
\hline \multicolumn{9}{|c|}{ Design Team Metadata (information) Requirements } \\
\hline $\begin{array}{l}\text { Room } \\
\text { Contained } \\
\text { Within }\end{array}$ & Space_ID & Space Identifier & Alpha / Numeric & N/A & 20 chars & N/A & $\begin{array}{l}\text { G11-WEIGHTS- } \\
\text { ROOM }\end{array}$ & $\begin{array}{l}\text { Unique ID of the space- } \\
\text { Revit Room Naming }\end{array}$ \\
\hline \multirow[t]{4}{*}{$\begin{array}{l}\text { Renewal able } \\
\text { - Finish }\end{array}$} & Finish & Finish & \multirow[t]{4}{*}{ Alpha / Numeric } & \multirow[t]{4}{*}{$\mathrm{m} 2$} & \multirow[t]{4}{*}{10 Chars } & \multirow[t]{4}{*}{$\begin{array}{l}\text { CODELIST } 32 \\
\text { Finishing Material }\end{array}$} & \multirow[t]{4}{*}{ PNT } & \multirow[t]{4}{*}{$\begin{array}{l}\text { Metadata only not } \\
\text { individually modelled }\end{array}$} \\
\hline & W_Fin_In & Wall Finish - Internal & & & & & & \\
\hline & W_Fin_In1 & Wall Finish - Internal 1 & & & & & & \\
\hline & W_Fin_Ex & Wall finish - External & & & & & & \\
\hline Fire Rating & F_Rate & Fire Rating & Alpha / Numeric & N/A & 11 chars & N/A & /60/60 FRR & $\begin{array}{l}\text { Fire Resistance Rating of } \\
\text { the asset a FRR60/60/30 } \\
\text { will be recorded as } \\
60 / 60 / 30 \text { (Stabilityl } \\
\text { Integrity/ Insulation) }\end{array}$ \\
\hline $\begin{array}{l}\text { Fire Barrier } \\
\text { Type }\end{array}$ & Fire_Bar & Fire Barrier & Alpha / Numeric & $\mathrm{N} / \mathrm{A}$ & - & $\begin{array}{l}\text { Code List 33: Fire } \\
\text { Barrier Type }\end{array}$ & FIREBAR & - \\
\hline $\begin{array}{l}\text { Known H\&S } \\
\text { issues }\end{array}$ & HIth_Sfty & $\begin{array}{l}\text { Health And Safety } \\
\text { Issues }\end{array}$ & Alpha / Numeric & $\mathrm{N} / \mathrm{A}$ & 250 chars & N/A & & Safety In Design \\
\hline $\begin{array}{l}\text { Specified } \\
\text { System }\end{array}$ & Spec_Sys & Specified System & Alpha / Numeric & $\mathrm{N} / \mathrm{A}$ & 20 chars & $\begin{array}{l}\text { Code List } 83: \\
\text { Specified System } \\
\text { Type }\end{array}$ & SS2 & $\begin{array}{l}\text { Indicates the Specified } \\
\text { System this assetis } \\
\text { associated with for } \\
\text { compliance with Building } \\
\text { Code. }\end{array}$ \\
\hline
\end{tabular}

Table 19: Metadata spreadsheet

Construction team metadata requirements:

- Supplier

- Installer

- Install cost

- Install date

- Installer warranty

- Manufacturer warranty

- Make/model

- RFID 
- Barcode

- Serial number

\begin{tabular}{|c|c|c|c|c|c|c|c|c|}
\hline Expected Life & Maint_Period & & Date & Time & - & N/A & $\mathrm{dd} / \mathrm{mm} / \mathrm{yyyy}$ & NAMS, IIMM \\
\hline \multicolumn{9}{|c|}{ Construction Team Metadata (information) Requirements in addition to keeping the design team metadata up to date / accurate. } \\
\hline Supplier & Supp & Supplier & Alpha / Numeric & N/A & - & N/A & - & - \\
\hline Installer & Inst & Installer & Alpha / Numeric & N/A & - & N/A & - & - \\
\hline Install Cost & Inst_Cost & Costwhen installed & Decimal & Currency & - & N/A & - & - \\
\hline Install Date & Inst_Date & Date Installed & Date & Time & - & N/A & - & - \\
\hline $\begin{array}{l}\text { sinstaller } \\
\text { Warranty }\end{array}$ & Inst_W & Installers Warranty & Date & Time & - & N/A & - & - \\
\hline $\begin{array}{l}\text { Manufacturer } \\
\text { Warranty }\end{array}$ & Manu_W & Manufacturer warranty & Date & Time & - & N/A & - & - \\
\hline Make/Model & Make_Model & Make Model & Alpha / Numeric & N/A & - & N/A & - & - \\
\hline $\begin{array}{l}\text { Reference } \\
\text { Code }\end{array}$ & Inst_W & Installers Warranty & Date & Time & - & N/A & - & - \\
\hline
\end{tabular}

Table 20: Metadata spreadsheet

\subsubsection{New Zealand Metadata Standards}

For this project the asset data associated with the model aligns with the New Zealand Asset metadata standard as defined above (this was a requirement of the clients' project deliverables) (see Appendix 7). The table below defines the Asset Meta Data Requirements for the BIM model for the ongoing asset and facility management utilisation of the project. The Model Element Author (MEA) as per the project stages in the MPDT (defined above) is responsible for updating the associated Asset Meta data requirements shown below where applicable. For example, the design team may specify a $1200 * 60$ vanity for the bathroom, the contractor would then install at his discretion a vanity of the size and the contractor would be responsible in updating the details, this being the manufacturer's information and the likes. The asset data inputs are defined in the BEP, acknowledging who will be responsible for inputting this data for the operation and maintenance of the gymnasium prior to, during and following construction. 


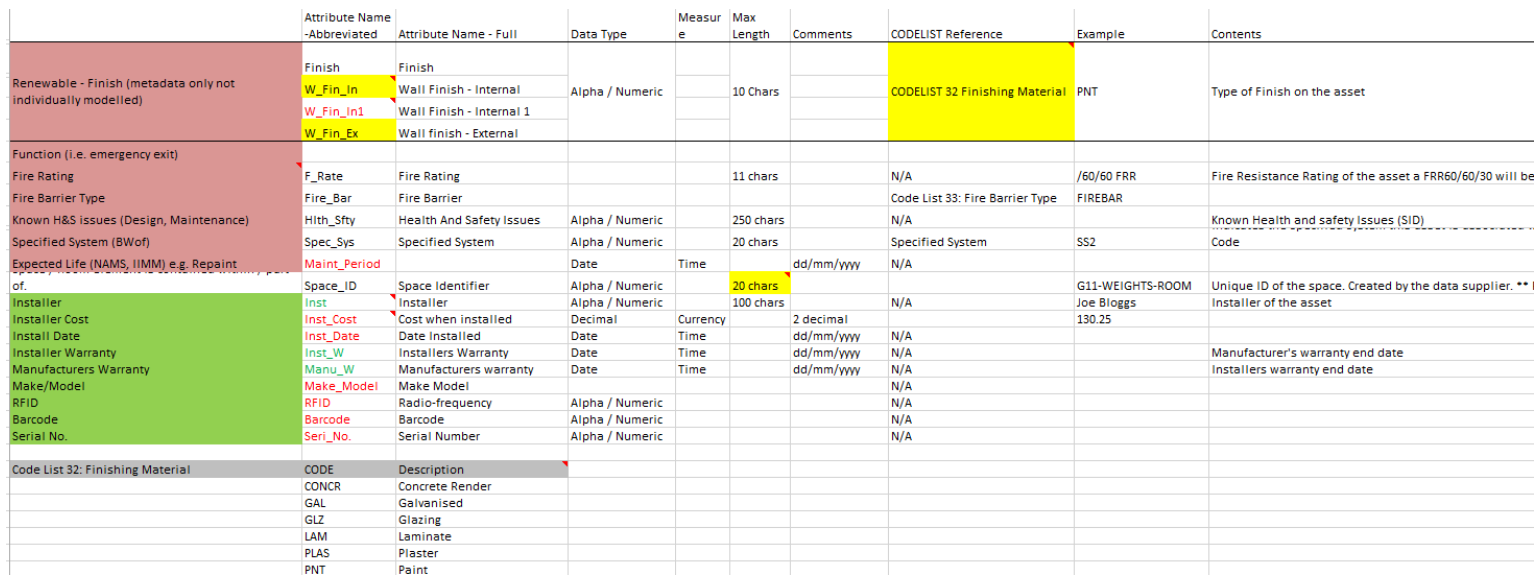

Table 21: Metadata spreadsheet

With the asset metadata spreadsheet is important to acknowledge as the common issue associated with the process of BIM to date is contractors use of BIM. More commonly contractors do not have the capability in design modelling to implement the data needed within the model. The example from above again a vanity of $1200 \times 600$ is specified by the design team, the contractor has chosen to install an Athena vanity wall hung and two taps, this information needs to be represented in the BIM model, the contractor fills the spreadsheet above in with this information in the required format this then be pushed back into the BIM model.

\begin{tabular}{|c|c|c|c|c|c|c|c|c|}
\hline Description & $\begin{array}{l}\text { Attribute Name - } \\
\text { Abbreviated }\end{array}$ & Attribute Name - Full & Data Type & Units of Measure & Max Length & $\begin{array}{l}\text { CODELIST } \\
\text { Reference }\end{array}$ & Example & Contents \\
\hline \multicolumn{9}{|c|}{ Design Team Metadata (information) Requirements } \\
\hline $\begin{array}{l}\text { Room } \\
\text { Contained } \\
\text { Within }\end{array}$ & Space_ID & Space Identifier & Alpha/ Numeric & N/A & 20 chars & N/A & $\begin{array}{l}\text { G11-WEIGHTS- } \\
\text { ROOM }\end{array}$ & $\begin{array}{l}\text { Unique ID of the space - } \\
\text { Revit Room Naming }\end{array}$ \\
\hline \multirow[t]{4}{*}{$\begin{array}{l}\text { Renewal able } \\
\text { - Finish }\end{array}$} & Finish & Finish & \multirow[t]{4}{*}{ Alpha / Numeric } & \multirow[t]{4}{*}{$\mathrm{m} 2$} & \multirow[t]{4}{*}{10 Chars } & \multirow[t]{4}{*}{\begin{tabular}{|l|} 
CODELIST 32 \\
Finishing Material
\end{tabular}} & \multirow[t]{4}{*}{ PNT } & \multirow[t]{4}{*}{$\begin{array}{l}\text { Metadata only not } \\
\text { individually modelled }\end{array}$} \\
\hline & W_Fin_In & Wall Finish - Internal & & & & & & \\
\hline & W_Fin_In 1 & Wall Finish-Internal 1 & & & & & & \\
\hline & W_Fin_Ex & Wall finish-External & & & & & & \\
\hline Fire Rating & F_Rate & Fire Rating & Alpha / Numeric & N/A & 11 chars & N/A & $160 / 60 \mathrm{FRR}$ & $\begin{array}{l}\text { Fire Resistance Rating of } \\
\text { the asset a FRR60/60/30 } \\
\text { will be recorded as } \\
60 / 60 / 30 \text { (Stability/ } \\
\text { Integrity/ Insulation) }\end{array}$ \\
\hline $\begin{array}{l}\text { Fire Barrier } \\
\text { Type }\end{array}$ & Fire_Bar & Fire Barrier & Alpha / Numeric & N/A & - & $\begin{array}{l}\text { Code List 33: Fire } \\
\text { Barrier Type }\end{array}$ & FIREBAR & - \\
\hline $\begin{array}{l}\text { Known H\&S } \\
\text { issues }\end{array}$ & HIth_Sfty & $\begin{array}{l}\text { Health And Safety } \\
\text { Issues }\end{array}$ & Alpha / Numeric & $\mathrm{N} / \mathrm{A}$ & 250 chars & $\mathrm{N} / \mathrm{A}$ & & Safety In Design \\
\hline $\begin{array}{l}\text { Specified } \\
\text { System }\end{array}$ & Spec_Sys & Specified System & Alpha / Numeric & N/A & 20 chars & $\begin{array}{l}\text { Code List 83: } \\
\text { Specified System } \\
\text { Type }\end{array}$ & Ss2 & $\begin{array}{l}\text { Indicates the Specified } \\
\text { System this assetis } \\
\text { associated with for } \\
\text { compliance with Building } \\
\text { Code. }\end{array}$ \\
\hline
\end{tabular}




\begin{tabular}{|c|c|c|c|c|c|c|c|c|}
\hline Expected Life & Maint_Period & & Date & Time & - & N/A & $\mathrm{dd} / \mathrm{mm} / \mathrm{yyyy}$ & NAMS, IIMM \\
\hline \multicolumn{9}{|c|}{ Construction Team Metadata (information) Requirements in addition to keeping the design team metadata up to date / accurate. } \\
\hline Supplier & Supp & Supplier & Alpha / Numeric & N/A & - & N/A & - & - \\
\hline Installer & Inst & Installer & Alpha / Numeric & N/A & - & N/A & - & - \\
\hline Install Cost & Inst_Cost & Costwhen installed & Decimal & Currency & - & N/A & - & - \\
\hline Install Date & Inst_Date & Date Installed & Date & Time & - & N/A & - & - \\
\hline $\begin{array}{l}\text { sinstaller } \\
\text { Warranty }\end{array}$ & Inst_W & Installers Warranty & Date & Time & - & N/A & - & - \\
\hline $\begin{array}{l}\text { Manufacturer } \\
\text { Warranty }\end{array}$ & Manu_W & Manufacturer warranty & Date & Time & - & N/A & - & - \\
\hline Make/Model & Make_Model & Make Model & Alpha/ Numeric & N/A & - & N/A & - & - \\
\hline $\begin{array}{l}\text { Reference } \\
\text { Code }\end{array}$ & Inst_W & Installers Warranty & Date & Time & - & N/A & - & - \\
\hline
\end{tabular}

Table 22: Metadata spreadsheet

The New Zealand Asset Metadata standard was developed to outline the specification for the delivery of digital data on elements associated to the building. The standard presents various formats that data may be delivered. Digital data files are to be provide through email, portable devices or cloud mediums (drop box). The standard describes and defines the data required and outlines the definitions, logic and foundations. The level of data includes three attributes, physical (material/diameter), metadata (construction) and asset management (condition).

The standard defines 103 different element types from wall materials to security asset type and door functions. Each element type falls into one of 26 data tables. The data table provides specific details for each element, an example of the roof attributes is defined below: 
Data Table 8: Roof Attribute and Validation File Format Instructions

\begin{tabular}{|c|c|c|c|c|c|c|c|c|c|c|c|}
\hline \multicolumn{12}{|c|}{ Roof Attributs and Validation File Format Instructions } \\
\hline $\begin{array}{l}\text { Attribute } \\
\text { Namme- } \\
\text { Abbreviated }\end{array}$ & $\begin{array}{l}\text { Attribute Name } \\
\text { - Full }\end{array}$ & $\begin{array}{l}\text { Data } \\
\text { Type }\end{array}$ & $\begin{array}{l}\text { Units of } \\
\text { Messure }\end{array}$ & $\begin{array}{l}\text { Max } \\
\text { Length }\end{array}$ & Comments & Contents & Example & $\begin{array}{c}\text { Goneral } \\
\text { Validation } \\
\text { Rulo }\end{array}$ & $\begin{array}{l}\text { Specific Validation } \\
\text { Rule }\end{array}$ & $\begin{array}{l}\text { CODELIST } \\
\text { References }\end{array}$ & $\begin{array}{c}\text { Legend } \\
\text { Physical attribute }-P \\
\text { Metadata attribute }- \text { M } \\
\text { Asset Management } \\
\text { Attribute - AMM }\end{array}$ \\
\hline Unique JD & Unique Idensfier & $\begin{array}{l}\text { Alphal } \\
\text { Numeric }\end{array}$ & & $\begin{array}{l}20 \\
\text { chars }\end{array}$ & $\begin{array}{l}\text { No commas } \\
\text { included }\end{array}$ & $\begin{array}{l}\text { Unique ID of the asset. Created by the data } \\
\text { supplier. }\end{array}$ & & $\begin{array}{l}\text { Field cannot } \\
\text { be empty }\end{array}$ & $\begin{array}{l}\text { If asset owner } \\
\text { provides in then this } \\
\text { must be used. }\end{array}$ & & 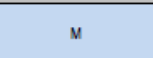 \\
\hline Build_ID & $\begin{array}{l}\text { Builana } \\
\text { Identffer }\end{array}$ & $\begin{array}{l}\text { Alshal } \\
\text { Numeric }\end{array}$ & & $\begin{array}{l}20 \\
\text { chars }\end{array}$ & $\begin{array}{l}\text { No commas } \\
\text { included }\end{array}$ & $\begin{array}{l}\text { Uniaue ID of the buildina. Created by the data } \\
\text { supplier. }\end{array}$ & 034517 & $\begin{array}{l}\text { Field cannot } \\
\text { be empty }\end{array}$ & $\begin{array}{l}\text { If asset owner } \\
\text { provides it then this } \\
\text { must be used. }\end{array}$ & & $\mathrm{M}$ \\
\hline Area & Area & Decimal & $\begin{array}{l}\text { Square } \\
\text { metres }\end{array}$ & wa & $\begin{array}{l}2 \text { decimal } \\
\text { places }\end{array}$ & Gross Area of the asset in square metres $\left(\mathrm{m}^{2}\right)$. & 5738.25 & 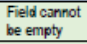 & Default $=-9999.99$ & & $\mathrm{P}$ \\
\hline Lood_Wind & $\begin{array}{l}\text { Wind Load } \\
\text { Rating }\end{array}$ & Decimal & $\begin{array}{l}\text { Kilonewt } \\
\text { ons per } \\
\text { square } \\
\text { metre } \\
\left(\mathrm{kNm} \mathrm{m}^{\mathrm{q}}\right)\end{array}$ & wa & $\begin{array}{l}2 \text { decimal } \\
\text { places }\end{array}$ & Wind load rating of asset & & $\begin{array}{l}\text { Field cannot } \\
\text { be empty }\end{array}$ & Default $=-9999.99$ & & M \\
\hline Lood_Fix & $\begin{array}{l}\text { Fixed Laad } \\
\text { Rating }\end{array}$ & Decimal & $\begin{array}{l}\text { Konowewt } \\
\text { ons ser } \\
\text { square } \\
\text { metre } \\
\left(k N m^{2}\right)\end{array}$ & wa & $\begin{array}{l}2 \text { decimal } \\
\text { places }\end{array}$ & Fixed load rating of asset & & $\begin{array}{l}\text { Field cannot } \\
\text { be empty }\end{array}$ & Default $=-.9999 .99$ & & $\mathrm{M}$ \\
\hline Const_Type & $\begin{array}{l}\text { Roof } \\
\text { Construction } \\
\text { Type }\end{array}$ & $\begin{array}{l}\text { Alphal } \\
\text { Numeric }\end{array}$ & & $\begin{array}{l}10 \\
\text { chars }\end{array}$ & $\begin{array}{l}\text { No commas } \\
\text { inclused }\end{array}$ & Indicates the Type of Construction & Skillion & $\begin{array}{l}\begin{array}{l}\text { Field cannot } \\
\text { be emply }\end{array}\end{array}$ & $\begin{array}{l}\text { Entry must be from } \\
\text { CODELIST }\end{array}$ & $\begin{array}{l}\text { Roof } \\
\text { Construction } \\
\text { Type } \\
\end{array}$ & $\mathrm{P}$ \\
\hline Root_Struc & $\begin{array}{l}\text { Roof Structure } \\
\text { Type }\end{array}$ & $\begin{array}{l}\text { Alphal } \\
\text { Numeric }\end{array}$ & & $\begin{array}{l}10 \\
\text { chars }\end{array}$ & $\begin{array}{l}\text { No commas } \\
\text { included }\end{array}$ & Indicates the Type of Framing & Truss & $\begin{array}{l}\text { Field cannot } \\
\text { be empty }\end{array}$ & $\begin{array}{l}\text { Entry must be from } \\
\text { CODELIST }\end{array}$ & $\begin{array}{l}\text { Roof } \\
\text { Structure } \\
\text { Type }\end{array}$ & $\mathrm{P}$ \\
\hline Frame_Mat & Frame Matenial & $\begin{array}{l}\text { Alshal } \\
\text { Numeric }\end{array}$ & & $\begin{array}{l}10 \\
\text { chars }\end{array}$ & $\begin{array}{l}\text { No commass } \\
\text { included }\end{array}$ & Frame nuterial of the asset & & 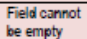 & $\begin{array}{l}\text { Entry must be from } \\
\text { CODELIST }\end{array}$ & $\begin{array}{l}\text { Frame } \\
\text { Material }\end{array}$ & $P$ \\
\hline Frame_Tr & $\begin{array}{l}\text { Frame } \\
\text { Treatment }\end{array}$ & $\begin{array}{l}\text { Alphal } \\
\text { Numeric }\end{array}$ & & $\begin{array}{l}10 \\
\text { chars }\end{array}$ & $\begin{array}{l}\text { No commas } \\
\text { included }\end{array}$ & Indicates the treatment applied to the Frame & & $\begin{array}{l}\text { Fieldid cannot } \\
\text { be emply }\end{array}$ & $\begin{array}{l}\text { Entry must be from } \\
\text { CODELIST }\end{array}$ & $\begin{array}{l}\text { Frame } \\
\text { Treatment }\end{array}$ & $\mathrm{P}$ \\
\hline Frame_Sp & Frame Spacing & Integer & $\begin{array}{l}\text { Millmetre } \\
\text { s }\end{array}$ & w/a & $\begin{array}{l}\begin{array}{l}\text { Whole } \\
\text { millimetres }\end{array} \\
\end{array}$ & The spacing bewween the frames & & $\begin{array}{l}\begin{array}{l}\text { Field cannot } \\
\text { be emply }\end{array} \\
\end{array}$ & Default $=-9999$ & & P \\
\hline Pid__Spk & Pidgeon Spkes & Alpha & & 1 char & Yes or No feld & Are Pidgeon Spiked fitted? & & 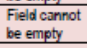 & Valid input: $Y, N$ & & $\mathrm{p}$ \\
\hline Pitch & $\begin{array}{l}\text { Pitch of The } \\
\text { Roof }\end{array}$ & Integer & Degrees & wa & Whole degrees & Indicates the angle of the Pitch & & $\begin{array}{l}\text { Field cannot } \\
\text { be emply }\end{array}$ & Default $=-9999$ & & $\mathrm{p}$ \\
\hline
\end{tabular}

Table 23: New Zealand Asset Metadata data table

The document is structured in a way that is easy to follow and includes various elements, as well as this a coding system has been developed for a common language approach as shown below:

The 2017 version is only a draft version and is expected to be reviewed as necessary by the National Infrastructure Unit.

Table 24: New Zealand Asset Metadata code list

Code List 77: Reinforcement Material
\begin{tabular}{|l|l|}
\hline Code & Description \\
\hline BRASS & Brass \\
\hline BRK & Brick \\
\hline CORK & Cork \\
\hline FBE & Fusion Bonded Epoxy \\
\hline GUNN & Gunnite \\
\hline HARD & Hardiplank \\
\hline HBD & Hard Board \\
\hline HG & Helicore Galvanised \\
\hline LAM & Laminate \\
\hline MARB & Marble \\
\hline
\end{tabular}

Code List 78: Reinforcement Type

\begin{tabular}{|l|l|}
\hline Code & Description \\
\hline ATCLV & Autoclave \\
\hline MOLD & Mold \\
\hline PRS & Pressure \\
\hline
\end{tabular}

Code List 79: Roof Construction Type

\begin{tabular}{|l|l|}
\hline Code & Description \\
\hline OGABLE & Open Gable \\
\hline SKL & Skillion \\
\hline
\end{tabular}

\subsubsection{Innovation of use of metadata}

Metadata associated with the models, see Appendix 14, the schedule is exported based on the Contractors BEP. The term specified system is associated with the compliance building code BWOF, this allows regular building systems to be inspected in the annual compliances (every commercial building is required to have an annual building inspection). As per the New Zealand Building performance standard, a building owner needs to renew a building warrant of fitness every 12 months signing, issuing and publicly displaying it to the public as proof that 
building life safety systems have been maintained and inspected (Building Performance NZ). Under the Building Act 2004, all buildings (other than residential) require a compliance schedule and annual warrant of fitness. This defines the systems in a building that need to be operated and maintained. For new builds when a building is presented with a consent the local council will issue a compliance schedule. The metadata associated with the gymnasium will match the compliance schedule for a BWOF in regard to naming conventions. An issue that could possibly arise in this situation is that the council presents the compliance schedule during the consenting process which comes after the design team have documented the majority of the data. The design team must ensure that the correct compliance schedule information is assigned to the BIM model. There may need to be a QA check before construction once consent has been approved and the compliance schedule is assigned to ensure both the model and schedules align.

Quality assurance on the associated data within the model shows some discrepancies and some double ups of the modelling parameters, multiple data fields showing the same information as shown below, this was picked up on and needs to be consolidated to only show one. Quality assurance is achieved by implementing the SOLIBRI tool (see description below).

\begin{tabular}{|c|c|c|c|c|c|c|c|c|}
\hline Description & $\begin{array}{l}\text { Attribute Name - } \\
\text { Abbreviated }\end{array}$ & $\begin{array}{l}\text { Attribute Name - } \\
\text { Full }\end{array}$ & Data Type & $\begin{array}{l}\text { Units of } \\
\text { Measure }\end{array}$ & Max Length & CODELIST Reference & Example & Contents \\
\hline Specified System & Spec_Sys & Specified System & $\begin{array}{l}\text { Alpha / } \\
\text { Numeric }\end{array}$ & N/A & 10 chars & $\begin{array}{l}\text { Code List 84: Specified } \\
\text { System Type }\end{array}$ & ss2 & $\begin{array}{l}\text { Indicates the } \\
\text { Specified System } \\
\text { this asset is } \\
\text { associated with for } \\
\text { compliance with } \\
\text { Building Code. }\end{array}$ \\
\hline
\end{tabular}

Figure 33: Naming convention asset Meta data spreadsheet 


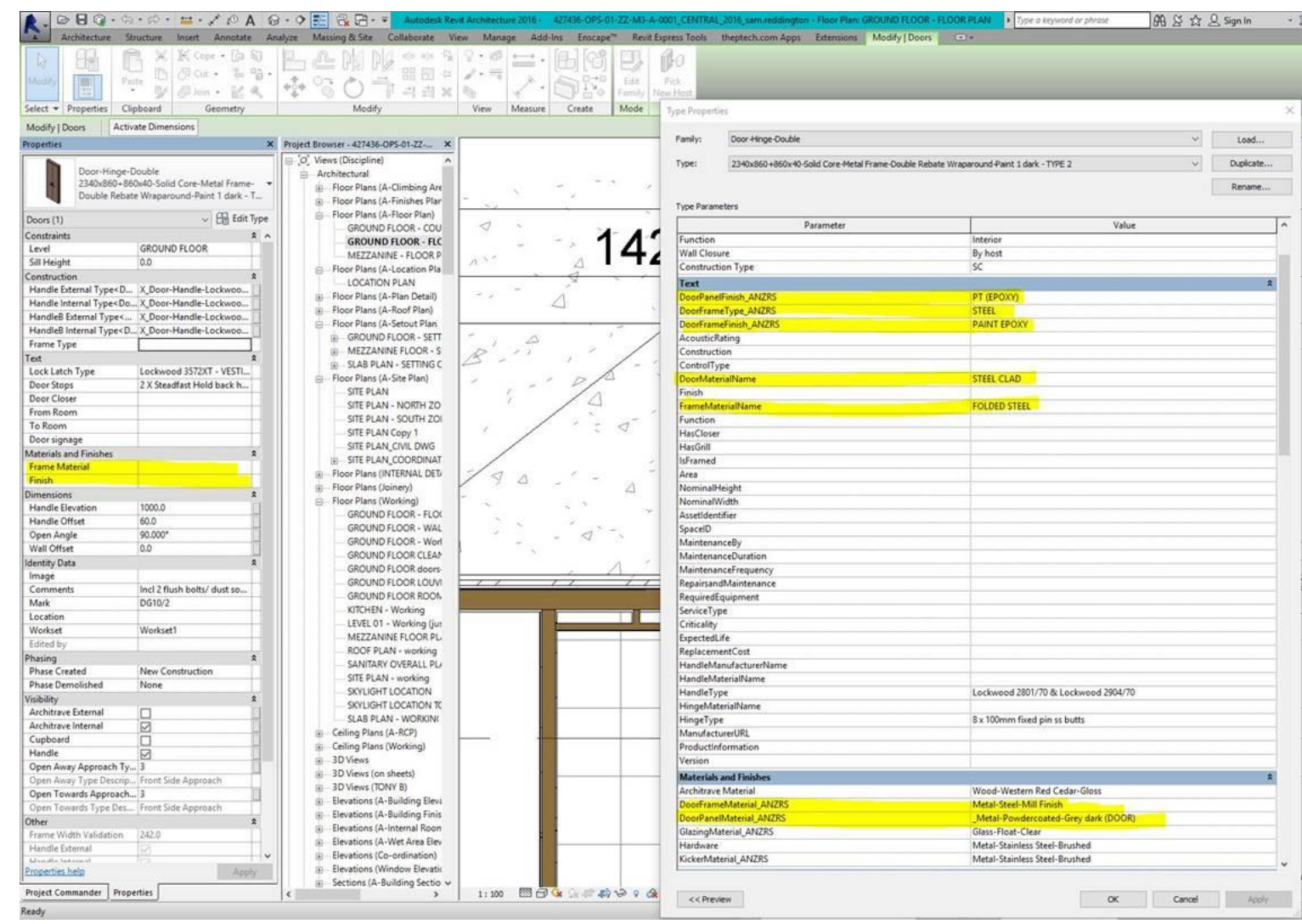

Figure 34: Solibiri Model Checker example

Solibri has produced three products, a model checker, a model viewer and IFC optimizer. For the gymnasium project the design team utilise the Solibri Model Checker. The main purpose of this tool is to provide an advanced clash detection tool that automatically analyses group clashes in terms of severity. Ultimately the tool finds problems quickly and easily and investigates the quality of the BIM files. 


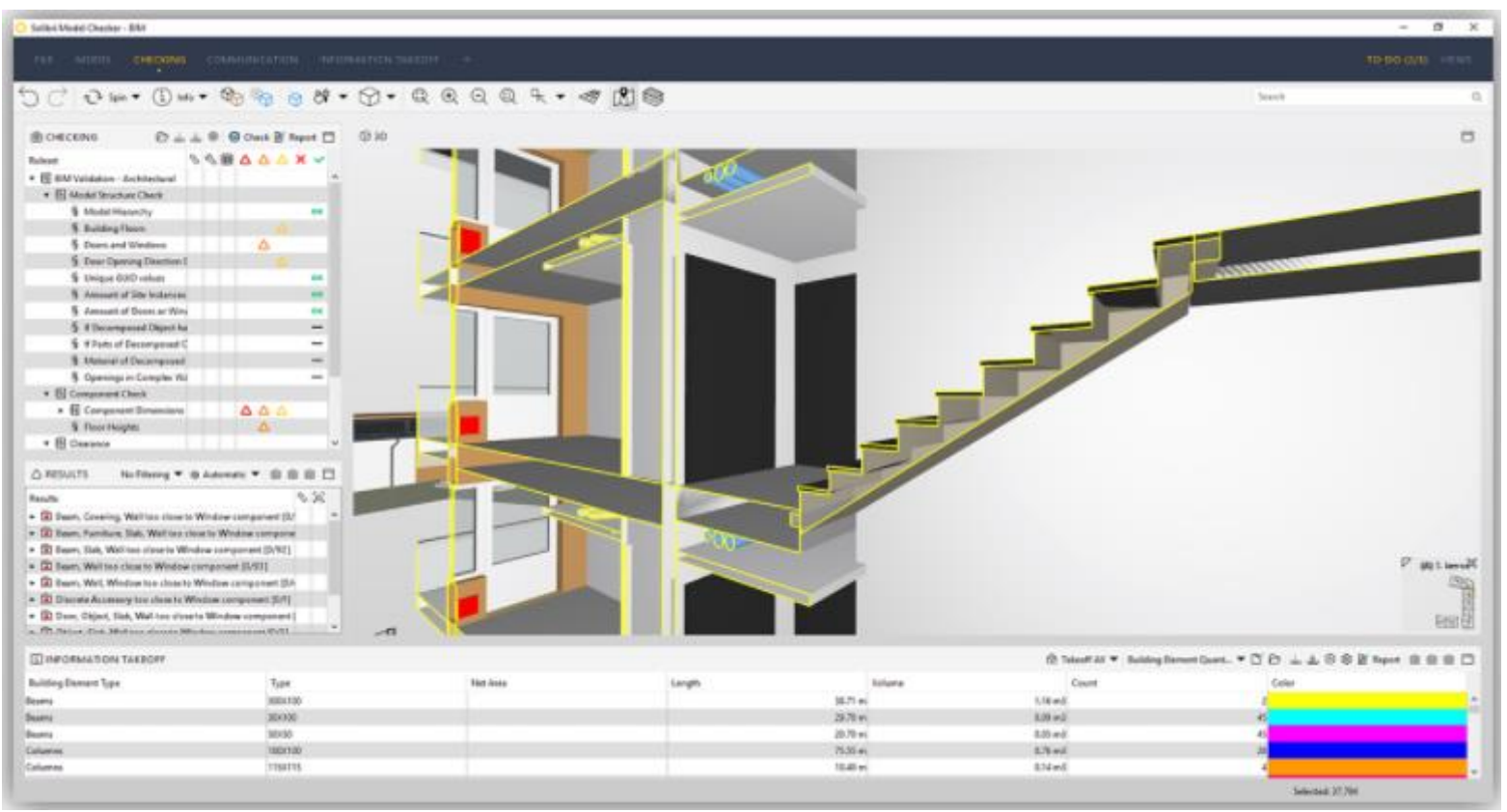

Figure 35: Solibiri Model Checker example

The Solibri tool allows two models made by different design teams to locate flaws across the two to ultimately avoid rework.

The Solibri Model Checker manages and tracks changes between two design versions of the same model.

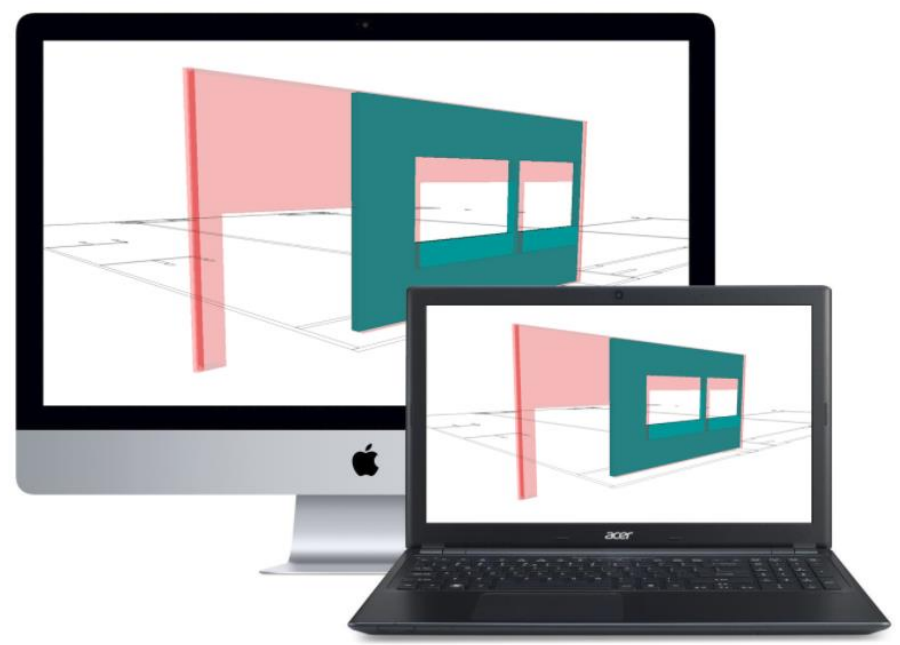

Figure 36: Solibiri Model visualisation 
This is able to easily be visualised and can verify model changes as shown in the image below.

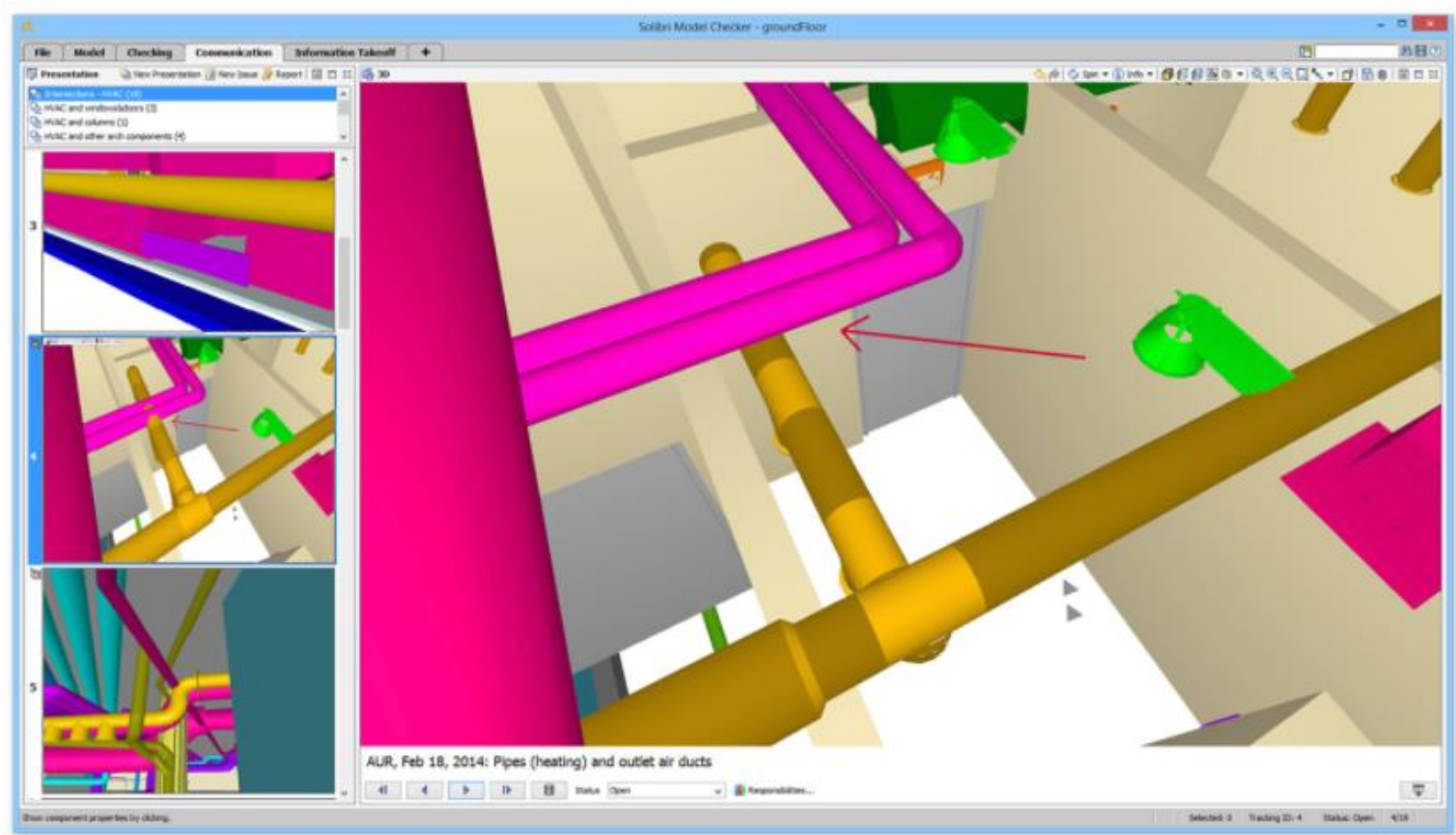

Figure 37: Solibiri Model Changes

Following the execution of checking the embedded data it was agreed that where there are differences then they will be matched against existing ANZRS/BIMMEPAUS/company specific parameters, the client needs to know the element is going to be maintained.

\begin{tabular}{|c|c|c|c|c|c|c|}
\hline \multirow{2}{*}{$\begin{array}{l}\text { ASSOCLATED } \\
\text { OUTDOOR UNIT }\end{array}$} & \multirow{2}{*}{ DESCRPTION } & \multirow{2}{*}{$\begin{array}{l}\text { NDNOUAL CONTROL ZONE } \\
\text { SERVED }\end{array}$} & \multirow{2}{*}{ UNIT TYPE } & \multicolumn{3}{|c|}{ ARFLOW } \\
\hline & & & & AIR FLOW (vs) & OUTDOOR AIRFLOW (Vs) & EXTERMAL S \\
\hline AssociatedWen_OP & Description & Location (BMA) & Type_ANZRS & $\begin{array}{c}\text { MinimumAirflow } \\
\text { ANZZRS }\end{array}$ & OutsideAirflow_ANZRS & Extstaticen \\
\hline T & T & 1 & T & T & T & \\
\hline & & & & & & \\
\hline & & $O P$ & & & & \\
\hline & & ANZRS & & & & \\
\hline & & $\begin{array}{l}\text { BMA } \\
\text { Bustem Parameter }\end{array}$ & & & & \\
\hline & & & & & & \\
\hline & & New & & & & \\
\hline
\end{tabular}

Figure 38: Naming Conventions

\subsubsection{Data in alignment with NZ Metadata Standard}

The information below represents the design team's level of thinking in the progress of the gymnasium, here the disciplines use their knowledge to inform the entire design team of where the concerns against issues raised. The design team had weekly meetings to discuss 
the ongoing progress of the project. Here the language is used to inform the reader of the discussion between parties.

The parameter "Expected Life OP" should be an integer (design life in years as per NZAMS). As defined in the NZAMS, the table below represents the attributes that are common across common networks and can be applied to all asset classes. The attributes represent metadata elements and asset metadata elements specific to each asset group. See appendix 14 for a full pdf version of this table.

\begin{tabular}{|c|c|c|c|c|c|c|c|c|c|c|c|}
\hline \multicolumn{12}{|c|}{ Common Attribute and Validation File Format Instructions } \\
\hline $\begin{array}{l}\text { Attribute } \\
\text { Name- } \\
\text { Abbreviated }\end{array}$ & $\begin{array}{l}\text { Attribute Name - } \\
\text { Full }\end{array}$ & Data Type & $\begin{array}{l}\text { Units of } \\
\text { Measure }\end{array}$ & $\begin{array}{c}\text { Max } \\
\text { Length }\end{array}$ & Comments & Contents & Example & $\begin{array}{c}\text { General } \\
\text { Validation } \\
\text { Rule }\end{array}$ & $\begin{array}{l}\text { Specific Validation } \\
\text { Rule }\end{array}$ & $\begin{array}{l}\text { CODELIST } \\
\text { Reference }\end{array}$ & $\begin{array}{c}\text { Legend } \\
\text { Physical attribute - P } \\
\text { Metadata attribute - M } \\
\text { Asset Management } \\
\text { Attribute - AM }\end{array}$ \\
\hline Unique_ID & Unique Identifier & $\begin{array}{l}\text { Alphal } \\
\text { Numenic }\end{array}$ & & $\begin{array}{l}20 \\
\text { chars }\end{array}$ & $\begin{array}{l}\text { No commas } \\
\text { included }\end{array}$ & Unique ID of the asset. Created by the data supplier. & & $\begin{array}{l}\text { Field cannot } \\
\text { be empty }\end{array}$ & $\begin{array}{l}\text { If asset owner } \\
\text { provides it then this } \\
\text { must be used. }\end{array}$ & & AM \\
\hline Owner & Owner & $\begin{array}{l}\text { Alphal } \\
\text { Numeric }\end{array}$ & & $\begin{array}{l}100 \\
\text { chars }\end{array}$ & $\begin{array}{l}\begin{array}{l}\text { No commas } \\
\text { included }\end{array} \\
\end{array}$ & Name of the asset owner. & $\begin{array}{l}\text { Wellington } \\
\text { City Council }\end{array}$ & $\begin{array}{l}\text { Field cannot } \\
\text { be empty }\end{array}$ & & & M \\
\hline Status & Status & $\begin{array}{l}\text { Alphal } \\
\text { Numeric }\end{array}$ & & $\begin{array}{l}10 \\
\text { chars }\end{array}$ & $\begin{array}{l}\text { No commas } \\
\text { included }\end{array}$ & The current operational state of the asset. & ABN & $\begin{array}{l}\text { Field cannot } \\
\text { be empty }\end{array}$ & $\begin{array}{l}\text { Entry must be from } \\
\text { CODELIST } \\
\text { Default = INUSE }\end{array}$ & $\begin{array}{l}\text { Asset } \\
\text { Status }\end{array}$ & M \\
\hline Const_Date & $\begin{array}{l}\text { Construction } \\
\text { Date }\end{array}$ & Date & Time & n/a & dd/mm/yyyy & $\begin{array}{l}\text { Date the asset was } \\
\text { constructed/builtinstalledrelinedrenewed }\end{array}$ & $\begin{array}{l}\text { EG: } \\
12 / 03 / 2000\end{array}$ & $\begin{array}{l}\text { Field cannot } \\
\text { be empty }\end{array}$ & Default $=31 / 12 / 9999$ & & M \\
\hline Source & Source & $\begin{array}{l}\text { Alpha I } \\
\text { Numenic }\end{array}$ & & $\begin{array}{l}10 \\
\text { chars }\end{array}$ & $\begin{array}{l}\text { No commas } \\
\text { included }\end{array}$ & $\begin{array}{l}\text { Data source or method that was used to collect the } \\
\text { data and populate the attributes }\end{array}$ & Field & $\begin{array}{l}\begin{array}{l}\text { Field cannot } \\
\text { be empty }\end{array} \\
\end{array}$ & $\begin{array}{l}\text { Entry must be from } \\
\text { CODELIST }\end{array}$ & Source & M \\
\hline H_Prec & $\begin{array}{l}\text { Horizontal } \\
\text { Precision }\end{array}$ & $\begin{array}{l}\text { Alphal } \\
\text { Numeric }\end{array}$ & & $\begin{array}{l}10 \\
\text { chars }\end{array}$ & $\begin{array}{l}\text { No commas } \\
\text { included }\end{array}$ & $\begin{array}{l}\text { Horizontal Precision to which the asset has been } \\
\text { captured }\end{array}$ & & 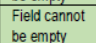 & $\begin{array}{l}\text { Entry must be from } \\
\text { CODELST }\end{array}$ & $\begin{array}{l}\text { Horizontal } \\
\text { Precision }\end{array}$ & M \\
\hline V_Prec & Vertical Precision & $\begin{array}{l}\text { Alphal } \\
\text { Numenic }\end{array}$ & & $\begin{array}{l}10 \\
\text { chars }\end{array}$ & $\begin{array}{l}\text { Nocoucummas } \\
\text { included }\end{array}$ & $\begin{array}{l}\text { Vertical Precision to which the asset has been } \\
\text { captured. }\end{array}$ & & $\begin{array}{l}\text { Feelid cannot } \\
\text { be empty }\end{array}$ & $\begin{array}{l}\text { Entry must be from } \\
\text { CODELIST }\end{array}$ & $\begin{array}{l}\text { Vertical } \\
\text { Precision }\end{array}$ & M \\
\hline Des_life & Design Life & Integer| & Time & naa & Whole number & $\begin{array}{l}\text { Indicates the Manufactured Life / expected life on } \\
\text { use. } \\
\text { Design life length in years }\end{array}$ & & $\begin{array}{l}\text { Field cannot } \\
\text { be empty }\end{array}$ & Default $=-9999$ & & AM \\
\hline Cost & cost & Decimal & Currency & n/a & $\begin{array}{l}2 \text { decimal } \\
\text { places }\end{array}$ & $\begin{array}{l}\text { Link field to Volume } 2 \text {. } \\
\text { Cost of the asset determined at time of construction } \\
\text { in dollars }\end{array}$ & 130.25 & $\begin{array}{l}\text { Field cannot } \\
\text { be empty }\end{array}$ & Default $=-9999.99$ & & AM \\
\hline Con_Ass_T & $\begin{array}{l}\text { Condition } \\
\text { Assessment } \\
\text { Type }\end{array}$ & $\begin{array}{l}\text { Alphal } \\
\text { Numenic }\end{array}$ & & $\begin{array}{l}10 \\
\text { chars }\end{array}$ & $\begin{array}{l}\text { No commas } \\
\text { included }\end{array}$ & Condition Assessment Type & $\begin{array}{l}\text { Desktop or } \\
\text { Physical } \\
\text { Inspection }\end{array}$ & $\begin{array}{l}\text { Field cannot } \\
\text { be empty }\end{array}$ & $\begin{array}{l}\text { Entry must be from } \\
\text { CODELIST }\end{array}$ & $\begin{array}{l}\text { Condition } \\
\text { Assessmen } \\
\text { t Type }\end{array}$ & AM \\
\hline Comments & Comments & $\begin{array}{l}\text { Alphal } \\
\text { Numeric }\end{array}$ & & $\begin{array}{l}250 \\
\text { chars }\end{array}$ & $\begin{array}{l}\text { No commas } \\
\text { included }\end{array}$ & Any additional comments that relate to this asset & & $\begin{array}{l}\text { Field may be } \\
\text { empty }\end{array}$ & & & M \\
\hline
\end{tabular}

Table 25: NZAMS asset classes

The parameter exists in the companies Shared Parameter File as an integer, but in the project another version (text) has been loaded. It is crucial that this is correct in the beginning of the project given that datatypes cannot be changed further down the track, it is imperative this is corrected before importing any data.

\begin{tabular}{|l|l|l|l|l|l|} 
Design Life & Integer & Time & n/a & Whole number & $\begin{array}{l}\text { Indicates the Manufactured Life / expected life on } \\
\text { use. } \\
\text { Design life length in years }\end{array}$ \\
\hline
\end{tabular}

Table 26: Parameters

The parameter Manufacturer Warranty OP (currency) also already exists in the companies Shared Parameter File as Manufacturer Warranty End Date OP (text). This allows for the format dd/mm/yyyy as specified in NZAMS. The data will be cast from string to date in excel or on import to the destination database. 
The parameter Installer Warranty_OP (text) already exists in the companies Shared Parameter File as InstallerWarrantyEndDate_OP (text).

The redundant parameters are identified in figure 39 , this should be deleted from the project before they inadvertently get populated with data too and these parameters are unable to be deleted

Figure 39: Solibiri Model Checker example

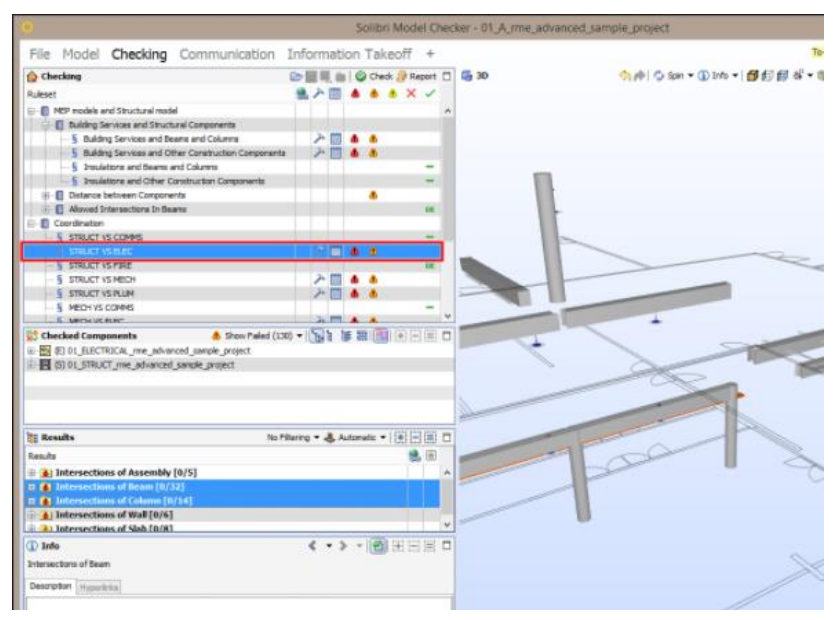

The Assembly Codes should be updated with Uniformat 2010 versions. For example being. Reloaded from Q: Idrive a local company drive. Fortunately, not too many door types to update (27 types used), and some are blank (Type 24, 5, S1).

The following was also identified in a quality assurance check:

1. Columns are not ordered alphabetically this can be confusing for the users.

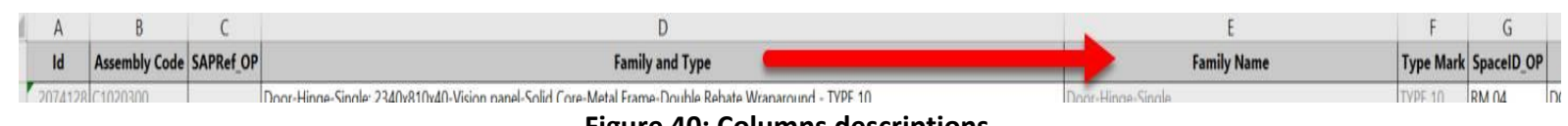

Figure 40: Columns descriptions

2. It isn't clear what the best way to group types is, however the design team acknowledge there needs to be individual references e.g. door 1127556 DG12/1 is in RM 12, the RM 12 (room) plays an important part

- When locating “Door-Hinge-Double_Panic Bar: 2340x870+870x40-Vision Panel-Metal Frame-Single Rebate Wraparound - TYPE 12" for example there are multiple types these need to be specific to rooms

- It is possible to manually select the door type and run a sum in excel but can the system run sums of how many within the entire model and extract this 'sorted' info from Revit via a BIM link. The individual items + total number? It isn't not yet clear the best approach in doing this. 


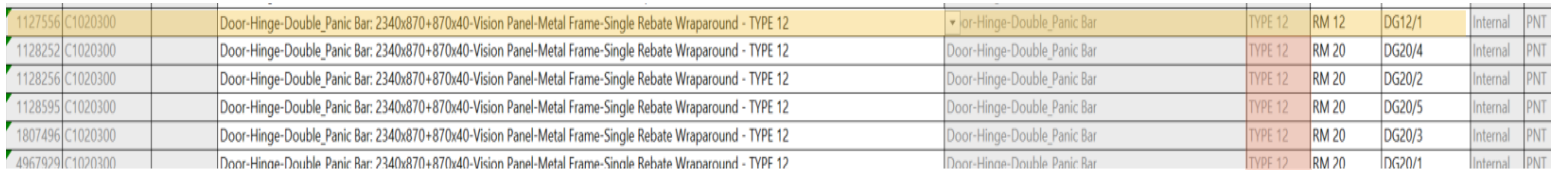

Figure 41: Naming conventions

3. Further to point 2 above, this relates to the unit of measure (UOM) within NZAMS

- For example: UOM = number = 6 (“Door-Hinge-Double_Panic Bar: 2340x870+870x40Vision Panel-Metal Frame-Single Rebate Wraparound - TYPE 12" )

- For other items like (m2) elements for example, painted wall surfaces, carpet the room book, tool plays a significant part, being able to identify the area of the element in a particular room will be important for the operational use of the project. The QA procedures in solibri will be utilised to check the data

4. The project column shown in column F "type mark" needs to have the ability to extract everything.

5. And column G "SPACEID_OP" also like point 4 needs that same ability of extracting all data. How does this handle walls and floors that go across multiple spaces? It is important to have the room book abilities for an operational aspect. The reason behind the need to extract all the data in columns $f$ and $g$ for example is there may be an audit required to check the door systems and being able to determine where these all are located without being on site will reduce time. As well as this, from a contractor's perspective this would work hand in hand with scheduling quantities.

6. Column Q "InstallerCost_OP" to "ReplacementCost_OP" needs to be removed as no contractor will provide this confidential information.

7. Column $\mathrm{K}$ is not needed "DoorFrameFinish_ANZRS" this will be covered by column J "Finish"

8. The company Asset Management team is to provide a database so that the design team can refer to and fill out column O "ExpectedLife_OP" (design life in years per NZAMS). It will only order alphabetically after the assembly code, type mark and family columns as they're the source for sorting information. 
In relation to Point 6: As for how to get that (graphical user interface) GUID (globally unique identifier), it is never exposed in the Revit GUI or schedules, but you can add the field UniqueID in the BIMLink definition. See below: See appendix 20 for a full break down of the spreadsheet below.

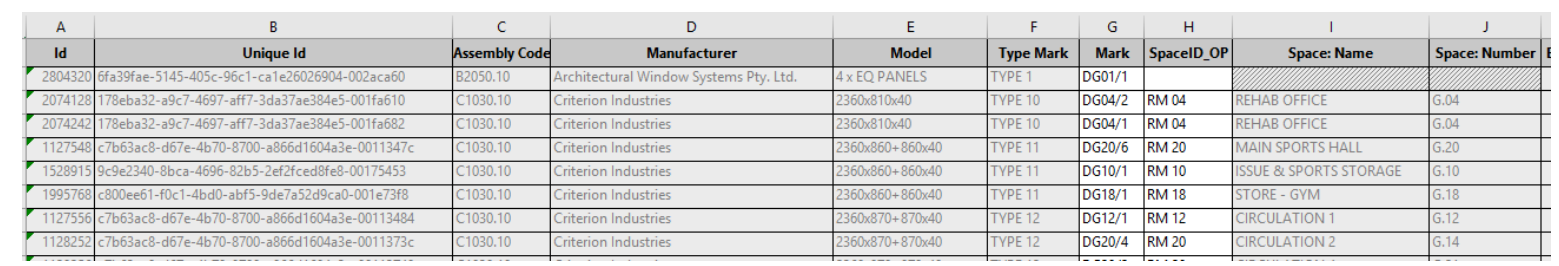

Figure 42: Graphical user interface

In relation to Point 2 above: Instance or Type export -to see GUIDs of elements, it implies that each Instance needs to be exported (one row per item) and it's up to the Asset Management software to collate via a GroupBy statement to get totals etc. (what that database is designed to do). The schedules contained within the Revit file are more for the design team's benefit, and if these were exported the total rows will mess with the import.

In relation to Point 3 above: Unit of Measure. Each row needs to be thought about as one instance (with GUID) then the UOM column cannot be a count of grouped items, but rather it is related to how that item is quantified. That being for most items (doors, a/c units, dampers) it will be a quantity, but for floors, walls, ceilings, perhaps others it will be a size or sqm. NZAMS says "Metres", "Time" and "Millimetres". This column could include "Quantity" or "Number Of"

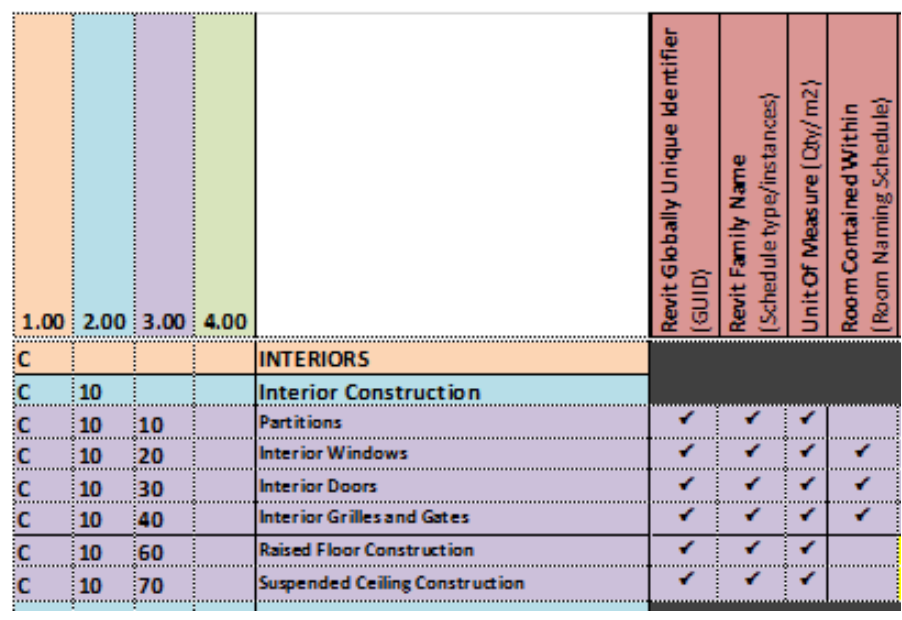

Table 27: Unit of measure column example "Metres", "Time", and "Millimetres". 
If the image below was correct in defining the Median typical life $=6$ years. (It is not beneficial to have four separate data fields (typical, range, min, max) therefore the median would be used for the typical life of any building element.

\section{A WALL FINISHES}

Decorations: Emulsion Paint: One mist and two coats; to brick/block walls, cement render/concrete, plaster walls

Results
Median typical life
6 years
Range
1 to 60 years
Median minimum life
4 years
Median maximum life
10 years
Factors to be considered when

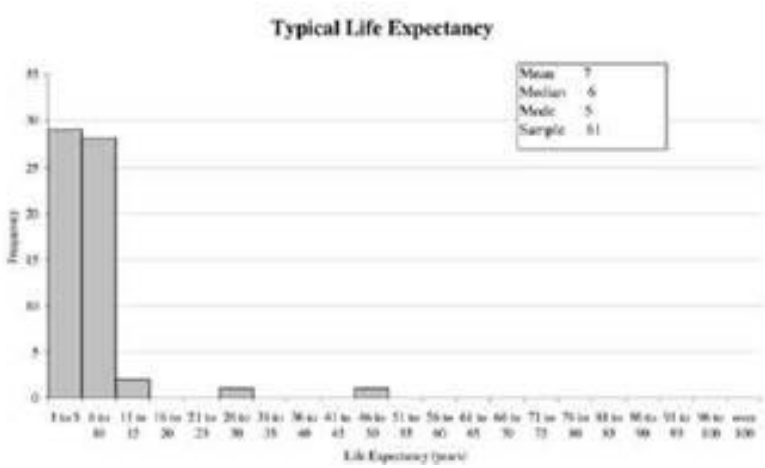

Figure 44: Asset Life Expectancy

In addition to this, the design team is to gather the installer/manufacturer warranty periods from the contractors/subcontractors, so the client understands what the warranty periods are and what the median typical life is. This will allow the AM/FM to make informed decisions (in addition to condition assessments) when the main table finish is likely to require renewing in this case.

It is worth noting that the GUID exported by BIMLink is the Revit UniqueID (8-4-4-4-12-8 hex)

Depending on how Solibri features in the workflow, there may be a requirement to transpose / export ifcGUID (specific naming convention). One possible method may be to store the ifcGUID on elements after an initial IFC export or make use of some tools such as the building coder. The building coder looks at a common problem in the AEC industry, how to correlate the globally unique identifiers which essentially is a naming convention when exporting DWF and IFC from Revit models and Revit elements. In a simplistic manner the question asks when exporting data how can all naming conventions be aligned as a single sense of truth to ensure that this is a standardised manner? For example a door is a door. 
GUID and Uniqueld, what is this? The building coder acknowledges Revit Uniqueld which identities a unique identifier for every element. It represents a 32 bit number which is the size of a Revit Element.

For example:

Creating a row of walls that the GUID part of the Uniqueld is the same for all of the walls, and the last 8 bytes differ and exactly represent their individual element ids. Here are the various ids of two walls, exported to both DWF and IFC:

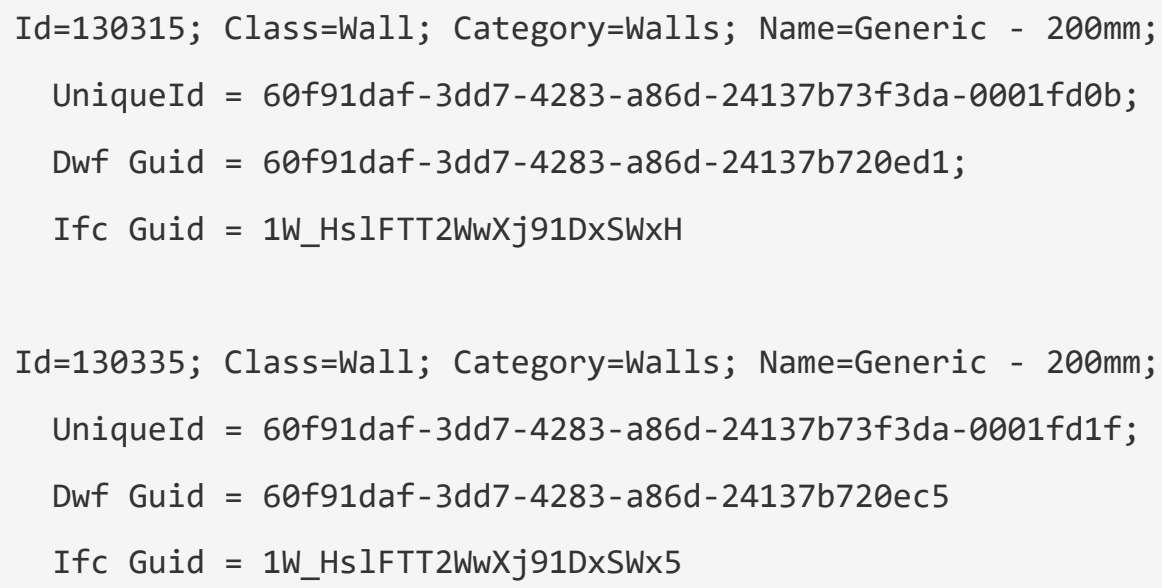

Figure 45: unique Identifier example

The first 16 bytes or 32 hex characters of the unique identifiers are identical and called Episodeld in Revit. The unique ids only differ in the 4 byte or 8 hex character suffix at the end. In the case above, the two differing suffixes for the walls are indeed their element ids in hexadecimal representation. Hexadecimal representation is a numeral system also known as hex, made up of 16 symbols as specified above. A numeral system is also known as decimal based on 10 digits, a hexadecimal uses the same principles and includes 6 symbols. Humans mostly use a decimal system being able to utilise their fingers. Computers often only use a binary system that is zeros before and after. In essence for the purpose of this research a hexadecimal is an old numbering system adopted in a BIM digital environment. 
There data displayed in the building coder identifies the below:

- $\quad$ The Uniqueld does not adhere to the standard GUID format.

- The DWF GUID does.

- The IFC GUID looks completely different from both.

In this discrepancy it shows DWF and IFC as being identical and refers to the both of them as GUID a form of naming format. So how does this link back to internal Revit database properties. There are four different rules associated with the data discrepancies depending on how these elements are exported/imported:

1. If the element is being exported after an IFC import, we preserve the GUID originally contained in the IFC Entity. This is a rare case.

2. If there is a one-to-one correspondence between a Revit Element and an IFC entity, we create the GUID by taking the GUID in the Episodeld of the element and exploring it with the element id.

3. For special IFC Entities that have no corresponding element in Revit, such as IfcBuilding and IfcProject, and for some elements that are duplicated, such as an opening for a window or door instance, we create the GUID by taking the Detach GUID of the project and exploring it with the element id.

4. For other IFC Entities, we create a GUID on the fly.

In principle, the above unique ID is a technically advanced language, it brings a complicated sequence however its overarching purpose represents a common unique data discrepancy as a unique ID for Revit data.

Quality assurance was utilised using the Solibri data tool as specified above. Solibri is critical to the workflow as it is being used to validate, check, track and change. To facilitate, the data needs to be run the building coders visual studio 2015, how can this be done? And how would that fit in with the current workflow being developed? This is still to be defined and falls outside of this research, as an opportunity for further research.

The "Unit of Measurement" (UOM) column in NZAMS is used to describe the units of measurement for each attribute (field) of building elements. This is in addition to the datatype 
- for example the attributes Gr_FI_Area and Load_Wind are both decimal, but the UOM column shows the actual units.

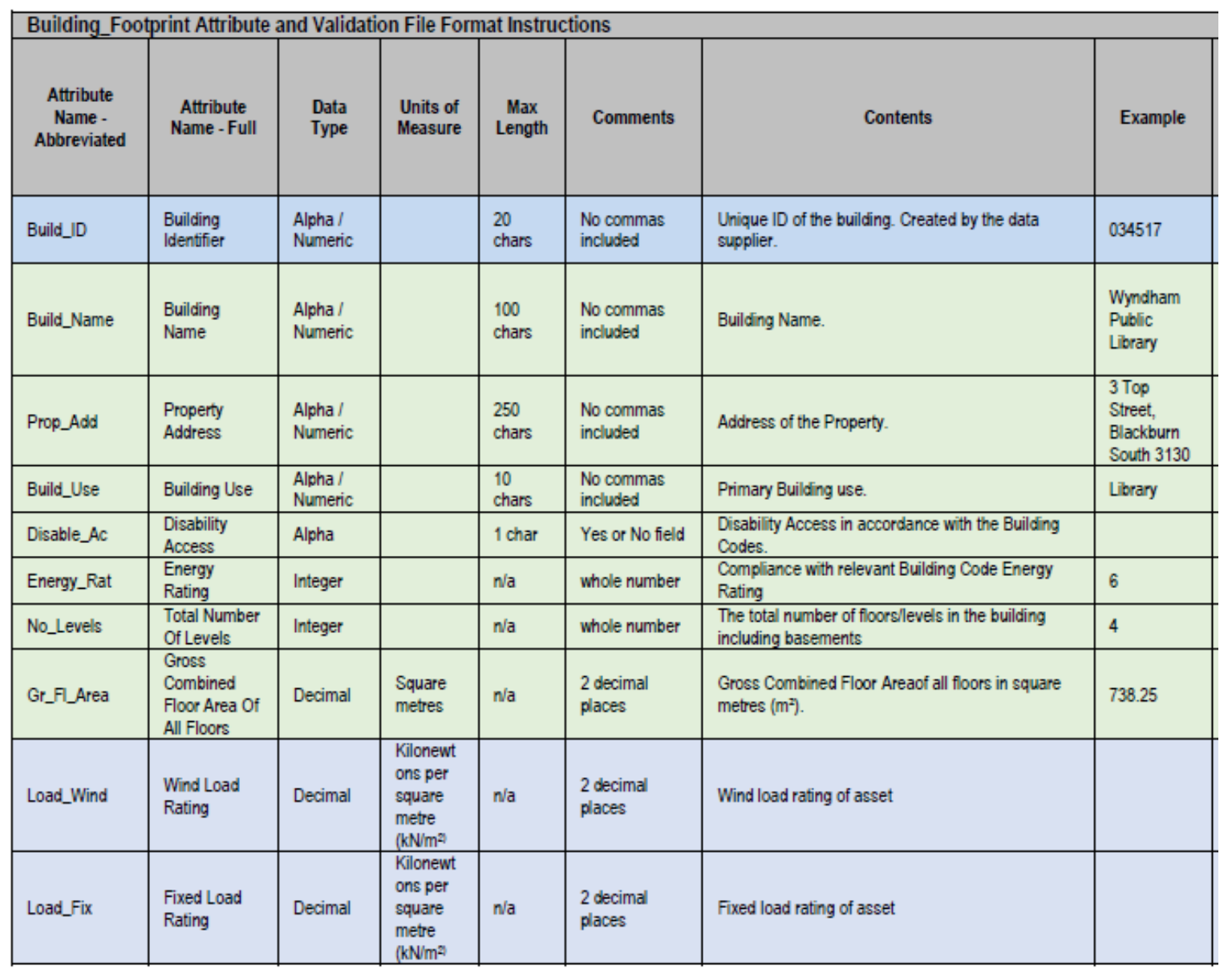

Table 28: NZAMS File Format Instructions

Where the UOM field is blank, it is inferred that there is no unit as such, hence the phrase 'where relevant'. In these cases, the default is simply the datatype on its own. For example. Integer, decimal, string see definition above. 
Where it gets confusing is that in the MPDT the design team have used the same column name "Unit of Measurement" to describe what is required for each building element (rather than an attribute of each element)

Table 29: Unit of measure column

The tick represents the elements need to be quantified as instructed by the design team.

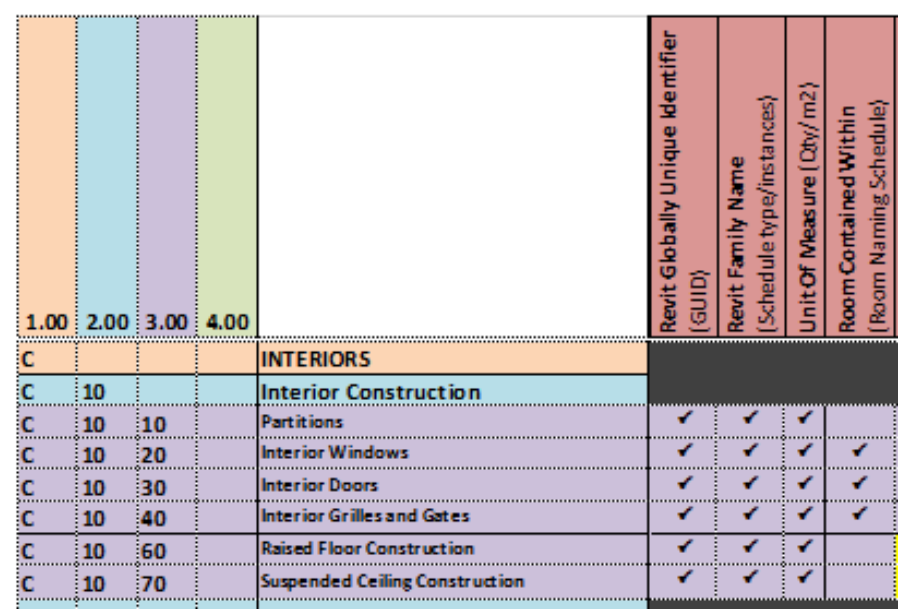

As shown below the UOM field could contain values "m2", "m3", "mm", "kg", and "Quantity" (or "Number Of" or even blank for those items that will be simply counted), and the actual values would be obtained by counting or summing values from another field.

Trying to push multiple datatypes into the one field (column) is not desirable, and without the UOM defined would be hard to decipher, so a modified version would suggest that it would look like this:

$\begin{array}{llll}\text { GUID } & \text { ElementType } & \text { UOM } & \text { Area } \\ \text { ID } 12345 & \text { Door Type X } & \text { <Quantity> } & \\ \text { ID } 12346 & \text { Door Type X } & \text { <Quantity> } \\ \text { ID } 12347 & \text { Door Type X } & \text { <Quantity> } \\ \text { ID } 123450 & \text { Painted wall Y } & \mathrm{m} 2 & 25 \\ \text { ID } 123451 & \text { Painted wall Y } & \mathrm{m} 2 & 5 \\ \text { ID } 123452 & \text { Painted wall Y } & \mathrm{m} 2 & 50\end{array}$

The UOM column is simply stating the units that each element is measured in, and the measure is found in another column.

The <Quantity $>$ entries could be blank, or say "Count". As they are the rows which would be counted. For example, that is how it would be expected to quantify those elements. 
In a normalised database these different elements may not even be in the same table, but this may suffice for this project as stated by the design team. Perhaps seeing the AM database down the track will clarify these items and identify what needs to be explored more.

The original intention was to keep all the UOM in one column from the design team, however whatever UOM is identified (in the MPDT as opposed to just a tick) creates an addition column for the output as below:

$\begin{array}{llllc}\text { GUID } & \text { Element Type } & \text { UOM } & \text { Area } & \text { Count } \\ \text { ID } 12345 & \text { Door Type X } & \text { <Count> } & 1 \\ \text { ID } 12346 & \text { Door Type X } & \text { <Count > } & 1 \\ \text { ID } 12347 & \text { Door Type X } & \text { <Count> } & 1 \\ \text { ID } 123450 & \text { Painted wall Y } & \mathrm{m} 2 & 25 & \\ \text { ID } 123451 & \text { Painted wall Y } & \mathrm{m} 2 & 5 & \\ \text { ID } 123452 & \text { Painted wall Y } & \mathrm{m} 2 & 50\end{array}$

The second part of the QA assurance looked at the additional granularity/direction of this information that is required in rooms for example what are the maintainable finishes and costs of room X, (where walls/floors extend across multiple room) how does the design team solve these issues? This is yet to be resolved and something that the design team is working towards. The current spreadsheet has "SpacelD_OP", "Space: Name" or "Space: Number" columns, filtering this gets simple results of things"RM01" room (doors).

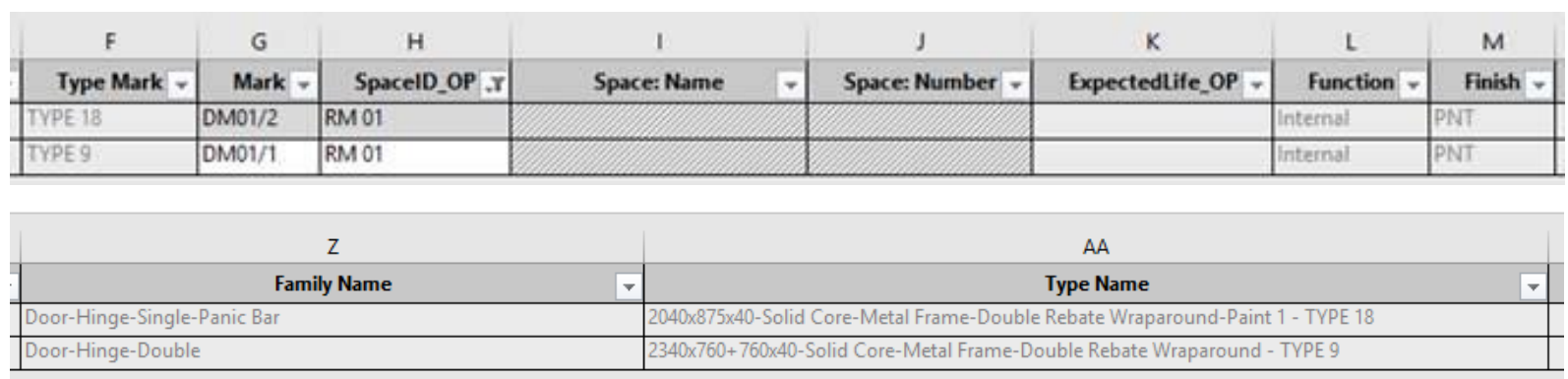

Table 32: Space ID classification spreadsheet 
This however will not work for items such as walls, ceilings and floors as the BIM model does not simply display these items room by room but in fact links these across the entire building. From a construction aspect the floor for example will be constructed at the same time.

The workflows being developed are shown below:

- $\quad$ Revit $\leftrightarrow \rightarrow$ BIMLink $<->$ Excel (all metadata)

$+$

- $\quad$ Revit $->$ RoomBook $->$ Excel (breakdown of the materials/m2... per room)

$+$

- $\quad$ Revit -> IFC -> Solibri to audit/check

It is suggested that the best use of time to develop the workflows would be to run this through Solbri and push it back into a BIMlink. A BIM link is simply a link that collaborates all elements and data associated with each element and links them together, For example, a door, however it may be visually displayed and combining a manufacturing detail with life expectancy and door finish.

The goal at this step was to continue developing the Revit <-> BIMLink <-> Excel workflow, get the output to an Excel, push that data back to Revit and utilise these files to see if they can be replicated (including a room book type equivalent output) via Solibri.

The following information needs to be achieved within the project:

1. Finish the definition/clarification and inputting of the metadata Shared Parameters into the project

2. Finish populating all the doors metadata, export via BIMlink and format as required

3. Repeat for walls, floors and plumbing fixtures as documented above

For quality assurance purposes the information required for the content of every (non-grey) cell. This could be. checking that Door type 10 is supposed to be 2360 high, and filling in the Fire rating. This needs to be implemented and inputted manually into the excel spreadsheet, this was not achieved in the Revit model correctly. 
The design team need to fill out the following in the easiest/quickest way possible. Be that in the excel spreadsheet or Revit itself. It's debatable which the quickest method is.
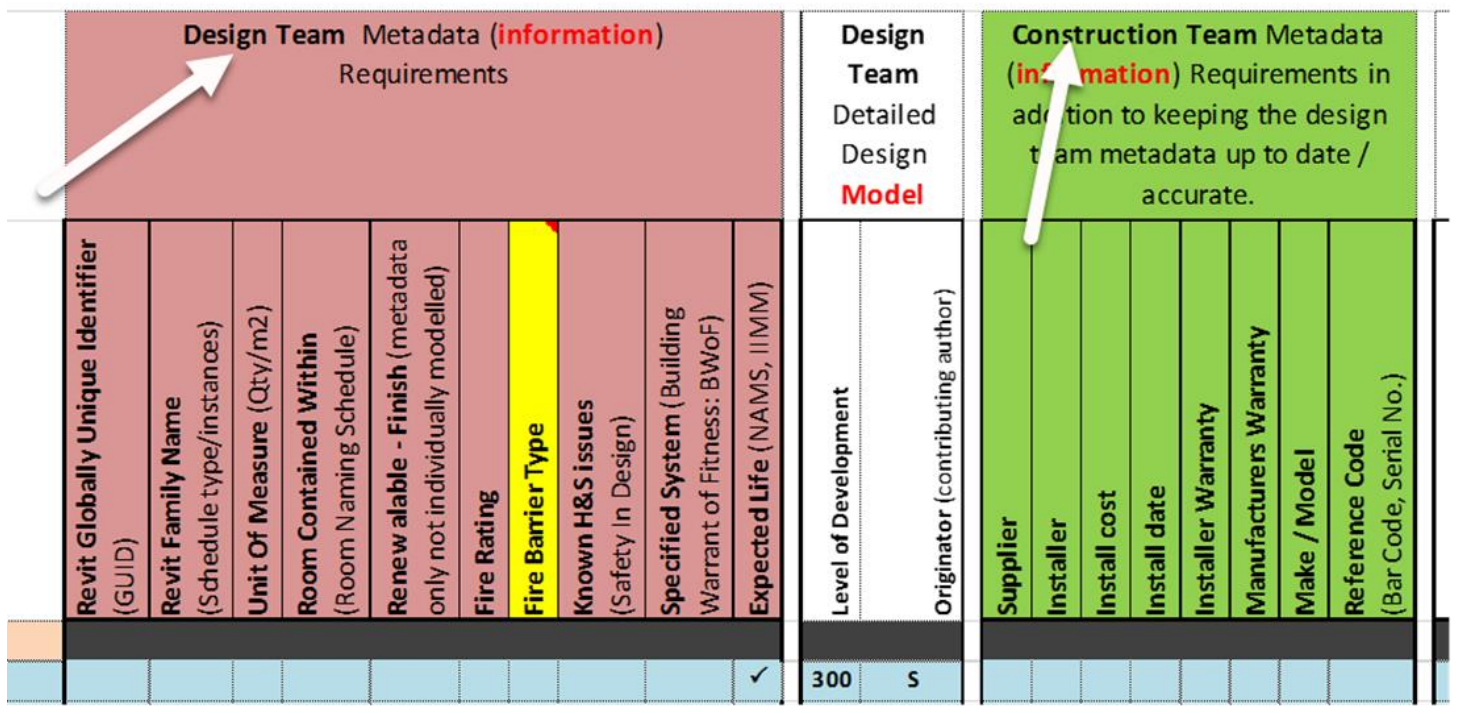

Table 33: Design team vs Construction team metadata

Positioning, navigation and timing (PNT) need to be documented which aligns to a NZAMS definition. In an ideal situation it would be useful having the correct type of paint for example with a description like -epoxy, or powder coat, or solvent enamel, or waterborne enamel, each of which are used in different situations on doors. Because of the stage of this design, it is likely this information would follow further down the track therefore a generic description of "Paint" would suffice at this stage of the design. For this design stage defining paint and the contractors' replacement costs and the dates are likely to be needed and replacement timeframes are critical. The fire rating cell shall be blank if not defined, given that this might mean there is no fire rating, or it might mean it is unable to be filled in yet. Blank fields are represented with N/A. The asset manager will define the parameters for the lifecycle of elements as they understand

The manufacturer column will be exculpated by the contractor. The design team will hand over the model documents with a generic field as the contractor may propose a substitute solution. The design team for example will specify a door at $90 \mathrm{~mm} \times 270 \mathrm{~mm}$ timber, the contractor may use their specified supplier and then input the exact discrepancies into the BIM model and this gives both the design and construction team some flexibility in regard to 
specific system choices. The design team may for some reason specify a product. This means that most elements are only detailed to LOD 300 (refer to details above). In order for the element to be detailed to LOD 500 for handover in asset and facilities management the contractor needs to implement the manufacturing details etc. The design team and contractors need to have a good relationship to ensure the use of data is accurate. Alternatively, the design team may embed the manufacturing information associated with the model elements, this would only be the case if the contractor did not have the ability to do so. For workflow purposes the party responsible for embedding the data as highlighted in the BEP should be responsible for doing this. This way it is clear who is responsible if data is incorrect or not correctly inputted.

The model was then updated, and data placed into the Excel files located in the common data environment this being the asset metadata spreadsheet located in the SharePoint file. This was done across the project for walls, floors, doors and plumbing as these elements are interconnected throughout the building.

Two files for each category were populated with data. One for Type parameters, and one for Instance parameters. The fields that are grey in the excel files, cannot be imported back into Revit. As shown below the two tables represent the doors in the model. See appendix 15.

\begin{tabular}{|c|c|c|c|c|c|c|c|}
\hline$\Delta$ & A & B & c & D & E & $\mathrm{F}$ & G \\
\hline 1 & Id & Family Name & Type Mark & FireRating_ANZRS & Expectedlife_OP & Manufacturer & DoorPanelHeight_ANZRS \\
\hline 2 & 5090997 & Door-Sliding-AWS Vantage Residential Series 542-109mm Frameless & TYPE 1 & n/a & refer Property & Architectural Window Systems Pty. Ltd. & 2698 \\
\hline 3 & 2752885 & Door-Hinge-Single & TYPE 10 & n/a & & & 2360 \\
\hline 4 & 2750120 & Door-Hinge-Double & TYPE 11 & $n / a$ & & & 2360 \\
\hline 5 & 2727089 & Door-Hinge-Double & TYPE 12 & $21 / 2$ is smoke/Mag & & & 2360 \\
\hline 6 & 6233144 & Door-Hinge-Double_Panic Bar & TYPE 12 & & & & 2360 \\
\hline 7 & 3146129 & Door-Face Slider-Criterion Industries Cascade Panama & TYPE 13 & $n / a$ & & $\begin{array}{l}\text { Criterion Industries } \\
\end{array}$ & 2400 \\
\hline 8 & 2757166 & Door-Hinge-Double & TYPE 14 & n/a & & & 2360 \\
\hline 9 & 2755890 & Door-Hinge-Single & TYPE 15 & $n / a$ & & & 2360 \\
\hline 10 & 2754236 & \begin{tabular}{|l} 
Door-Hinge-Single \\
\end{tabular} & TYPE 16 & $\mathrm{n} / \mathrm{a}$ & & & 2360 \\
\hline 11 " & 3117489 & Door-Hinge-Single & TYPE 17 & $n / a$ & & & 2000 \\
\hline 12 & 6306858 & Door-Hinge-Single-Panic Bar & TYPE 18 & $n / a$ & & & 1980 \\
\hline 13 " & 5799681 & Door-Hinge-Single & TYPE 19 & $n / a$ & & & 2360 \\
\hline $14^{\prime}$ & 2729038 & Door-Hinge-Double & TYPE 2 & $n / a$ & & & 2360 \\
\hline 15 & 6256934 & Door-Hinge-Double_Panic Bar & TYPE 2 & $n / a$ & & & 2360 \\
\hline $166^{\prime}$ & 2730462 & Door-Hinge-Double & TYPE 3 & $n / a$ & & & 2360 \\
\hline $17^{\prime}$ & 5352957 & Fence-Hinge-Double & TYPE 31 & $n / a$ & & & 2600 \\
\hline 18 & 5430668 & FENCE-Hinge-Single & TYPE 32 & $n / a$ & & & 2600 \\
\hline 19 & 5430372 & FENCE-Hinge-Single & TYPE 33 & $n / a$ & & & 2600 \\
\hline 20 & 6256924 & Door-Hinge-Double_Panic Bar & TYPE 6 & $n / a$ & & & 2360 \\
\hline 21 " & 2755251 & Door-Hinge-Single & TYPE 7 & $n / a$ & & & 2360 \\
\hline 22 & 2751644 & Door-Hinge-Single & TYPE 8 & $n / a$ & & & 2360 \\
\hline 23 & 2753518 & Door-Hinge-Double & $\begin{array}{l}\text { TYPE } 9 \\
\end{array}$ & $n / a$ & & & 2360 \\
\hline 24 & 5132449 & 5231_Door Single Slider (OP) & TYPE S1 & $n / a$ & & & 1980 \\
\hline
\end{tabular}

Table 34: Type parameters information column 
The second table shows the door instances and has more design parameters than the above table. This includes specified systems (For example for BWOF), finishing type PNT - paint family name for example

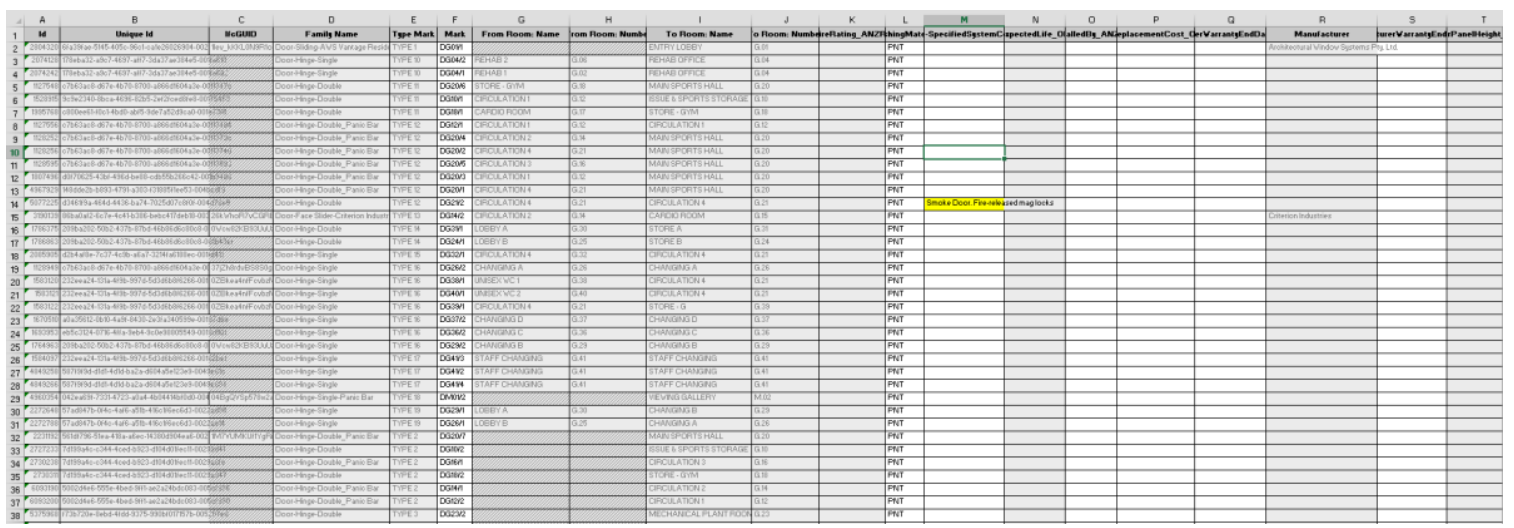

Table 35: Instance parameters information column

Where parameters are named NZAMS Code_OP this is shown in the Codelists in the NZAMS document and is specific for different project types. However, if no such code exists, the design team will leave this blank. The design team needs to develop non-standard items and should prefix it, so it can be identified as being non-standard, at this stage it is not clear how this will be solved.

\section{Building Code Lists}

Figure

Code lists standardise terminology by providing a range of item descriptions for a particular attribute. For a number of attributes specified in the data tables, you must input a code list entry as set out in the Code Lists.

Consultants please note that if an entry does not exist within the code list, you should get in touch with your client manager contact to arrange for its inclusion.

The code list entries will be constantly reviewed added to and amended as the need arises.

NZAMS Building Code List

To identify the element adding data to, the Id finder found in the first column with the Select by ID tool can be used:

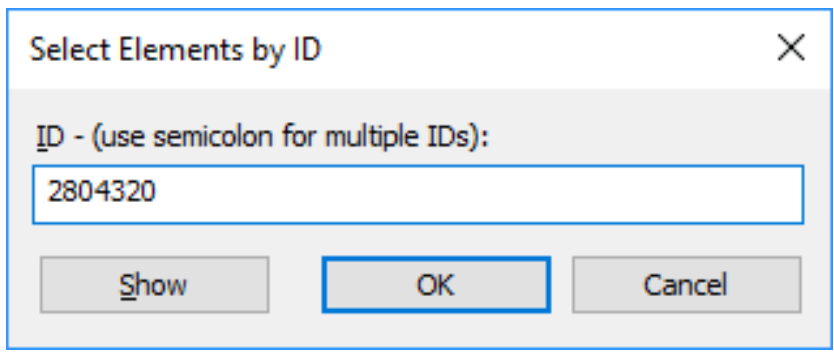

Figure 47: Element ID for Revit 
However, it is possibly easier to edit some of this information directly in Revit but will be on a case by case basis. If it is easier to edit in Revit this must done first (most likely by the design team), and then the excel file (with newly added information) will need to be re-exported, before filling out additional info in Excel. This is because if you push back blank cells from Excel, that's what you'll get in Revit, effectively overwriting what has just been undertaken.

Minor tweaks were required for type parameters (this was a manual input situation). If the design team are able to understand and define the logic, this may resolve the need exporting / populate scenario for future parameters.

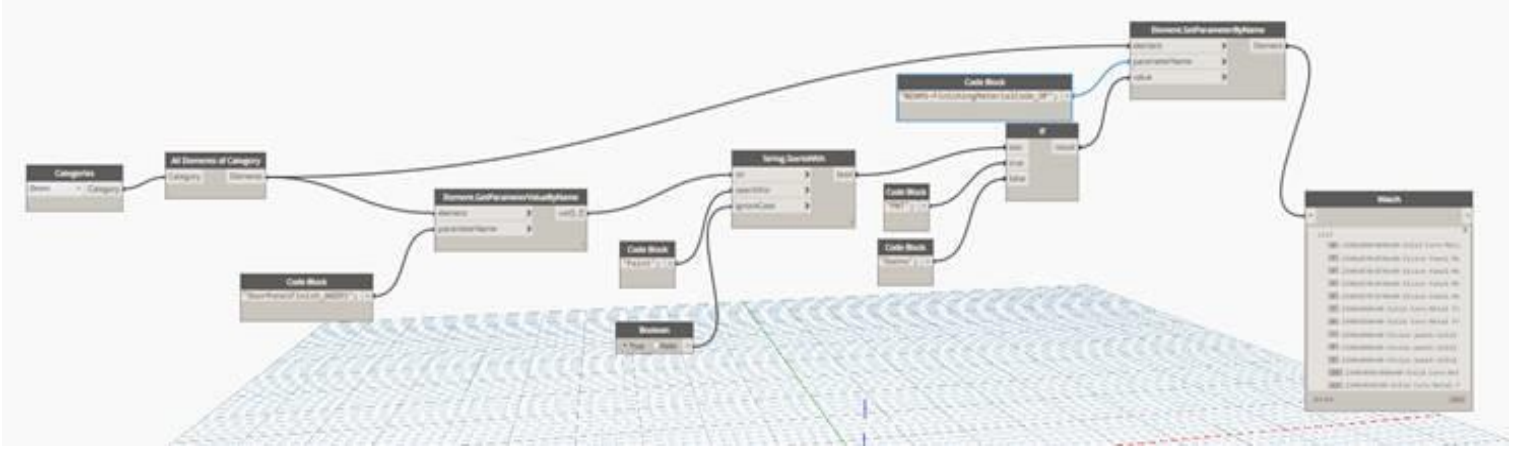

Figure 48: Revit Schedule Programming

As part of the quality assurance check the design team were to complete the following aspects:

1. Finalise the nomenclature and variables of the shared parameters and ensure they are in the project file, as shown below:
a. Instance/type
b. Integer, etc. (as defined above)
c. UOM Unit of Measurement (as defined above)
d. Add field "UniquelD"

2. Remove surplus (redundant) parameters from the project file that are not required. Delete data that has no relevance to the project, the design team will run quality assurance across all inputted data and remove the unnecessary information

3. Prepare Revit file to export Doors, Walls, Floors, Windows and plumbing fixtures as mentioned above indicated on the excel spreadsheets 
4. Update BIM Link settings as per aforementioned steps

5. Format the outputted excel file from BIMLink to match the NZDF/NZAMS requirements. Align the naming conventions essentially.

a. Provide updated excel file to the client to continue testing of the SAP integration (this will be defined as a further opportunity for research).

6. Populate the (BIMLink) excel file with data that's missing and can be filled out a. FireRating_ANZRS, - It is important to use consistent / standard nomenclature 90/90/90 - no spaces for example

b. SepcifiedSystemBWOF_OP, - now called NZAMS-SpecifiedSystem_OP - fill out using codes from NZAMS Codelist 89, p253 as shown below:

Code List 89: Specified System Type

\begin{tabular}{|l|l|l|l|}
\hline Code & Description & Code & Description \\
\hline SS1 & Automatic systems for fire suppression & SS9 & Mechanical ventilation or air \\
\hline SS2 & Automatic or manual emergency & SS10 & Building maintenance units \\
\hline SS3 & Electromagnetic or automafic doors or & SS11 & Laboratory fume cupboards \\
\hline SS4 & Emergency lighting systems & SS12 & Audio loops or other assistive \\
\hline SS5 & Escape route pressurisation system & SS13 & Smoke control systems \\
\hline SS6 & Riser mains for use by fre services & SS14 & Emergency power systems for, \\
\hline SS7 & Automatic back-flow preventers & SS15 & Other fire safety systems or \\
\hline SS8 & Lifts, escalators, travelators, or other & SS16 & Cable cars \\
\hline
\end{tabular}

7

c. ExpectedLife_OP (referring to BICS expected life doc) fill out using figures from BICS Life Expectancy document

7. "Push" data back via BIM Link to Revit, filling excel spreadsheets out to import back into the model

8. Provide updated Revit files (that include the data) to the nominated party to test the process to achieve the excel output desired + a room book type output

9. Update MPDT UOM column to show the UOM required (count, $\mathrm{m} 2$, for example)

10. Investigate if "export ifcGUID" is required

a. Implement "export ifcGUID"/ builder coder approach 
11. Repeat for all remaining building elements.

Shared parameters were added to elements based on the categories specified in the MPDT, the roof, walls and the likes. "Roof" doesn't get "room contained within", as these elements generally follow the whole room (Doors, Walls, Floors, Plumbing Fixtures, and for Windows).

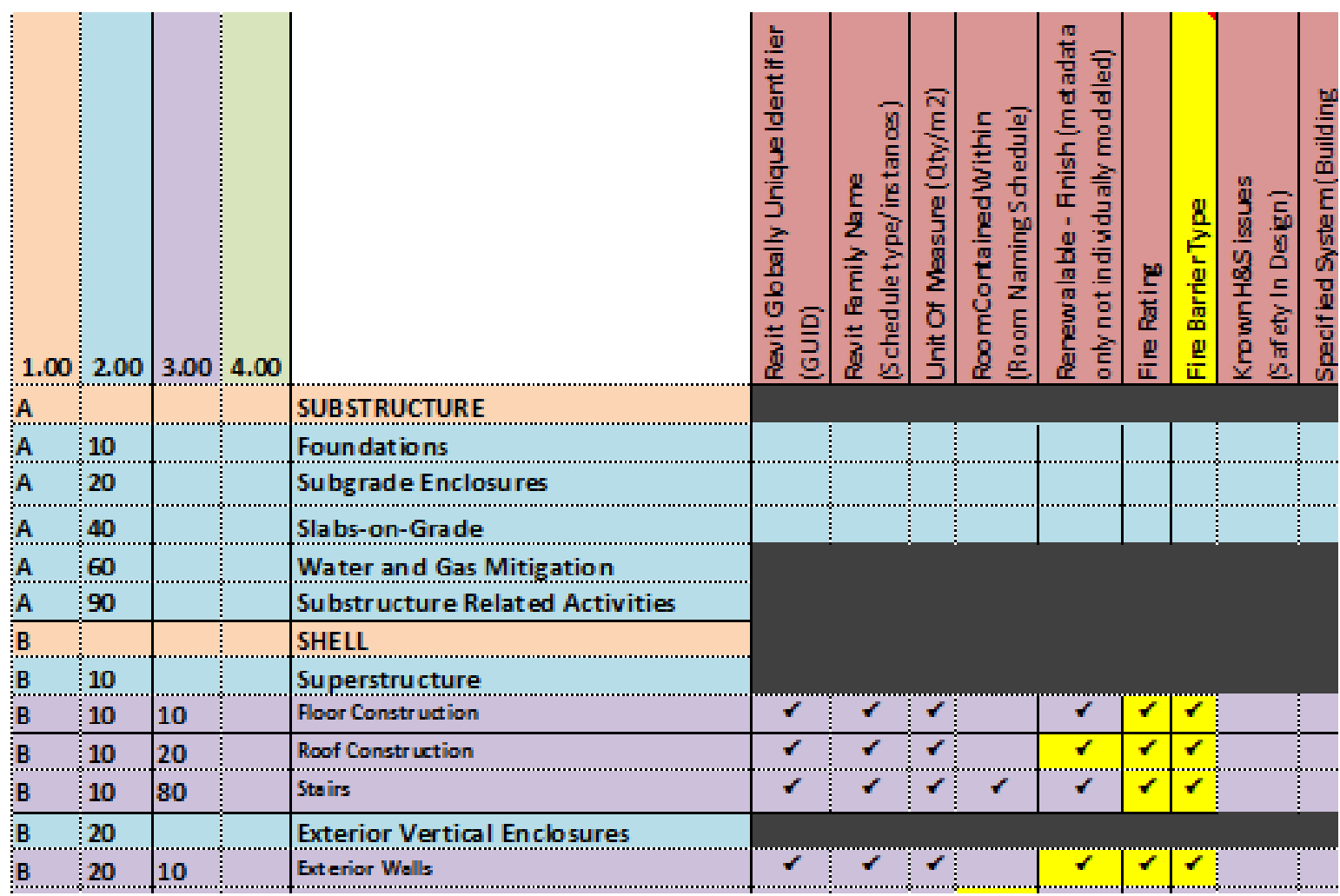

Table 37: MDPT Shared Parameters

Created schedules (prefixed AM: Asset Management) using shared parameters, ifcGUID and included UniqueID in the BIMLink exports. - To get the ifcGUID in see steps below: By exporting to IFC first, and storing as per below. Although, the ifcGUID is generated from the UniqueID even without storing it should be consistent each time. Some (limited) testing proves this. The below diagram alludes to this in the revit structure: 


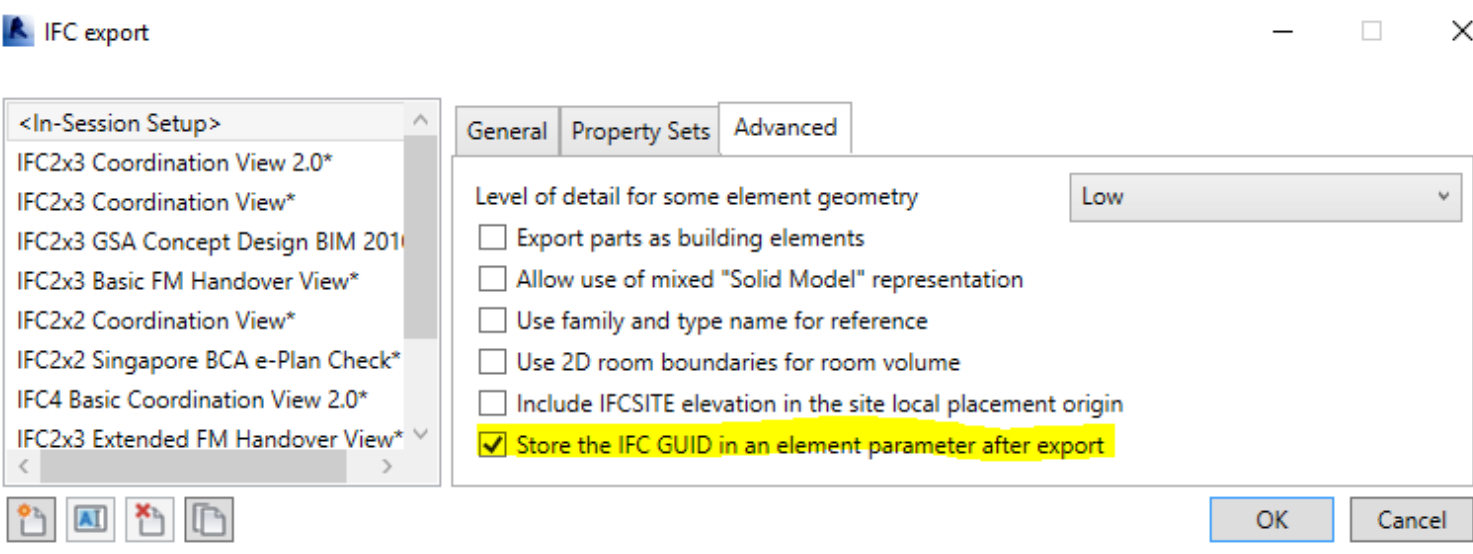

Figure 49: IFC export tab

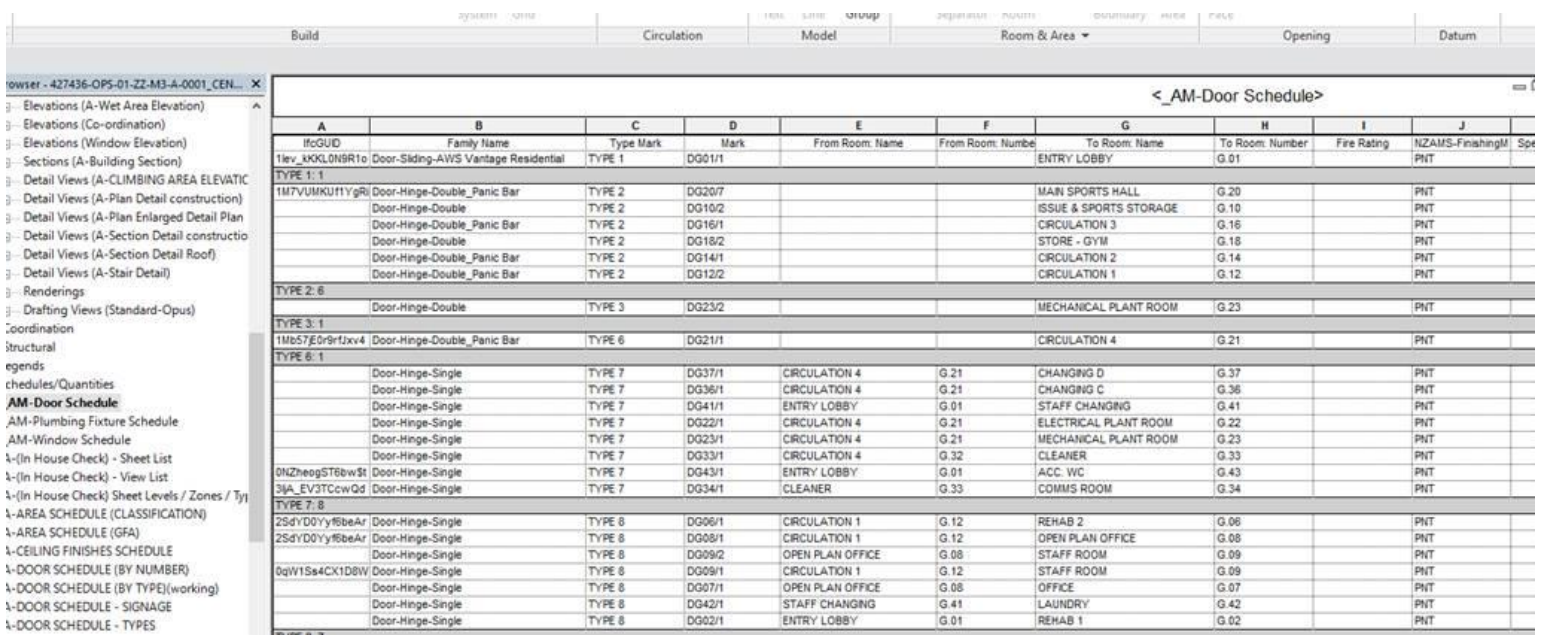

Table 38: Existing Parameters

Most of the data required can be drawn out of existing parameters and it is not desirable to have the same data sitting in two places - the premise of the whole database approach and streamline the use of data set to avoid this. However, there are cases, like the Finish where the client wants PNT (which aligns with their current systems). This still needs to align with the naming conventions for a BIM project, the design team could write a rule that says if it's prefixed with $x x x$, then populate this other field with yyy. This keeps both the client and designer happy in regard to common material names to the client compliant one? Creating a XXX prefix that covers all materials and then have additional descriptors when required - this may be the answer. Then in these circumstances the "material" will just extract the first three letters to be client compliant for example xxxPNT. 
Where a particular parameter is listed in the NZAMS having come from one of the pre-defined CODELISTS in the appendix, then it is expected by the client that it will only be one of those codes. Parameters have been created name: NZAMS-????Code_OP - meaning that it is a placeholder for an NZAMS Code which must be taken from the list. It is suffixed_OP as it is one Opus have created. In reality it would be ideal if the NZAMS provided those parameters in a similar way to ANZRS.

The design team asked the question of what is the DoorFunctionCode_OP, and re: the FinishingMaterialCode is that an additional parameter needing to be manually filled or can this be extracted from the existing materials attached to the object?

It would be desirable to achieve the values from existing parameters (where possible) currently these need to be manually filled out (though can be done in mass). However, depending on the items, and the extent to aligning to NZAMS, this may be able to be done programmatically. When looking at the provided CODELISTS, some of the codes have direct or indirect relationships to existing parameters.

For example: Door Function - not in the Asset Metadata Requirements (Contractors BIM Specification), but a Function column was in the AssetRegister.xls, Function = DoorFunction and this can be defined in the table:

Code List 21: Door Function

\begin{tabular}{|l|l|}
\hline Code & Description \\
\hline DIS & Disable Access \\
\hline EMR & Emergency \\
\hline FIRE & Fire Service \\
\hline REG & Regular \\
\hline
\end{tabular}

Code List 36: Finishing Material

\begin{tabular}{|l|l|l|l|}
\hline Code & Description & Code & Description \\
\hline CONCR & Concrete Render & POLISH & Polish \\
\hline GAL & Galvanised & STEEL & Steel \\
\hline GLZ & Glazing & STGLASS & Stained Glass \\
\hline LAM & Laminate & TILE & Tile \\
\hline PLAS & Plaster & TMBR & Timber \\
\hline PNT & Paint & \multicolumn{2}{|l}{} \\
\cline { 2 - 3 } & & &
\end{tabular}

Table 39: NZAMS code list 
As well as this the finishing material is defined above.

As far as populating this data, types first, then instance. Either edit type parameters inside Revit prior to export or export type parameters to Excel, edit and import back into Revit, then export instance parameters after that.

Figure 50: Data populating

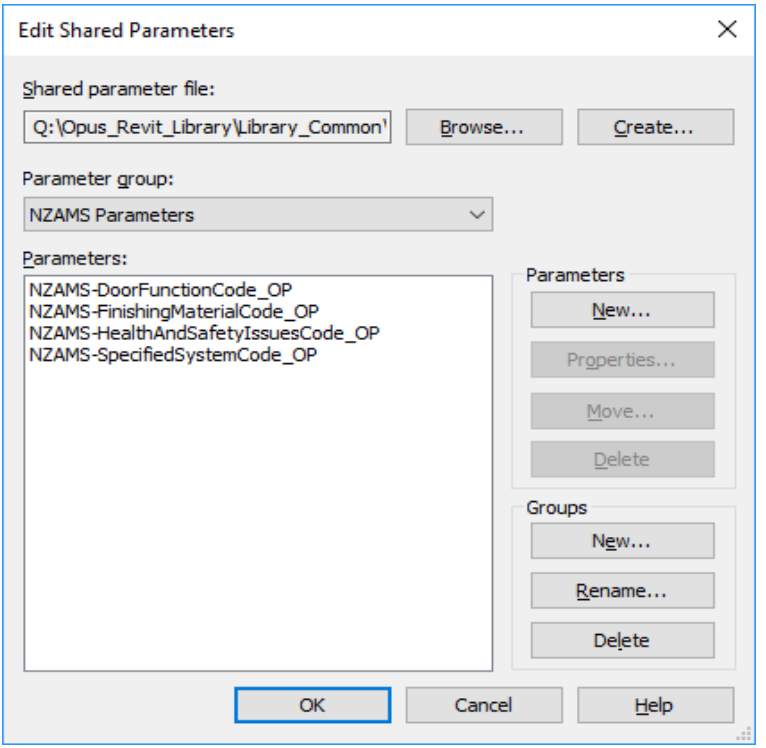

Floors need further thought due to the fact floor finishes will be more of interest, with structural floors tending to cover many rooms. There were some mistakes that came out of the revit including duplicated types:

Wall types and Window types are disorganised (assuming no-one ever expected/understood the types to be used for BIM). There is always a degree of making things work in revit that is faster when not worrying about scheduling. Because scheduling is one of the crucial element in this project there is no short fall allowed in the Revit design model. The model has some anomalies, however sometimes project goals mean that housekeeping items are not given as much attention as presented below: 


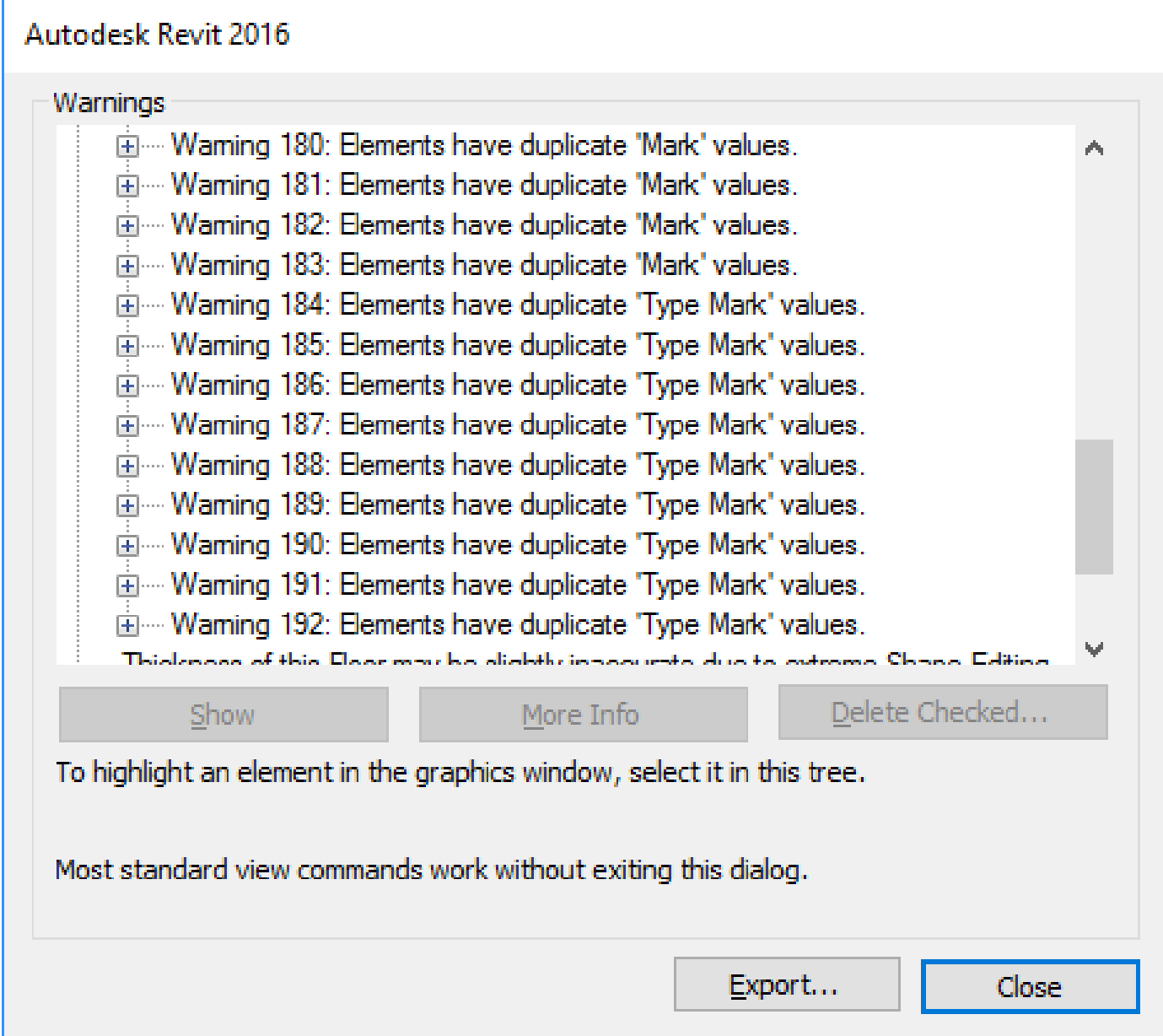

Figure 51: Autodesk warning clash detection

Ceilings have not been included yet, as this was to be a cut down export in the first instance, this needs to be included at a later point. In essence the design team were unsure how to include these shared parameters.

Not all the fields (and subsequently codelists) for walls have been defined, the MPDT does not include all those contained in the NZAMS (Residential Housing and Light Commercial Buildings Vol 1). It is from a subset agreed with the client. 


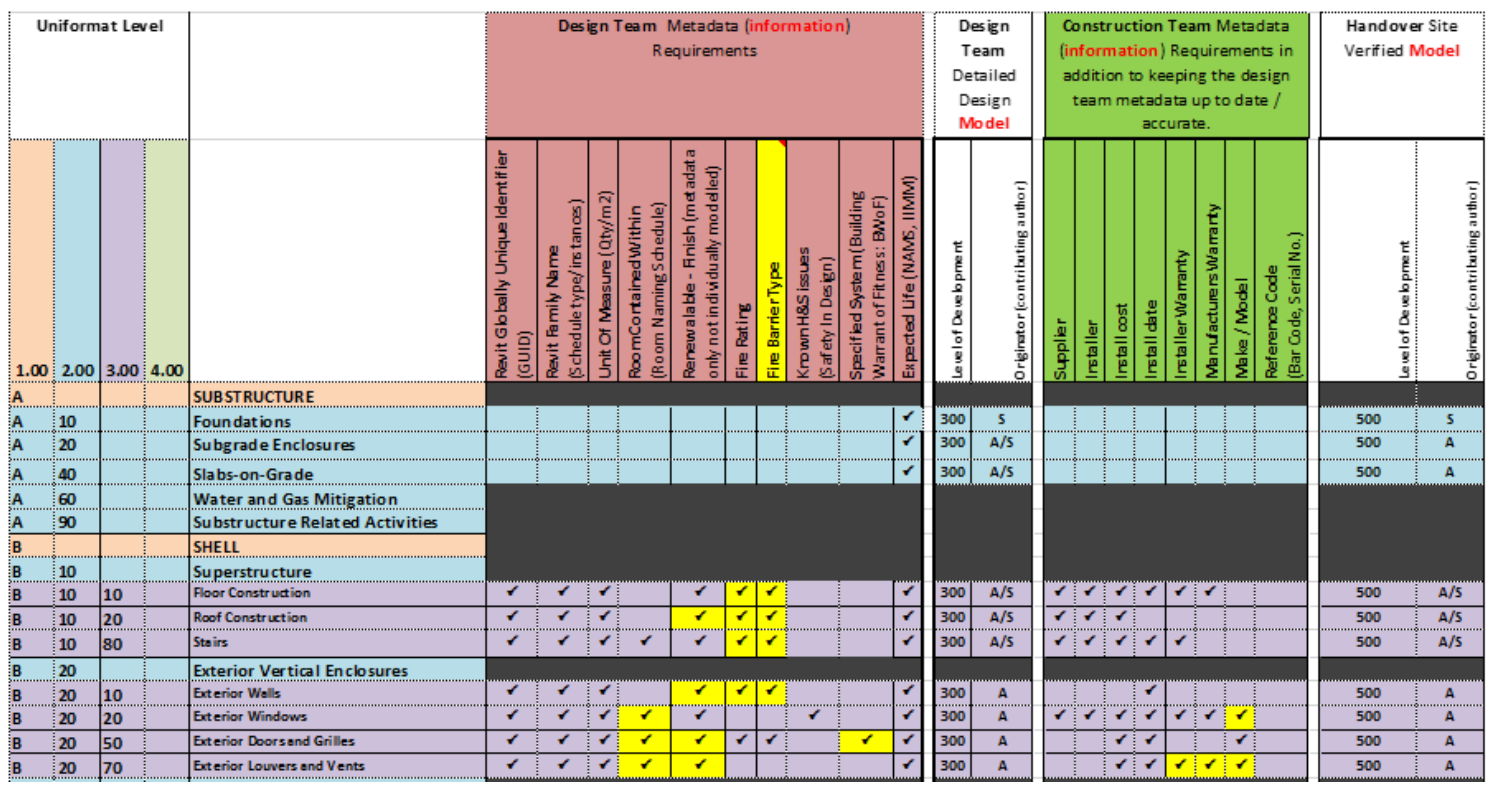

Table 40: Asset metadata requirements

The door fields stand and is a method by which to filter out nested families (door hardware etc.). At this stage a hidden field in Revit, BIMLink has no way to deal with these discrepancies. The data can re-import the values entered in the spreadsheets, later this will need to be actioned as a review.

From an asset management point of view in regards to the expectant life span of any given element the example presents: Short answer = For our aluminium windows Galv Steel (the bottom one of the 6) is closest equivalent for lifetime/repaint.

Long explanation: This list appears to be from the $1800 \mathrm{~s}$, as in the $20^{\text {th }}$ and $21^{\text {st }}$ centuries in modern countries the material aluminium is often used for windows (polyester powder coated or anodised) in everything except the very occasional instance. Softwood generally means pine in NZ. Buildings often use aluminium frames and sashes. (In houses and light commercial there is a softwood (or MDF) sill/jambliner. The Sill is only mentioned in 1 of those 6 categories. Does this allude to the fact that these categories may need updating? If so how is this actioned?

In the Gym the window encasement design is aluminium (polyester powder coated or anodised) Casement, aluminium sash (and softwood jambliner), some top hung. 
From the list provided, Galv Steel is closest equivalent for lifetime/repaint. It is adequate to use a best guess approach.

\begin{tabular}{|c|c|c|c|c|}
\hline $\begin{array}{l}\text { 2F Windows } \\
\text { and External } \\
\text { Doors }\end{array}$ & $\begin{array}{l}\text { Windows: Softwood Casement: Sidg/fng: } \\
\text { hardwood cills; weather-stripping; fitted with } \\
\text { fasteners; preservative stained base coat } \\
\text { Windows: Treated Soltwogrs: Single light; } \\
\text { ventilators; weatherstripping; opening sashes } \\
\text { and fanlights } \\
\text { Windows: Hardwood Casement Top hung: } \\
\text { hardwood cills; weather-stripping; fitted } \\
\text { with fasteners } \\
\text { Windows: Softwood: Purpose made frames; } \\
\text { treated; rebated and moulded } \\
\text { Windows: Hardwood: Purpose made frames; } \\
\text { rounded; rebated check grooved } \\
\text { Windows: Polyester Powder Coated Galvanised } \\
\text { Steel: Top/side hung; opening lights; weather } \\
\text { stripping; frames bed in mastic, pointed one side }\end{array}$ & $\begin{array}{l}40 \\
30 \\
40 \\
45\end{array}$ & $\begin{array}{l}27 \\
20\end{array}$ & 60 \\
\hline
\end{tabular}

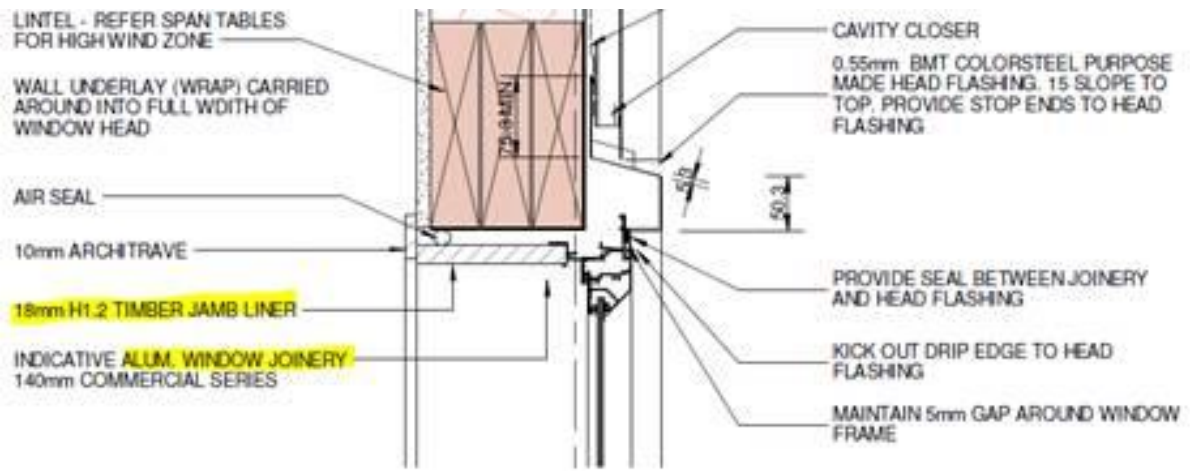

Figure 52: Window Detailing

In this instance the Doors scheduling is similar Ext hinged doors - galv steel frame-see image below:

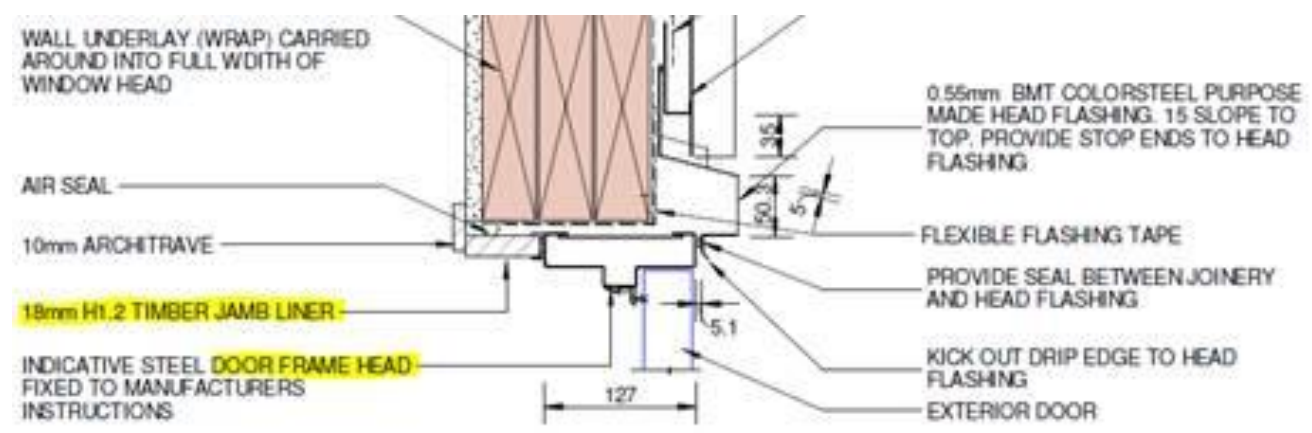

Figure 53: Door schedule detail 


\subsubsection{Internal correspondence of Quality Assurance on BIM model}

Design Team Meeting Thursday 17 August 2017-Gymnasium Project

The purpose of this meeting was to understand the processes/data assigned to the model and simulate a quality check to ensure those requirements as per the BEP and asset Meta data spreadsheet have been populated correctly.

The room naming conventions are currently categorised under groups, this is because of the brief, the brief (BEP) indicates these rooms are called this because of the NZAMS standard and the clients existing asset system. As one of the key objectives is to pilot this project for existing and future assets ensuring a consistent naming convention is paramount to streamline any asset and facilities management.

\begin{tabular}{|c|c|c|c|}
\hline 1 & Room Number & Room Name & Location \\
\hline 2 & \multicolumn{3}{|l|}{ ACTIVITY SPACE } \\
\hline 3 & G.11 & WEIGHTS ROOM & GROUND FLOOR \\
\hline 4 & G.13 & WEIGHTS \& FITNESS ROOM & GROUND FLOOR \\
\hline 5 & G.14 & CARDIO ROOM & GROUND FLOOR \\
\hline 5 & 6.16 & CARDIO ROOM & GROUND FLOOR \\
\hline 7 & G.18 & OUTDOOR CLIMBING AREA & GROUND FLOOR \\
\hline B & G.19 & MAIN SPORTS HALL & GROUND FLOOR \\
\hline 9 & M.01 & INSTRUCTIONAL GALLERY & MEZZANINE \\
\hline 0 & M.02 & VIEWING GALLERY & MEZZANINE \\
\hline 1 & \multicolumn{3}{|l|}{ AMENITIES } \\
\hline 2 & G.25 & CHANGINGA & GROUND FLOOR \\
\hline 3 & G.26 & ACC. WCA & GROUND FLOOR \\
\hline 4 & G.27 & $A C C, W C B$ & GROUND FLOOR \\
\hline 5 & G.28 & CHANGING B & GROUND FLOOR \\
\hline 6 & G.35 & CHANGING C & GROUND FLOOR \\
\hline 7 & G.36 & CHANGING D & GROUND FLOOR \\
\hline 8 & G.37 & UNISEX WC 1 & GROUND FLOOR \\
\hline 9 & G.39 & UNISEX WC 2 & GROUND FLOOR \\
\hline$! 0$ & G. 40 & STAFF CHANGING & GROUND FLOOR \\
\hline 1 & G.41 & LAUNDRY & GROUND FLOOR \\
\hline 2 & G.42 & $A C C . W C$ & GROUND FLOOR \\
\hline 3 & \multicolumn{3}{|l|}{ CIRCULATION } \\
\hline 4 & G.01 & ENTRY LOBBY & GROUND FLOOR \\
\hline
\end{tabular}

Table 41: Room number and naming conventions

In the Revit model the space usage on the left-hand side has been set up to match the room location for the data as specified above within the Solibri Model Checker. 


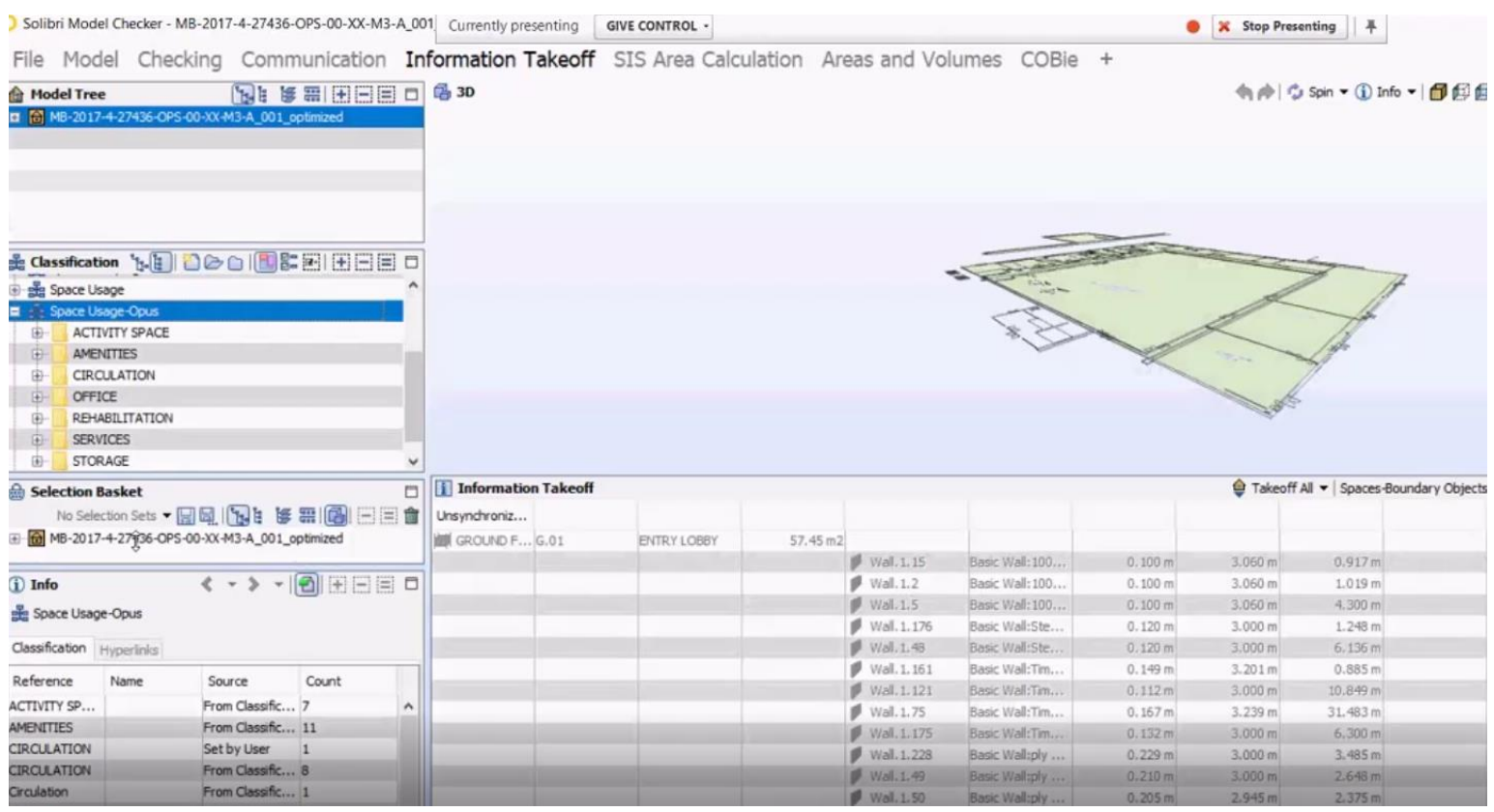

Figure 54: Type parameters information column

Once this is in place then you have the ability to see how elements are classified around the building and then start to see if the right elements are in their desired spaces. Through reviewing of the spaces against the digital model it was clear a few discrepancies needed tweaking across the model.

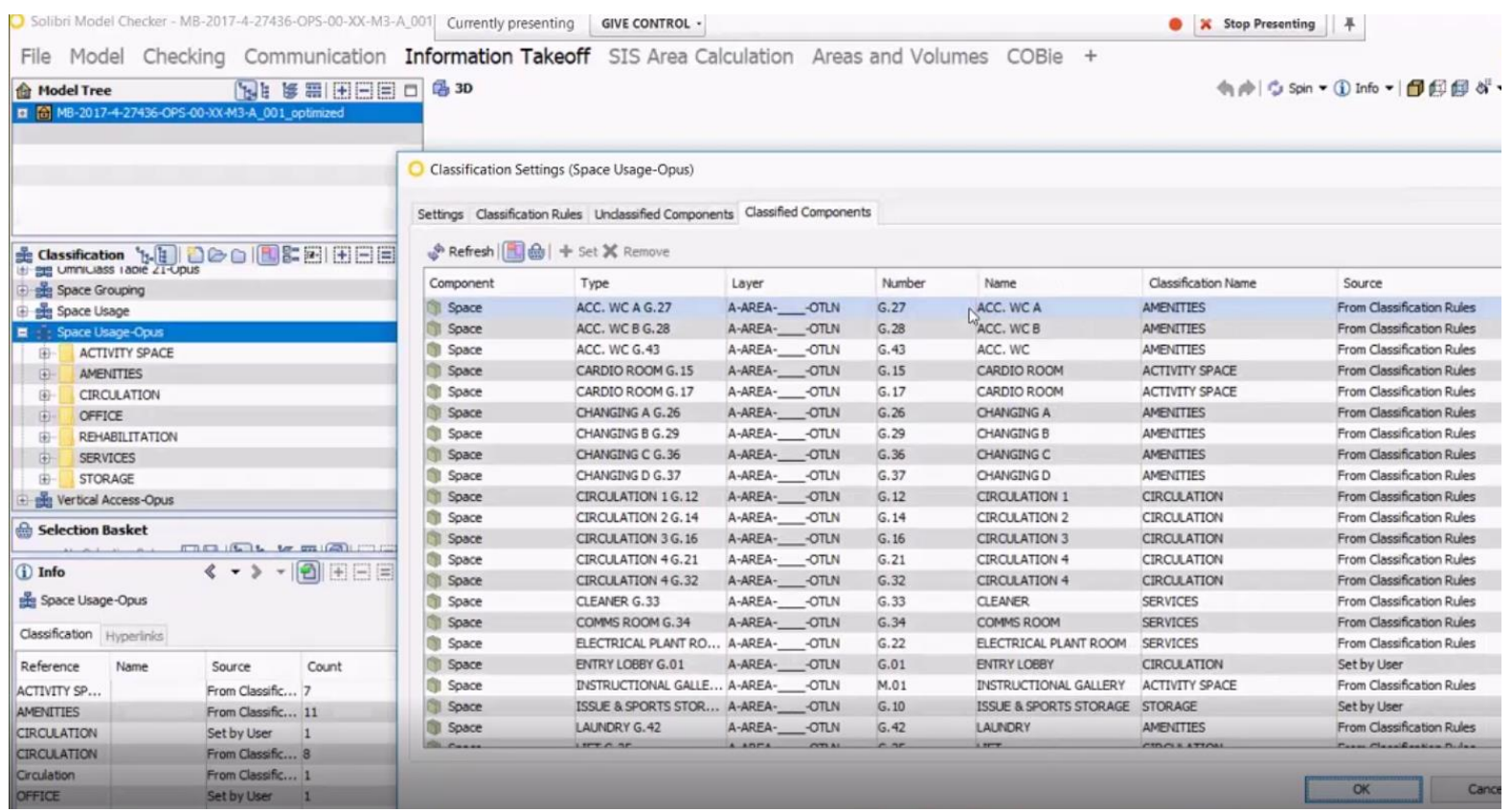

Figure 55: Type parameters information column 
In an organised platform, a briefing document would immediately show how elements and components are set up in a particular way allowing the user to navigate around different components and areas. A briefing document is important for the project as a reference tool, not only for the duration of the projects development but also if clarification is needed at any stage of the project.

Within the Solibiri model tool there is a tool known as space boundary objects classified as an "information takes off". It is set up by looking at different levels of a building room, areas and associated elements and reports concisely, identifying individual elements as well as pieces together aspects that make up the room. One issue acknowledged is for example when you select the slab, this goes across the entire floor of the building not just that room. Secondly an issue with internal walls is apparent, depending on how you look at the data, the internal walls may be double take, what the design team are trying to achieve is to get a simple path to understand a sqm for specific areas. This is a way of looking at data for the entire building but for the purpose of Asset and Facilities Management this way of looking at it does it no justice, the information needs to be broken down

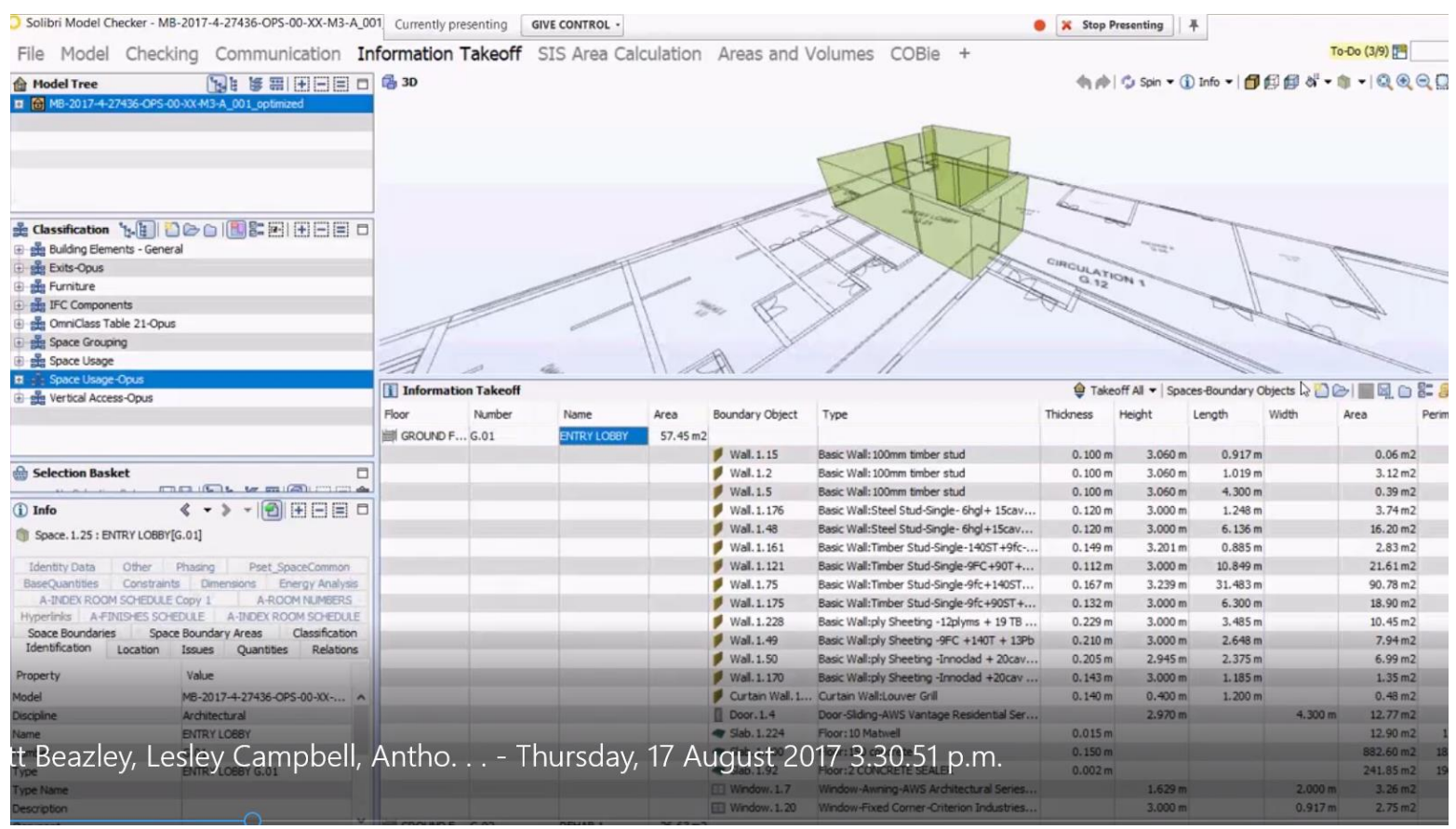

Figure 56: Solibri Model Checker information take off 
The Solibri tool is useful for identifying areas in an overall space, that binds rooms for example. Space usage column suites classification system.

Ceiling, floor and wall column codes come through within this tool, so for an example CL 01 can be said that the model has $x$ amount of wall coverage and this costs $x$ amount of dollars for the client's operational benefits. What the design team is seeing within the Solibri checker is an element has been given a name and all the information has been extracted and by the default settings which is incorrect in some instances. The design team need to revisit the wall covering codes as it is not being extracted from a parameter that is up to date, this needs double checking.

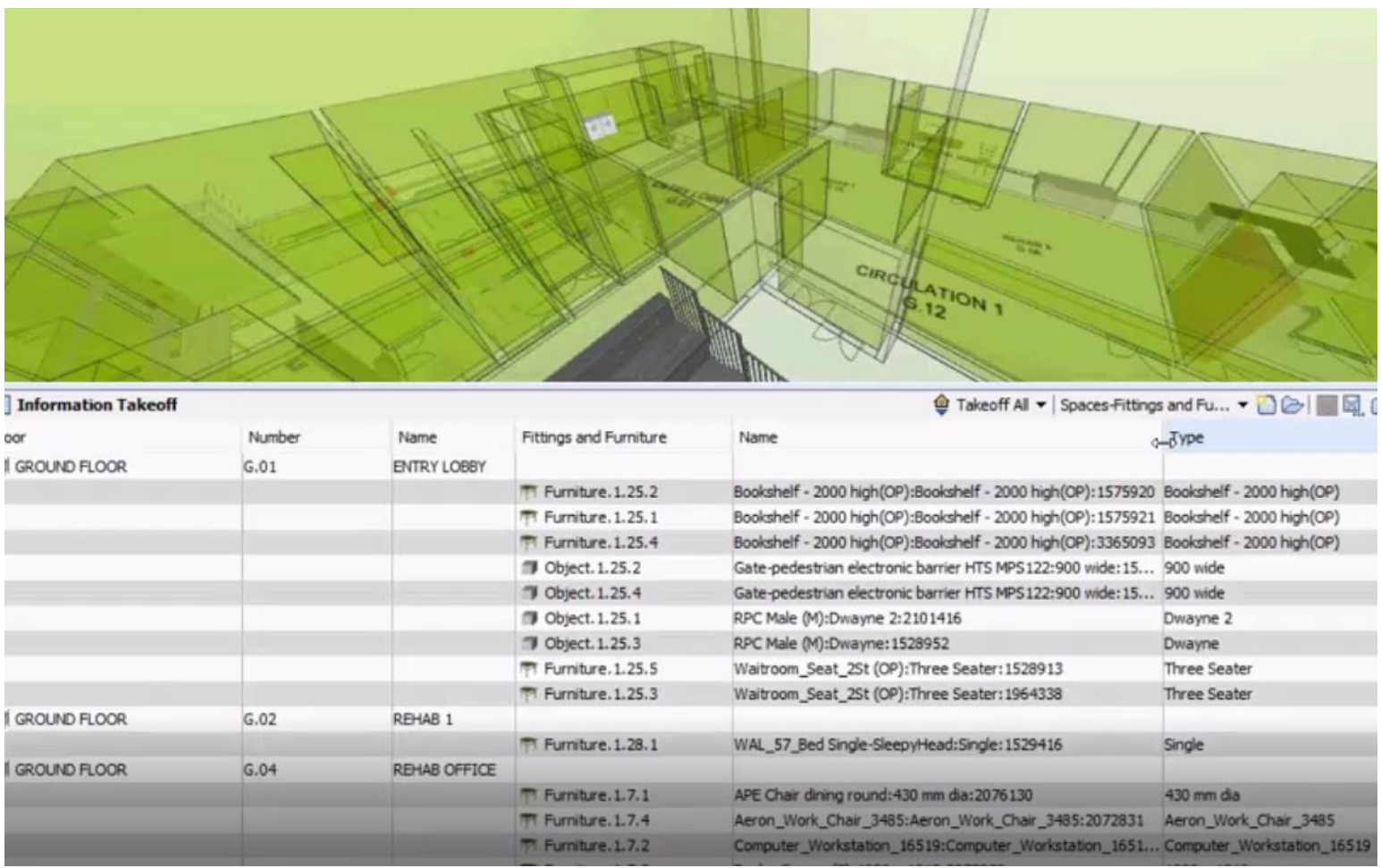

Figure 57: Wall descriptions from solibri

The following steps are to be utilised within the Solibri checker for Information take off, when highlighting under furniture and fittings (just this column), click on the column which navigates the user to the room from a 3D perspective, this can then be extracted as an excel spreadsheet which allows this data to be migrated into data sets. 

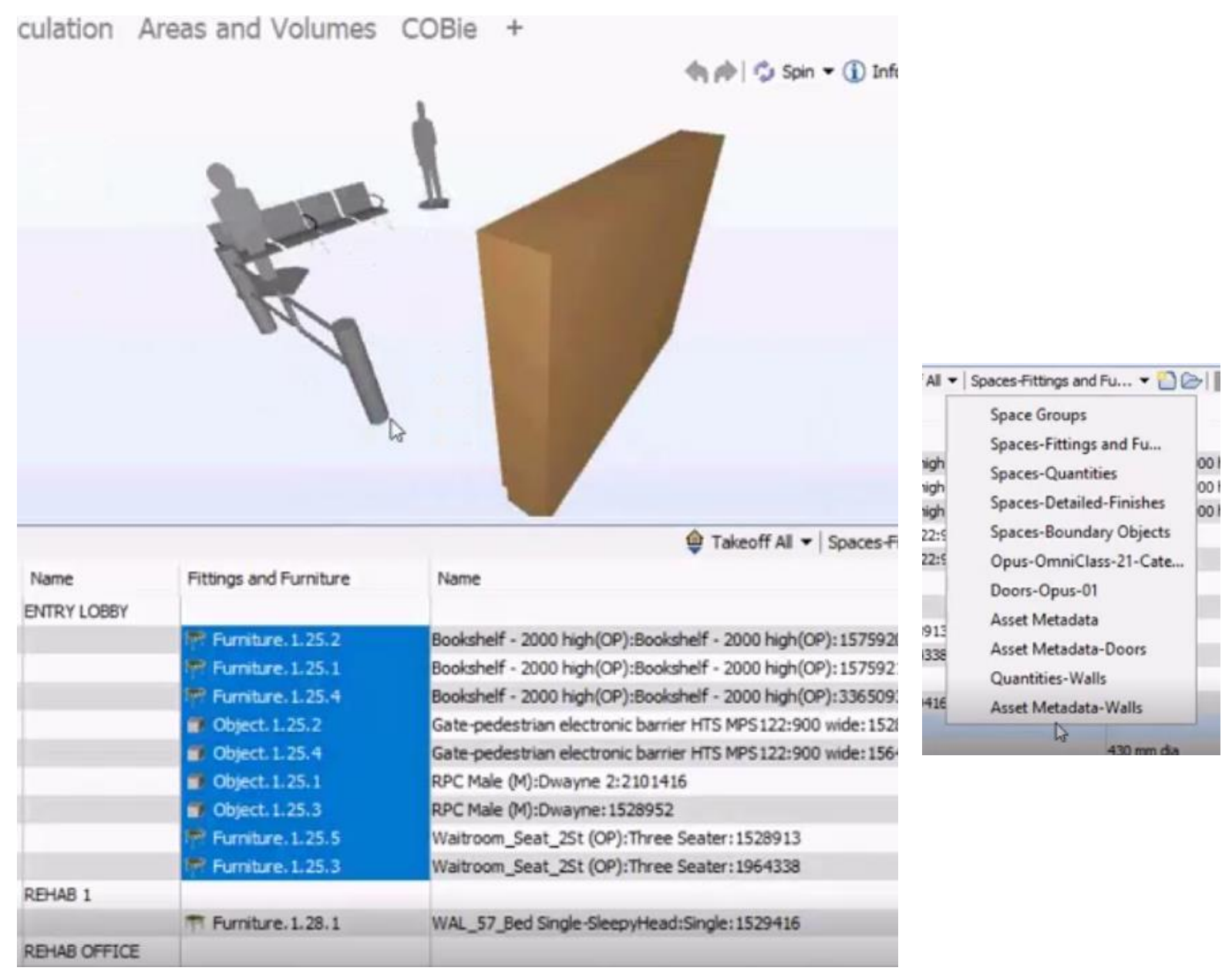

Figure 58: Solibri areas and volume tab

Making sense of the LOD and MEA (see definitions above) is important in this aspect of the process. The BIM forum document should be referred to when looking at a particular element of the sport stadium design. The information needs to be defined at this level, the data is over laid with the asset and metadata as defined in the BIM forum specification, additional columns of what metadata for various elements is included, the design team need to define when the asset metadata is needed.

The asset Meta data information can be viewed in the solibri tool and for example a wall and all the information associated with it can be displayed as shown in the figure below: 


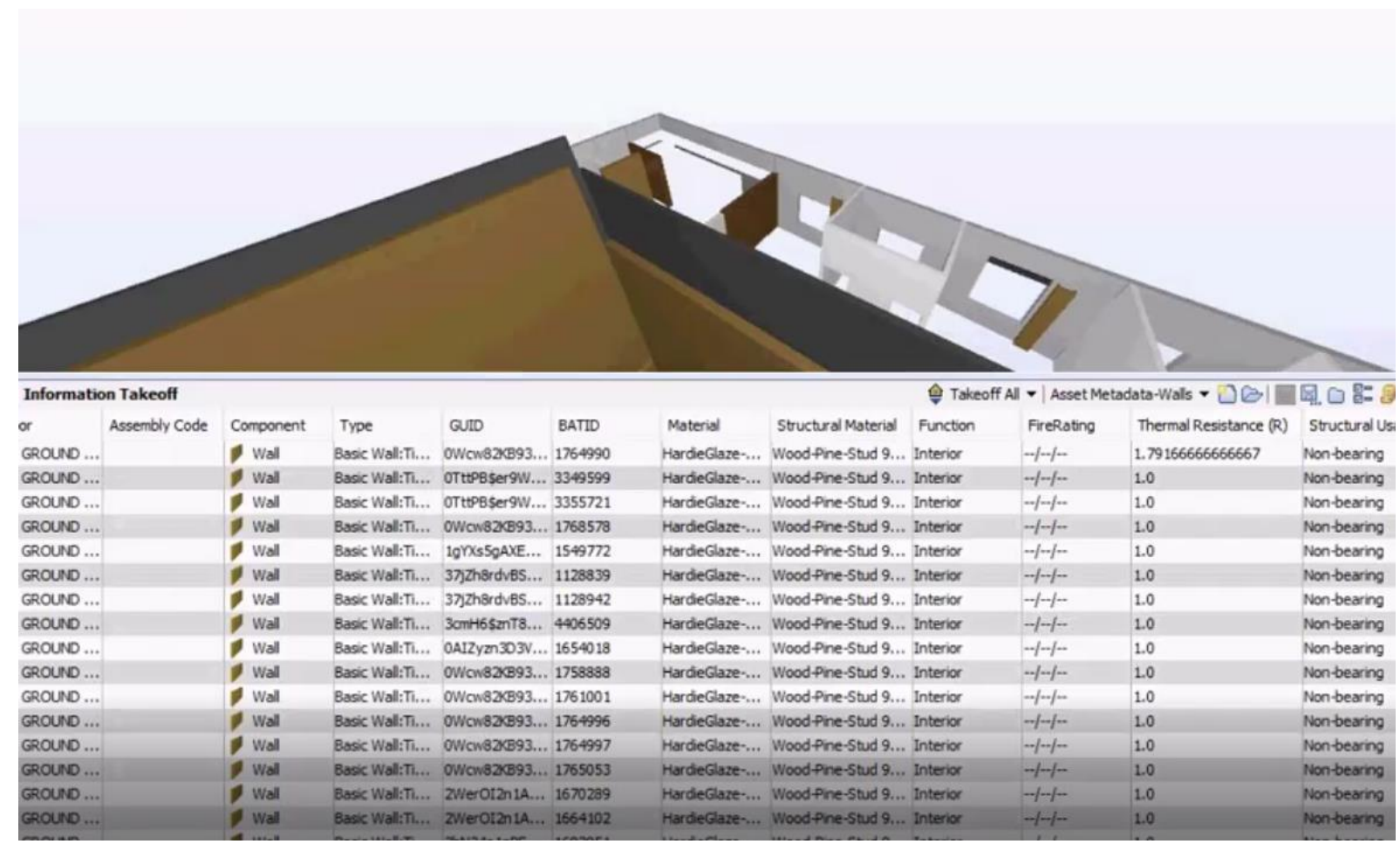

Figure 59: Asset metadata information

If the parameters exist in the model they can be found here, for example acoustic is not in the model so is not associated within the system.

The asset data parameters that needed to be associated are as follows and different for each element for example a door requires different inputs compared to a ceiling, the Revit ID has been removed as in other projects it gets way too complicated and the data becomes over bearing. 


\begin{tabular}{|c|c|c|c|}
\hline \multicolumn{4}{|c|}{$\sin 1$} \\
\hline & Model Elements & Asset Meta Data Parameters & Des \\
\hline \multicolumn{4}{|c|}{ Architecture } \\
\hline \multirow{6}{*}{\multicolumn{2}{|c|}{ Location / Spatial elements }} & Revit ID number & \\
\hline & & Keynote & \\
\hline & & Phasing & \\
\hline & & Condition Score & \\
\hline & & Life Cycle (no. years) & \\
\hline & & Maintenance Cost & \\
\hline \multirow{2}{*}{\multicolumn{2}{|c|}{ Floors }} & Levels & \\
\hline & & Floor Type & \\
\hline 1 & \multirow{3}{*}{ Walls } & Wall Type & \\
\hline 2 & & Fire Rating & \\
\hline 3 & & Acoustic Rating & \\
\hline 4 & \multirow{8}{*}{ Doors } & Level, Room & \\
\hline 5 & & Door Type & \\
\hline 5 & & Door Number & \\
\hline 7 & & Frame Finish & \\
\hline$\beta$ & & Panel Finish & \\
\hline$\theta$ & & Fire Rating & \\
\hline p & & Acoustic Rating & \\
\hline 1 & & Seale & \\
\hline
\end{tabular}

Figure 60: Type parameters information column

The parameter/value associated to the model elements is currently represented by a star symbol (see figure below), it needs something that relates to the phases of the project and can be another way of grouping information, and once this is defined the model author is able write a new rule/language for future parameters. In developing these aspects within the gymnasium project this will be able to be mirrored for the business' future projects. In doing so the BIM parameters will be more efficient as currently the project outlined is primarily used for lessons learnt and to develop a business as usual approach. 


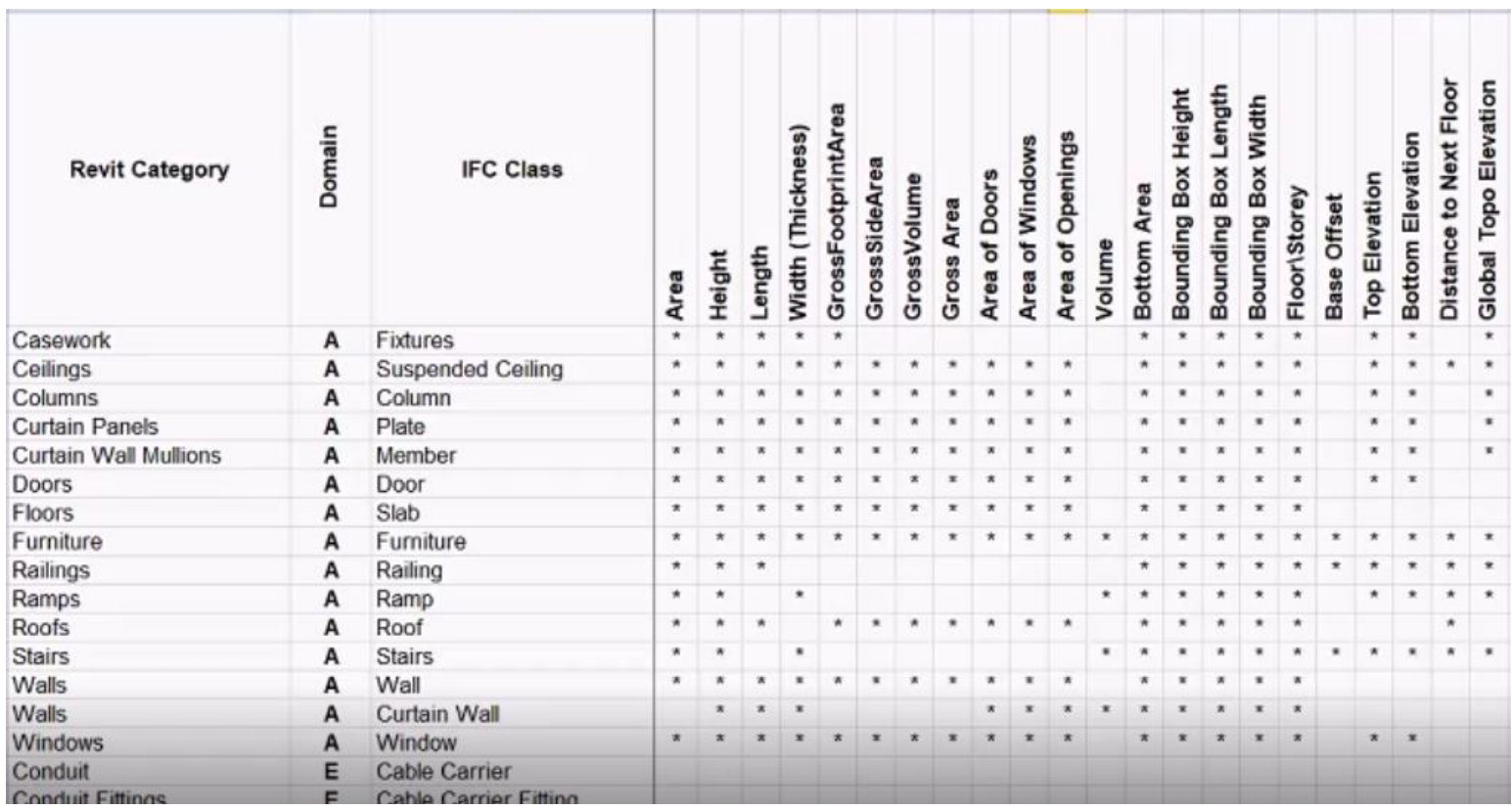

Figure 61: Parameter value

When relating data traits to phases, for example preliminary design and detailed design, this allows the data to be defined at different levels and stages and can outline what needs to be done at certain stages. This was being followed in the LOD table. In Solibri you are able to set up a rule in ruleset folders and this allows for architecture checks, electrical checks and the likes. The spreadsheet is able to be analysed to see what data is required, for example the design team can see preliminary design and detailed design and decipher the changes between the two design stages. 


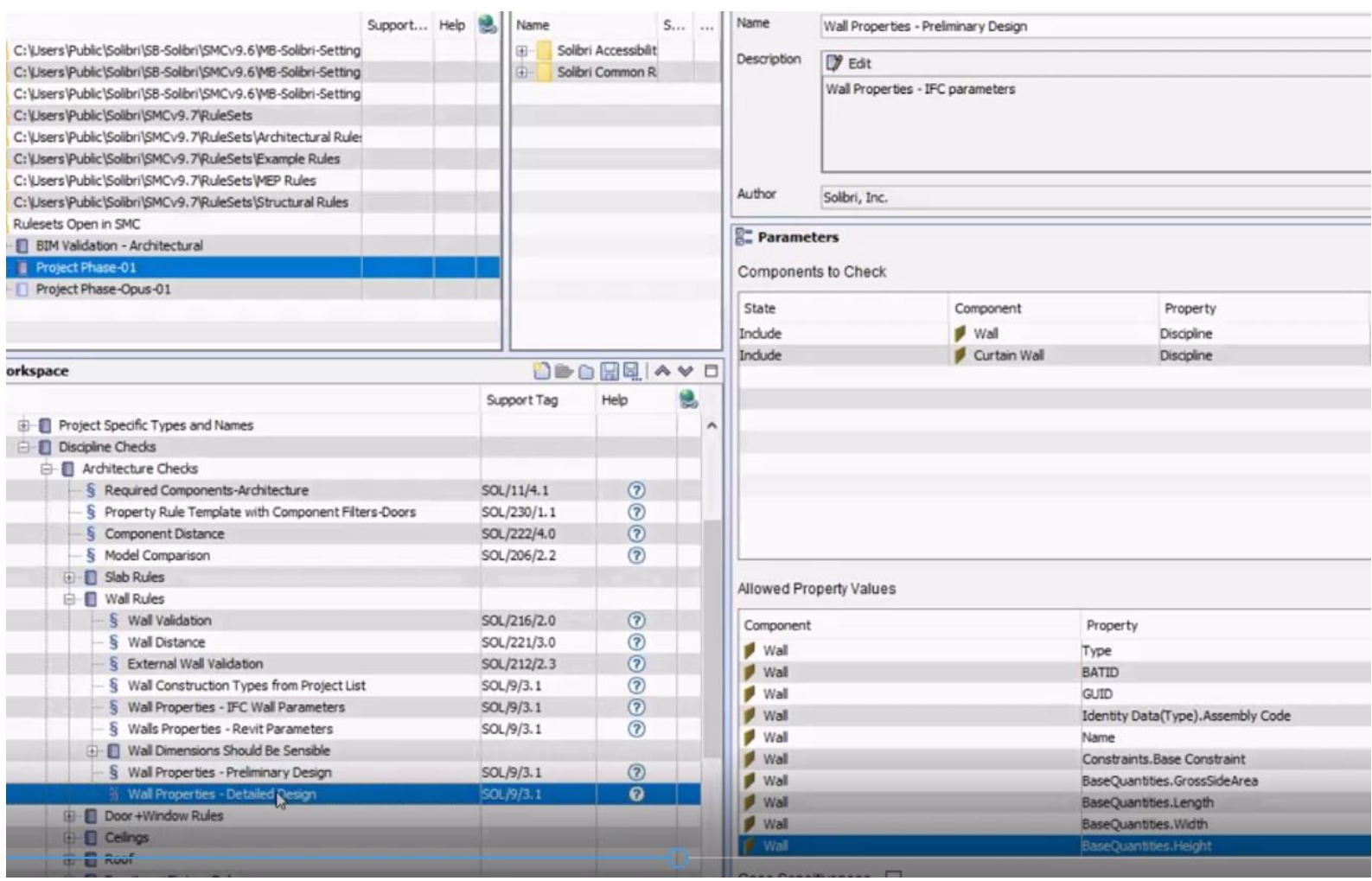

Figure 62: Solibri Model Checker design phases

As the project is expected to have multiple design phases the information breaks down will not be followed below detailed design due to time restrictions. An important factor for the gymnasium is to identify at construction completion what will need to be added to the documentation for operational purposes

It is expected that the universal naming convention adopted will be Uniclass as this can be imported/exported with any design tool. For this project the design team have utilised Revit naming conventions in the Solibri tool, as this project is likely to go beyond for future use, this naming convention may become redundant. The design team need to ensure that they future proof their work as this could create a limitation in time.

Omniclass naming conventions have been developed which aligns with uniformat, in classification setting the objects will be checked if the element has particular values aligned with this, if it is not classified it will say it isn't classified within the Revit category. You can see straight away what has not been classified as shown in the figure below 


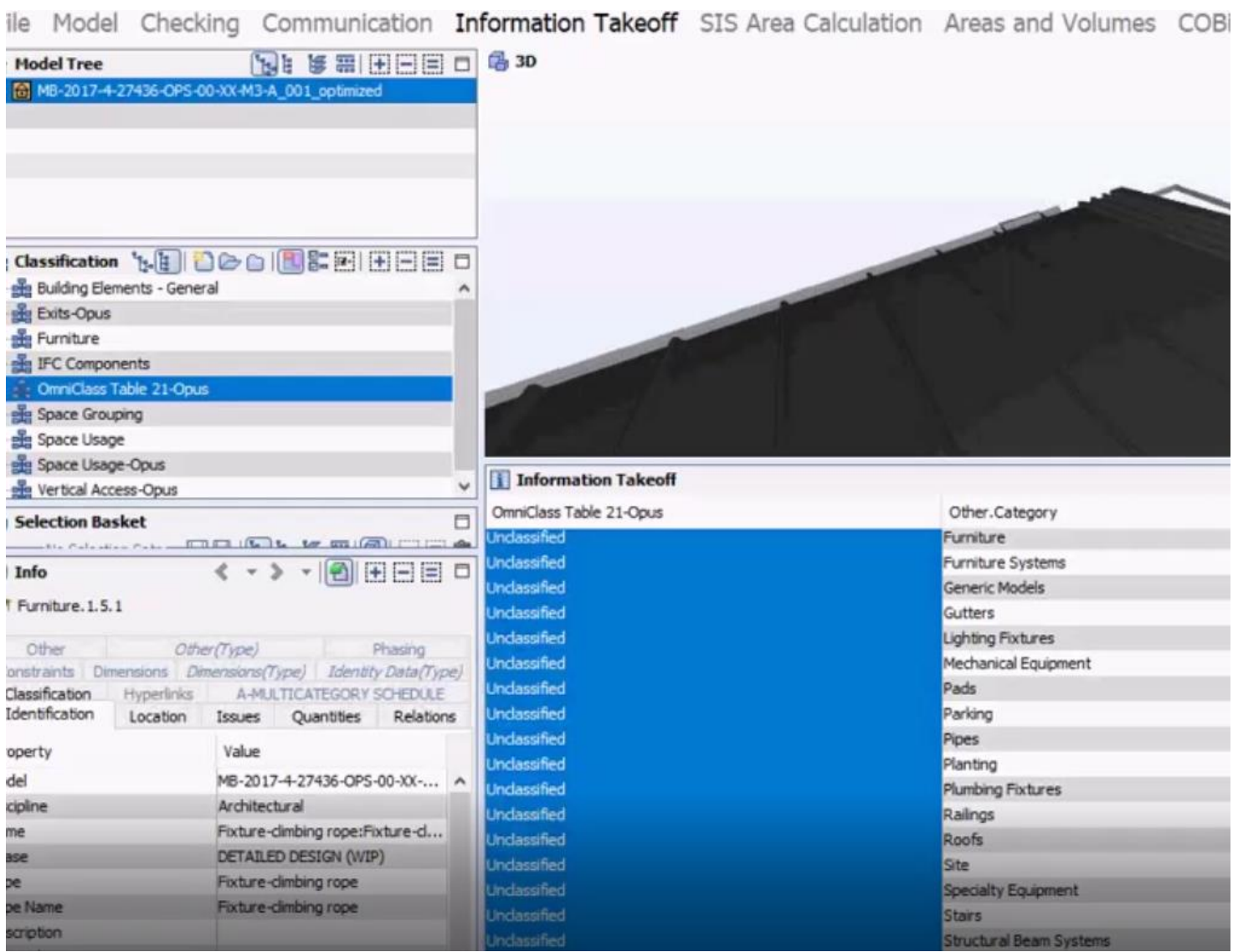

Figure 63: Solibri ominiclass table

The information take off tab in Solibri allows the user to view elements and can identify whether they are classified or unclassified, there is the function to view this in Revit but does not report as easily as Solibri does, Solibiri has the ability to export an excel spreadsheet, as well as a graphical package. The Solibri tool allows omniclass elements to be viewed and analysed from different angles that can be spatial checks and object checks for example. If the asset management team wanted to do a metadata check of doors for instance, this can be set up or specifically set up for what the client desires. The BIM model user can set this up as a standard QA procedure to provide an information check, to ensure the client is receiving what they should expect. If the client is defining check points they need a QA system that is developed in parallel with the likes of a BEP. An issue that has arisen in the past is that there is no QA plan in place and commonly the QA aspect of a project is when the consultants hand over the project and associated attributes and the client is forced to trust the project. Often this is due to a lack of understanding from both parties. 


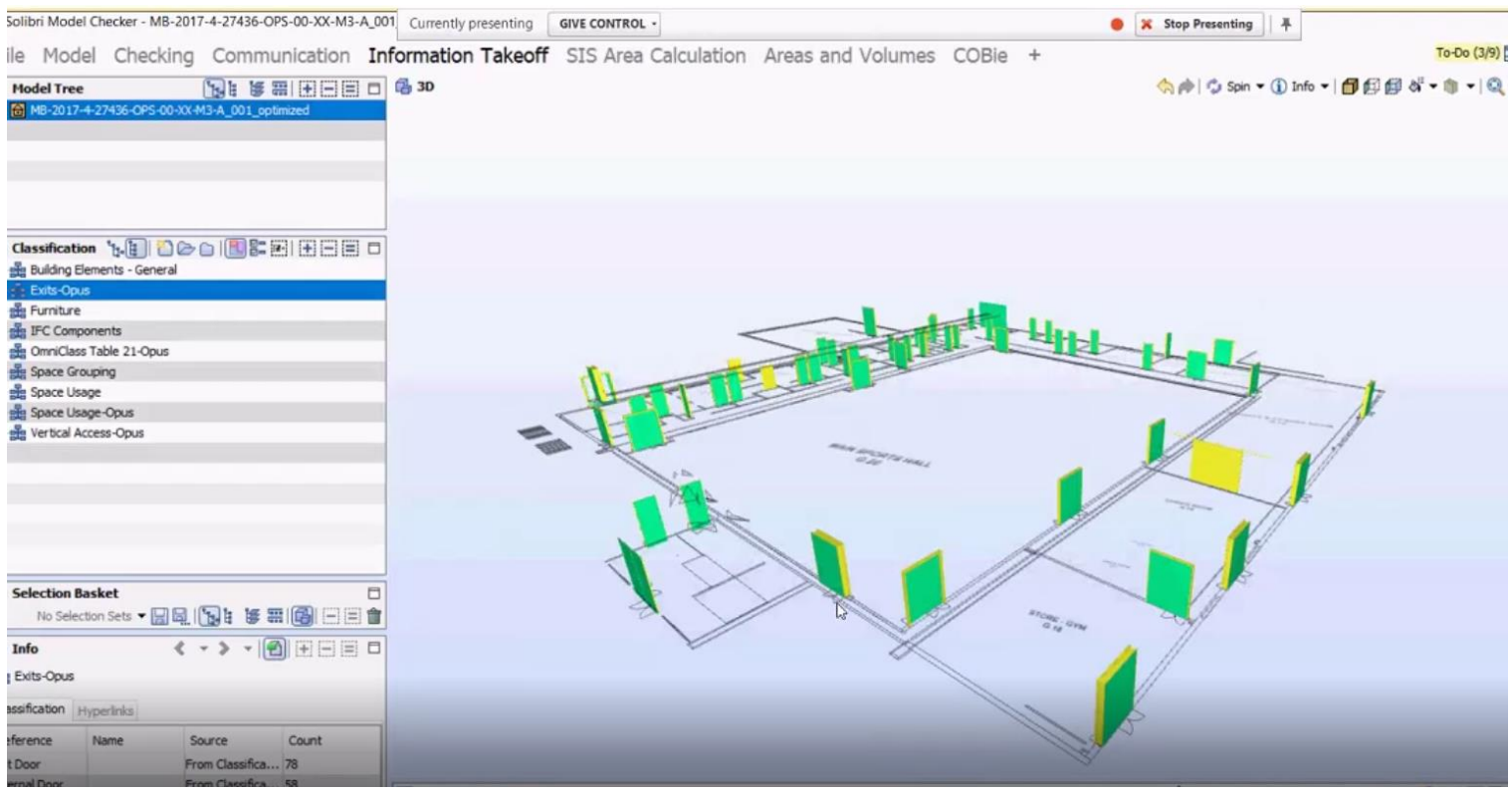

Figure 64: Parameter value model exits for example

The gymnasiums Asset Management team has implemented all of the parameters that the client requires exporting, for example schedules, these haven't all been put into the model, and the next stage will be exporting theses schedules to the design team. The project is currently on hold due to the client's budget constraints.

The visual BIM associated to Meta data within the excel spreadsheet at this stage has not been embedded back into the model. The main reason for the 3D BIM is to see the visual spaces. It is faster to set up with BIM link export. - This is having checks on volumes and rooms and checking the entire model and category to understand the relationships within the model. Solibri work is based on an exported file that has come out of Revit, checked on Solibri, any work on BIM link is checking the model and has no Solibri relationship if this then identifies a change from BIM link to the Revit model, the updated data is able to be uploaded to Solibri from the Revit model. BIM link is a convenient way of linking Revit, if the information was to go back into Solibri from a changed Revit model then these changes will be highlighted.

The only need for linking the data back into the Revit model is purely if the data was then needed to be utilised within another software tool this being the likes of Autodesk tools. The design team are providing the client the native application, this being the Revit model agnostic application this being the IFC and associated metadata (the spreadsheet). Solibri is 
not part of the contractual obligations and is only utilised for QA and checking of the processes. QA/QC procedures were introduced by the design team for their benefits only.

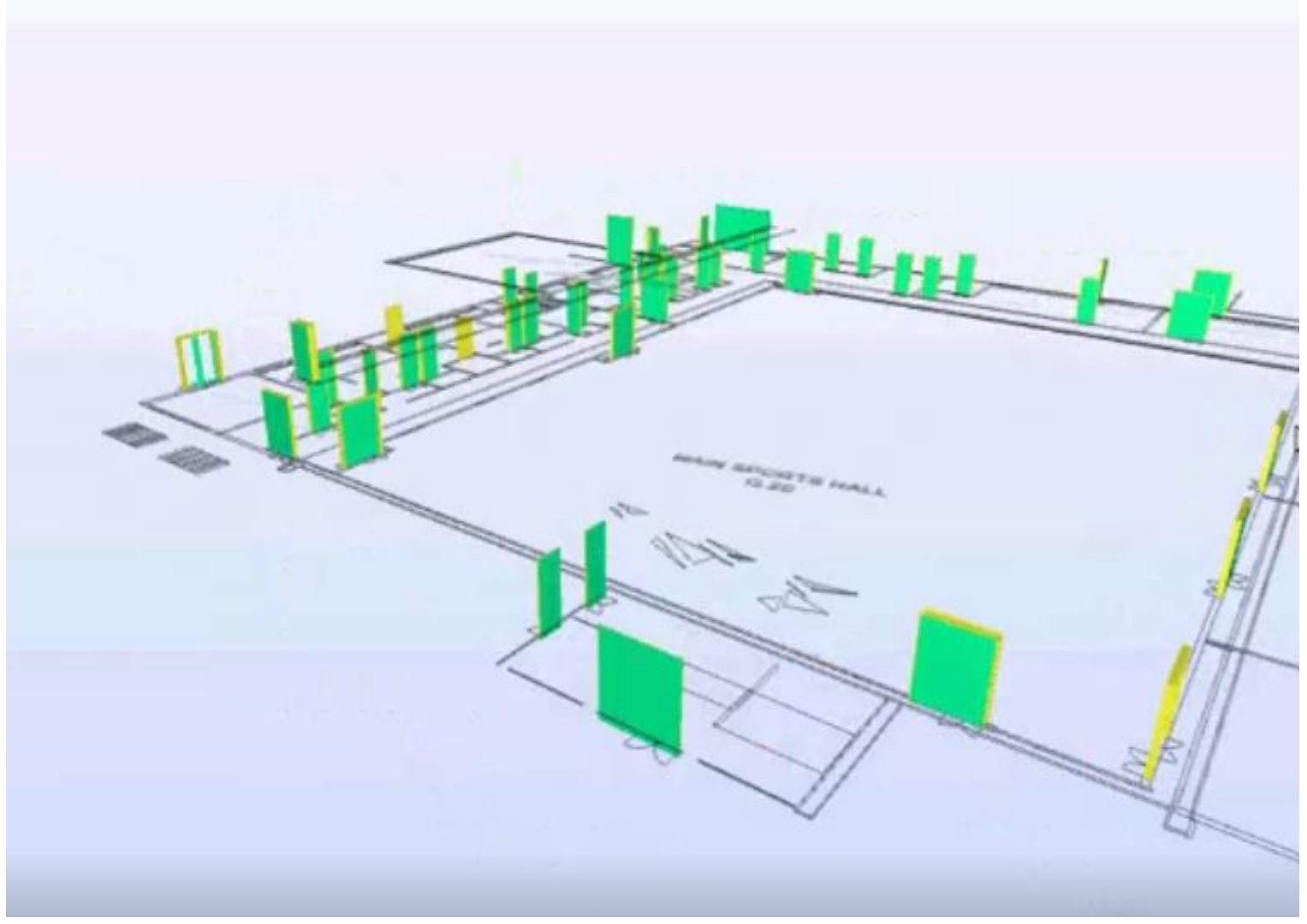

Figure 65: Element data selection (Solibri)

Having a clear picture of what data is needed for the specific project requirements and understanding the data you can plug into Solibri and to define these parameters is a crucial turning point for the design team to escalate from this project. This will be saved into a raw folder and under each design step, i.e. detailed preliminary whatever. Here the design phases can be compared to analyses data traits. 


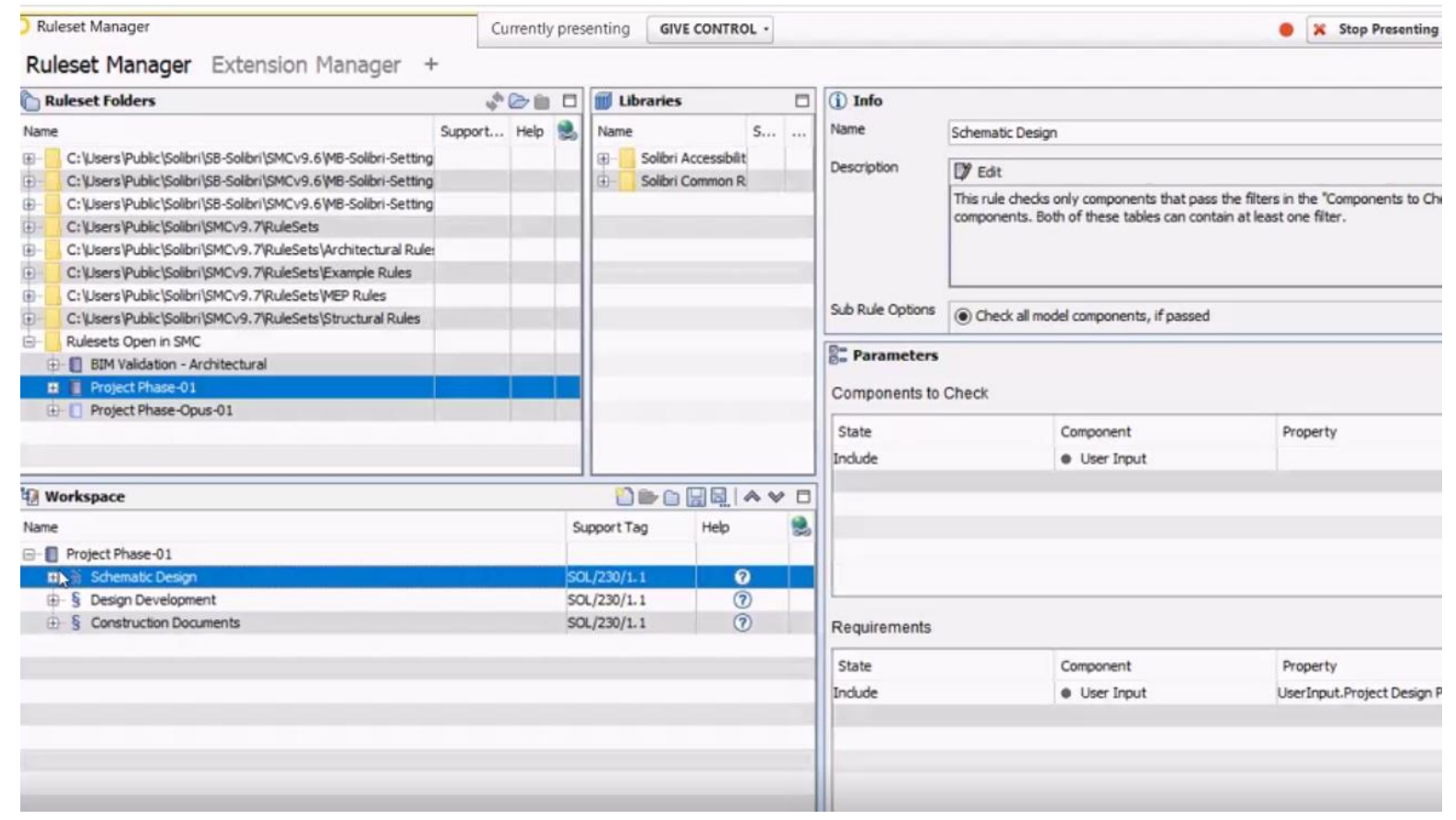

Figure 66: Design Phase selection

From this, then checking each discipline. Basic checks - there will be more detailed design checks as the process and design increases. How have you extracted the information? All can be customised to suite project.

Next steps, extract this from the knowledge and be able to run these themselves, perfect concept and needs to be documented as a workflow training.

If the design team does not populate the rule sets from how the process has been carried out, it is difficult to see how it has been set up, workflow will allow for this. Without the defined workflow, the embedded data procedures become redundant and is not able to be escalated at a later date. So therefore, the learning from this project are not defined. Solibri is a very extraordinary tool, however some of the Solibri attributes can be achieved in Revit Solibri, you can see the data faster and are able to set up rules that check processes specific to the desired outcomes and objectives. Revit only has the capabilities to check the raw data. The value of Solibri is that it is a one stop shop, allows for clash detection, federation, sucking data, rule-based checking and much more. 
A new version of the companies BEP was modified in August from the UK audit accreditation of level 3 BIM, here the contractor extracted cheat sheets from BEP to define certain parameters with the project

Such advancements included Building Information Modelling (BIM). Unmanned aerial and ground systems (UAS and UGS), autonomous machineries', and equipment and advanced building materials which have allowed for fundamental production in the construction industry. With this in mind, the rate of innovation and change has flat lined over sometime. It can be speculated that adopting BIM has meant a decline in innovation possibly due to limiting complexity within a model.

\subsubsection{Client survey correspondence}

To align the client expectations with the project deliverables in regard to the operation of this building the company set up a trial questionnaire that was to be facilitated to specific client representatives. The reason behind this, is that clients often don't understand what they are wanting to know therefore assets are often overloaded with un-useful data. The spreadsheet as shown below represents a horizontal decision trees, this was developed by the asset management team as a way of alluding the client down a specific path to answering asset management modules. The tree begins with a basic question of do you own assets right through to do some of the assets needs routine cleaning and replenishment of consumables (see Appendix 17). 


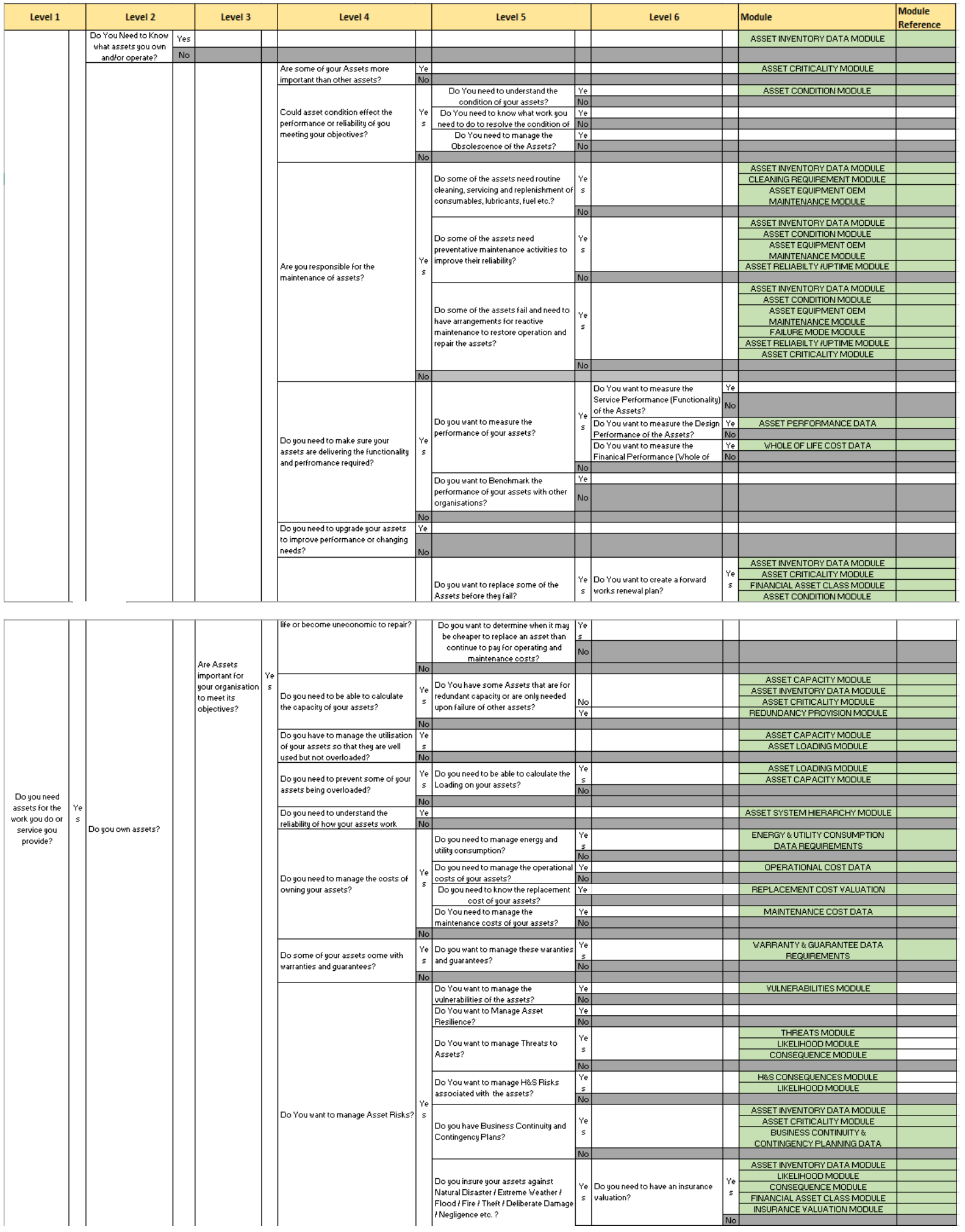

Table 42: Asset Management Tree

After defining these parameters these were then turned into a Qualtrics survey. Qualtrics is a survey primarily for external organisations as an easy tool to navigate a user through 
questions and for this purpose to allude the user to a set of modules for their assets. Currently this is still being reviewed and developed and has not been escalated further due to the complexity of the asset tree diagram. The next step for this development is to redefine and simplify the client questions.

\subsubsection{Internal Correspondence of Asset Requirements}

\section{Asset metadata alignment Meeting Friday 20 October 2017}

The purpose of this meeting was to discuss the Asset Management Decision tree (as shown in appendix $x x$ ) and the process of managing assets for the client, defining who the client is and who will be managing what and to what level of detail does each audience require. These questions need to be answered to ensure the correct information is stored within the model An audience column was added to the right-hand column defining who the people are likely to use each module etc.

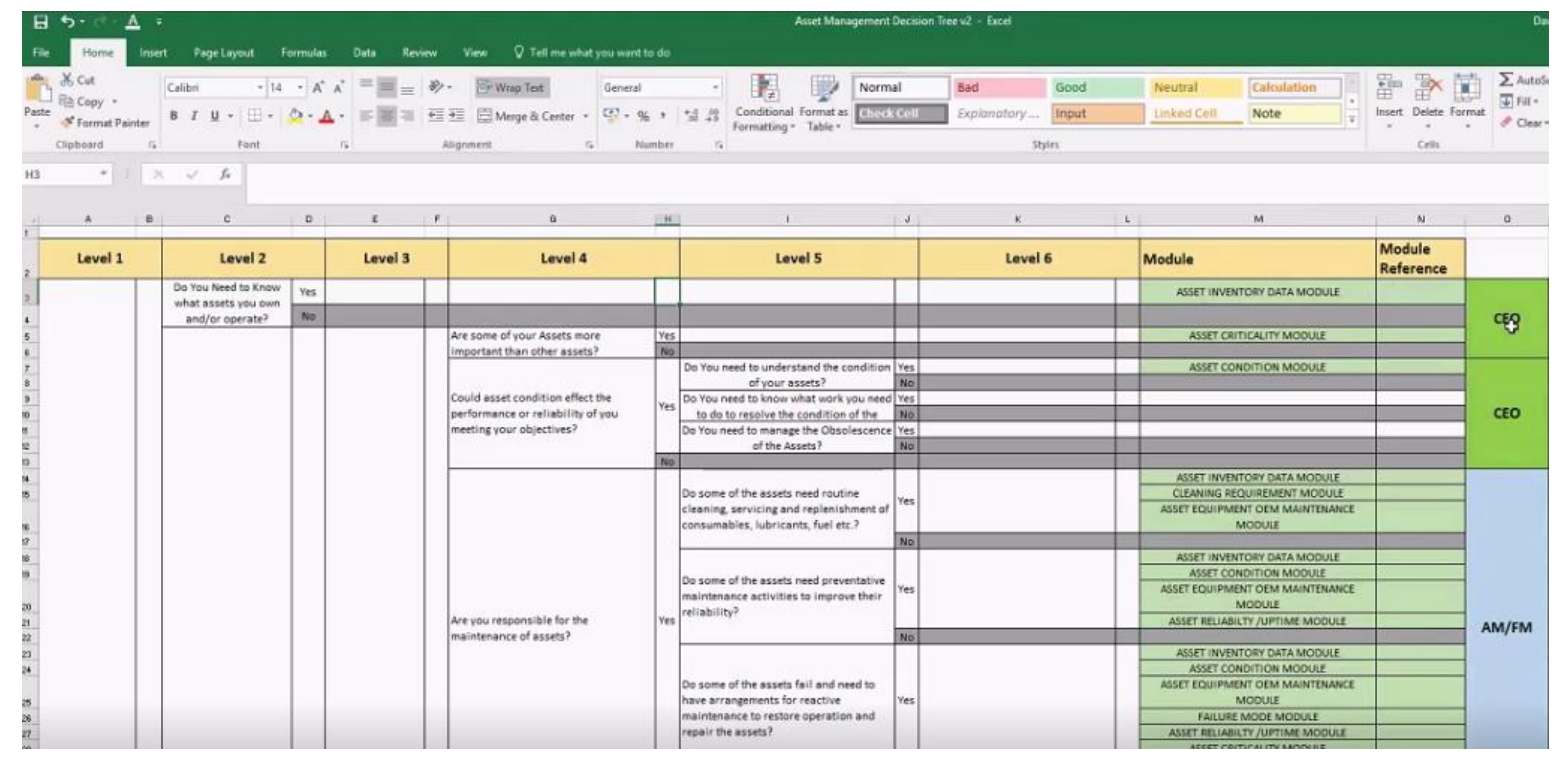

Table 43: Levels within the Asset Management tree

High level questions were populated aimed at audiences such as the CFO and CEO. The iso55000.01 standard has 169 tick boxes, turning these into an accreditation assessment could be helpful for this project. 


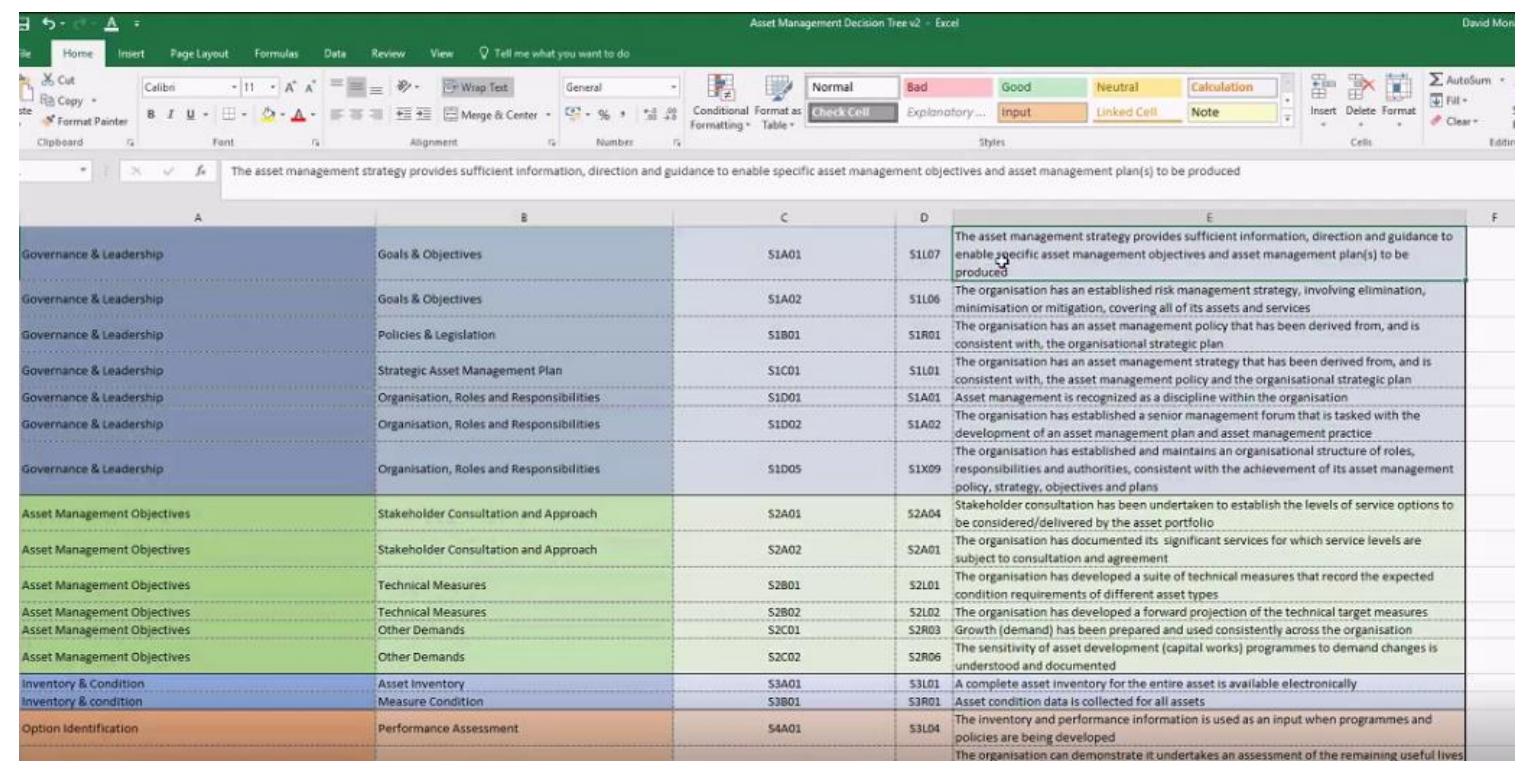

Table 44: Asset Management Strategies

All volumes of iOS 3 have been analysed and the fundamental aspects as defined by the asset management team have been populated to formulate questions. The Royal commission of Jubail, was utilised as a case study to indicate how mature their adoption of AM is. AGAP analysis of where the government in question sits in the market and where they ought to be.

\subsubsection{Jubail Royal Commission Infrastructure Programme}

The Saudi Arabian city of Jubail holds the significance of the largest civil engineering project for the last three decades. The objective of this project has been tasked to implement an approach to effectively manage infrastructure and the built environment to manage the Operations and

Maintenance of the city. The project is located in the Arabian Gulf which is predominantly an industrial city. The city was the first to be a location point for oil.

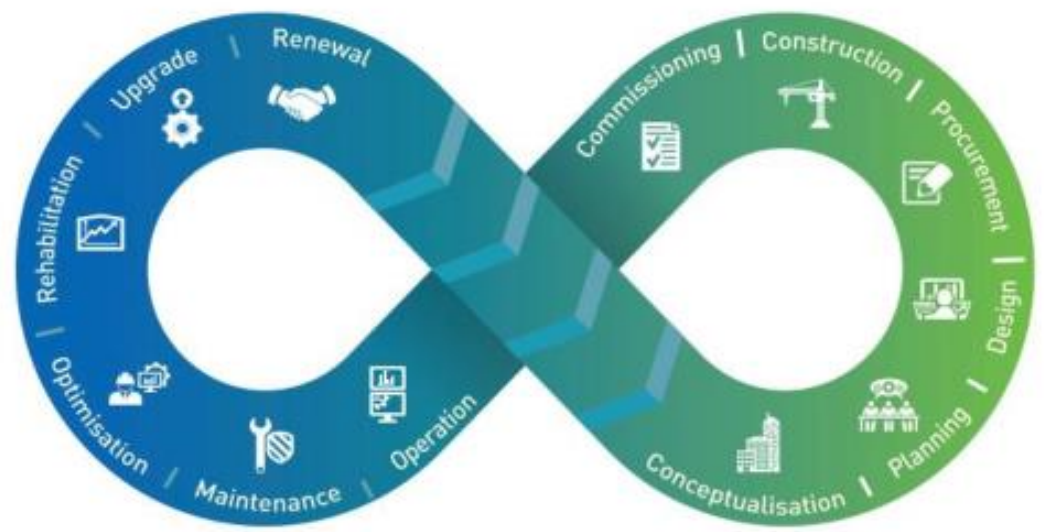

Figure 67: Project lifecycle diagram The expanding city aligns with the infrastructure plan first developed in 1975. Part of the implementation plan is to modernise and move with technological advancements and to 
reflect technology in this way. The city operation and maintenance sector (O\&M) is broken into five core departments; Roads, Buildings, Landscaping, Irrigation and Sanitation/General Utilities. Jubails assets are ageing and with the combination of the expanding population and aged assets the government speculates that the current funding may not be enough to sustain the existing service levels. In 2008 a three-year pilot scheme was introduced and showed remarkable success across a range of situations. The success of this pilot scheme was used to initiate the transformation scheme in 2014. The main objective of this project was to standardise Project Management operations of Jubails O\&M with PMI's methodologies. Opus aligned with Al-Joaib Engineering to provide the royal commission in Jubail processes that were world leading in Asset Management in practice and capabilities

Innovation through automation- the new Asset Management Model includes framework implementing decision making processes, asset performance, management protocols and information systems. The programmes main task is that the model will control the assets in one location (for example a BIM model system) where maintenance needs, performance and management is ordered numerically. The system allows operators to remotely manage and auto control, this could be the lights and air con system for example and are shut down at night but can be easily manipulated. The possibility of being able to open a valve $30 \mathrm{~km}$ away and shut this within two seconds, detect leaks and schedule over 200,000 operations at once is possible. The overall project involves lifecycle costing, statistical analysis, simulation and value management.

In 2010 the Saudi Arabian Government introduced the National Transformation Program 2020. The objectives defined above are presented in the illustration below 
Strategic Objectives of Vision 2030

Enable Citizens to obtain a suitable residence

Equip individuals with financial planning tools

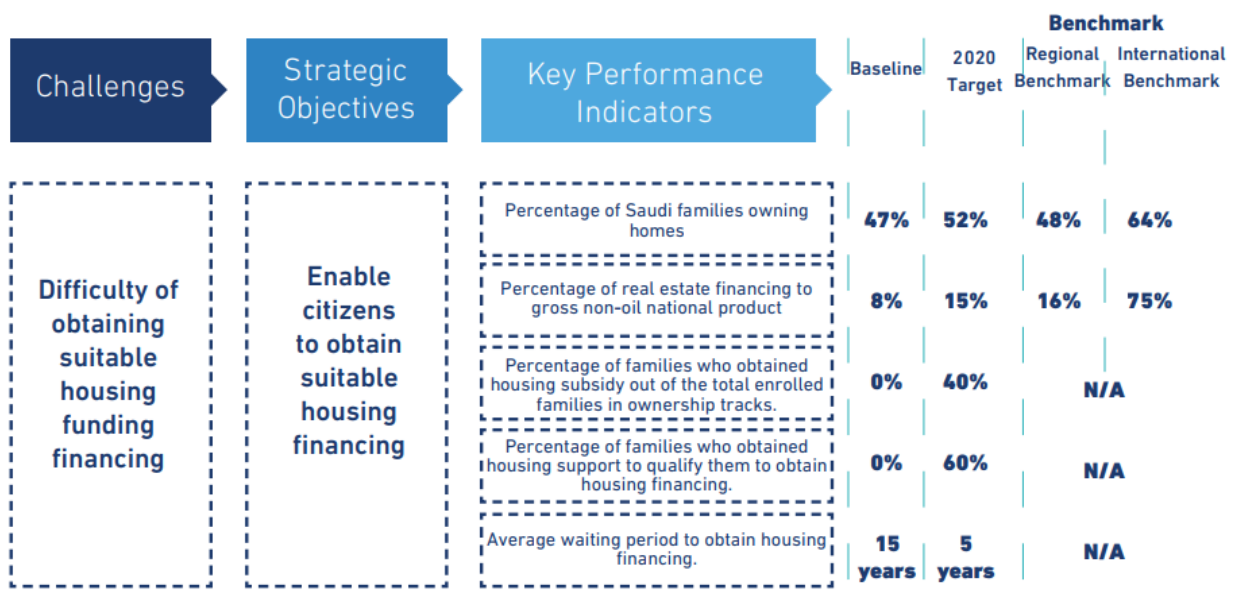

Figure 68: Project Strategic Objectives

To achieve the desired objectives the national model was set out in a 5-staged process as defined below:

1. Phase One. Identifying the Challenges Faced by Each Government Entity in Fulfilling the Vision and Establishing 2020 Interim Targets

2. Phase Two. Developing Initiatives Designed to Reach the Strategic Objectives

3. Phase Three. Developing Detailed Implementation Plans for the Initiatives

4. Phase Four. Promoting Transparency in the Publication of Targets and Outcomes Phase Five: Auditing,

5. Continually Improving, Launching New

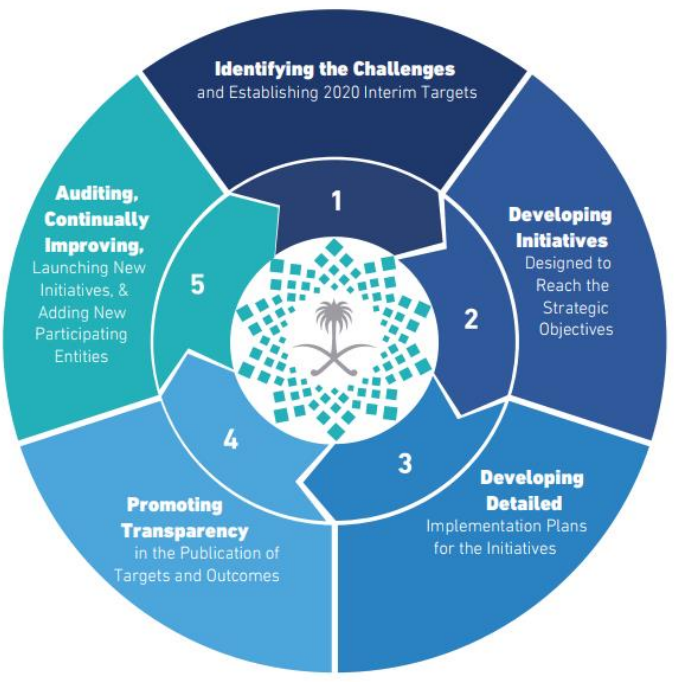
Initiatives, and Adding New Participating Entities 
These phases were launched across 24 governance bodies:

For each governing body different KPI's have been set up to target the specific sector. The model employs global best practice strategies including performance measurement indicators, project portfolio management methodology. In regard to innovation the Saudi Arabian government sets to uphold the latest innovation within the AEC industry. For the last 20 years Building Information Modelling has become more utilised and the advantages of adopting such processes are becoming clearer and effective for

\begin{tabular}{|c|c|c|c|}
\hline Participant & $\begin{array}{l}\text { Number of strategic } \\
\text { objectives }\end{array}$ & $\begin{array}{l}\text { Number of } \\
\text { indicators }\end{array}$ & $\begin{array}{l}\text { Number of } \\
\text { targets }\end{array}$ \\
\hline Ministry of Justice & 7 & 21 & 19 \\
\hline Ministry of Finance & 6 & 12 & 12 \\
\hline Ministry of Economy and Planning & 6 & 13 & 7 \\
\hline Ministry of Health & 16 & 17 & 16 \\
\hline Ministry of Communications and Information Technology & 10 & 17 & 17 \\
\hline Ministry of Commerce and Investment & 7 & 10 & 9 \\
\hline Ministry of Municipal and Rural Affairs & 7 & 25 & 24 \\
\hline Ministry of Civil Service & 5 & 11 & 11 \\
\hline Ministry of Culture and Information & 4 & 10 & 9 \\
\hline Ministry of Environment, Water, and Agriculture & 16 & 35 & 35 \\
\hline Ministry of Energy, Industry, and Mineral Resources & 15 & 24 & 24 \\
\hline Ministry of Labor and Social Development & 13 & 37 & 37 \\
\hline Ministry of Housing & 3 & 11 & 11 \\
\hline Ministry of Education & 8 & 20 & 19 \\
\hline Ministry of Transportation & 9 & 15 & 15 \\
\hline Ministry of Haj and Umrah & 5 & 15 & 10 \\
\hline Saudi Commission for Tourism and National Heritage & 4 & 16 & 16 \\
\hline Sports Authority & 4 & 7 & 5 \\
\hline Royal Commission for Jubail and Yanbu & 9 & 12 & 10 \\
\hline King Abdulaziz City for Science and Technology & 7 & 12 & 12 \\
\hline King Abdullah City for Atomic and Renewable Energy & 4 & 8 & 8 \\
\hline Institute of Public Administration & 2 & 4 & 4 \\
\hline Saudi Arabian General Investment Authority & 5 & 12 & 11 \\
\hline Saudi Food and Drug Authority & 6 & 7 & 5 \\
\hline Total & 178 & 371 & 346 \\
\hline
\end{tabular}
to implement.

The SA government look to introduce automated modelling across their government assets that is digital modelling and provide operational services within these digital models, exactly how this will be done and aligned is not yet recognised. In theory aligning one of the world's biggest infrastructure economies appreciates the benefits of Building Information Modelling and realises its potential as a problem solver in regard to more efficient operation and maintenance from design modelling systems such as Building Information Modelling. 


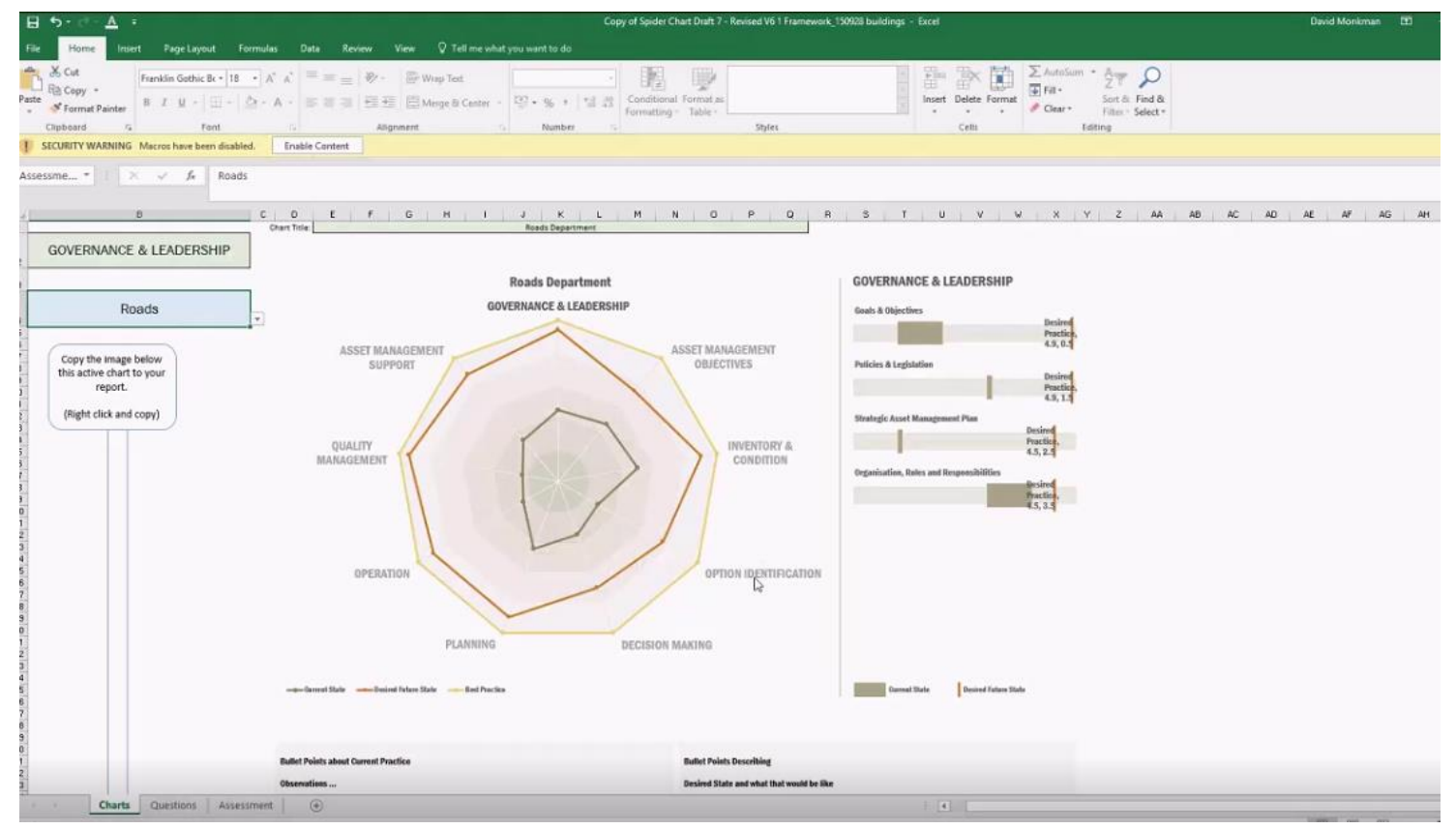

Figure 71: Parameter value

Aligning this with the company's asset management development a Viso decision tree was developed as shown above, questions for Asset Management in relation to governance were identified. In response all aspects were pulled together to develop synced questions and to identify a preliminary framework against the asset management objectives.

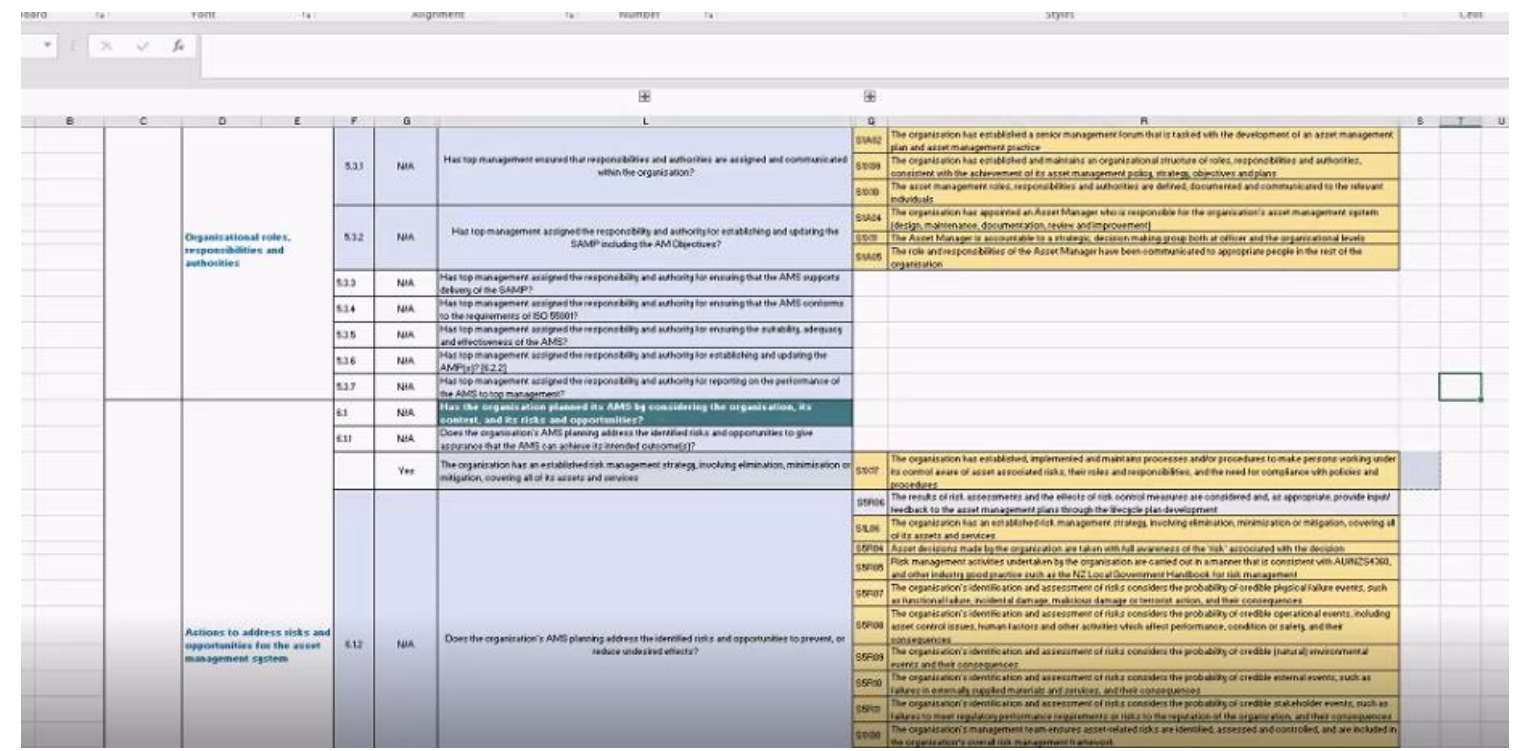

Figure 72: Asset Management Questions

The table above was created as a question spreadsheet to highlight possible information that may be needed to be defined from the operations team to the design team to ensure data 
collaboration. The table above is complicated and moving away from the data aspect of the project.

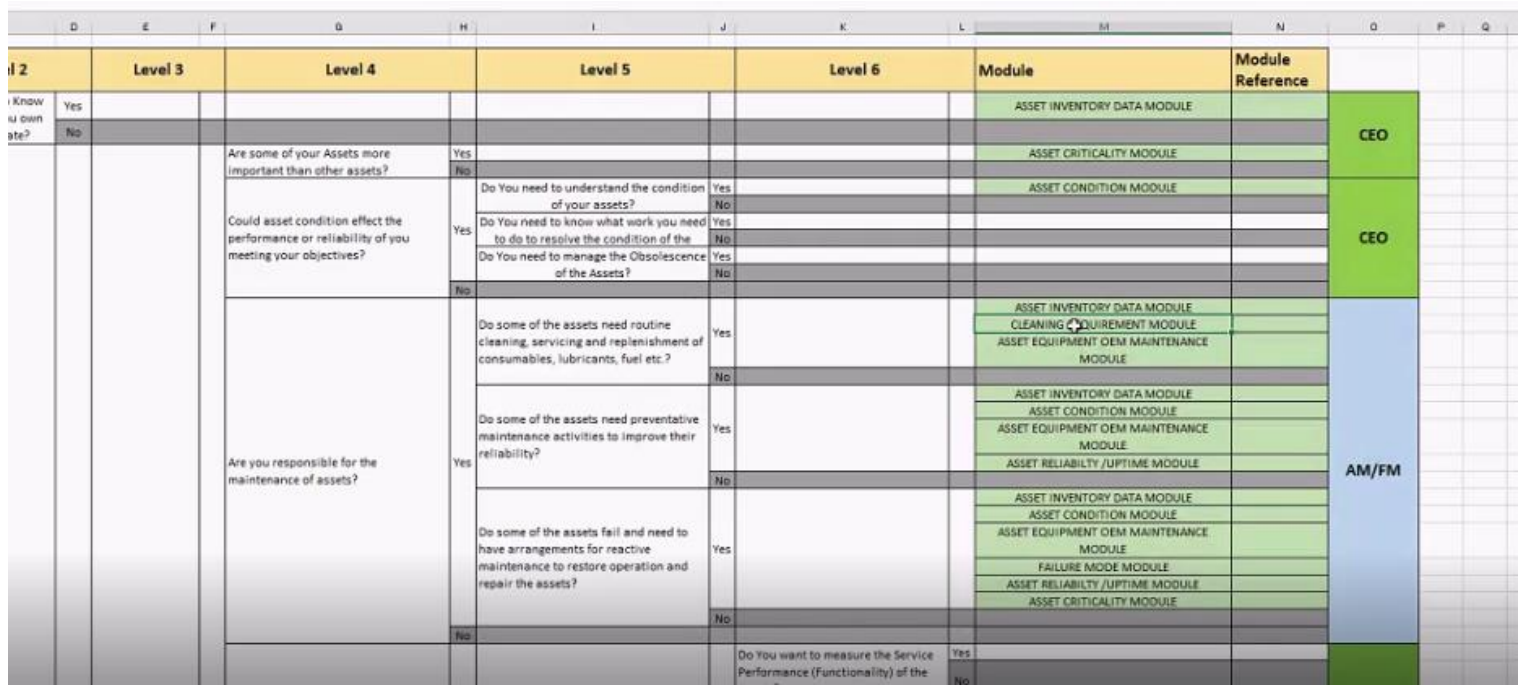

Figure 73: Simplified Decision Tree

The decision tree as pictured above has been refined from the original table in figure 73 . The facilities management team may need to understand cleaning aspects for example, the data then needs to specify size floor areas. The decision tree works on the basis that the user is in this case a facilities manager and is prompted down a path as opposed to being asked questions. Keeping it simple and direct will allude to with the Meta data being accurate and not overloaded. Once you know the data fields, these need to be matched to the elements,

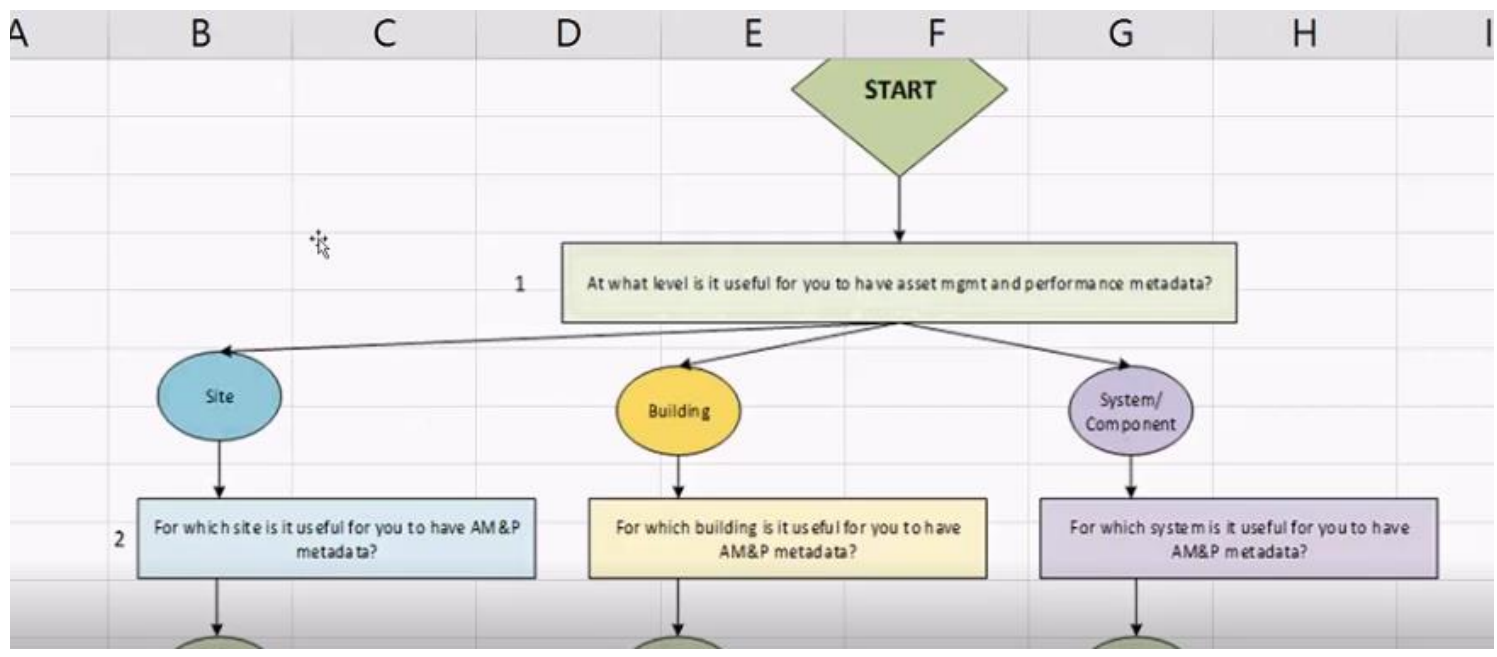

Figure 74: Uniformat Decisions 
The figure above is based on uniformat classifications, however has excluded the uniformat codes. This allows for a more strategical Approach as often clients when asked cannot specify what is needed. The client has to be informed on what needs to be gathered from a data perspective. The BIM modelling tool doesn't exclusively provide a recipe for data the Revit is just simply a data field. A process needs to be developed for a data scheme of what data is required and a code that is provided from the BIM model, data is provided from outside sources, as documented above one of the current issues is populating information back into the model. The BIM is what is achieved from the design construction drawing and BIM will be the data base (BIM geometric vision) that is excluded but extracted from the BIM and bought back in through the workflow of the excel worksheets. These questions can be asked prior to a design/BIM model to understand exactly what is needed and how they want to manage their assets and as the objective is not to be efficient and privy with the data to reduce excess data.

Applying the data to existing state and then seeing how this can be applied to a new BIM model requires separate workflows. Depending on the maturity of the existing asset portfolio, the extent of the data will vary. In this case the client are not the experts and do not know what data they need company $\mathrm{x}$ as a provider needs to deliver these answers. Prior to the commencement of the gymnasium project the contractor needed to understand the requirements of the client's assets prior to a project pilot study.

A way of understanding the client's needs is specified in the example of cleaning, how frequently is this required, when is this going to be carried out and who is going to do it. Ultimately defining what the end result will be and what the goal is, for example hygiene it is about saying ok the facilities manager may be worried about hygiene this then requires the client to look at areas $\mathrm{x}, \mathrm{y}$ and $\mathrm{z}$.

The client needs to understand for their own benefits what level of outcome for management purposes is required. For example, how does the maintenance provider work out sub components of a building, analysing all components of the building is important. Currently the client's problem is identifying what they need to solve and understand what they are 
supposed to be doing, the process of understanding how to maintain the assets, controls, limitations, preferences and risks will identify a possible solution.

The required output for the gymnasium is a list of data, providing the process that enables the client to make the informed decisions, and builds in IP for the service provider within the tool for tailored tools. The success factor ensures the relevant questions are being asked that often don't necessarily get asked throughout the design process.

The two components of the gymnasium project are the metadata and digitalising from start to finish as well as enterprising the asset management systems SAP and maximo (client's current systems).

In line with the requirements and inputs above, Opus developed an Asset register for the Whenuapai gymnasium as shown in appendix 18 . The excel spreadsheet has several columns that present data, from Revit ID number to function and renewable finish. The column that is the most beneficial for the next stage of the asset management process is the SAP section. The columns and information look at data currently populated in the SAP system comparable to that of the design model for the gymnasium. The example presented shows the Whenuapai plugged into the client SAP system comparing data integrity. It is expected that more of this is likely to be adapted as the project further develops.

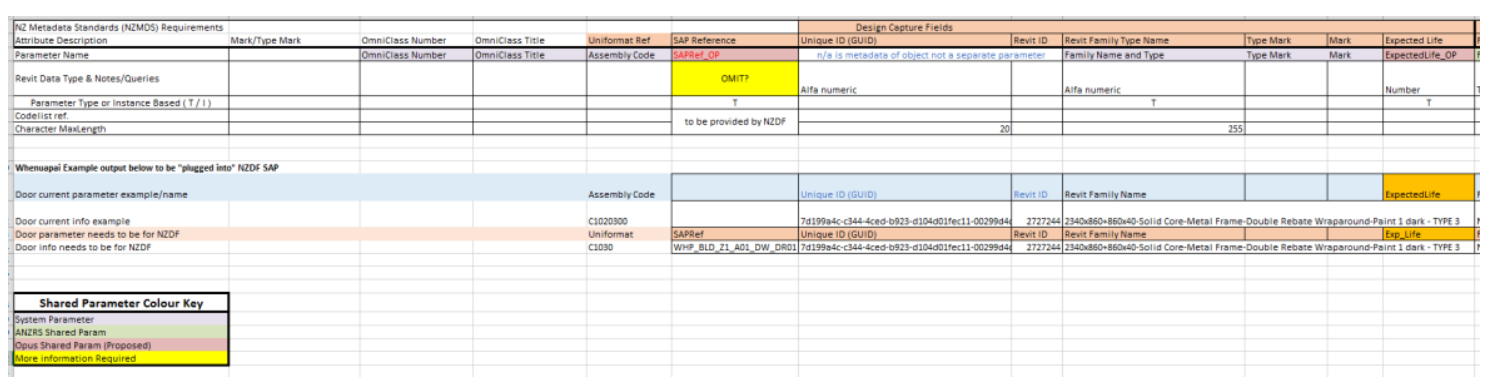

Figure 75: Design Capture fields 


\subsubsection{Current client SAP system in line with BIM Modelling}

The next phase of the Whenuapai Gymnasium project is matching a BIM environment Asset Management system to the one that is currently utilised. In section 7.1.4 the use of the Asset Management system is defined. Furthermore, for operational and planned maintenance is optimised in a Work Management System as the main maintenance tool across all of the clients' sites. The Facilities Managers utilise the software tool SPM assets in line with the Work Management System (WMS), to reduce the whole of life costs for the assets both systems require the most up to date data. The current system includes basic reporting functions within the existing tool. The system has a life cycle and project planning tool within the analysis section. The reporting section of the tool allows the user to analyse the data at the property and component level. One example of the analysing and reporting tool is the opportunity to collate planned maintenance. The SPM asset software retains information at three levels as shown below, the system has additional information such as Utility Systems as well as templates. Often data is introduced at the wrong hierarchy level.

The data records show 20,823 counts of data representing 218,244 components with over

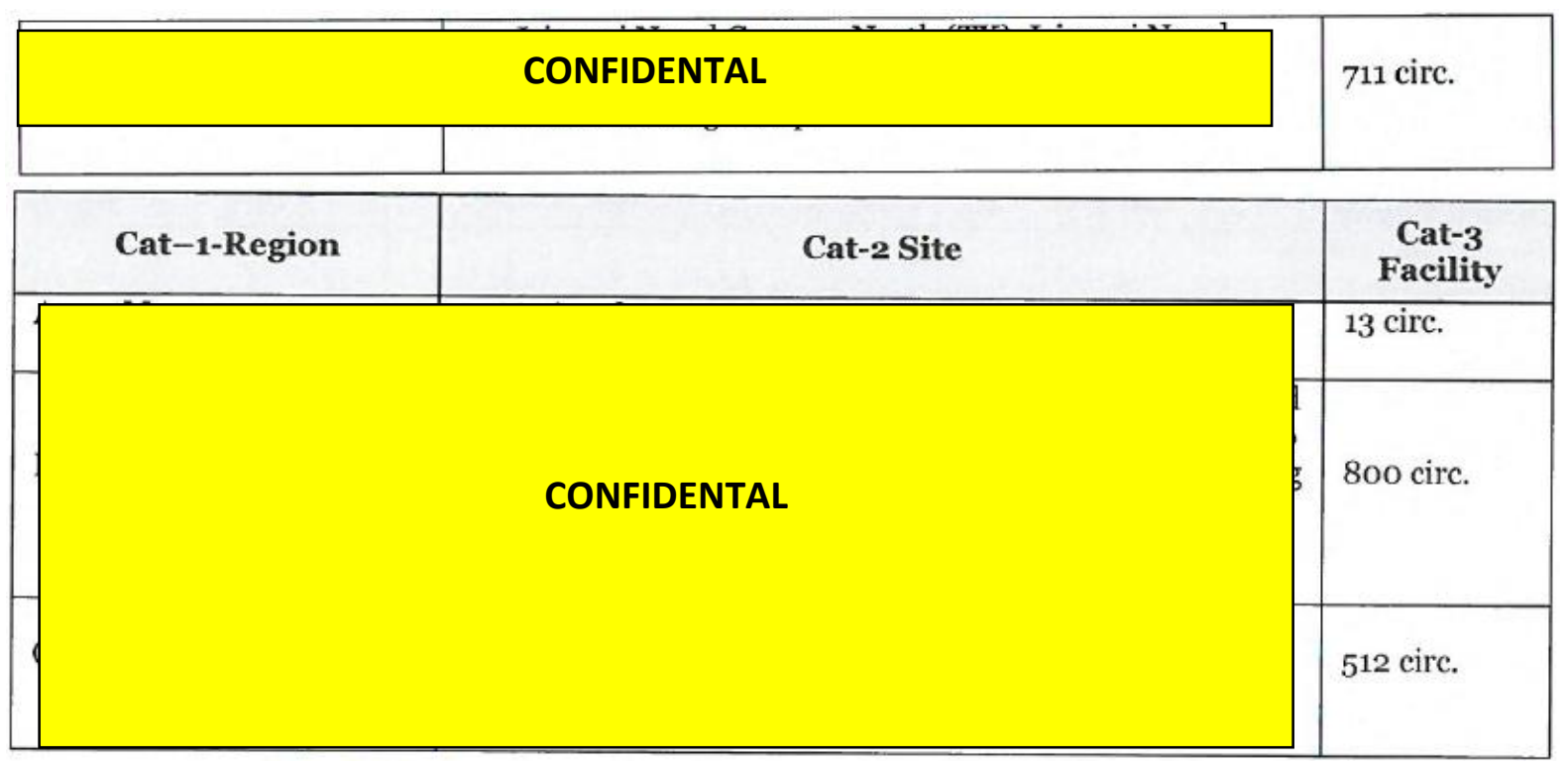

800 property areas that do not have data recorded against them. This indicates that the Facilities manager does not have all of the data up to date which can assume that the facilities management operations does not fully rely on the SAP/WMS systems. The WMS tool being utilised manages the work orders tasks and expected outcomes of these tasks. The WMS systems issues works order for the asset management team to deliver on inspection there were multiple work orders not being delivered particularly in scheduled and unscheduled activities. This alludes to one of two things, either the work is not being carried out or the 
WMS system is not being utilised correctly. The audit revealed that the SAP system although present was not typically used. The most important aspect for the client's to utilise for asset management purposes is both the planned maintenance and condition assessments. Although it doesn't appear that the client's AM/FM managers rely fully on their current system the majority of their assets across their bases data is stored within these systems. The easiest way of introducing a BIM asset management environment is to align these with the current deliverables for the ease of the staff and the data documentation.

\subsubsection{Revit BIM Link for contractors}

This section of the report documents the key achievement of the gymnasium project for the utilisation of BIM in Asset and Facilities Management and relates to the BIM Link.

The contractors' spreadsheet is achieved by Revit <-> BIM Link <-> Excel. This workflow is acknowledged as the most important component in achieving BIM in asset and facilities management.

The excel spreadsheet is part of the database behind Revit. The Revit is updated, pushed through to excel, updated in excel pushed back to Revit and repeated. Using Excel democratises the data and gives the supply chain something easy to edit and engage with, which eliminates the issue of contractors whom are unable to use such design tools.

The key success to this stage is implementing and understanding the BIM link. The BIM link as specified above and is achieved by ideate BIM link. Because most contractors are not familiar with BIM the design team needed to find a communication system that did not require knowledge of BIM.

"With Ideate BIMLink, Autodesk Revit users can pull information from a file into Microsoft Excel and push volumes of precise, consequential BIM data back into your Revit model with speed, ease and accuracy. Data management tasks and workflow take a small fraction of the time they once took. The cumulative advantage means more than hours freed. You gain unprecedented access to the Revit modeling data you need, for an enhanced workflow". 
Many big construction projects that have utilised Building information modelling within their design team have implemented a form of BIM link. For WSP the Hanking Center in Shenzen utilised the BIM link as a way of managing the data in their models. The Revit add in solution was developed by ideate enabling users to move data from a Revit model into an Excel spreadsheet and then push the update model back into the Revit data.

For the gymnasium project the contractors are given the excel spreadsheet as shown in Appendix 21, the contractor fills the spreadsheet in accordance to the BEP as shown in Appendix 10. Once the project is completed the excel sheet it provided back to the design team, the design team populate the data back to the Revit model, the ideate BIM Link is a plug in attached to Revit. In order for the model to be issued to the client as fully Asset/Facilities Management compliant a design member is required to check the data and ensure all elements have the correct associated metadata, Solibri checker in this instance was utilised.

\subsubsection{Conclusion of Whenuapai Gymnasium}

In early 2018 the client held the construction phase of the project due to financial restrictions internally, however this is forecasted to take place at some stage in 2018. The project from an asset and metadata perspective is completed to $100 \%$ (at the design stage) with requirements for further input from the contractors. What is next, the model will be handed over with the assigned metadata ranging from elements in LOD 200-350, at this stage no element is in the 400-500 details as these specifications become the decision of the contractor. The service providers' design team have detailed each element in regard to data input as shown in appendix 12. The data for each element was defined by the facilities manager as specified above. The next stage of the project will require careful data input from the contractors to return to the design team for deliverables in the asset management space. The design team are currently working towards aligning the data from this model to the current SAP system, the focus on this point is not the data as such but finding a solution that is viable for the use of the client's assets. It is not likely that Opus will utilise the performance of Autodesk off the shelves products like BIM 360 glue/ops. It is suggested that the client may only utilise BIM on the projects going forward and progress to SPM assets. 


\subsection{CONCLUSIONS}

There is no one approach of data inputs that can be utilised over different projects recognising different design aspects. The data needed within a BIM project is specific to each design project, however there are common attributes that are highlighted. The main concern of BIM for asset and facilities management is to not overload the model with data and to ensure that the client receives a model with concise data. Two aspects come into play, educating the client on what information he or she needs and ensuring that the flow of data from designer to contractor is done correctly. This means that the designer is to input data where deemed necessary and the contractor is to return to the designer the essential data that reflects exactly how the design is replicated in construction. In essence this all sounds easy but there are a few issues that need to be addressed before BIM is fully utilised in this space. The biggest issue is the incompetence of the contractor to use a design tool like Revit to input their data. Designers have recognised this issue and have introduced a spreadsheet that is given to the contractor to input data such as manufacturing details. The second issues arise when the spreadsheet is handed back to the design team to import back to the model. The BIMlink here remains uncertain and it is not as easy as just copying and pasting the information into the model. It does however allow the designer to manually input the data but with this comes time and money. In essence the facilities manager would still receive a fully integrated BIM model for the use in asset and facilities management but would endure the design fees of handling the data. Research strongly suggests that the market is working to develop this BIM link and introduce a tool that input the data straight into the Revit model. In reality BIM for Asset and Facilities Management has a process, there is some tweaking to be made but ultimately it can be achieved. It is crucial to ensure that all parties involved with the project have strong communication from pre-design and that each party is clear on their roles and responsibilities right throughout the project. 


\subsection{Benefits of BIM in Asset and Facilities Management}

The greatest perceived benefits include:

- Improved co-ordination throughout the entire design stage

- A no surprises design

- A single point of truth for data and building element information

- $\quad$ Better management of assets through understanding every aspect of the design with a continual updated model/drawing sheets

- $\quad$ Reduced time resourcing and costs

- $\quad$ BIM allows for better decision making

- Better client communication

\subsection{Potential Barriers of Building Information Modelling for Asset and Facilities}

\section{Management}

- Ultimately the client is the party fronting the cost for the project, the client's lack of knowledge on what BIM can do is perceived to be the greatest barrier as clients are likely to drive this.

- There is speculation that the average facilities manager/ asset manager does not have the ability to use design tools that have BIM capabilities, New Zealand facilities managers need to be upskilled.

- There is not a satisfactory method suggested for the operation stage that says follow these steps and here are your outcomes. It may not be necessary to have a method defined but rather this is a case by case basis. It is also assumed that as BIM progresses this will be developed.

- With any project cost controls a huge part of the decision-making process and introducing BIM increases design fees, if clients see the benefits of BIM and identify the potential benefits, the cost factor will ultimately be decreased in the long run. Educating these clients will be the only way to mitigate this issue

\subsection{Misconceptions of Building Information Modelling}

General misconceptions:

- $\mathrm{BIM}$ is a tool rather than a process 
- Increased work load for designers - more to do than a typical project when in fact it is business as usual

- Lack of control and liability with the models

- Regardless of the governments drive to mandate BIM or not there is still demanding to use this process

- It is believed that duty of care from the design participants will be increased with collaborative shared models. BIM models still create clarity on whom produced particular elements so effectively the designer's obligations would remain the same.

- Peoples understanding of BIM often assumes increased use of software and having to increase software capabilities, the main drive of BIM is to efficiently increase the process of technology not to re-introduce the wheel

- There is no information to suggest the government is likely to get behind BIM in the New Zealand construction industry and there is a lot of speculation to suggest that this could reduce the uptake, the New Zealand construction industry considering its size has adapted positively and it is likely this will continue to increase with or without government enforcement.

\subsection{Building Owners vs Design team and who is the beneficiary}

This research makes it clear that both developers and designers stand to win in a BIM contract both financially and innovatively. It is believed that as BIM creates huge certainty in the design phase the contractor does not benefit. As the design process creates significant clarity and visibility for the construction phase and deliveries there is little opportunity to hide profit margin. Traditionally because design was not as clear contractors could hide costs, the contractors should be more efficient as there should be a no surprises design. Although in most BIM contracts it does not specify whom owns the model at the end of completion it can be assumed that the model will be owned by the building owner, the building owner stands to win in this case and all the information on their asset is filed in one source. 


\subsection{Global use of Building Information Modelling}

The following conclusions respond to points raised in the literature review and analysis of business as usual approach, and the BIM project $P$.

Potential barriers include:

- Unskilled people to produce the required models and necessary data

- Unskilled people to understand the required data needed

- $\quad$ Resilience in change in work places

- $\quad$ Clients do not see the benefits of the costs to introduce BIM

- $\quad$ Huge upfront costs with little added value

This research has identified that although Building Information Modelling is in a premature state globally, being able to identify the necessary data needed for an operational phase is key and to do so a BIM expert with the knowledge to understand this level of information is key as well as a client that is willing to believe and pay for the process. As the industry matures, educating experts will increase and naturally so will the client willingness to adopt the process. Building Information Modelling for Asset and Facilities Management is challenging and not fully developed, however, this research identifies many positive benefits when adopting this process.

\subsection{RECOMMENDATIONS \& NEXT STEPS}

This research positively suggests that BIM will be fully utilised in the Asset and Facilities Management space within the next two years. What does the industry need to do to get to the point where this step becomes a certainty?

\section{Workflows are key.}

This research identifies a clear need for defined workflows across the project.

Workflow efforts need to target data import and exporting and specifically the exporting from a contractor's inputs back into the digital model. In developing the BIM link contractors need to be considered and bought into the process. This will involve the efforts in teaching and providing the contractors with the ability to be able to deliver the information needed within a BIM model. As it stands, there is a BIM model that has been developed by the design team 
creating specific data, the next step is for the contractor to be given the model and input specific details such as manufacturing details.

An issue currently, is that the design team automatically assumes that the contractors have the ability, one to understand the BIM model and can use the design tool (normally Revit) as well as to understand what is needed. Secondly there is a false pretence that the contractor is going to be able to use the model to input the data. Often contractors are not willing to adopt these procedures nor are they willing to utilise a modelling tool that changes from there day to day general practice. It can be found that contracting companies which are particularly bigger than others have adopted Revit design modelling processes and have the capabilities within their team to utilise this tool.

Significantly there is a huge education lacking in design tool modelling and something that is assumed to be resolved slowly as generation's progress. The AEC industry have acknowledged this issue and looked into other ways of being able to implement the contractor's data requirements back through to the design model. In order to achieve the correct data in a model at the conception of asset and facilities management the most efficient way currently is suggested to be by excel spreadsheet. What is being seen to be carried out is that the design team will still require the data from the contractor but instead of providing the information to the contractor via model this will be done through an excel spreadsheet. The design team will populate the excel sheet with the requirements needed from the contractor, the contractor will fill these out and send this back to the design team. The biggest issue currently lies at this stage. Once the contractor has provided this information to the design team the data needs to be imported back into the model this is known as a BIM link. There is no developed solution at this stage to do this and creates the limitation in providing a fully developed asset management BIM. The AEC industry is very close to resolving this and can be expected to be resolved in a short period of time.

\subsection{OPPORTUNITIES FOR FURTHER RESEARCH}

Building Information Modelling in Asset and Facilities Management is relatively untouched both in practice and research. This provides a lot of potential for further research not only directly with this topic but in related topics as well. 
The following research questions warrant further research:

- What is the most effective way to flow and input data from design team to Revit model and contractor to model ready for Operational use?

- What is the most effective way to educate Building Owners on Building Information Modelling for asset management?

- What is the most effective way to educate the wider construction industry of BIM's benefits and whom is the party that should be responsible for conducting this?

- How fixed are parts of the construction industry in utilising two dimensional drawings and specifications and is it likely to see them

- Does the New Zealand Government have a part to play in ensuring the New Zealand AEC industry utilises Building Information Modelling more efficiently?

- What would a national BIM standard for Asset and Facilities Management look like?

- In order to maximise the investment in BIM and Asset Management what would an asset policy that addresses BIM and Asset Management jointly look like?

- What does an appropriate client requirements framework for BIM in asset management look like and how can this be communicated through the supply chain?

- What are the processes for creating an open BIM process to reduce segregated silos and why is it valuable to do so?

- How do Building owners feel about the contractual obligations of BIM?

- Should the New Zealand government follow the same procedures as the UK and mandate BIM in government construction projects?

- Doe the existing Building stocktake in New Zealand require better processes? When is it likely that the NZ stock are likely to run into huge expenditure? 


\subsection{REFERENCES}

A. Haddock,. (2017). Review of Contract for Company X. Wellington, New Zealand.

Aconex. (2016). What is BIM? Retrieved June 8, 2017, from https://www.aconex.com/what-is-BIM

Autodesk. (2017). What does Revit do? Retrieved February 3, 2018, from

https://www.autodesk.com/products/revit-family/overview\#

Awe, J. (2017). Autodesk Project Quantum: the future of BIM? AEC Magazine, 1-10. Retrieved from https://www.aecmag.com/59-features/1241-autodesk-project-quantum-revit-bim

BIM Acceleration Committee. (2014). New Zealand BIM Handbook, (July), 1-20. Retrieved from http://www.building.govt.nz/UserFiles/File/Publications/Building/Technical-reports/nz-bim-handbookupdated.pdf

BIMForum. (2015). Level of Development Specification. BIM Forum, 195.

BRANZ. (2016). The New Zealand BIM Handbook, (November), 1-29.

British Institute of Facilities Management. (2014). What is Facilities Management. British Institute of Facilities Management.

British Institute of Facilities Management. (2015). Bim case studies for asset and failities management, (September).

British Standards Institution. (2013). PAS 1192-2: 2013, 1(1).

Bryde, D., Broquetas, M., \& Volm, J. M. (2014). ScienceDirect The project bene fi ts of Building Information Modelling ( BIM ). JPMA, 31(7), 971-980. https://doi.org/10.1016/j.ijproman.2012.12.001

Building Research Establishment. (2016). Meeting Construction 2025 Targets.

BuildingSMART. (2017). BIM Basic Information Delivery Manual, 1(1), 2-3.

Charette, R. P., \& Marshall, H. E. (1999). UNIFORMAT II Elemental Classification for Building Specifications, Cost Estimating, and Cost Analysis, 103. Retrieved from http://www.fire.nist.gov/bfrlpubs/build99/art080.html

Cunningham, P. (2015). Government as Client : Using Building Information Modelling on NZ construction projects. New Zealand. Retrieved from http://www.branz.co.nz/cms_show_download.php?id=6a8627b294bd5e2b533c46550b7ebf3fef169c0a Delany, S. (2018). Classification.

Ghaffarianhoseini, A., Tookey, J., Ghaffarianhoseini, A., Naismith, N., Azhar, S., Efimova, O., \& Raahemifar, K. (2017). Building Information Modelling (BIM) uptake: Clear benefits, understanding its implementation, risks and challenges. Renewable and Sustainable Energy Reviews, 75(September), 1046-1053. https://doi.org/10.1016/j.rser.2016.11.083

Gurevich, U., Sacks, R., \& Shrestha, P. (2017). BIM adoption by public facility agencies : impacts on occupant value. Building Research \& Information, O(0), 1-21. https://doi.org/10.1080/09613218.2017.1289029

Havakis, G. (2017). New Zealand Asset Metadata Standard - Residential Housing and Light Commercial Buildings, 1(August).

Hooper, M. (2015). Bim standardisation efforts - The case of Sweden. Journal of Information Technology in Construction, 20(October 2014), 332-346. 
IPWEA, I. of P. W. E. A. (2015). Meeting ISO 55001 Requirements for Asset Management, (limm).

James, S. A. (2015). The Business Value of BIM in China. SmartMarket Report. Retrieved from

https://www.construction.com/toolkit/reports/bim-business-value-china

Management, A. (2013). everaging the Relationship between L BIM and Asset Management Current Situation Relationship between BIM and Asset Management Building Information Modelling and Asset

Management Green economy, (September).

Masterspecs New Zealand. (2016). International BIM Object standard.

McPartland, R. (2017). What is a BIM Execution Plan? Retrieved May 1, 2017, from

https://www.thenbs.com/knowledge/what-is-a-bim-execution-plan-bep

Mergenschroer, M. (2015). Implementing BIM 360 Ops for Arkansas Children ' s Northwest Hospital - An

Open Book.

Ministry of Business innovation and employment. (2017). National Pipeline Construction Report 2017, (5), 1-

64. Retrieved from http://www.mbie.govt.nz/publications-research/research/construction-sectorproductivity/national-construction-pipeline-report-2017.pdf

Mohan, V. (2013). It Asset Management Selected Best Practices. SolarWinds Worldwide.

NBS. (2016). What is Building Information Modelling? Retrieved January 9, 2018, from https://www.thenbs.com/knowledge/what-is-building-information-modelling-bim

New Zealand Treasury. (2015). The Thirty Year New Zealand Infrastructure plan. Retrieved from http://purl.oclc.org/nzt/i-1785\%0Ahttp://purl.oclc.org/nzt/i-1785

Newton, R. S. (2015). BIM Workflows are evolving. AEC Magazine.

Nicał, A. K., \& Wodyński, W. (2016). Enhancing Facility Management through BIM 6D. Procedia Engineering, 164(June), 299-306. https://doi.org/10.1016/j.proeng.2016.11.623

Oti, A. H., Kurul, E., Cheung, F., \& Tah, J. H. M. (2016). Automation in Construction A framework for the utilization of Building Management System data in building information models for building design and operation. Automation in Construction, 72, 195-210. https://doi.org/10.1016/j.autcon.2016.08.043

Philip;, D. (2012). BIM : The UK Government Strategy. Bips Konference 2012.

Real Asset Management. (2017). Facilities Management Software.

Reding, A. (2014). BIM in New Zealand - an industry-wide view. EBOSS. Retrieved from http://www.eboss.co.nz/bim-in-nz-an-industry-wide-view

RJHA limited. Procurement Options for NZ Construction Contracts (2010). New Zealand: Procurement Options for NZ Construction Contracts. Retrieved from http://www.rjha.co.nz/wpcontent/uploads/2011/12/71211-Procurement-Options-for-NZ-Construction-Contracts.pdf

Roepke, B. (2016). Introducing Autodesk Forge and its role in BIM workflows - A success story with NBS ? The rise of the cloud.

Singh, I. (2017). BIM adoption and implementation around the world: Initiatives by major nations. Retrieved from https://www.geospatialworld.net/blogs/bim-adoption-around-the-world/

Singh, V. (2014). Building Information Modeling ( BIM ) for Facilities Management--Literature Review and Future Needs, (January). https://doi.org/10.13140/RG.2.1.3052.5525 
Smith, P. (2014a). BIM \& the 5D Project Cost Manager. Procedia - Social and Behavioral Sciences, 119, 475484. https://doi.org/http://dx.doi.org/10.1016/j.sbspro.2014.03.053

Smith, P. (2014b). BIM implementation - Global strategies. Procedia Engineering, 85, 482-492. https://doi.org/10.1016/j.proeng.2014.10.575

SPM Assets. (2016). Building Asset Intellegence.

Standards, R., National, T., Standard, B. I. M., States, U., States, N. B. I. M. S., Standard, N. B. I. M., ... NBIMS. (2015). National BIM Standard - United States ${ }^{\circledR}$ Version 3. National BIM Standard - United States Version 3, 2(Idm), 3-4. https://doi.org/10.1016/S0040-4039(01)82124-9

Stewart, J., Saxton, N., Associate, S., Ellison, M., \& Watts, R. (2014). Building Information Modelling From a Practical and Legal Perspective, (June), 1-17.

Tan, J. Y. and Y. (2011). Collaboration in Building Information Modeling. Georgia, United States. Retrieved from http://www.dbl.gatech.edu/sites/www.dbl.gatech.edu/files/Yinzi-Jianqui.pdf

Tardif, M., \& Aeronautics, T. N. (2017). buildingSMART alliance Construction Operations Building information exchange ( $C$... buildingSMART alliance Construction Operations Building information exchange ( $\mathrm{C} \mathrm{...}$ Page 2 of 2, (July 2008), 2008-2009.

The BIM Hub. (2016). Lis of BIM Softwares \& Providers.

Udorm, K. (2012). BIM: Mapping out the legal issues.

Vysotskiy, A., Makarov, S., Zolotova, J., \& Tuchkevich, E. (2015). Features of BIM implementation using autodesk software. Procedia Engineering, 117(1), 1148-1157.

https://doi.org/10.1016/j.proeng.2015.08.248

Wondimu, P. A., Hailemichael, E., Hosseini, A., Lohne, J., Torp, O., \& Lædre, O. (2016). Success Factors for Early Contractor Involvement (ECI) in Public Infrastructure Projects. Energy Procedia, 96(1876), 845-854. https://doi.org/10.1016/j.egypro.2016.09.146

\subsection{APPENDICIES}

See attached pen drive ADATA Haddock for all appendix related to the document. 